\title{
U d'/ of Ottawa
}

H|||||||||||||||||||||||-||39003006583230 

Digitized by the Internet Archive in 2010 with funding from University of Ottawa 



\section{LES}

\section{MAMMIERES}

DE LA

\section{PROVINCE DE QUÉBEC \\ PAR \\ C. E. D I O N E}

Conservateur du Musée Zoologique de 1'Université Laval Membre associé de 1" "American Ornithologist Union" Auteur de

"Les Oiseaux du Canada "

du "Catalogue (annoté) des Oiseaux de la Universit: d'O//2/, Prov̀ince de Québec"
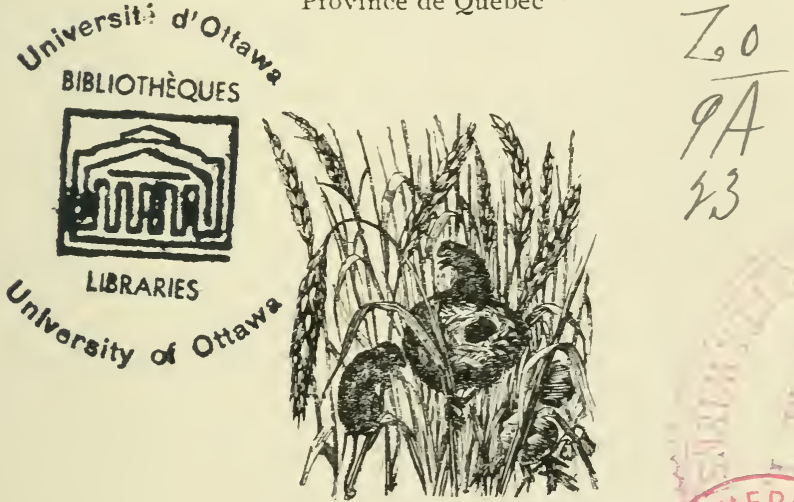

QUÉE B E C

SCIENTIAE

DUSSALLT \& PROLIX, IMPRIMETRS 


$$
\begin{aligned}
& \text { QL } \\
& 721 \\
& .05 M \\
& 1902
\end{aligned}
$$




\section{PRÉFACE}

La Faune mammalogique de la province de Québec était encore à faire et, depuis longtemps, on désirait une description technique de tous nos Manmifères indigènes avec l'historique de leurs mœurs ; en effet, à l'exception de certains articles de revues sur quelques-unes de nos grandes espèces, rien de complet n'a été publié sur ces animaux pourtant si intéressants à étudier dans leurs habitudes et si importants au point de vue économique.

J'ai donc essayé de combler cette lacune en publiant ce petit ouvrage, qui est le résultat de plus de vingt années de recherches et d'observations sur nos Mammifères.

Je n'ai rien épargné dans ces recherches, et tout en demeurant dans les limites du vrai, je me suis efforcé de rendre ce travail aussi intéressant qu'utile. A cet effet, je l'ai illustré de citations de naturalistes et autres dont l'autorité, quant aux extraits que j'en cite, ne saurait être mise en doute.

Afin de faciliter l'intelligence des descriptions techniques contenues dans cet ouvrage, $j$ 'ai inclus dans l'introduction une petite étude anatomique et physiologique des Mammifères considérés au 
point de vue du squelette, de leurs organes et de leurs fonctions.

La classification et la nomenclature adoptées sont des plus récentes; toutefois je dois ajouter que je n'ai attaché qu'un in térêt secondaire à quelques sousespèces ou variétés d'espèces que certains auteurs se plaisent à créer. Ces créations sont regrettables, dans la plupart des cas, car ces variétés, le plus scuvent basées sur de légères différences de teintes dans le pelage, comme aussi sur la grandeur ou la petitesse de la taille (quelques lignes à peine parfois) dues, en maintes circonstances, aux milieux dans lesquels ces animaux se développent, ne me semblent pas assez sérieuses et sont, je crois, de nature à rendre aux débutants l'étude des sous-espèces très laborieuse, surtout si l'on considère que les noms que l'on a ainsi adoptés sont susceptibles d'être remplacés par d'autres.

Enfin on trouvera quelques petites clefs destinées à faire reconnaître, de suite et en quelques mots, les différents ordres et familles énumérés dans le corps de l'ouvrage; ces clefs ne s'adaptent qu'aux Mammifères de la province.

Les gravures sont des reproductions extraites de divers ouvrages.

Malgré tout le soin que j'ai apporté à ce travail, je ne saurais toutefois me flatter d'avoir fait un ouvrage complet. Notre province est si vaste et nos animaux ont été si peu étudiés et, par suite, sont si peu connus, qu'il n'eșt pas improbable que certaines espèces, 
parmi les petites surtout, aient échappé à nos recherches et qu'une étude postérieure n'ajoute encore à l'histoire de leurs mœurs et à la découverte probable de nouvelles espèces.

Néanmoins j'ose espérer que ce travail sera utile à ceux qui désirent avoir une idée plus complète des Mammifères qui peuplent nos immenses forêts, aussi bien que de ceux qui habitent les profondeurs de notre beau fleuve.

C.-E. DIONNE. 



\section{INTRODUCTION}

L.es Mammifères appartiennent à la grande division des animaux vertébrés et, dans cette catégorie, ils occupent le rang le plus élevé, puisque chez eux l'organisation acquiert son plus haut degré de perfection ; ils jouissent, en effet, des sensations les plus délicates et les plus multiples, comme ils font preuve des mouvements les plus variés ; mais c'est surtout par leur instinct, qui est souvent porté jusqu'à ses dernières limites de développement, qu'ils se font particulièrement remarquer, si bien que, chez un grand nombre d'espèces, on serait tenté de croire que ces êtres sont doués d'une certaine lueur d'intelligence.

"Sans nier, dit Claus, l'abîme profond qui sépare l'intelligence humaine de l'intelligence des Mammifères les mieux doués, on peut cependant affirmer que les conditions élémentaires de l'entendement et de la sensibilité se rencontrent aussi dans ce qu'elles ont de plus essentiel chez ces animaux. Le Mammifère possède le discernement et la mémoire, il peut former des idées, juger et faire des inductions ; il témoigne du penchant et de l'amour pour celui qui lui fait du bien, de l'aversion, de la haine et de 
la colère contre son ennemi. Les facultés intellectuelles des Mammifères sont susceptibles de développement et de perfectionnement, restreints cependant dans des limites relativement étroites, suffisamment indiquées par l'absence du language articulé. La docilité de certains Mammifères, la faculté avec laquelle on les dresse et on les élève, ont fait d'eux les animaux domestiques, les compagnons de l'homme. Toujours le penchant naturel et inconscient, l'instinct, en un mot, joue un grand rôle dans la vie des Mammifères. C'est lui qui pousse de nombreuses espèces à construire de vastes galeries et des édifices, dont le perfectionnement nous étonne. " (I)

Les Mammifères se distinguent facilement des autres classes de vertébrés par l'enisemble des principaux caractères ci-après énumérés: par leur sang chaud et rouge, leur circulation double, leur viviparité, leur corps recouvert de poils, en tout ou en partie, sauf chez quelques espèces qui en sont totalement dépourvues; mais ils sont surtout caractérisés par la présence d'organes de lactation propres à la sécrétion d'un liquide qui doit servir à l'alimentation des petits durant leur première période d'existence.

Les Mammifères possèdent tous une charpente osseuse qui se compose de pièces solides et réunies les unes aux autres au moyen de ligaments, l'assemblage de ces os constitue le squelette. Il sert à sou-

(1) Claus, Traité de Zoologie, p. 1458. 
tenir les parties molles qui le recouvrent, à protéger les organes les plus essentiels à la vie, à déterminer les formes et les proportions des animaux. Organe

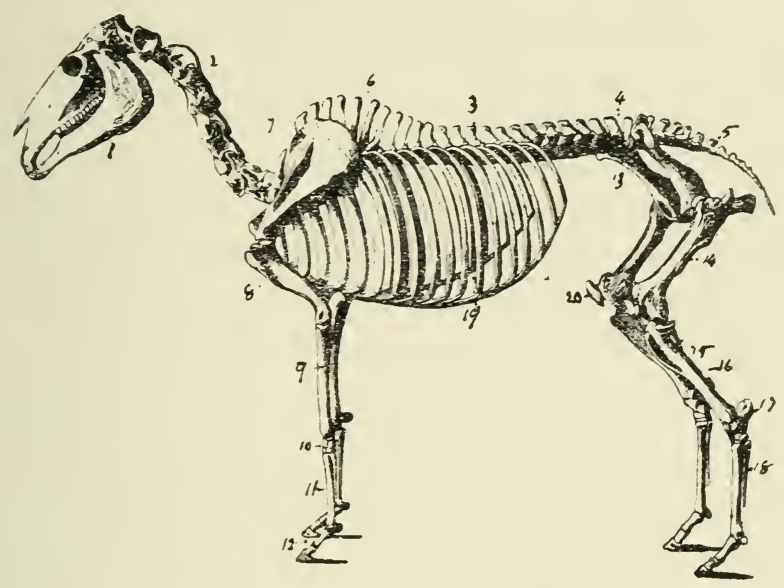

Fig. I.-SQUelette du Cheval.

I, Maxillaire inférieur ; 2, vertèbres cervicales ; 3, vertèbres dorsales ; 4 , vertèbres lombaires et sacrées ; 5 , vertèbres caudales; 6 , apophyses épineuses ; 7 , omoplate ; 8 , humérus ; 9 , cubitus et radius; IO, carpe : II, métacarpe ; I2, phalanges; I3, bassin ; I4, fémur; I5. I6, péroné et tibia ; 17 , calcaneum ; I8, taise ; I9, côtes ; 20 , rotule.

passif de la locomotion, le squelette, muni de ses muscles qui en forment la partie active, sert encore au transport de l'individu d'un lieu à un autre, et la réunion des deux constitue ce que l'on appelle organe de la locomotion. Les os sont formés d'une substance organique, l'osséine, et de substances inorganiques telles que le carbonate et le phosphate de chanx; ils s'accroissent et s'entretiennent par 
l'extérieur, au moyen du périoste, membrane qui les enveloppe.

Chez les Mammifères le squelette se compose de trois parties, la tête, le tronc et les membres; la tête se partage elle-même en deux sections, le crâne et la face. Le crâne, placé à la partie supérieure et postérieure de la tête, a la forme d'une boîte ovalaire, et se compose des os suivants: en avant, au-dessus des yeux, le frontal; en haut et sur les côtés, les deux pariétaux; en arrière, l'occipital; sur les côtés à la partie inférieure, les temporaux; en bas et en avant, l'ethmö̈de; également en bas et au centre, le sphénoïde. La face est située en avant et au-dessous du crâne; elle se divise en mâchoire ou maxillaire supérieur et en mâchoire ou maxillaire inférieur; la première est formée par les os maxillaires supérieurs, palatins, malaires, nasaux, lacrymaux, les cornets inférieurs et le vomer, ce dernier seul étant impair; la mâchoire inférieure est formée d'un seul os. L'os hyö́de, qui est situé à la base de la langue, peut être considéré aussi comme faisant partie de la face, de même que les dents qui garnissent les mâchoires. Les dents se partagent en incisives, en canines et en molaires; ces dernières se divisent ordinairement en vraies et en fausses molaires ou prémolaires. Les os de la tête sont solidement liés ensemble, à l'exception de la mâchoire inférieure qui s'articule avec le temporal.

Le tronc ou colonne vertébrale est formé d'anneaux osseux traversés par la moëlle et hérissés 
d'apophyses plus ou moins développées parmi lesquelles se distinguent surtout, par leur grande étendue, les apophyses épineuses situées sur le dos et les apophyses transverses, sur les côtés. Le tronc est divisé en régions cervicale, dorsale ou thoracique, lombaire, sacrée et caudale ou coccygienne.

La région cervicale se compose toujours de sept vertèbres, quelle que soit la longneur du cou, à l'exception toutefois du Lamantin qui n'en a que six et des Bradypes dont le nombre est de huit ou nenf. La première vertèbre qui s'articule avec la tête à l'occiput, par deux condyles, a reçu le nom d'atlas, et la seconde, celui d'axis; ces deux vertèbres sont les plus mobiles et suffisent à tous les mouvements de la tête. La région dorsale comprend de dix à douze vertèbres, mais on en rencontre ordinairement douze ; ces dernières se distinguent par le grand développement de leurs apophyses épineuses. La région lombaire se compose de deux à neuf vertèbres, mais en moyenne il y en a de cinq à sept; ces vertèbres présentent un corps plus considérable que les autres, avec des apophyses transverses très développées. Les vertèbres sacrées se soudent de très bonne heure, de manière à ne former qu'une seule pièce appelée sacrum.

Enfin la région coccygienne ou caudale, qui termine la colonne vertébrale, prend chez quelques mammifères un très grand accroissement et les vertèbres se chiffrent parfois jusqu'à quarante.

La poitrine ou le thorax est une grande cavité 
osseuse de forme ovoïde, occupant la partie antérieure du tronc et renfermant les organes essentiels à la circulation et à la respiration ; cette cavité est formée sur les côtés, par les côtes, qui sont unies aux vertèbres dorsales d'où elles se dirigent tranversalement en voute, pour s'articuler avec le sternum, os allongé et aplati d'avant en arrière, placé à la partie antérieure et moyenne de la poitrine, et qui résulte lui-même de la jonction de plusieurs pièces ; il porte, chez quelques espèces, une crête au milieu. Un certain nombre de côtes, à la partie postérieure: ne se rendent pas au sternum, mais elles s'unissent entre elles à leur extrémité par des cartilages; on les nomme alors fausses côtes. Les côtes correspondent toujours en nombre égal aux vertèbres dorsales.

On appelle bassin une vaste cavité osseuse située à la partie inférieure du tronc, s'articulant en arrière avec le sacrum; le bassin est formé de deux os irréguliers, larges et plats, nommés os illiaques, innommés, ou os des hanches, et chacune de ces pièces est elle-même formée de trois os: l'ileum, le pubis et l'ischium.

Le bassin sert de point d'appui aux membres postérieurs, et lorsque ces derniers manquent, com. me dans les Cétacés, le bassin n'existe pas. On y remarque cependant, situés dans les chairs, deux os représentant les ischions.

Les membres antérieurs ou thoraciques comprennent: l'épaule, formée par l'omoplate, et unie au 
sternum par la clavicule, lorsqu'elle existe ; l'humerus, le cubitus et le radius, le carpe et le métacarpe.

Le carpe est formé de deux rangées de petits os; la première rangée comprend le scaphoïde, le semilunaire, le pyramidal et le piciforme; la seconde, le trapèze, le trapèzoïde, le grand os et. l'os crochu; puis le métacarpe composé de quatre ou cinq os, parfois d'un seul, auxquels s'ajoutent les doigts variant en nombre de un à cinq et munis de trois phalanges chacun; cependant le cinquième ou le pouce, lorsqu'il existe, n'en a ordinairement que deux.

Les membres postérieurs comprennent le fémur, qui s'articule avec le bassin, le tibia et le péroné ou fibula, et le tarse, lequel comprend deux rangées de petits os, qui sont l'astragale, le calcaneum ou talon, le scaphö̈de, les trois os cunéiformes et le cuboïde. Le métatarse correspond aux parties analogues des membres antérieurs. Au devant de l'articulation, entre la jambe et la cuisse, se trouve enclavé dans les tendons, un os aplati que l'on appelle rotule.

Les divers mouvements exécutés par les animaux ont tous pour résultat le déplacement de quelques os du squelette, qui est revêtu d'organes essentiellement contractiles, appelés muscles et solidement fixés aux os par des fibres blanches serrées dont l'assemblage prend le nom de tendons; il existe dans les chairs des membranes de même nature appelées aponévroses.

Sous l'action du système nerveux, les muscles ont 
la faculté de se contracter ou de. s'allonger pour faire mouvoir ensemble ou séparément les différentes parties du squelette. Les muscles que l'on appelle communément la chair, sont composés de fibres charnues groupées en faisceaux, de grandeur et de formes variables, généralement de couleur rouge, conséquence du sang dont elles sont imprégnées.

La direction des muscles est ordinairement parallèle, perpendiculaire ou oblique à l'axe du corps ou à celui des membres, et leurs fonctions varient suivant la place qu'ils occupent. Distribués dans toutes les parties du corps, ils sont en nombre considérable et quelques anatomistes en comptent plusieurs centaines qui tirent leurs noms de leur position, de leur forme ou de leur usage. Leur énumération serait trop longue à faire ici.

Les pertes incessantes occasionnées dans l'économie animale par l'action des organes du mouvement, sont réparées au moyen de matières animales ou végétales qui, par suite de certaines modifications, s'assimilent à l'individu qui se les approprie. C'est à ces diverses transformations des aliments qu'on a donné le nom de digestion, et les organes qui contribuent à l'accomplissement de cette fonction se nomment appareils digestifs.

L'appareil digestif se compose d'un tube de longueur variable qui forme, dans l'intérieur du corps, plusieurs détours; il présente sur son parcours des renflements plus ou moins considérables dans lesquels les aliments subissent leurs transformations. 
L'orifice antérieur du canal digestif s'ouvre par une large cavité nommée bouche, dans laquelle se trouvent les appareils de la mastication, de l'insalivation et de la déglutition, et où les aliments subissent leur première préparation. Organe de préhention, la bouche, toujours fendue transversalement, est munie à l'extérieur de deux lèvres mobiles et charnues et à l'intérieur, de deux mâchoires garnies de dents, à l'aide desquelles les matières alimentaires sont divisées et broyées; c'est ce qu'on appelle la mastication. On y rencontre aussi des glandes dont la fonction est de sécréter la salive, liquide alcalin qui sert à humecter et à réduire en pâte les aliments divisés par les dents; c'est l'insalivation. La déglutition ou le passage des aliments dans l'estomac s'opère au moyen de la langue qui, en s'appliquant à la voûte du palais, chasse ces matières dans le pharynx, commencement du canal intestinal proprement dit, puis de là dans l'cesophage et enfin de ce dernier dans l'estomac qui y fait suite. Ce transport des aliments est effectué par les contractions successives des muscles du pharynx et des fibres de l'œsophage.

Comme le pharynx se trouve situé près de l'épine dorsale, en arrière du larynx, les aliments, dans leur trajet, passent au-dessus du tube respiratoire. L'orifice de ce tube se ferme par une valvule, l'épiglotte, qui empêzhe les aliments d'y pénétrer; les fosses nasales sont également protégées contre les matières 
alimentaires par le voile du palais, repli de la peau interne, qui en ferme momentanément l'entrée.

L'estomac est une sorte de sac déterminé par une dilatation plus ou moins considérable de l'intestin, dont l'orifice supérieur, le cardia, communique avec l'œsophage, et l'inférieur, le pylore, avec le dundenum. Il est situé à la partie supérieure et gauche du ventre au-dessous du diaphragme, membrane musculaire mince, très large et placée obliquement entre le thorax et l'abdomen. A peine les aliments sont-ils entrés dans l'estomac qu'ils sont pressés de toute part par les contractions de ses parois, s'imprègnent du suc gastrique, sécrété par ses follicules, puis transformés en une pâte homogène et grisâtre, qu'on nomme le chyme, ils passent par petites portions dans le duodenum ou commencement de l'intestin grêle, pour y subir une seconde digestion au contact de la bile et du suc pancréatique sécrétés par deux glandes, le foie et le pancréas. Le foie, qui sécrète la bile, est partagé en lobes; il occupe le haut de l'abdomen vers la droite, s'appuyant contre l'estomac. Le pancréas est une glande oblongue placée transversalement dans un repli du duodenum; le suc qu'il sécrète a beaucoup d'analogie avec la salive.

La seconde digestion achève de transformer la masse alimentaire en substance nutritive et la sépare en deux parties, les excréments et le chyle; les premiers sont rejetés au dehors après avoir parcouru toute la longueur du canal intestinal, et le 
chyle est absorbé sur son parcours par les vaisseaux chylifères pour se mêler au sang et porter dans toutes les parties de l'être, l'aliment nécessaire à l'entretien de la vie.

Les intestins sont maintenus en place par le péritoine, membrane qui les recouvre en partie ou les embrasse dans ses replis. A la suite de l'estomac, l'intestin se divise en deux parties : l'une antérieure, plus étroite et plus longue, est l'intestin grêle; l'autre postérieure, plus large et plus courte, est le gros intestin. La longueur du canal intestinal varie ; il est, en général, plus long chez les Herbivores que chez les Carnivores.

L'estomac n'est pas conformé de la même manière chez tous les Mammifères; il est très simple chez les Carnassiers et plus encore chez les Phoques et les Marrsouins, tandis qu'il est beaucoup plus compliqué dans les Herbivores et surtout les Ruminants, comme on le verra plus loin.

Chez tous les Mammifères la respiration est aérienne, même chez ceux qui vivent dans l'eau; elle consiste dans l'acte par lequel le sang noirâtre ou veineux est mis en contact, dans les poumons, avec l'air atmosphérique qui le transforme en sang rouge ou artériel ; elle s'effectue à l'aide des poumons qui en sont les principaux organes; ces derniers sont au nombre de deux, inégaux, celui de droite étant le plus gros, de forme conoïde, entourés d'une membrane séreuse nommée plèvre; ils sont de nature spongieuse, de couleur rosée, et sont divisés 
en un ou plusieurs lobes. Ils occupent, avec le cœur, toute la cavité thoracique.

L'air qui est amené aux poumons, passe par la bouche ou les narines et pénètre dans un canal qui s'ouvre dans le gosier à la base de la langue et au devant de l'cesophage; ce canal, à son ouverture, forme le larynx, organe de la voix, puis se continue jusque dans la poitrine par la trachée artère; cette dernière est formée de plusieurs anneaux cartilagineux et élastiques, excepté en arrière où elle est simplement membraneuse, puis elle se bifurque en deux tubes appelés bronches, qui pénètrent dans les poumons en se ramifiant.

Dans l'inspiration, les poumons se dilatent par suite de l'air qui les pénètre; la cavité de la poitrine s'agrandit et le diaphragme, qui a la forme d'une voûte, se contracte et refoule en bas les viscères abdominaux ; l'air est ensuite expulsé au dehors par les contractions des poumons, qui reviennent sur euxmêmes, par celles des muscles de la poitrine qui en diminuent la capacité, et aussi par celles des muscles de l'abdomen qui refoulent les viscères avec le diaphragme.

Si la respiration est une des conditions essentielles à l'entretien de la vie, la circulation n'en est pas moins une fonction également indispensable de l'existence. En effet, c'est par la circulation que les principes nutritifs sont transportés dans toutes les parties de l'organisme. Le cœur, les artères et les veines, voilà ce que l'on appelle appareil de la circu- 
lation, et le sang en est le liquide qui l'alimente.

Le cœur est un organe musculeux, de forme conique, entouré d'une membrane séreuse nommée péricarde; il est placé dans la poitrine sur la ligne médiane, dans l'espace qui sépare les deux poumons ; sa pointe est considérablement inclinée vers la gauche. Cet organe est creux et offre quatre cavités: deux supérieures, les oreillettes, et deux inférieures, les ventricules; une cloison médiane et imperforée sépare le ventricule et l'oreillette droite de ceux de la partie gauche. On appelle artères les vaisseaux qui partent du cœur, et on nomme veines ceux qui ramènent le sang au cœur. Le tronc principal des artères, l'aorte, sort du ventricule gauche $d u$ cœur, se recourbe à une courte distance en forme de crosse, et descend le long de la colonne vertébrale, distribuant des artères plus petites qui se ramifient elles-mêmes dans toutes les parties du corps; une autre artère sort du ventricule droit pour se ramifier dans les poumons, après s'être divisée en deux branches. Les artères sont formées de tuniques résis. tantes et très extensibles, leur permettant de supporter sans se rompre les mouvements des liquides qui s'y précipitent. Les veines, également distribuées dans toutes les parties du corps, ont pour fonction de ramener le sang noir au cœur par la veine cave supérieure et la veine cave inférieure. Les veines sont d'une texture moins résistante et moins extensible que les artères, aussi le sang y coule d'une manière plus uniforme; elles ont aussi des ramifica- 
tions plus nombreuses et sont situées moins profondément. De l'extrémité des artères, le sang passe al1x veines à travers de fines ramifications que l'on nomme réseau capillaire.

La circulation est double chez les Mammifères. Le sang est toujours rouge; il est composé du plasma, de gaz en dissolution et de globules; ces derniers sont des corps solides, microscopiques, et se partagent en globules rouges et en globules blancs; le plasma, qui est la partie liquide, est incolore et renferme les éléments réparateurs des organes; on y rencontre dissouts de l'albumine, de la fibrine, des sels et autres matières; dans les gaz en dissolution se retrouvent de l'oxigène, de l'azote et de l'acide carbonique. C'est à la présence des globules rouges que le sang doit sa coloration.

Sous l'action des contractions musculaires du ventricule gauche, le sang est lancé dans l'artère aorte qui le distribue dans tout l'organisme, puis il est ramené par les veines caves dans l'oreillette droite du cœur; il descend alors dans le ventricule droit qui se contracte et le repousse dans les poumons par l'artère pulmonaire, où il vient en contact avec l'air atmosphérique qui lui communique de l'oxigène, et le débarrasse de l'acide carbonique dont il est chargé. C'est alors qu'il reprend sa couleur vermeille. Des poumons, le sang revient par les quatre veines pulmonaires dans l'oreillette gauche pour descendre dans le ventricule du même côté qui le pousse de nouveau dans l'aorte. 
Entre les oreillettes et les ventricules, il existe une valvule qui se ferme au moment où les rentricules se contractent pour empêcher le sang de remonter dans les oreillettes; il en existe également une à l'entrée des artères afin que le sang ne puisse revenir vers le cœur, lorsque ce dernier se dilate.

Si l'on compare ensemble le système nerveux chez. les vertébrés, cet agent indispensable des fonctions de la sensibilité et du mouvement, on constate qu'il est construit absolument d'après le même plan dans tous les animaux de cette catégorie, mais son volume acquiert un développement et une perfection d'autant plus grands que l'on se rapproche davantage des animaux supérieurs.

Le système nerveux préside aux fonctions de relation comme à celle de nutrition ; c'est par lui que les. impressions reçues par les organes des sens sont communiquées au cerveau; c'est également par lui que les ordres sont transmis à l'organisme ; en un mot, il préside à toutes les attributions de ce que l'on appelle la vie animale, c'est-à-dire la sensibilité, la volonté et l'instinct.

Le système nerveux se divise en système nerveux cérébro-spinal, et en système nerveux ganglionnaire ou sympathique. Le premier consiste en une masse nerveuse plus ou moins considérable, située à l'intérieur du crâne et de la colonne vertébrale; sur les parois de cette dernière sortent des nerfs sensitifs et moteurs qui se distribuent dans toutes les parties de l'animal. On donne le nom d'encéphaie à cette por- 
tion de la masse nerveuse située à l'intérieur du crâne, et de moëlle épinière à celle qui, sous la forme d'un gros cordon blanchâtre, est située à l'intérieur de la colonne vertébrale. Organe d'une extrême importance et à structure très délicate, l'encéphale est protégé contre les agents extérieurs par le crâne qui est très résistant, et à l'intérieur par trois membranes, une fibreuse très forte adhérant au crâne, la dure-mère, une seconde séreuse, l'arachnö̀de, ainsi nommée par ce qu'elle ressemble à une toile d'araignée, et la troisième, cellulaire, la pie-mère, dont la texture est très délicate et qui recouvre immédiatement l'encéphale. Entre la pie-mère et l'arachnoïde il existe un liquide qui protège encore le cerveau. La moëlle épinière est également enveloppée par les mêmes membranes et protégée par les vertèbres qui s'entrelacent toutes afin d'offrir plus de résistance aux secousses extérieures. Les deux parties principales que renferme la boîte crânienne sont le cerveau et le cervelet; le premier est un organe très volumineux occupant toute la cavité supérieure du crâne; il est de forme ovalaire et est divisé sur la ligne médiane en deux parties,nommées hémisphères, à la surface desquelles se voient de nombreux sillons et plusieurs éminences contournées sur elles-mêmes, que l'on appelle circonvolutions cérébrales. Cependant les Rongeurs en ont peu et quelques autres mammifères en sont dépourvus. Le cervelet, situé à la partie postérieure et inférieure du crâne, est bien moins considérable que le cerveau, et d'une 
nature moins consistante. Les nerfs rachidiens sont des espèces de cordons blancs qui prennent naissance à la moelle épinière, à l'intersection des vertèbres, par deux racines, l'une antérieure et l'autre postérieure, qui s'unissent à leur sortie des vertèbres; une partie de ces nerfs entre en communication avec le système nerveux ganglionnaire,et l'autre se distribue dans la partie postérieure et antérieure du corps. Ces derniers ont pour fonctions de transmettre au cerveau les sensations de ces divers organes, et de communiquer aux muscles l'influence de la volonté émanant du cerveau. On a constaté par des expériences que la racine antérieure des nerfs rachidiens préside aux mouvements et est insensible à la douleur, tandis que la racine postérieure produit la sensibilité seulement.

On compte une quarantaine de paires de nerfs, dont une douzaine sortent du crâne et les autres de chaque côté de la colonne vertébrale. Ils tirent leurs noms de leur position et de leurs fonctions. Parmi ceux qui innervent particulièrement la tête, on retrouve les nerfs olfactifs, optiques, auditifs, trijumaux et autres.

Le système nerveux ganglionnaire se compose d'un grand nombre de petits filets nerveux, réunis en petites masses que l'on nomme glanglions, liées entre elles par des cordons médullaires, et distribuées le long de la partie antérieure de la colonne vertébrale. Le système nerveux ganglionnaire préside aux fonctions de la nutrition, de la respiration, de (2) 
la circulation et de la digestion, d'une manière régulière et périodique, indépendamment de la volonté.

Les animaux émettent des sons divers pour exprimer les différents sentiments qui les animent; ces sons se produisent par l'air qui, chassé des poumons, pénètre dans la trachée artère qui se resserre en fente à la partie antérieure pour former le larynx, organe essentiel à la production du son. Le larynx est tapissé à l'intérieur par des muscles dont deux surtout exercent les fonctions de cordes vocales; ces dernières, en vibrant, permettent et interceptent alternativement le passage de l'air ; de là la production des sons. Les autres organes tels que les cavités buccale et nasale, et autres, ne servent qu'à modifier le timbre de la voix.

Le toucher réside dans la peau qui se partage en deux couches, l'une extérieure, l'épiderme, et l'autre intérieure, le derme; entre ces couches il existe une muqueuse qui contient du pigment, matière colorante qui donne la couleur au poil et à la peau des animaux. Le derme est la partie la plus épaisse de la peau et aussi la plus importante ; c'est dans cette couche que s'implantent les poils; c'est là que sont situées les glandes qui sécrètent la sueur; c'est là aussi qu'aboutissent des muscles et des filets nerveux qui lui communiquent le mouvement et la sensibilité. Les muscles de la peau se nomment le peaucier qui, chez quelques mammifères, enveloppe presque tout le corps. Le sens du toucher réside plus par- 
ticulièrement sur les parties nues des animaux, tels que les lèvres, le nez et autres.

Le sens du goût est celui qui perçoit et discerne la saveur des aliments; il réside à la surface de la langue et surtout à sa base. C'est dans les papilles dont elle est hérissée et dans lesquelles aboutissent des filets nerveux, que s'opère la sensation gustative. Les papilles les plus remarquables par leur dimension et leur nombre sont placées à la base de la langue.

Le sens de l'odorat est celui qui perçoit les odeurs. Chez les Mannmifères il existe deux fosses qui s'ouvrent à l'extrémité du museau et que l'on nomme fosses nasales; le réceptacle qui les entoure est désigné sous le nom de nez, qui est quelque fois plus au moins allongé en forme de groin ou de trompe ; une cloison cartilagineuse le divise en deux parties. Le nez n'existe pas dans les Cétacés souffleurs, et les narines, désignées sous le nom d'évents, sont situées à la partie supérieure de la tête; il n'y a qu'un évent chez les Dauphins. Les fosses nasales sont creusées dans trois cornets dans lesquels se distribue le nerf olfactif et qui sont à replis d'autant plus nombreux que l'odorat est plus subtil. Elles sont tapissées à l'intérieur par une muqueuse qui a reçu le nom de membrane pituitaire. Cette membrane n'est sensible aux odeurs que dans la partie qui tapisse la voute des fosses nasales.

Dans l'aspiration, les particules qui s'échappent 
des corps odorants, viennent frapper la partie superieure de la muqueuse pituitaire et alors l'impression se produit.

Les yeux sont des organes globuleux placés dans des cavités osseuses appelées orbites et communiquant avec le nerf optique; l'œil se compose de la rétine, la choroüde avec l'iris, la sclérotique avec la cornée, le cristallin, le corps vitré, et de diverses parties accessoires. La sclérotique est une membrane fibreuse, blanche, très solide, qui enveloppe le globe de l'œil; elle devient transparente en avant et constitue alors la cornée; la choroïde est une membrane vasculaire noircie par un pigment foncé surtout en arrière; elle est située en dedans de la sclérotique et elle s'accroît en avant pour former l'iris; le pigment qu'elle contient a pour effet d'éteindre les rayons lumineux qui ont traversé l'œil. Chez les Carnassiers, les Ruminants, les Solipèdes et les Pinnipèdes, la choroïde offre un tapis formé soit de cellules soit de fibres, et c'est à la présence de ce tapis que l'œil de ces animaux a la faculté de luire dans l'obscurité. La rétine, partie essentielle de l'œil, est une membrane nerveuse qui tapisse la surface interne de la choroïde; elle est formée par l'épanouissement du nerf optique; le corps vitré est une sorte de gelée incolore et transparente qui occupe la plus grande partie de la cavité de l'œil; le cristallin qui est placé devant le corps vitré, a la forme d'une lentille bicunvexe, transparente, susceptible de changer de courbure 
et de s'accommoder aux distances; l'humeur aqueuse est un liquide moins dense que le corps vitré, il est situé entre le cristallin et la cornée; l'iris, ordinairement coloré, est un diaphragme elliptique placé devant le cristallin; il est percé au centre d'une grande ouverture qui forme la pupille; cette dernière est susceptible de se dilater ou de se contracter selon la plus ou moins grande quantité de rayons lumineux qui l'affecte. L'œil est mu par six muscles principaux, dont quatre droits et deux obliques.

Les paupières sont des replis de la peau qui s'ouvrent et se ferment à volonté à l'aide de deux mus. cles. Les larmes sont sécrétées par des glandes lacrymales, situées dans la région supérieure des paupières; ces dernières lorsqu'elles se ferment ramènent les larmes sur les yeux pour les lubrifier, puis ce liquide descend dans le nez par un petit canal appelé naso-lacrymal. Chez quelques mammifères ce canal s'ouvre sur la surface de la peau à l'entrée de la narine.

L'œil peut être comparé à une chambre noire munie d'une lentille convergente qui, par une petite ouverture, donne accès à l'intérieur, aux rayons lumineux; ces derniers se convergent en traversant la lentille et vont fixer l'image au fond de la chambre noire qui est mise au point. De même les ondes lumineuses, après avoir traversé la cornée et l'humeur aqueuse, passent par la pupille qui se contracte si la lumière est vive, et se dilate dans le cas 
contraire, puis elles pénètrent dans le cristallin, où elles se convergent pour aller ensuite fixer l'image sur la rétine au fond de l'œil, après avoir traversé le corps vitré ; l'impression est alors transmise au cerveau par le nerf optique.

Comme dans la chambre noire, l'image apparaît réduite et renversée.

Le sens de l'ouïe est destiné à la perception des sons produits par les mouvements rapides des corps, et transmis par des ondes sonores, l'oreille en est l'organe. Cette dernière se divise en oreille externe, oreille moyenne et oreille interne. Lioreille externe est formée par le pavillon et le conduit auditif; le premier est la partie saillante, qui prend aussi le nom de conque, et est de formes et de dimensions diverses ; très grand chez certaines Chauves-Souris, il devient nul dans les Mammifères aquatiques et souterrains. Le conduit auditif est creusé dans l'os temporal; des poils se voient à l'entrée et des glandes y sécrètent un liquide, le cérumen, qui empêche les insectes et la poussière de pénétrer à l'intérieur. L'oreille moyenne, que l'on appelle encore caisse du tympan, est une chambre étroite creusée dans le rocher à la suite du conduit auditif; la partie externe est formée par le tympan, membrane mince tendue obliquement et susceptible de vibrer; la partie externe offre deux ouvertures, la fenêtre ovale et la fenêtre ronde, situées l'une audevant de l'autre. Dans l'intérieur on retrouve une série de petits osselets, que l'on appelle le marteau, 
dont le manche est comme soudé à la face interne du tympan; l'enclume qui s'articule avec la tête du marteau, et dont l'une des branches s'unit à l'os lenticulaire; puis ce dernier s'articule avec l'étrier qui est engagé dans la fenêtre ovale; ces pièces sont mobiles et sont mises en action par deux muscles, dont l'un est fixé au marteau et l'autre à l'étrier. L'oreille moyenne communique avec le pharynx à l'aide d'un tube cartilagineux appelé trompe d'Eustache, qui permet à l'air d'y pénétrer lorsque l'animal boit ou avale des aliments. L'oreille interne ou labyrinthe est placée plus profondément dans le temporal ou rocher; elle se compose de trois parties principales, le vestibule au centre, les canaux semi-circulaires en dehors et le limaçon en dedans. Le vestibule est situé entre le limaçon et les canaux semi-circulaires; il est formé de deux ampoules à parois molles et minces, l'une désignée sous le nom d'utricule et l'autre de succule; le vestibule communique avec la chambre moyenne par la fenêtre ovale; les canaux semicirculaires sont trois tubes en demi-cercle s'ouvrant sur le vestibule, ils ont une ampoule à l'une de leurs extrémités; le limaçon, ainsi nommé parcequ'il représente la forme de certaines coquilles de mollusques gastéropodes, est un tube décrivant de deux à cinq tours de spires, selon les différentes espèces de Mammifères ; il est divisé en deux parties par une lame en spirale, une de ses parties communique avec la chambre moyenne par la fenêtre 
ronde, et l'autre s'ouvre dans le vestibule. La plus grande partie du nerf auditif vient aboutir dans la lame spirale, dans laquelle se trouve le canal cochléaire; ce canal offre des rangées de cellules ciliées ou fibres radicales microscopiques, et leur ensemble constitue l'organe de Corti.

Les ondes sonores en pénétrant dans l'oreille parcourent toutes ses cavités, mettent en vibration. ses différents organes et viennent ébranler le nerf auditif, qui transmet ses impressions au cerveau.

Chez les Mammifères, la vie ne s'entretient pas toujours au moyen d'aliments de même nature; tous ces animaux n'ont pas un régime commun et uniforme ; ce régime, au contraire, est souvent très varié. Ainsi, nous rencontrons des espèces qui se nourrissent exclusivement de chair, souvent même de chair palpitante; on les appelle carnivores. D'autres ne vivent que d'herbes; ils ont reçu le nom d'herbivores. Un certain groupe mangent des insectes, des larves, des vers et autres petits animaux analogues; ce sont les insectivores. Puis viennent les frugivores qui, comme leur nom l'indique, se nourrissent des fruits durs de différents arbres, de grains et graines de diverses sortes. Enfin il y a une dernière catégorie dont la nourriture se $\mathrm{com}^{-}$ pose de toutes espèces d'aliments; ils sont connus sous le nom d'omnivores. Toutefois ces divisions ne sont pas strictement exclusives; en effet, il y a des insectivores qui se nourrissent de chair comme il y a des carnivores qui détruisent de petits inver- 
tébrés. De même, parmi ceux qui se nourrissent d'herbes ou de fruits, il s'en rencontre qui font un usage simultané de ces deux espèces d'aliments.

La forme et la taille qu'affectent les Mammifères offrent de nombreuses variations; il y a des colosses conme il y a des pygmées. On trouve des mammifères qui ont quatre membres avec depuis un jusqu'à cinq doigts, d'autres n'ont que deux membres seulement et $f_{-1}$ core sont-ils transformés en nageoires; d'autres encore voient se développer sur leur front des excroissances cornées ou bien leur nez s'allonger «n trompe.

Ces différences de formes et de taille sont tout de même en rapport avec le milieu dans lequel vivent ces animaux, comme elles sont également adaptées à leur régime. Ainsi, tel animal destiné par sa nature à se nourrir de proies vivantes, plus ou moins grosses, plus ou moins agiles, aura un corps élancé et souple, des muscles puissants et la force nécessaire pour assurer la capture de sa proie. Les Taupes, que leur vie souterraine dérobe à nos regards, sont munies de mains et d'ongles robustes pour creuser des galeries dans le sol, afin d'y chercher des vers; il en est de même des autres espèces de fouisseurs dont les membres sont conformés pour ce genre de vie. Les espèces arboricoles, se nourrissant de fruits, ont des membres déliés et souples, qui leur permettent de grimper sur les arbres et de les parcourir en tous sens.

Les membres de la Chauve-Souris sont transfor- 
més en ailes, et, à l'instar de l'oiseau, elle parcourt l'espace pour y chercher sa nourriture. Ces masses vivantes, les Cétacés, de même que les Phoques, affectent dans leur corps la forme d'un poisson et leurs membres sont transformés en nageoires qui les rendent aptes à vivre de la même vie et dans les mêmes milieux que les poissons. Ainsi, tout est proportionné au genre de vie, à la taille et à la force de chaque individu, avec une sagesse et une profondeur de vues vraiment admirables.

Et maintenant, si nous jetons un regard sur les autres classes du règne animal, pour ne mentionner que ce dernier, nous y voyons également que tous les êtres qui nous sont connus ont été formés d'après un plan raisonné qui s'harmonise admirablement avec les milieux et les besoins de chaque espèce, ce qui démontre à l'évidence que tout dans la nature a été coordonné par une Intelligence divine, qui s'est plue à créer ces myriades d'existences, aux formes et aux couleurs si variées, vivant dans les abîmes des mers, à la surface de la terre ou dans le sol, et dont un si grand nombre resteront éternellement inconnues des savants, éternellement ignorées de l'homme qui s'imagine que tout a été créé à son intention et pour sa jouissance. 


\section{LES MAMMIFERES}

DE $A$

\section{PROVINCE DE QUÉBEC}

CLEF POUR LA DISTINCTION DES ORDRES DE MAMMIFERES

Mâchoires dépourvues de canines; incisives, 2 en haut et 2 en bas ou 4 en haut et 2 en bas; taillées en biseau; longueur maximum 30 pouces... GLIRES.

Mâchoires pourvues de canines petites ; taille petite ; longueur maximum 4 pouces; membres libres... INSECTIVORA

Mâchoires pourvues de canines petites; taille peLite; membres réunis par une membrane adaptée pour le vol..... ........................................... CHIROPTERA

Corps piciforme; membres postérieurs manquant; queue large et aplatie, disposée horizontalement; aquatiques. Cetacea

Taille très grande; doigts des membres enveloppés dans un sabot...............................................
Canines fortes et très développées ; incisives I 2 en UNGLLATA tout, quelquefois moins; ongles des doigts forts et bien apparents. Longueur minimum 8 pouces. Carnivores.....

FERE

\section{ORdRE GLIRES.-RONGEURS}

Les Rongeurs sont, de tous les Mammifères, les plus nombreux et les plus répandus sur la surface du globe; on les rencontre en effet depuis la zone torride jusqu'au milieu même des neiges éternelles. 
Partout où la végétation n'est pas entièrement éteinte, nous sommes sûrs d'y retrouver leur trace; mais c'est surtout dans les régions tempérées et équatoriales qu'ils se montrent les plus abondants et les plus variés en espèces.

Comme cet ordre renferme $u n$ grand nombre d'espèces, il serait bien difficile de les classer d'après leur physionomie générale, car cette dernière varie avec les familles et même avec les espèces; ainsi les uns ont un corps allongé et élancé, tandis que chez les autres, il est court et trapu; quelques-uns sont recouverts de poils épais et soyeux, d'autres de longs piquants; un certain nombre ont la queue nue ou bien recouverte de poils courts, tandis que chez plusieurs elle est ornée de poils longs et touffus; parfois même cet appendice est rudimentaire. Mais le principal caractère commun qui permet de classer ces animaux avec certitude, repose dans le mode de dentition. Chez eux, en effet, les incisives, au nombre de deux à chaque mâchoire, quelquefois quatre à la mâchoire supérieure, sont fortes et tranchantes; elles sont taillées en biseau et implantées dans l'alvéole en forme d'arc, et de plus elles repoussent à mesure qu'elles s'usent; les canines manquent ; les molaires, qui sont à surface rugueuse, sont toujours séparées des incisives par un espace vide.

Les Rongeurs sont de petite ou de moyenne taille, le Castor étant le plus gros. Ils sont plantigrades. La plupart ont le train de devant plus bas. 
que celui de derrière, de sorte que ces animaux sautent plutôt qu'ils ne marchent. Leurs facultés sont peu développées; aussi sont-ils, pour la plupart, incapables d'employer la ruse pour se dérober à la poursuite de leurs ennemis, leur seule ressource consistant à fuir ou à se cacher dans le premier trou qu'ils rencontrent. On remarque toutefois qu'un bon nombre se montrent très habiles dans l'art de construire leurs habitations.

Ces animaux se nourrissent de végétaux, tels que fruits de toutes sortes, racines, écorces d'arbres; feuilles, légumes, herbes; quelques-uns ajoutent au besoin des substances animales. Les uns vivent par paires, les autres par bandes; il y en a qui grimpent avec agilité et passent la plus grande partie de leur vie sur les arbres; d'autres qui se creusent des terriers pour s'y cacher; d'autres, enfin, qui confectionnent, à l'exemple des oiseaux, de magnifiques nids. Le grand nombre habitent les forêts ; plusieurs établissent domicile dans les champs ; quelques-uns préfèrent le voisinage de l'homme et s'attachent, pour ainsi dire, à ses pas. Dans les régions froides, quelques espèces sont sujettes au sommeil hibernal; un certain nombre s'amassent des provisions qu'elles placent à proximité de leur demeure pour la saison d'hiver; d'autres enfin recherchent journellement leur nourriture, se contentant de ce qu'elles peuvent rencontrer à cette saison de l'année.

La fécondité des Rongeurs est surprenante. Dans 
la plupart des cas, la femelle met bas de trois à six fois dans l'année et de plusieurs petits chaque fois. Aussi bien ces animaux seraient-ils les dominateurs de la terre s'ils n'avaient, dans les oiseaux de proie, les carnassiers, les maladies et les pluies de longue durée, autant d'ennemis qui les détruisent en quantité.

Lorsque certaines espèces apparaissent en grand nombre, elle peuvent devenir nuisibles à l'agriculture. C'est pourquoi le cultivateur qui redoute le voisinage des carnassiers pour ses animaux domestiques, doit également craindre ces êtres petits et faibles, sans moyen de défense, qui cependant causent souvent des dommages considérables en détruisant les produits agricoles et en dévorant les plantes jusque dans leurs racines.

\section{CLEF POUR LA DISTINCTION DES FAMILLES DE RONGEURS}

Incisives, 6 en tout, dont 4 en haut; queue très courte ; oreilles longues, dents $28 \ldots \ldots \ldots \ldots \ldots \ldots \ldots$ LEPORID $A$ :

Incisives, 4 en tout.

Pelage muni de longs piquants ; taille moyenne

ERETHIZONTID.E

Taille petite ; queue et membres postérieurs très longs. ZAPODID.E

Taille petite ; membres de longueur moyenne; molaires, 2 ou 4 en haut et 2 ou 3 en bas de chaque côté de la mâchoire. MURIDA

Queue large, aplatie et écailleuse; tạille 30 pcs CAstorid

Queue longue et touffue ; molaires, 4 ou 5 en haut, et 4 en bas de chaque côté de la mâchoire. Scruridx 


\section{FAMILLE LEPORIDE. LIÈVRES.}

Formule dentaire. $-i \cdot \frac{2-2}{1-1} m \cdot \frac{6-6}{5-5}$ (i)

Les Léporidés sont faciles à reconnaître par la présence de quatre incisives à la mâchoire supérieure, dont une paire est située en arrière de la paire principale ; les membres postérieurs sont plus longs que ceux de devant; les oreilles sont très longues ; la queue est très courte et touffue; les yeux sont grands; le pelage est épais et doux au toucher.

Les Lièvres sont des animaux timides et craintifs que le moindre bruit effraie et fait fuir.

\section{Genre LEPUS, Linné.}

Mêines caractères que ceux de la famille.

\section{Lepus americanus, (ERXLEBEN).}

\section{I,e Iièvre d'Amérique.}

Pelage, en été, d'un brun canelle pâle, mélangé de noir ; le cou et la poitrine d'un brun jaunâtre ; le menton, la gorge et le reste des parties inférieures, blancs. En hiver le pelage devient blanc à l'extrémité, le fond du poil restant gris de plomb; cette dernière teinte est séparée du blanc par une étroite bande de brun roux. Longueur 20 ; queue $I \mathrm{I} / 2$; oreilles 3 . (2)

Le Lièvre, que tout le monde connaît, est très commun dans toutes nos forêts, mais il choisit de

(I) Les chiffres de la ligne supérieure indiquent le nombre de dents de chaque côté de la mâchoire supérieure; ceux de la ligne inférieure correspondent à celles de l'autre mâchoire. $i=$ incisives ; $c=$ canines ; $p m=$ prémolaires ; $m=$ molaires.

(2) Toutes les mesures sout en pouces, à moins d'indication contraire. 
préférence celles dont le bois est très touffu, parce qu'il y trouve probablement plus de sécurité. Il préfère aussi les endroits élevés et secs aux terrains bas et humides; il ne quitte jamais la forêt pour se répandre dans les terres cultivées, comme le fait son congénère d'Europe ; ce n'est qu'accidentellement qu'il s'en écarte; il évite même de se trouver dans

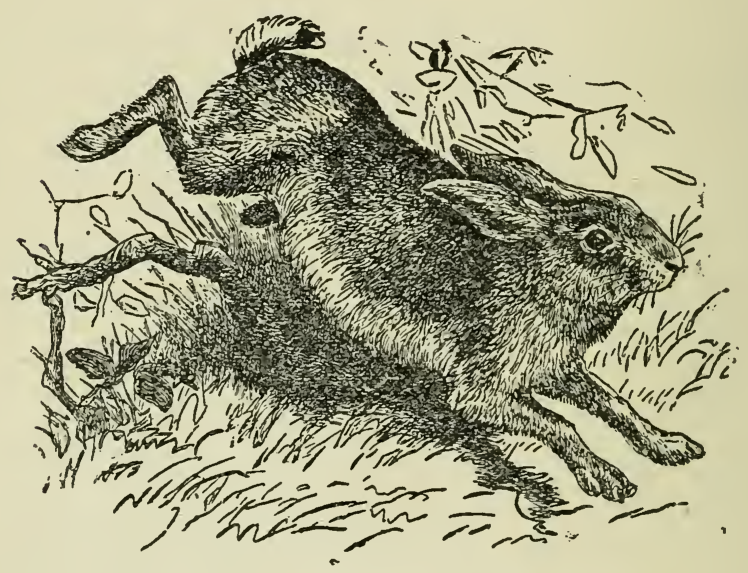

Fig. 2.-Le Lièvre d'Amérique.

des clairières où il pourrait plus facilement devenir la proie des oiseaux carnassiers; aussi ce pauvre animal a-t-il besoin de veiller à sa conservation, car il a à craindre bien des ennemis, comme les oiseaux de proie, les belettes, les martes, les lynx, les renards. Mais celui qui exerce le plus de ravages chez lui, est sans doute l'homme, qui en détruit 
considérablement, soit au fusil soit au moyen de collets.

Pour se garantir en quelque sorte de tant d'ennemis, il a été doué par la nature d'une grande agilité et d'un bon instinct; la longueur de ses pattes postérieures ajoute encore à la rapidité de ses mouvements, surtout lorsqu'il franchit quelque hauteur. Lorsqu'il est poursuivi, son instinct le guide à se réfugier au plus épais de la forêt et à revenir plusieurs fois dans le même chemin afin de dépister son agresseur, et, par ce subterfuge, il réussit souvent à lui échapper. Le Lièvre est d'un naturel timide et craintif. Si à cela l'on ajoute qu'il est doué d'une ouie excessivement développée, on comprend aisément qu'il ne peut jouir longtemps d'un doux repos; aussi le moindre bruit lui fait-il peur; une feuille sèche qui tombe près de lui, le croassement d'une greinouille, la brise qui souffle à travers le feuillage, suffisent souvent pour le mettre en fuite; mais il revient l'instant d'après, car il quitte rarement l'endroit qui l'a vu naître, à moins qu'il n'en soit chassé.

Le Lièvre est nocturne, il cherche sa nourriture la nuit, le soir ou le matin de bonne heure; ce n'est que pressé par la faim ou chassé de son gîte, qu'on le voit durant le jour. Toutefois il n'est pas rare, au printemps, à l'époque des amours, de le rencontrer tard dans la première partie du jour.

Il se nourrit de plantes tendres et succulentes; mais lorsque la neige recouvre le sol, il se contente 


\section{$-34-$}

de l'écorce du saule, du peuplier, du bouleau, ainsi que des bourgeous de pins.

A l'automne, sous notre latitude, le changement de couleur du pelage s'effectue vers le commencement de novembre, à la tombée des premières neiges. Au printemps, c'est en avril qu'il reprend sa livrée d'été.

La femelle met bas en mai de quatre à six petits. Il est probable cependant qu'elle a encore des jeunes une deuxième fois en juillet. Elle les dépose dans un nid qu'elle prépare sous un tronc d'arbre renversé ou dans un enfoncement quelconque qu'elle tapisse d'herbes sèches; les petits peuvent quitter le nid après dix ou douze jours et pourvoir eux-mêmes à leur nourriture. Le mâle prend également soin des jeunes.

La chair du Lièvre, quoique sèche et d'un gotit particulier, est cependant très recherchée.

\section{FAMille EREThIZONTID E. PORCs-Epics.}

Formule dentaire. $-i \cdot \frac{1-1}{1-1} m \cdot \frac{4-4}{4-4}$

Les molaires sont pourvues de racines à la base; les membres antérieurs sont terminés par quatre doigts et les postérieurs par cinq, munis d'ongles longs, comprimés et recourbés; le museau est recouvert de poils courts.

Les Porcs-Epics sont des rongeurs d'assez forte taille, au corps lourd et trapu, dont la peau est hérissée de longs piquants que l'on aperçoit à travers le poil ordinaire. 


\section{Genre ERETHIZ0N, F. Cuvier.}

Jambes courtes et fortes ; ongles forts ; queue courte, épaisse, déprimée et recouverte de poils et de piquants.

\section{Erethizon dorsatus, (LinNé).}

Le Porc-Epic du Canada.

Poil long, d'un noir brunâtre mélangé de blanc jaunâtre sur le dos; les piquants qui recouvrent tout le corps, à l'exception des parties inférieures, sont d'un blanc jaunâtre avec la pointe brune, et d'une longueur variant depuis un pouce jusqu'à quatre; les poils les plus longs atteignent une longueur de cinq à six pouces. Longueur totale, 35 à 40.

Les jeunes sont d'un noir uniforme et n'ont pas de piquants.

Le Porc-Epic habite l'est de l'Amérique septentrionale. On le rencontre dans les forêts où il n'est point rare,surtout vers le nord. Son corps est ramassé, sa démarche est lourde et, sans cette terrible armure dont sa peau est recouverte, il deviendrait une proie facile pour les carnassiers; mais il est rare que ces derniers l'attaquent. Si l'un d'eux cependant s'élance sur lui, il s'en retourne bientôt avec le museau et la bouche garnis de piquants qui se sont détachés de l'animal ; car il est faux que le Porc-Epic lance ses piquants à distance, comme quelques personnes le croient ; mais ils tiennent peu à la peau et l'extrémité, qui est pointue et finement barbelée dans la direction de la base, pénètre facilement dans les chairs et n'en sort que difficilement, de sorte que ces piquants se détachent plutôt de leur base. 
Lorsque le Porc-Epic prévoit quelque danger, il cherche à se réfugier dans un trou, et s'il ne peut en trouver, il hérisse alors ses piquants, baisse la tête entre ses pattes de devant, et attend son agres. seur qui presque invariablement s'en retourne en poussant des cris de douleur.

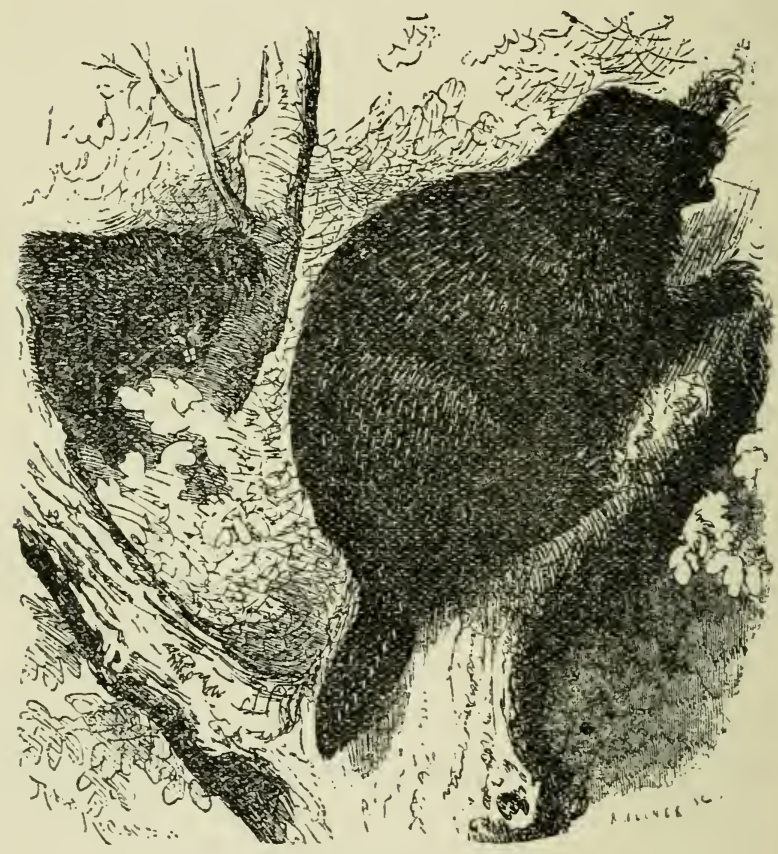

Fig. 3 -Le Porc-Epic du Canada.

Quoique d'habitudes nocturnes, cet animal se rencontre assez souvent pendant le jour. Il vit 
d'herbe en été, mais en hiver il se nourrit de l'écorce des arbres, particulièrement de celle de la pruche, dont il dépouille le tronc jusqu'à une grande hauteur. Toutefois les ormes, les peupliers et les sapins, souffrent aussi de ses attaques. On peut aisément retracer sa présence par l'examen des arbres dont l'écorce a été ainsi enlevée. Les jeunes arbres sont ceux qu'il préfère d'avantage. Armé d'ongles forts et acérés, il grimpe bien facilement sur les arbres, où on peut le voir souvent.

Audubon nous a donné quelques détails intéressants sur un Porc-Epic, qu'il a gardé en captivité pendant l'espace de six mois. "Dans plusieurs occasions, dit-i1, nous fûmes témoin de la manière dont il se servait de ses piquants formidables pour se rendre invulnérable contre les attaques de ses ennemis.

"Il sortait fréquemment de sa cage pour se promener dans le jardin. Il était devenu très doux et ne montrait aucune inclination vicieuse; quand nous l'appelions en lui présentant une pomme ou autre fruit, il tournait lentement la tête vers nous, nous regardait d'une manière suppliante, puis il venait prendre le fruit de notre main, se levait debout et le portait avec les pattes à sa bouche. S'il trouvait la porte de notre étude ouverte il y entrait, s'approchait lentement de nous, se frottant à nos jambes, nous regardait comme pour nous supplier de lui donner d'autres friandises; souvent nous cherchions à le mettre en colère, il ne fit jamais usage 


\section{$-3^{8}-$}

de ses piquants contre nous; mais à peine nn chien avait-il fait son apparition, qu'aussitôt il se mettait sur la défensive, il baissait le museau, hérissait ses piquants, remuait la queue d'une manière menaçante, montrant ainsi qu'il était prêt à se défendre.

"Un gros chien querelleur et féroce du voisinage, avait l'habitude d'entrer dans notre jardin par un trou pratiqué sous la clôture. Un matin, de bonne heure, nous le vîmes s'élancer sur un objet dans un coin du jardin, c'était sur notre Porc-Epic qui était sorti de sa cage durant la nuit. Le chien ne semblait pas tenir compte de l'attitude menaçante du Porc-Epic, et supposant probablement qu'il avait affaire à un animal pas plus fort qu'un chat, il s'élança sur lui la gueule ouverte. A l'instant le Porc-Epic sembla doubler de taille, et lui asséna un fort coup de queue, qui lui fit lâcher prise et pousser des cris de douleur. Il avait la gueule, la langue et le museau garnis de piquants ; il ne pouvait fermer la gueule et il s'empressa de quitter le jardin. Ce fut une leçon qui lui servit, et rien ne put le décider à revenir dans cet endroit où il avait été si mal reçu. Quoiqu'on lui enlevât de suite les piquants, nous remarquâmes que sa tête resta enflée pendant plusieurs semaines, et ce ne fut que deux mois plus tard qu'il guérit." (I)

Audubon ajoute encore que son captif souffrait beaucoup de la chaleur, et qu'il finit par ne plus sortir

(1) Audubon \& Bachman, Quadrupeds of North America, London, I847-54. Vol, I, pp. 280-8r. 
de sa cage; il gémissait et ne faisait plus aucun monvement; finalement il refusa toute nourriture. Le voyant en cet état, on le porta à son arbre favori : l'animal commença par en ronger l'écorce, mais le lendemain il était mort.

La femelle met bas deux fois dans l'année et de deux ou trois petits chaque fois, qu'elle dépose soit dans un arbre creux, soit dans un enfoncement de rocher. La première portée à lieu vers le commencement de mai ou à la fin d'avril.

\section{FAMILLE DIPODID瓜. MÉRIONeS.}

Formule dentaire. $-i \cdot \frac{1-1}{1-1} m \cdot \frac{3-3}{3-3}$ ou $\frac{4-4}{3-3}$

Queue, plus longue que le corps, déliée et peu velue; les incisives supérieures sont comprimées et cannelées; les doigts sont au nombre de cinq à chaque membre.

Ces petits mammifères se distinguent par la longueur excessive des membres postérieurs comparés à ceux de devant qui sont très courts, aussi procèdent-ils plutôt par sauts.

\section{Genre ZAPUS, Coues.}

Taille petite; oreilles moyennes; yeux assez petits ; membres postérieurs trois fois plus longs que ceux de devant, très grêles; le pouce des membres antérieurs est rudimentaire; la queue est très longue, arrondie et peu recouverte de poils courts.

\section{Zapus hudsonius, (Ziмm.)}

\section{La Mérione de la Baie d'Hudson.}

Molaires supérieures, quatre de chaque côté ; pelage d'un brun jaunâtre clair, entremêlé de poils noirs ; ces der- 
niers sont plus abondants sur le dos et forment une large bande longitudinale plus foncée; le dessous du corps et les pieds sont blancs. Longueur, 3 ; queue, 5 .

Cette petite Souris est distribuée dans presque toute l'Amérique Septentrionale, surtout vers le nord. Dans plusieurs endroits de la province on la

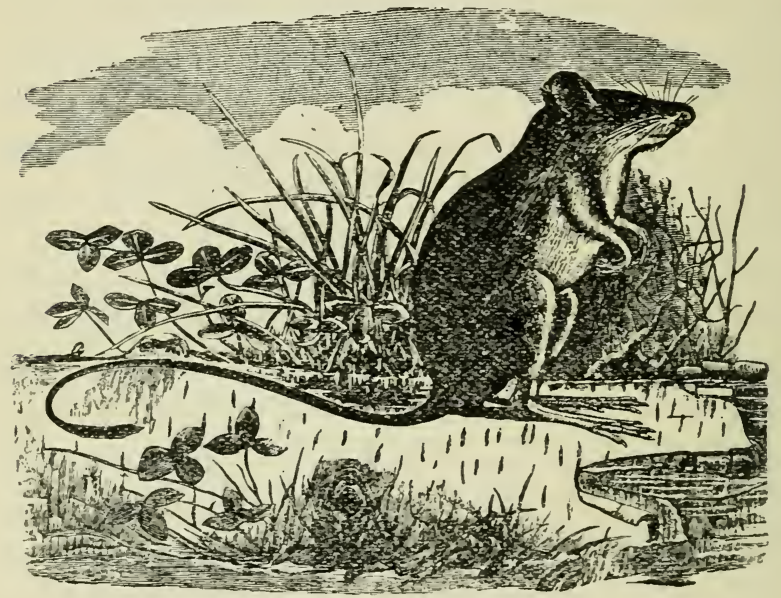

Fig. 4.-Mérione de la Baie d'Hudson.

nomme Souris sauteuse, à cause des bonds prodigieux qu'elle exécute lorsqu'elle est poursuivie ; ces sauts atteignent une longueur de trois à huit pieds. Aussi est-elle très difficile à capturer même sur un terrain uni. Lorsqu'elle n'est pas inquiétée, elle marche comme une autre souris, sans faire de bonds. La longueur de sa queue ne saurait la faire 
confondre avec les autres rongeurs de même taille. Cette petite Souris se plaît dans les endroits couverts de buissons, à la lisière des forêts, au bord des ruisseaux, ainsi que dans les prairies et les terres cultivées. A l'automne, je l'ai souvent surprise abritée sous des gerbes de grain ou sous des amas de foin, et elle s'éloignait avec tant d'agilité et de rapidité qu'elle semblait à peine toucher la terre à chaque saut. C'est au crépuscule, quelquefois même durant le jour, yu'elle cherche sa nourriture, qui consiste en bourgeons, faînes, noisettes, herbes, baies et graines de toutes sortes.

Elle met bas trois fois dans la saison et de deux à quatre petits chaque fois; elle pose son nid sous des racines d'arbres, dans des trous sous terre à une faible profondeur, dans de petites fentes de rochers, etc. Ce nid est tapissé d'herbes sèches, de plumes d'oiseaux et de poils d'animaux.

A l'automne, dans les régions froides, elle se creuse dans le sol, à une certaine profondeur, un nid qu'elle tapisse de feuilles, puis elle s'y endort enroulée en boule, pour ne s'éveiller qu'au printemps. Dans les endroits plus au sud on peut la voir active pendant toute l'année.

Plusieurs sous-espèces ont été créées, dont une se trouve dans notre province, au Labrador et à Godbout; elle a pour nom Z. h. ladas, Bangs. Elle diffère de l'espèce précédente par une taille un peu plus forte ; la bande du dos est ordinairement moins apparente. 


\section{Zapus insignis abietorum, PREBLE. La Mérione des bois.}

Cette variété ne possède que trois molaires supérieures de chaque côté ; son pelage est d'un jaune chamois teinté de gris foncé sur les côtés du corps ; dessous blanc; les joues, le partie antérieure du cou et une petite ligne qui sépare la partie colorée du blanc du dessous du corps, sont d'un jaune plus vif que les parties supérieures. La bande du dos se rétrécit à mesure qu'elle se rapproche de la queue. De taille plus forte que la précédente.

Cette sous-espèce a été remarquée au lac Edouard, à Godbout et dans Ontario. Elle se plaît dans les forêts, les buissons et surtout près des cours d'eau

\section{Famille MURID瓜. Rats, Campagnols, etc.}

Formule dentaire. $-i \cdot \frac{1-1}{1-1} m \cdot \frac{3-3}{3-3}$,

Ces animaux sont surtout caractérisés par l'absence de prémolaires sauf un genre exotique, de sorte que le nombre de dents se trouve réduit à seize en tout. Ce nombre aussi minime est peut-être le seul caractère important qui puisse les faire reconnaître avec certitude.

Les Muridés sont très nombreux en espèces et sont répandus sur tout le globe ; c'est parmi eux que l'on rencontre les espèces les plus petites à l'exception peut.être des Musaraignes.

\section{SOUS-FAMILLE MICROTINA.}

Corps ramassé ; mouvements lents ; yeux petits ; oreilles peu apparentes en dehors du poil; jambes courtes; incisives très larges, souvent plus larges que longues. 


\section{Genre FIBER, Cuvier.}

Ce genre comprend les mammifères les plus gros de la famille; la queue, qui est presque aussi longue que le corps, est comprimée latéralement, et est presque dépourvue de poils; les pieds de derrière affectent une position oblique et les doigts sont réunis entre eux par une membrane.

\section{Fiber zibethicus, (LINNÉ).}

\section{Le Rat-Musqué.}

Pelage très fourni, lustré et doux au toucher, d'un brun foncé lavé de roux en dessus, passant au gris cendré en dessous ; yeux petits ; oreilles garnies de poils et en partie cachées dans le pelage. Longueur II ; queue Io.

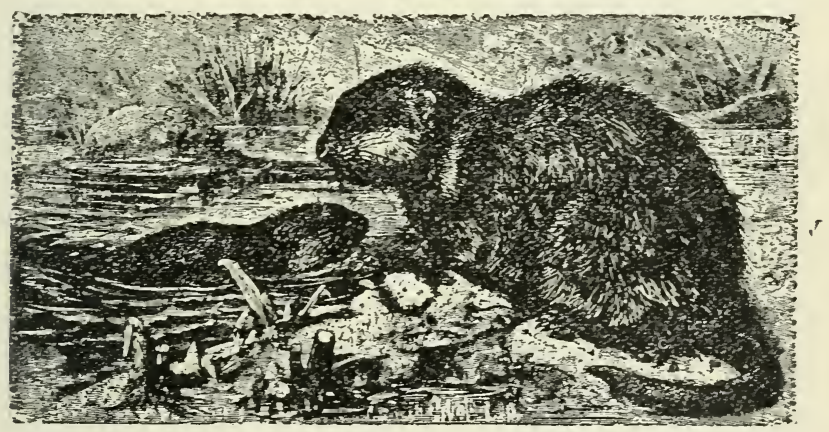

Fig. 5.-Le Rat-2Iusqué.

Le Rat-Musqué habite l'est de l'Amérique du Nord et, comme ses habitudes sont aquatiques, c'est près des cours d'eau, des étangs, des écluses de moulins, etc., qu'on le rencontre. Il se montre commun partout, et chez nous, il n'y a peut-être 
pas de petits ruisseaux ou étangs qui ne tarissent pas, sur le bord desquels ne vivent quelques familles de Rats-Musqués.

Cet animal est nocturne; il se nourrit de racines et de plantes aquatiques et autres; cependant à l'automne, lorsqu'il se trouve à proximité des habitations et qu'il peut pénétrer dans les caves, il aime à s'y repaître de carottes, navets, patates, etc., qu'il transporte même dans son réduit. Il visite également les vergers à cette époque de l'année pour manger des pommes tombées à terre; il est aussi friand des grandes espèces de mollusques d'eâl douce, dont on retrouve les coquilles accumulées aux alentours de sa retraite.

A l'arrière saison, sur une des rives qu'il fréquente, il cretse une ou plusieurs galeries obliques dont la principale peut atteindre une longueur de huit à douze pieds, avec issue sous l'eau et à l'extrémité de laquelle il pratique un élargissement ou chambre, qui peut avoir de quinze à vingt pouces de diamètre et même: plus; c'est dans cette chambre, tapissée de feuilles sèches, qu'il habite en famille durant l'hiver, pour l'abandonner ensuite au printemps. C'est là également, ou dans un des couloirs, qu'il accumule ses provisions d'hiver. Cette chambre est située parfois si près de la surface du sol, qu'elle est souvent enfoncée par les animaux domestiques qui fréquentent ces parages.

Dans les endroits où l'eau atteint une profondeur de deux à six pieds, le Rat-Musqué se construit 
souvent une hutte avec des roseaux, des racines, des joncs ou autres plantes aquatiques et terrestres, qu'il accumule et entrelace avec celles qui émergent du fond, de manière à former une espèce de dôme au dessus de l'eau. Il arrive aussi qu'il place cette hutte à travers des racines de troncs d'arbres qui s'y rencontrent; au centre de cet amas d'herbes, il pratique un trou avec une entrée sous l'eau et une sortie sur un des côtés à sa partie supérieure. Quelques naturalistes prétendent qu'il mêle de la boue à ces accumulations de végétaux, qui sont sans doute des provisions qu'il amasse pour l'hiver et qu'il vient ensuite ronger à loisir.

Quoique nocturne, le Rat-Musqué se montre assez souvent durant le jour, surtont dans les journées sombres. Quelque lourds et taciturnes que paraissent ces animaux, ils ne manquent pourtant pas d'agilité et de gaîté, lorsqu'ils sont dans l'eau et qu'ils se croient en sécurité. Audubon nous a laissé une intéressante page sur leurs mœurs: "Par une belle nuit, dit-il, on peut les voir dans les étangs des moulins, dans les pièces d'eau profonde et tranquille; ils jouent, ils nagent de tout côté, laissant dans l'eau de longs sillons; ils s'arrêtent près des touffes d'herbes, sur les pierres d'où ils peuvent atteindre un point d'appui au-dessus de l'eau ou sur les bords de l'étang; ils s'asseyent sur la rive et de là ils sautent à l'eau l'un après l'autre. De temps à autre on en voit un couché, immobile à la surface de l'eau, le corps paraissant 
très aplati, il donne par intervalles un léger coup avec sa queue comme le fait le castor, puis il disparaît subitement... A une distance de dix ou vingt verges, le Rat-Musqué, reparaît de nouveau, pour recommencer le même manège ou se joindre à ses compagnons. Pendant ce temps, d'autres sur la rive se nourrissent d'herbes, arrachent des racines de différentes espèces de plantes pour les transporter ailleurs. On dirait que ces animaux forment une petite communaute joyeuse et ne demandent autre chose pour être heureux que le repos et la tranquillité. Un coup de feu tiré dans ce moment les fait tous fuir avec précipitation; à la flamme du fusil tous plongent à l'eau et se réfugient dans leur demeure. Durant le jour, la vue leur fait defaut et il est alors possible de les tuer lorsqu'ils nagent, mais pendant la nuit il est très difficile de les atteindre; pour réussir il faut que le chasseur soit placé de telle sorte que l'animal ne voit pas la flamme que fait le fusil en partant." (I)

Dans les terres cultivées, lorsque les Rats-Musqués se montrent communs, ils causent souvent des dommages par le grand nombre de galeries qu'ils creusent sous terre et que les animaux défoncent, ainsi que dans les écluses de moulins où l'eau pénètre dans ces galeries et cause souvent des inondations sur les terrains avoisinants.

La femelle met bas de cinq à sept petits, en avril oul mai.

(I) Audubon. Quadrupeds of N. A., Vol. I, pp. II2-II3. 
On capture facilement les Rats-Musqués au moyen de pièges tendus sur leur passage. Outre l'homme qui lui fait la guerre, le vison est encore pour lui un ennemi redoutable: il le poursuit sous l'eau et pénètre même dans sa'retraite pour l'égorger. Lorsqu'il est attaqué il se défend vigoureusement.

On a donné à cet animal le nom de Rat-Musqué, parce qu'il répand, au printemps surtout, une forte odeur de musc que sécrètent des glandes spéciales.

Dans quelques écrits français, le Rat-Musqué porte le nom d'Ondatra, mais j'ai préféré lui conserver le premier nom sous lequel il est particulièrement connu et qui le caractérise si bien.

\section{Genre SYNAPTOMYS, Baird.}

Les animaux de ce genre tiennent lieu d'intermédiaires entre les Lemmings et les Campagnols; leurs incisives sont cannelées.

\section{Synaptomys fatuus, BANGS.}

\section{Le Campagnol lemming.}

Poil long et doux au toucher, d'un brun grisâtre, plus foncé en dessus et plus clair en dessous; tête large; moustaches longues. Longueur 4 ; queue $3 / 4$.

Cette espèce a été capturée au lac Edouard; elle se voit aussi dans le Nouveau-Brunswick, le Maine, etc. Les forêts et les lieux marécagenx ou humides semblent être les endroits qu'elle affectionne davantage.

3. Genre ricRoTUS, Schrank.

Oreilles petites, plus ou moins cachées dans le poil; 
museau obtus; tête large, front bombé; yeux petits ; corps gros ; membres courts ; quatre doigts en avant, cinq en arrière.

\section{Microtus pennsylvanicus. (ORD.) \\ Le Campagnol des champs.}

Pelage d'un brun grisâtre, plus foncé sur le dos, passant au cendré clair en dessous ; ongles des membres antérieurs pas plus longs que ceux des membres postérieurs. Longueur, 4 ; queue, I $1 / 2$.

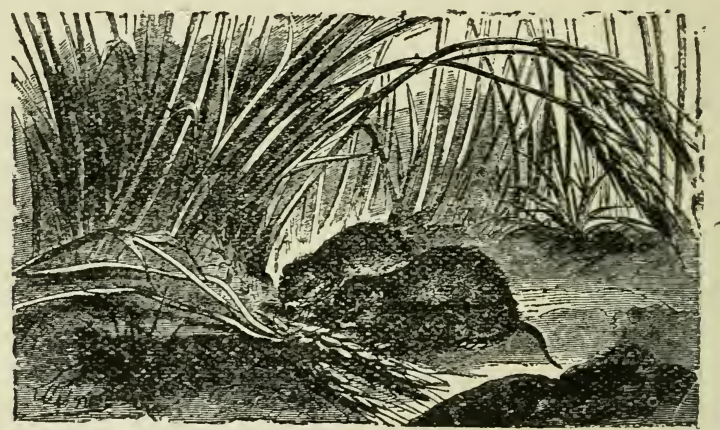

Fig, 6.-Le Campagnol des champs.

Ce petit animal que tout le monde connaît sous le nom de Mulot, est commun dans la province; comme il l'est également dans l'est de l'Amérique du Nord; il habite de préférence les prairies et les terres cultivées où il trouve en abondance, dans les racines des jeunes plantes, une nourriture qu'il préfère à toute autre. Pendant la belle saison, il vit sous terre dans une petite galerie de quelques pou- 
ces de profondeur, que souvent la charrue du laboureur met à découvert au printemps et à l'automne.

Lorsque la saison froide se fait sentir et que la terre commence à geler, le Mulot abandonne alors son trou pour se construire, avec des herbes sèches, une petite cabane qu'il place sur le sol dans un léger enfoncement, et dans laquelle il ménage une ouverture sur le côté. Lorsque la neige tombe, elle s'accumule autour du nid et finit par se durcir au contact de la chaleur qui s'échappe du petit animal, à travers sa cabane, de sorte que cette petite couche de glace le protège suffisamment contre le froid.

Si, à l'époque de la moisson, le cultivateur laisse dans son champ des gerbes de grain pendant un certain temps, il est sûr, lorsqu'il les enlève, d'y trouver des Mulots qui y ont établi domicile et qui se nourrissent à même le grain qu'elles contiennent.

Lorsque la neige recouvre le sol, il vit encore aux dépens des racines d'herbe en se frayant des sentiers sous la neige; il ronge même l'écorce des arbres fruitiers ou autres qui se trouvent à proximité de sa demeure et cela à plusieurs pieds de hauteur quand il le peut.

Le Mulot met bas plusieurs fois dans la saison d'été, et de quatre à huit petits chaque fois.

Ses ennemis sont nombreux; outre le renard qui le chasse même en hiver, tous les petits carnassiers et les oiseaux de proie lui font la guerre, la nuit comme le jour, car il sort aussi bien le jour que la nuit, et ses moyens de défense sont absolument (4) 
nuls. Lorsque ce petit animal se montre en quantité, il devient souvent nuisible pour le cultivateur.

Deux sous-espèces ont été décrites : l'une, l'acadicus, se trouvant dans la Nouvelle-Ecosse, et l'autre, la fontigenus, qui se rencontre dans quelques endroits du Canada.

\section{Genre EVOTOMYS, Coues.}

Oreilles bien visibles excédant le pelage ; molaires pourvues de racines.

\section{Evotomys gapperi, (Vigors.)}

Le Campagnol à dos roux.

Pelage d'un brun roux ou roux marron en dessus formant une bande longitudinale sur le dos, passant au gris jaunâtre, entremêlé de poils bruns sur les côtés du corps ; les parties inférieures sont d'un blanc jaunâtre sale. Longueur, $3 \frac{1}{2}$; queue, I.

Par sa coloration rousse du dos, cette espèce est facile à distinguer de la précédente. On la rencontre dans la province, au sud jusqu'au Massachusetts et dans la Pennsylvanie. Je l'ai souvent trouvée dans les bois près de Québec et des chasseurs in'ont assuré en avoir vu pendant l'hiver, à plusieurs lieues au nord de cette ville, pénétrer la nuit dans leur cabane pour se nourir aux dépens de leurs provisions de bouche.

Ce Campagnol vit dans les bois, il recherche sa nourriture aussi bien la nuit que le jour; elle consiste dans les fruits du hêtre, les graines de 
toutes sortes, baies, racines, etc. Ein hiver, il se contente de l'écorce des arbres. Il habite un trou sous terre.

La femelle met bas plusieurs fois dans la saison et ordinairement de deux à quatre petits; elle place son nid sous les racines des arbres, dans des souches à demi pourries, ou autres endroits analogues.

\section{Genre PHENACOMYS, Inerriam.}

Molaires grandes et fortes, munies de deux racines. Sans roux sur le dos.

\section{Phenacomys latimanus, MerRIaM.}

Le Campagnol à grosses pattes.

Pelage d'un brun rouille pâle en dessus et blanc en dessous ; membres gros. Longueur, $3 \frac{1 / 7}{4}$; queue, I.

On donne cette espèce comme se rencontrant depuis le Labrador au sud jusqu'à Peninsula Harbor, dans l'ouest d'Ontario.

\section{Sous-FaMILLE CRICETIN王.}

Incisives étroites, comprimées et pourvues de racines ; molaires supérieures avec tubercules formant deux séries dans les espèces d'A mérique.

\section{Genre PEROMYSCUS, Gloger.}

Taille petite aux formes sveltes, aux mouvements vifs; pelage doux au toucher et quelque peu lustré; oreilles grandes, arrondies; yeux grands et saillants; pattes de derrière allongées; queue déliée, longue et recouverte de poils. 


\section{Peromyscus canadensis, (MILLER).}

\section{La Souris à pattes blanches du Canada.}

Parties supérieures d'un brun jaunâtre clair, plus foncé sur le dos; les parties inférieures et les pattes d'un blanc pur. Les jeunes sont d'un gris de plomb. Longueur, 4 ; queue, 4.

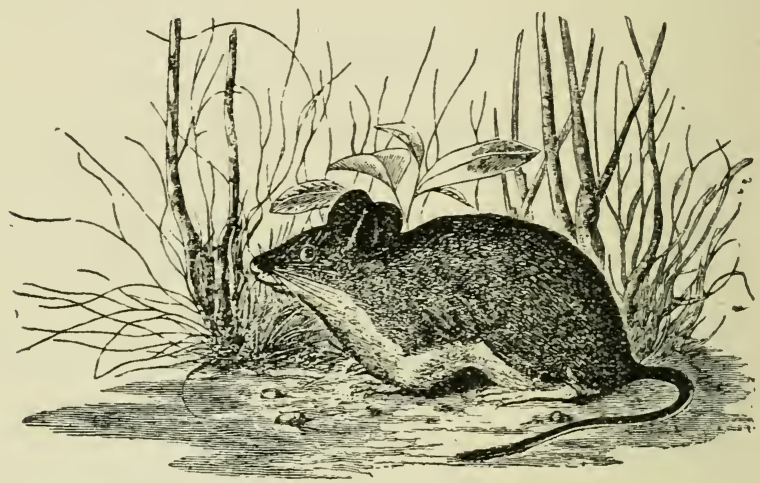

Fig. 7.-La Souris à pattes blanches.

Cette espèce se reconnaît facilement par ses pattes entièrement blanches. On la rencontre dans l'Amérique du Nord, où elle est commune. C'est une jolie petite créature vive et éveillée mais d'une nature timide et craintive; en captivité elle n'est point farouche et s'apprivoise aisément. Elle se plaît dans la forêt où elle grimpe avec beaucoup d'agilité sur les arbres; aussi choisit-elle souvent un arbre creux pour y faire sa demeure qu'elle place parfois à une hauteur considérable du sol; elle la tapisse à l'intérieur d'herbes, de feuilles et de 
mousse. Lorsqu'elle trouve un nid abandonné par des pics, elle s'en empare et l'accommode à ses besoins. De plus, Audubon nous dit qu'il est reconnu que cette espèce s'empare des nids abandonnés par des oiseaux, tels que ceux du merle-chat, de l'étourneau à ailes rouges, di viréo aux yeux rouges $\epsilon t$ de la grive des bois, qui tous sont placés sur des branches d'arbres.

Sa nourriture consiste en fruits durs et en graines de toutes sortes, mais elle a une préférence marquée pour les fruits du hêtre ou faînes. Cette Souris s'amasse des provisions pour la saison d'hiver; elle est nocturne; tontefois, on peut la voir marcher souvent le jour sur la neige, et si quelques cabanes de bûcherons ou autres se trouvent à proximité de son habitation, elle ne manque pas de leur rendre visite la nuit, pour se nourrir des provisions que l'on y apporte. On dit aussi qu'elle mange la chair des oiseaux morts.

La femelle met bas deux ou trois fois dans l'année et de quatre à six petits chaque fois.

\section{SOUS-FAMILE MURIN.E.}

Incisives comprimées, molaires supérieures tuberculeuses, disposées en trois séries de tubercules; museau pointu.

\section{Genre MUS, Linné.}

Incisives lisses en avant; queue longue et écailleuse ; plante des pieds nue.

Nous n'avons pas de représentant indigène de 
ce genre dans notre faune, et les trois espèces qui suivent nous viennent de l'ancien continent.

\section{Mus decumanus, Pallas.}

\section{Le Surmulot.}

D'un gris brunâtre, plus clair en dessous, avec les pattes d'un blanc sale; queue presque aussi longue que la tête et le coips.

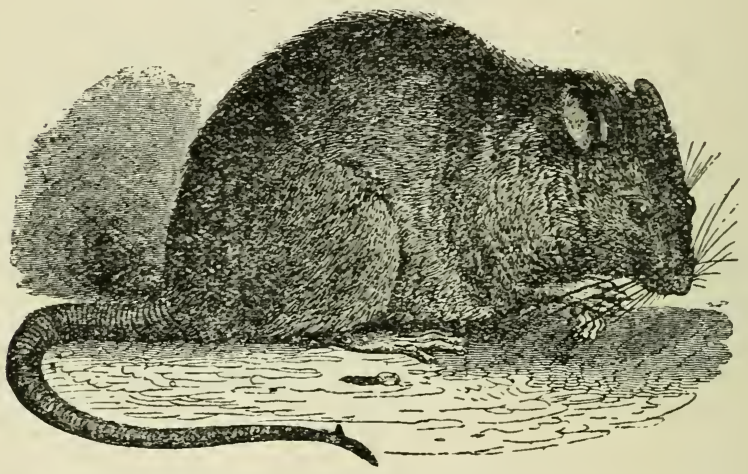

Fig. 8.-Le Surmulot.

Tout le munde connaît ce détestable voisin que l'on nomme le Rat, et qui semble ne s'attacher à l'homme que pour lui nuire. On le rencontre en effet presque partout où ce dernier a fixé sa demeure ; il choisit pour domicile les caves, les greniers, les écuries, les granges, les jardins, les cours, les égouts, les quais, se fixe dans les vides des boiseries, entre l'épaisseur des planchers; enfin partout où la vie lui paraît facile, sans toutefois s'éloigner trop des habita- 
tions, et il transporte dans son nid tout ce qu'il peut traîner. De granivore qu'il était à l'origine, il s'est fait carnassier et même omnivore; il mange la chair des animaux même en putréfaction, des ordures aussi bien que des fruits et des graines de toutes sortes ; il tue les jeunes poussins qu'il mange; il pénètre aussi dans les endroits où l'on engraisse les porcs et il ronge parfois la peau et les oreilles de ces animaux que l'excès de graisse rend insensibles ou incapables de se défendre; il aime également les œufs, le lait, etc., enfin il s'attaque à tout, et l'homme n'a aucune boisson ni substance alimentaire que le Rat ne consomme pas, et ce qu'il ne peut manger, il le salit ou le ronge.

Pour se procurer sa nourriture rien ne l'arrête : il ronge les bois les plus durs, perce des trous sous les constructions, désagrège le mortier entre les pierres des murs et finit souvent, avec le temps, par se frayer un passage ; il ronge même le plomb et l'étain pour satisfaire ce désir irrésistible de ronger; enfin il fait autant de dégâts qu'il peut en faire, et les propriétaires de bâtiments où l'on emmagasine les céréales, les fruits et autres substances alimentaires ne connaissent que trop ses multiples déprédations.

Le Rat est hardi et rusé, il ne donne pas toujours dans les pièges qu'on lui tend; il est aussi courageux que féroce et il défend bravement sa vie contre les belettes, les chats et autres ennemis.

Le Rat nage très bien, et peut même parcourir d'assez longues distances sur l'eall. 
La femelle met au monde de sept à douze petits chaque fois et cela plusieurs fois dans l'année ; aussi le Rat se multiplie-t-il avec une étonnante rapidité, et l'homme est souvent impuissant à le combattre. Heureusement que les chiens, les chats, les belettes, les oiseaux de proie, les maladies, ainsi que la guerre qu'ils se font entre eux, diminuent de beaucoup leur nombre.

Toutefois cela n'empêche pas qu'ils pullulent dans les villes, et si nous voulons avoir une idée approximative de leur nombre, nous n'avons qu'à jeter les yeux sur les deux statistiques suivantes, prises dans la ville de Paris: ainsi en quatre semaines, dans un seul abattoir, on en a tué seize mille, et dans cette année néfaste de $187 \mathrm{r}$, plus de six cent mille furent capturés dans les égouts.

L'Orient paraît être la patrie du Rat, d'où il aurait pénétré en Europe au XVIIIe siècle; puis vers 7775 il faisait son apparition en Amérique, transporté par des vaisseaux voiliers.

\section{Mus rattus, Linné.}

\section{Le Rat noir.}

Cet animal a une teinte plus foncée que le précédent ; il est ordinairement d'un brun de suie, un peu plus clair en dessous avec les pattes brunâtres. Même taille.

Ce Rat qui a été transporté en Amérique vers I 544, s'est vu supplanté par son congénère dont il a d'ailleurs les habitudes. Il est cependant d'un naturel moins féroce. 
Les Rats blancs que l'on garde en captivité sont des cas d'albinisme de cette espèce.

\section{Mus musculus, Linsé.}

La Souris commune.

Pelage d'un gris foncé, lavé de jaunâtre, plus clair en. dessous; queue longue.

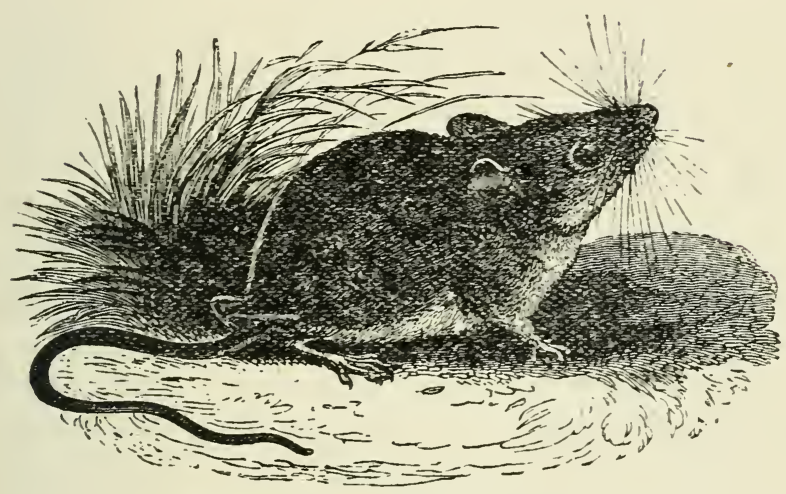

Fig. 9. - La Souris commune.

C'est également à l'ancien continent que nous devons la Souris. A l'exemple du rat, dont elle a les habitudes, elle recherche le voisinage de l'homme; mais c'est surtont dans les greniers, dans les vides des planchers, dans les lambris, derrière les boiseries des appartements, qu'elle fixe sa demeure. Grâce à sa petite taille, elle pénètre par les moindres trous dans les appartements, s'introduit dans les armoires, dans les tiroirs de meubles, 
où l'on est souvent embarrassé de savoir comment elle est entrée.

Elle se nourrit des mêmes aliments que ceux de l'honıme, mais elle préfère le pain, le lard, le fromage, le sucre, les fruits, les farines, les grains de toutes sortes, voire même la chandelle, et pour arriver à son but, elle désagrège le mortier des murs $e^{t}$ perce des trous dans du bois souvent très dur.

Cependant si la Souris ne se bornait qu'à sa nourriture, ses dégâts seraient encore assez insignifiants ; mais pour le plaisir de ronger, elle s'attaque aux livres des bibliothèques, aux pièces des musées, au linge et aux marchandises de toutes sortes, qu'elle réduit souvent en poussière et qu'elle salit, de telle sorte que ses déprédations peuvent amener des pertes considérables.

En dehors de ces méfaits, la Souris est pourtant un joli petit animal. Sa peau est tendre et son pelage doux; ses membres sont d'une grande délicatesse, ses yeux sont vifs et animés; elle court et grimpe à merveille, elle est douce et inoffensive, elle est gracieuse dans tous ses mouvements, elle est prudente et observe tout. Si on la tolère elle finit par s'liabituer à l'homme et à courir sous ses yeux; elle vient même manger ce qu'on lui offre, et on finirait par l'aimer, si on pouvait oublier ses méfaits.

Il est pourtant des personnes qui ne peuvent jamais s'habituer à ce petit animal et sa vue leur inspire toujours de l'effroi, particulièrement aux 
femmes qui souvent poussent des cris et s'enfuient avec précipitation.

La Souris produit plusieurs fois dans l'année et de six à huit petits chaque fois. Elle compte parmi ses ennemis les chiens, les cliats, les belettes et les pièges que l'homme lui tend.

\section{Famille CASTORIDE, Castors.}

Formule dentaire. $-i \cdot \frac{\mathrm{I}-\mathrm{I}}{\mathrm{I}-\mathrm{I}} \mathrm{m} \cdot \frac{4-4}{4-4}$

Les animaux de cette famille se distinguent par une forte taille, un corps lourd et vigoureux; leurs membres antérieurs sont munis de cinq doigts adaptés pour creuser le sol et pour saisir fortement les objets; les doigts pos-. térieurs, également au nombre de cinq, sont unis entre eux par une peau membraneuse; la queue est très forte, très aplatie en forme de rame et écailleuse; les oreilles sont courtes; la claricule est persistante; les incisives sont saillantes et très fortes, pouvant servir à ronger le bois le plus dur; elles repoussent fortement à mesure qu'elles s'usent ; les molaires sont à couronnes plates.

Les Castors sont pourvus de deux sacs glandnleux qui sécrètent une matière grasse, à odeur forte, peu agréable, au goût âcre et de couleur rougeâtre ; elle est connue sous le nom de castoreum, et on l'emploie en médecine.

Les organes génitaux dans les deux sexes aboutissent au rectum, de sorte qu'il n'y a qu'une seule ouverture commune à l'extérieur.

Cette famille est peu nombreuse en espèces, et son parcours géographique ne s'étend qu'à l'Améque septentrionale et au nord de l'ancien continent. 


\section{Genre CASTOR, Linné.}

Mêmes caractères que ceux de la famille.

Castor canadensis, KuHL. Le Castor du Canada.

Corps épais, massif, plus gros en arrière qu'ell avant; pieds courts, surtout ceux de devant. Pelage épais, d'un brun roux, plus foncé en dessus. Longueur, 30 ; quete, 19.

Le Castor était autrefois très commun et se rencontrait dans toute l'Amérique du Nord, depuis le Mexique jusqu'aux extrêmes limites du bois au nord; mais la chasse à outrance qu'on lui a faite de tout temps pour sa fourrure, en a énormément diminué le nombre, et l'a même fait disparaître totale. ment de plusieurs localités du Canada, comme de la république voisine. Une autre cause qui contribue aussi, pour une large part, à son extinction graduelle ainsi qu'à celle de tous nos animaux des bois, est la disparition petit à petit de nos forêts. Toutefois cet animal est encore assez commun dans certaines parties boisées de la province.

Les Castors sont des animaux nocturnes et sociables; ils vivent en famille dans des cabanes qu'ils construisent au bord des cours d'eau. Ils érigent aussi des écluses qui, de tout temps, ont fait l'admiration des personnes qui les ont vues.

Lorsqu'une colonie de Castors a choisi un cours d'eau sur le bord duquel elle peut ériger une cabane et trouver en même temps des matériaux pour la construction d'une écluse, afin de donner 


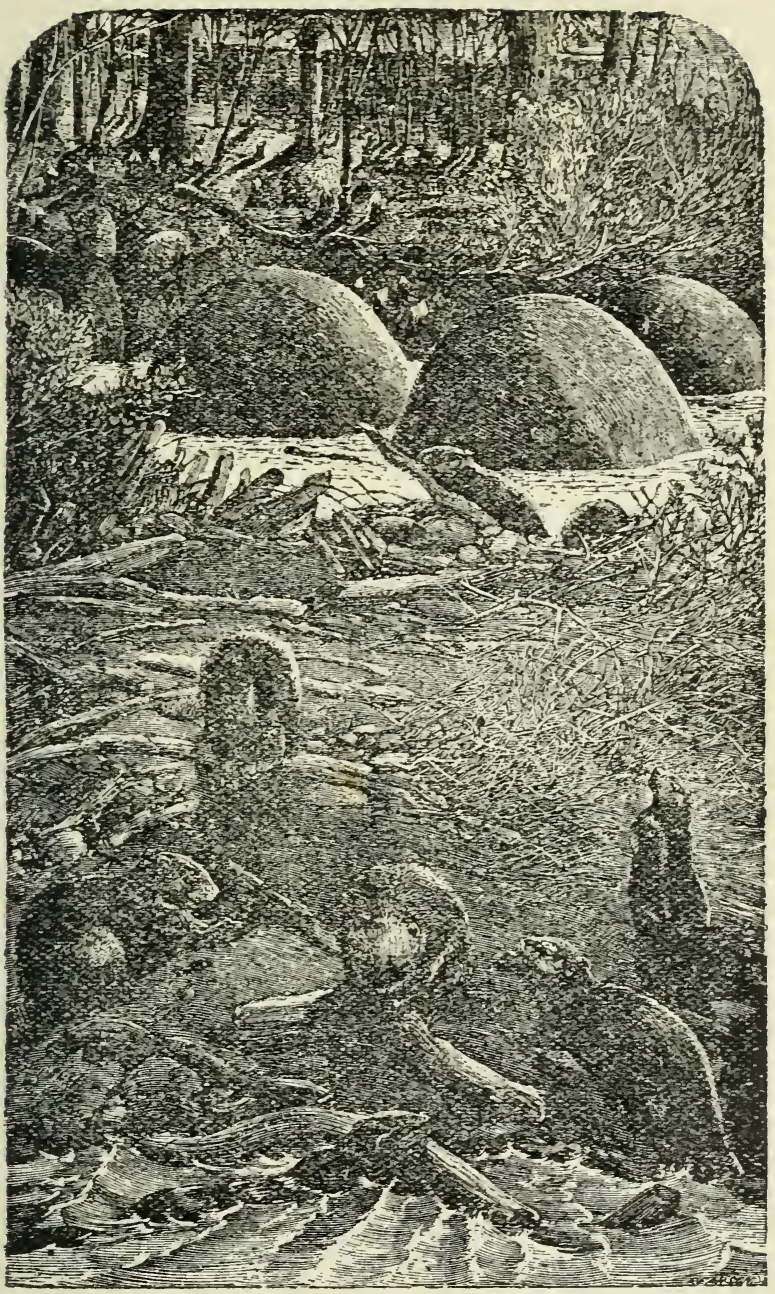

Fig. Io.-Les Castors chez eux. 
à l'eau une plus grande profondeur et un niveau plus égal, chacun se met à l'œurre. Des arbres variant de cinq à huit pouces de diamètre et quelquefois beaucoup plus, sont rongés à la base et lorsqu'ils sont tombés, en quelques coups de dents ils détachent les branches du tronc. Puis ce dernier est divisé en bûchettes de quatre à six pieds de longueur, transportées ensuite à l'eau où elles sont implantées l'une à côté de l'autre, dans des trous creusés à cet effet dans le lit de la rivière. Les Castors y transportent ensuite des branches d'arbres, de la boue, des feuilles, de la mousse, qu'ils accumulent et durcissent avec leurs pattes et leur queue, de telle sorte que la digue atteint souvent à la base une épaisseur de douze pieds. Elle s'épaissit encore par l'accumulation de la terre et des matières régétales que l'eau y transporte, ainsi que par les branches qui y prennent souvent racine et poussent des rameaux. Si un accident survient à la digue, celle-ci est réparée la nuit suivante, car les Castors ne travaillent que la nuit.

Il arrive quelquefois que les Castors se contentent de jeter un ou quelques arbres à travers le courant lorsque les deux rives sont assez rapprochées, puis ils comblent les vides au moyen de branches, de boue, etc. Lorsqu'une colonie se fixe sur les bords d'un lac, elle ne construit pas de digue, puisque la nappe d'eau lui offre un niveau et une profondeur suffisants. Il en est de même pour ceux qui vivent isolément. 


\section{$-63-$}

Quand le travail de la digue est terminé, chaque famille s'occupe de la construction d'une cabane assez spacieuse pour la contenir, c'est sur une des rives en amont de l'écluse qu'elle sera érigée; elle est souvent située si près de l'eau qu'une partie de sa base se trouve submergée. Cette cabane est construite avec des morceaux de bois, des branches, de la mousse et de la bone, et offre ordinairement l'apparence d'un four ; elle est assez résistante pour braver la pluie et les vents les plus impétueux.

Sous cette hutte, une ou plusieurs galeries obliques sont creusées et s'ouvrent sous l'eau, de sorte que ces animaux sont en communication constante avec l'élément qui est en quelque sorte toute leur vie. Cette cabane peut atteindre une hauteur de quatre à huit pieds et un diamètre de neuf à douze pieds. Elle est assez spacieuse pour contenir un couple avec quelques petits; il est rare qu'on en trouve un plus grand nombre réunis dans la même retraite.

Chaque Castor occupe un lit sur lequel il vient se reposer et dormir; il est fait d'herbes sèches ou plus souvent de l'écorce fibreuse d'arbıes rendue très molle par le froissement. Ces lits sont placés les uns à côté des autres et disposés en cercle près des parois intérieures de la cabane, le centre étant laissé libre.

Quelques auteurs prétendent que les cabanes de Castors sont souvent construites au-dessus de l'eau. Elles sont alors bâties sur une espèce de pilotis, et 
sont divisées en deux compartiments : l'un, entièreinent sous l'eau, contient les amas de provisions pour l'hiver, et l'autre, situé au-dessus du niveau de l'eau, communique au dehors par un trou, et à l'eau par un autre orifice percé au centre de la cabane.

Il ne faut pas croire que les cabanes de Castors, pas plus que leurs digues, sont construites avec symétrie, d'après un plan uniforme; au contraire, tous les matériaux qui entrent dans leurs constructions sont entassés pêle-mêle, sans ordre, et n'offrent de régularité que juste ce qu'il faut pour que le but soit atteint. C'est là tout ce qu'ils demandent et tout ce qu'ils sont capables de faire.

Les Castors sont des animaux très propres et très actifs en même temps. Ils vont souvent visiter leurs digues afiri de s'assurer que tout est dans l'ordre, ou pour réparer les accidents qu'elles peuvent avoir éprouvés. Cependant il arrive qu'il se rencontre des individus qui ne veulent point travailler ; ils sont alors chassés, dit-on, sans merci du donicile conmun. Voici ce que nous dit Audubon à ce sujet :

"C'est un fait singulier, dit notre trappeur, que parmi les Castors il y en a qui sont paresseux et ne veulent pas travailler du tout, soit pour aider à construire des cabanes, des digues, ou pour abattre des arbres pour la provision d'hiver. Ceux qui sont laborienx battent ces paresseux et les forcent à s'éloigner, leur rongeant parfois une portion de la queue ou les blessant sur une partie quelconque du corps. 
"Ces Castors paresseux sont plus faciles à prendre au piège que les autres, et les trappeurs les manquent rarement. Ils ne creusent qu'un seul trou, qui origine sous l'eau, pour se diriger obliquement vers la surface du sol, ayant ainsi une longueur de vingt-cinq à trente pieds. Lorsqu'ils ont faim, ils sortent de ce trou pour chercher de la nourriture et y retournent avec le bois qu'ils se sont procuré, pour en manger l'écorce.

"Ils ne font jamais de digues; ils habitent quelquefois cinq ou sept ensemble, et ce sont tous des mâles. Il n'est pas du tout improbable que ces infortunés animaux ont, comme dans le cas des mâles de bien d'autres espèces d'animaux, été entraînés à se battre avec d'autres de leur sexe, et qu'après avoir été vaincus et chassés de leur demeure commune, ils sont devenus oisifs par nécessité. Les Castors laborieux, au contraire, vivent ensemble, mâles, femelles et jeunes. " (I)

Le Castor est un animal très farouche en mêwe temps que très prudent ; lorsqu'il nage, il ne laisse hors de l'eau que la partie supérieure de la tête et le museau, le corps étant complètement submergé. Les pattes de derrière seules lui servent pour nager, il utilise celles de devant pour le transport de ses matériaux. Lorsqu'il est surpris, il frappe l'eau de sa queue; dont le bruit peut être entendu à une distance considérable, puis il disparaît sous l'eau, et

(I) Audubon, Quatrupeds of $N_{.:} A$., Vol I., p. 352.

(5) 
avec lui tous ceux qui se trouvent dans les alentours. Cet animal n'a pas beaucoup d'ennemis à redouter, à part l'homme, car ses dents sont des armes terribles qu'il sait utiliser au besoin.

Le Castor se nourrit de l'écorce de divers arbres et arbustes, entr'autres du bouleau, du peuplier et du saule; il affectionne aussi les racines de certaines plantes aquatiques, comme celles des nénuphars qui croisent dans nos lacs. Il s'amasse pour l'hiver des provisions de branches grosses et petites, des espèces d'arbres ci-haut mentionnées, qu'il accumule sous l'eau, à proximité ou dans sa cabane, et dont il ronge l'écorce à loisir durant l'hiver.

: La femelle met bas en avril ou mai de trois ou quatre petits. Le Castor prend quelques années avant d'atteindre son entier accroissement.

On le capture au moyen de pièges tendus sous l'eau avec des branches de peuplier ou de bouleau comme appâts, et dans cette circonstance il se noie ; mais si on lui tend des pièges sur le sol, et s'il s'y prend par une patte, presque toujours il la coupe avec ses dents pour recouvrer sa liberté. II

\section{FAMILLE SCIURIDIE. ECUREUILS, MARMOTTES}

Formule dentaire. $-i \frac{1-1}{I-1} ; m \cdot \frac{5-5}{4-4}$

La inolaire antérieure de la mâchoire supérieure disparaît souvent ; le tibia et le péroné sont toujours distincts; les membres antérieurs sont terminés par quatre doigts, plus un pouce rudimentaire ; les postérieurs par cinq doigts; le front est large et aplati ; les yeux sont saillants et vifs ; la queue est assez longue, toujours velue et souvent touffue. 
A l'exception des Polatouches, tous sont diurnes; leur nourriture consiste principalement en fruits durs, tels que noix, faînes, noisettes, céréales ; quelques-uns cependant vivent d'herbes; la plupart sont armés d'ongles forts et acérés; ceux-là grimpent avec prestesse et passent leur vie sur les arbres, ne descendant à terre que rarement; d'autres demeurent constamment sur le sol et habitent des terriers.

Les espèces arboricoles sont, sans contredit, les plus gaies et les plus agiles de tous les Mammifères.

\section{Geare ARCTOMYX, Schreber.}

Ces animaux sont de taille assez forte; le corps est lourd et trapu; les jambes sont courtes; les ongles sont adaptés pour creuser dans le sol; la tête est large et aplatie; les abajoues sont peu déreloppées : la queue est plutôt courte, aplatie et touffue; les oreilles petites.

\section{Arctomyx monax, (LiNiś). La Marmotte du Canada.}

Pelage entremêlé de noir brunâtre, de gris et de fauve, avec le sommet de la tête, le derant des pattes et la queue d'un noir brunâtre, mélangé quelquefois de grisâtre; le dessous du corps variant du roux jaunâtre au brunâtre; les oreilles arrondies et ordinairement grisâtres. Longueur, I $41 / 2 ;$ queue, $63 / 4$.

La Marmotte, que l'on nomme communément Siffleur, se rencontre dans l'est de l'Amérique du Nord, jusqu'à la Baie d'Hudson au nord. Eille se plaît particulièrement dans les endroits recouverts 
de roches, sur le versant des montagnes ou des petites collines, à la lisière des bois, dans les champs et même dans la forêt. Quoiqu'elle s'apprivoise très bien en captivité, elle est pourtant très farouche à l'état sauvage; elle ne sort de son trou qu'avec beaucoup de prudence, elle en inspecte les alentours, se dresse sur ses pattes de derrière, écoute et regarde de tous côtés afin de s'assurer que tout est tranquille dans son canton, et, si rien ne décèle la présence d'un ennemi, elle se décide alors à aller à la recherche de sa nourriture, sans toutefois s'éloigner trop de son gîte, afin de pouvoir y entrer au moindre danger.

La Marmotte vit de bourgeons de diverses sortes, de feuilles, d'herbes de toutes espèces ; mais sa nourriture favorite est le trèfle. Elle ne dédaigne pas non plus les céréales, voilà pourquoi on la rencontre fréquemment dans les prairies et les champs cultivés. Lorsqu'elle mange, elle s'assied sur son train de derrière, dans une position verticale.

La Marmotte, à l'encontre des autres espèces de sa famille, ne grimpe pas ou, si elle le fait, ce n'est que bien maladroitement et sur les branches inférieures des arbres seulement ; là elle se tapit pour y demeurer des heures quand elle n'est pas dérangée. Elle habite un terrier qui est presque toujours situé sur le versant de quelque montagne; l'entrée en est ordinairement sous une roche ou entre les racines d'un arbre. Ce trou varie dans sa direction; il est d'abord creusé obliquement en montant, puis il 
prend une direction horizontale pour se continuer jusqu'à une vingtaine de pieds en décrivant une courbe quelconque, pour se terminer en un élargissement ou chambre d'environ un pied de diamètre ou plus. C'est dans cette chambre, tapissée de fenilles et d'herbes sèches, que la Marmotte vit isolée ou par couple, et dans laquelle elle dort durant l'hiver, enroulée sur elle-même, le nez entre les pattes de derrière et la queue ramenée sur ces dernières. La galerie principale peut avoir deux ou plusieurs couloirs latéraux, dans lesquels elle dépose ses excréments.

Lorsque la Marmotte est surprise elle laisse échapper un sifflement aigu, fort et strident, qui choque l'oreille; de là vient le nom de Siffleur qu'on lui donne.

Elle met bas de quatre à six petits, de bonne heure en été.

La Marmotte sort aussi bien le jour que la nuit; elle passe souvent la plus grande partie de la journée à dormir à l'entrée de sa demeure, se chauffant au soleil. Lorsqu'elle est attaquée, elle se défend courageusement et ses morsures sont considérables. On la capture facilement au moyen de pièges tendus près de son trou.

Une sous-espèce $A$. m. canadensis, (ERXL.) se verrait depuis Québec et l'ouest d'Ontario vers le nord; elle serait plus petite et à pelage plus foncé. 


\section{Genre TAMIAS, Illiger.}

Dos ayant de trois à cinq bandes noires; queue plus courte que le corps, non touffue ; abajoues très développées ; oreilles de grandeur moyenne ou petites ; corps plus trapi que dans les espèces qui suivent.

\section{Tamias striatus, (Linné). \\ Le Tamias rayé.}

Pelage d'un jaune roux, passant au grisâtre sur les épaules et le dessus du cou; cinq bandes longitudinales noires se voient sur le dos, les trois du centre sont séparées par deux bandes grises; les deux dernières, par une bande

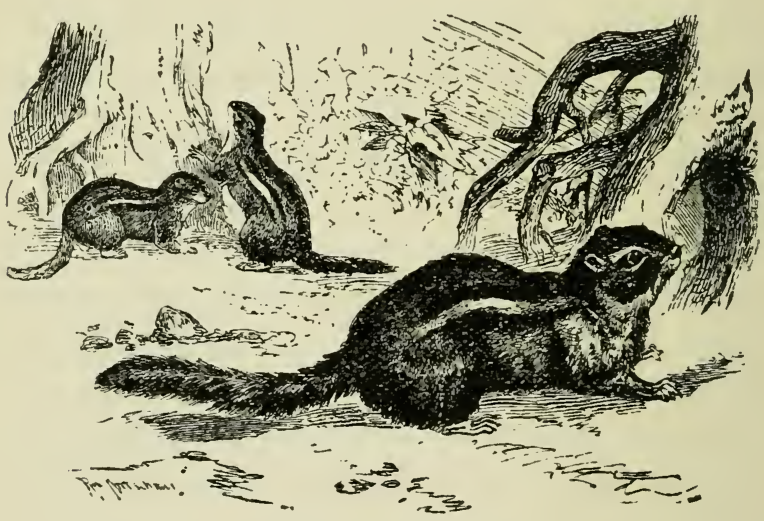

Fig. 11,-Le Tamias rayé.

blanclie sur chaque côté du corps ; le dessous de ce dernier est blanchâtre; la queue est noirâtre, mélangée de roux clair; une bande blanche se voit au-dessus et au-dessous de l'œil. Longuenr, $5^{3 / 4}$; queue, $4^{1 / 4}$. 
Ce gentil petit aninal, que l'on nomme vulgairement le Suisse, est commun dans presque toutes nos forêts; la beauté de son pelage, ainsi que: la légèreté et la vivacité de ses mouvements, en font un des plus jolis mammifères de nos régions boisées. Il habite un terrier qu'il creuse sous des souches, des troncs d'arbres renversés, sous des amas de branches et autres endroits où il puisse se trouver en sûreté. D'ordinaire il ne grimpe pas, mais lorsqu'il est poursuivi par un animal, s'il ne peut trouver de trou pour se cacher, il grimpe sur un arbre, à une certaine distance de terre ; mais dans cette position, il se trouve si mal à l'aise que souvent il commence à descendre lors même qu'on le guette encore, et c'est alors qu'il tombe dans la gueule de son ennemi qui l'attend au pied de l'arbre.

Le Suisse est curieux; il aime à se rendre compte de ce qui se passe autour de lui; mais au moindre bruit, il court se réfugier au milieu des broussailles, dans un trou ou autres endroits. Lorsqu'il est surpris, il jette un cri que l'on peut traduire par ces notes: Chip, pr, $r, r, r$, puis il se sauve avec toute la rapidité dont il est capable.

L'automne est pour ce petit animal l'époque du, travail ; aussi avec quelle activité transporte-t-il dans ses magasins les provisions qu'il y amasse pour la saison de l'hiver. L'observateur peut alors le voir se diriger prestement et avec une certaine satisfaction vers son trou, les abajoues distendues et remplies de graines, souvent de grain volé dans les 
champs voisins, lorsque la forêt ne lui en fournit pas suffisamment. La quantité de graines qu'il s'amasse est considérable, souvent beaucoup plus qu'il ne peut en consommer durant l'hiver. Non content d'en remplir les chambres de son terrier, il fait encore des amas ailleurs, sous des feuilles sèches, des racines, etc., pour les oublier la plupart du temps. Ces provisions consistent en glands, faînes. noix, noisettes, céréales et autres. Tard à l'automne, il ferme l'entrée de son terrier et passe l'hiver à l'intérieur, sans souci du froid et des ouragans qui se déchaînent au-dessus de lui; il n'en sort qu'au printemps suivant.

On dit qu'en captivité le Suisse devient morose et méchant. Il ronge tout et mord au moindre agacement et il ne vit pas longtemps ainsi privé de sa liberté. Il met bas en mai de quatre ou cinq petits.

Ses ennemis sont les petits carnassiers, les oiseaux de proie et les renards. On le capture facilement au moyen de trappes ou de pièges.

Comme les teintes de ce petit animal varient, on en a fait deux variétés, dont la sous-espèce, lysteri (Richardson), serait celle qui habite l'est et le nord de l'Amérique; elle est de coloration plus pâle et de taille plus forte.

\section{Genre SCIURUS, Linné.}

Corps élancé; tête courte, très large entre les yeux ; oreilles longues; incisives comprimées ; abajoues nulles; 
queue ordinairement aussi longue ou plus longue que le corps avec les poils dirigés sur les côtés ; dos sans bandes.

\section{Sciurus hudsonicus, ERXLEBEN.}

\section{L'Ecureuil roux.}

Pelage d'un gris fauve pâle, lavé de roux jaunâtre rif sur le dos, la queue et le devant des pattes; les parties inférieures blanches; une étroite bande noire se voit sur les côtés du corps à la jonction du blanc et du gris fauve; la plupart des poils de la queue sont, à leur extrémité, de couleur fauve pâle, précédée d'une bande noire. Longueur, $63 / 4$; queue, 6.

L'Ecureuil est bien le petit animal le plus agile et le plus gracieux des hôtes de nos forêts, en même temps qu'il en est le plus connu et le mieux aimé. Il nous plaît par l'élégance de ses formes, par la finesse de sa physionomie, la vivacité du regard, la grâce et la rapidité de ses inouvements; tout enfin nous intéresse, tout est beau en lui, soit qu'il folâtre avec ses semblables, soit qu'il cherche sa nourriture. On le voit grimper le long des arbres, sauter de branche en branche, glisser pour ainsi dire sur l'écorce avec une rapidité telle que l'œil peut à peine le suivre dans ses évolutions. De temps en temps on peut l'entendre jeter son petit cri joyeux en imprimant à sa queue un brusque mouvement.

L'Ecureuil décèle souvent sa présence par un cri assez fort et perçant que l'on peut traduire par ces notes : tchir-r-r-r-r.

Ce petit animal n'est pas absolument sauvage ; la vue de l'homme ne l'effraie pas, on dirait même 
qu'elle excite sa curiosité ; si on fait semblant de le poursuivre, il s'éloignera peu à peu en sautant d'arbre en arbre, se cachant souvent derrière leur tronc; mais si on se tient immobile, il finira presque toujours par s'approcher de bien près de la personne qui fait l'objet de sa curiosité, et même il poussera la hardiesse jusqu'à sauter sur elle; si à ce moment cette dernière fait un mouvement, à l'instant le pauvre petit animal est déjà rendu bien loin.

L'Ecurenil fait son nid dans des troncs d'arbres creux, dans des souches à demi pourries, dans des trous creusés dans la terre, au pied des arbres. Il le façonne suivant ses besoins. A l'automne, il s'amasse une provision de noix, de faînes, de noisettes et autres fruits durs ou graines de diverses sortes, qu'il entasse dans son magasin, après en avoir enlevé les écales, et qu'il sait retrouver au besoin. Il commence de bonne heure à faire sa récolte; il n'attend pas toujours que les fruits soient tombés de l'arbre pour les transporter dans son magasin, il va lui-même les détacher de la branche en coupant la tige qui les retient.

Il ne s'enferme pas dans son gîte durant l'hiver, comme le fait son cousin le suisse; on peut le voir folâtrer sur les arbres et marcher sur la neige pendant cette saison, excepté dans les tempêtes où il se tient caché dans son nid.

Quelque gentil que soit l'Ecureuil, il ne laisse pas cependant d'être nuisible lorsqu'il se trouve en grand nombre, car il consomme non seulement des grains 
de toutes sortes, mais il détruit encore beaucoup d'œufs d'oiseaux. Il n'est pas essentiellement arboricole puisqu'il marche très bien et souvent sur le sol.

L'Écureuil se fait facilement à la captivité surtout lorsqu'il est pris jeune; il se familiarise bientôt jusqu'à venir prendre sa nourriture dans la main de ses maîtres, à recevoir leurs caresses, même à sortir de sa cage et prendre ses ébats dans les appartements. Un exercice qu'il aime est de faire tourner un rouleau posé dans sa cage. Cependant la perte de sa liberté lui enlève beaucoup de sa gaieté et de son activité.

La femelle met bas de bonne heure au printemps de quatre à six petits.

L'Ecurenil compte au nombre de ses ennemis tous les carnassiers, et surtout les ois:aux de proie.

\section{Sciurus carolinensis, (GMelis). L'Ecureuil gris.}

Couleur générale d'un gris blanchâtre, teinté de jaune brunâtre sur le dessus du dos et souvent sur la tête; le dessous du corps est blanc; les poils de la queue sont, à la base, d'un jaune brunâtre, suivi d'un anneau noir, leur extrémité est blanche. Longueur, I0 1/2; queue, 10 à I 2 , de la base jusqu'à l'extrémité des poils.

Cet animal varie beaucoup dans la coloration de son pelage qui offre toutes les gradations depuis le gris jusqu'au voir profond.

On rencontre cette espèce dans le sud de la pro- 
vince, dans celle d'Ontario et da:s le nord et l'est des Etats-Unis.

Ce bel Ecureuil a à peu près les mêmes mœurs que le précédent, mais comme sa taille est plus forte il est aussi un peu plus lourd et moins vif. Dans certains endroits des Etats-Unis où il se montre

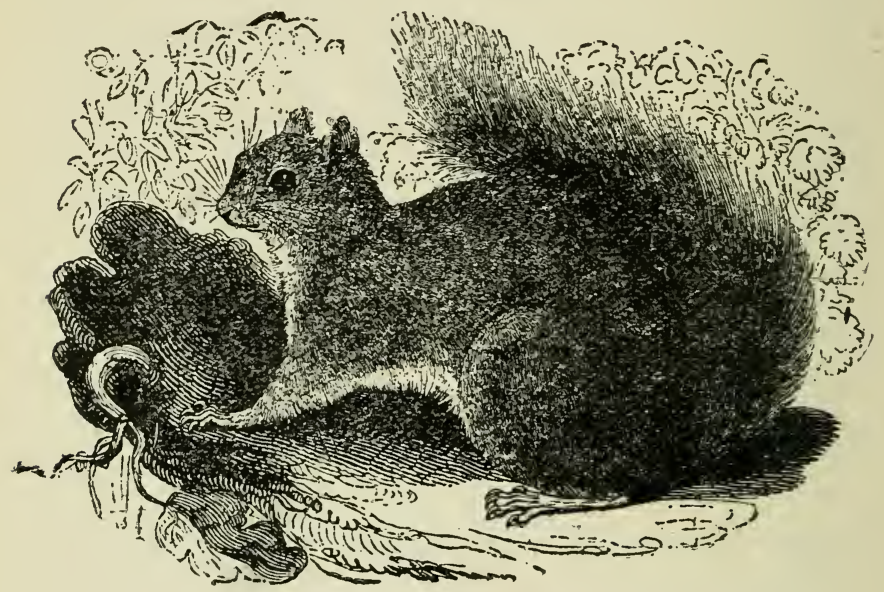

Fig. 12.-I,'Ecureuil gris,

commun, il a souvent causé des dommages considérables aux moissons, car lorsque les fruits de la forêt se font rares, il visite les champs cultivés comme le font d'ailleurs ses congénères.

Un fait digne de remarque chez cette espèce, c'est son déplacement en masse d'un endroit à un autre; il est probable que ces migrations sont dues au manque de nourriture dans les lieux où ils se trou- 
vent. Toutefois on remarque que ces animaux sont gras au moment de leurs migrations, ce qui laisserait supposer qu'une autre cause pourrait motiver ce déplacement.

L'Ecureuil fait son nid dans un arbre creux, mais on dit que vers le sud des Etats-Unis, où il n'a pas à redouter les rigueurs atmosphériques, il construit ce nid à découvert sur une branche, comme le font les oiseaux.

La femelle met bas deux ou trois fois dans l'année et de trois à cinq petits chaque fois.

Trois variétés de cette espèce ont été faites dont une, la $S$. c. leucotis, appartient au nord et serait la nôtre.

\section{Genre SCIUROPTERUS, F. Cuvier.}

Le principal caractère de ce genre consiste dans une extension considérable de la peau des flancs, qui enveloppe les membres de chaque côté, de manière à former une sorte de parachute qui sert à soutenir ces animaux lorsqu'ils sautent d'un arbre à un autre; la prémolaire supérieure d'en avant n'est point caduque; la queue est touffue et aplatie.

\section{Sciuropterus sabrinus, (SHAw). \\ Le Polatouche du Canada.}

Pelage fourni et très doux au toucher, d'un brun jaunâtre ou brun canelle lustré en dessus; dessous du corps blanc lavé de jaune crème vers les côtés. Longueur, 7 ; queue, $4 \frac{1}{4}$.

Le Polatouche, plus communément connu sous le nom d'Ecureuil volant, est commun dans nos 
forêts. C'est un animal essentiellement nocturne, qui dort tout le jour, pour ne s'éveiller qu'au crépus-

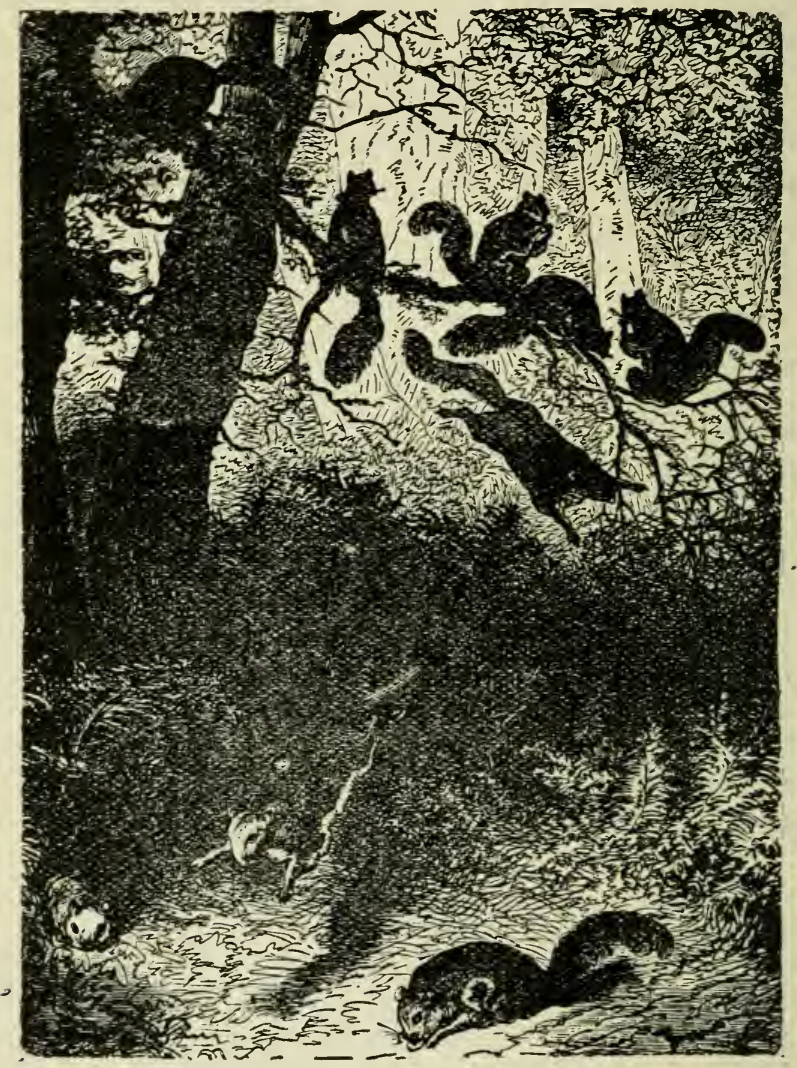

Fig. 13,-Groupe de Polatouches.

cule et prendre ses ébats sur les arbres ou rechercher sa nourriture. Il vit en société dans un arbre 
creux ou dans des nids abandonnés par les pics, et qu'il tapisse d'herbes et de feuilles sèches. Il est essentiellement arboricole et ne descend à terre que très rarement, car il marche difficilement sur le sol ; mais sur les arbres il ne manque pas d'agilité ; il se montre actif et gai. Un exercice qui lui est familier est de grimper au sommet d'un arbre et de s'élancer dans l'espace, les pattes et la queue étendues, pour aller tomber sur une des branches inférieures d'ur arbre voisin ; c'est aussi un des moyens de salut qu'il met en pratique pour échapper à un ennemi qui le poursuit.

Audubon, qui a été témoin de l'un de ces exercices que tout le monde n'a pas l'avantage de voir, nous le raconte ainsi, en parlant de l'espèce commune qui habite les Etats-Unis :

"C'était au commencement de l'automne, la température était chaude et calıne comme à cette saison de l'année. Une demi-heure avant le coucher du soleil, la nature silencieuse semblait se reposer; les oiseaux s'étaient retirés dans la forêt ; l'engoulevent avait déjà commencé son vol nocturne; çà et là la cliauve-souris rouge prenait ses ébats dans l'air, et cependant aucun Ecureuil n'avait encore fait son apparition. Tout à coup on en voit un qui sort de son trou et grimpe jusqu'à la cîme de l'arbre, un autre le suit bientôt, puis des douzaines surgirent et commencèrent leur vol gracieux des branches supérieures de l'arbre aux branches inférieures; de temps à autre, on en voyait un qui s'élançait des 
plus hautes branches d'un grand chêne, ses membranes déployées et la queue tendue, glissant en diagonale dans l'air jusqu'à ce qu'il eut atteint la base d'un arbre voisin à cinquante verges de distance, et au moment où on s'attend à le voir toucher terre, soudainement il remonte et va se poser sur le tronc de l'arbre, pour grimper à son sommet et se précipiter de nouveau des plus hautes branches dans les inférieures de l'arbre qu'il venait de quitter. Des multitudes de ces petites créatures prenaient part à cet exercice, il n'y en avait pas moins de deux cents ; un grand nombre quittaient les arbres en même temps, s'entre-croisaient, glissant comme des esprits dans l'air, semblaient n'avoir d'autre objet en vue que de s'abandonner à cette joyeuse inclination.." (I)

Lorsque ces animaux sont dans leurs nids, il suffit de frapper sur le tronc de l'arbre pour les faire tous sortir ; quelques-uns montent à la cîme, se tapissent sur une branche et attendent là que le danger soit passé ; d'autres sautent sur un arbre voisin.

L'Ecureuil volant dort enroulé sur lui même, le nez entre les pattes de derrière et la queue ramenée sur ces dernières.

Sa nourriture consiste en fruits analogues à ceux des espèces précédentes. Il fait aussi à l'automne une provision de ces mêmes fruits qu'il entasse dans les compartiments deson nid qu'il ne quitte pas de l'hiver.

(1) Audubon, Quadrupeds of $N$. A., Vol.Ier., p. 218. 
La femelle met bas de quatre ou cinq petits, auxquels elle est fort attachée et qu'elle protège autant qu'elle en est capable. On rapporte qu'une femelle ayant ses petits dans un arbre que le feu menaçait de détruire, les transporta un à un au péril de sa vie dans un lieu plus sûr. Audubon mentionne un fait qui montre également combien l'amour maternel peut l'emporter sur la douleur physique. On avait capturé un jour une mère avec ses petits que l'on avait mis en cage: "Pendant une nuit un ou plusieurs rats étaient parvenus à atteindre les petits, et avaient pu ronger leur chair à travers les barreaux de la cage, laissant la peau et la tête presque intacts ; la mère elle-même avait eu les os des cuisses broyés et la chair mangée jusqu'à l'os; de bonne heure le lendemain, nous fûmes témoin d'un fait vraiment touchant: la mère qui faisait pitié à voir ainsi mutilée, oubliant ses souffrances, essayait encore de nourrir ses petits qui n'étaient plus que des cadavres à demi rongés. " (I)

Privé de sa liberté, l'Ecureuil volant se montre doux et il s'apprivoise aisément, mais il dort tout le jour enroulé sur lui-même, de sorte que ce n'est pas un animal bien intéressant à garder en captivité.

(I) Audubon. Quadrupeds of .V. A., Vol. 3, p. 204. 


\section{ORdRE INSECTIVORA.-TAupes, Musaraignes.}

Les Insectivores sont tous de petite taille et sont pourvues de trois sortes de dents, les incisives, les canines et les molaires; ces dernières sont hérissées de tubercules coniques ; leurs membres sont conformés pour la progression plantigrade et dans la plupart des cas; leurs doigts sont munis d'ongles propres à fouir.

La présence de canines chez eux ne saurait les faire confondre avec les espèces précédentes de même taille.

Cette famille se rapproche des Chéiroptères par le nombre et la structure des dents.

Les Insectivores sont nombreux et sont répandus sur toute la surface du globe, excepté en Australie. Chez nous, ils se réduisent à deux familles seulement représentées par un petit nombre d'espèces.

Ce sont des animaux timides qui creusent, pour la plupart, des galeries souterraines, se nourrissent d'insectes et de vers qu'ils détruisent en quantité ; leurs habitudes sont nocturnes. On les rencontre dans les champs, le long des haies, dans les bois, au bord des lacs et des rivières.

Ces petits êtres sont très voraces, et, si leur taille secondait leur rapacité, ils seraient aussi à craindre que les Carnassiers; mais ils sont si petits qu'ils ne peuvent guère détruire que des petits invertébrés, pour la plupart nuisibles à l'agriculture. 
CLEF POUR LA DISTINCTION DES FAMILLES D'INSECTIVORES

Pieds antérieurs de grosseur moyenne; oreilles externes bien apparentes. SORICIDAE

Pieds antérieurs très larges; sans oreilles externes apparentes.

TALPID.E

\section{Famille SORICID无, Musaraignes.}

Les Musaraignes sont bien les mammifères les plus petits qui existent sur la terre et leur taille exiguë ne saurait être surpassée en petitesse, si ce n'est peut-être par la souris naine de l'ancien continent. Leur forme extérieure rappelle quelque peu celle de la souris ordinaire; leur museau est pointu et allongé en forme de trompe; leurs oreilles sont visibles et assez grandes; les pieds de devant sont à peine plus gros que ceux de derrière; tous sont terminés par cinq doigts munis d'ongles ; leur démarche est presque entièrement plantigrade; leurs yeux sont petits et ordinairement cachés dans le poil; les dents varient en nombre de vingt-huit à trente-deux en tout, dont douze pour la mâchoire inférieure.

Les Musaraignes détruisent un grand nombre d'insectes, de larves et de limaces; elles s'attaquent parfois aux vertébrés de petite taille. Elles ne sont pas sujettes au sommeil hibernal.

\section{Genre SOREX, Linné.}

Dents coloriées, au nombre de trente à trente-deux ; queue plus courte que la tête et le corps; oreilles grandes ; yeux petits; ongles courts et recourbés.

\section{Sorez albibarbis, (COPE).}

\section{La Musaraigne à moustaches blanches.}

Parties supérieures d'un gris ardoise foncé, un peu plus 
clair aux parties inférieures, avec le menton grisâtre ou blanchâtre. Pieds longs. Longueur, $3 \frac{1}{2}$, queue, $2 \frac{1}{3}$.

Cette espèce, dans la province, a été rencontrée à Godbout ; elle se voit aussi au sud jusqu'à la Pennsylvanie.

\section{Sorex personatus, (GEOF. ST-HILAIRE). La Musaraigne commune.}

Pelage d'un brun châtain foncé en dessus, se modifiant en un gris cendré en dessous ; pieds de longueur ordinaire ; dents, trente-deux. Longueur, $23 / 4$; queue, I.

C'est la plus petite de nos Musaraignes; elle est commune dans nos bois, ainsi que dans tout le Canada et le nord des Etats-Unis. On la rencontre souvent sous les feuilles desséchées à la recherche de sa nourriture. Elle est très active et très vive.

\section{Sorex hoyi, BAIRd.}

\section{La Musaraigne de Hoy.}

Pelage d'un brun châtain foncé, passant au gris cendré en dessous, à l'exception de la gorge et de la poitrine qui sont teintées de brun jaunâtre ; dents, trente ; pieds petits. De taille un peu plus forte que la précédente.

Cette espèce a été remarquée à Godbout sur la côte nord; elle se montre également dans la Nouvelle-Ecosse, le Manitoba, la Colombie britannique ainsi que dans le nord des Etats-Unis.

\section{Genre BLARINA, Gray.}

Oreilles petites, cachées dans le poil; pieds de forme 


\section{$-85-$}

ordinaire; queue courte, à peine aussi longue que la tête ; dents, trente-deux.

\section{Blarina brevicauda, ( $\mathrm{SAY}$ ).}

\section{La Musaraigne à queue courte.}

Pelage épais et soyeux, d'un gris cendré foncé, plus clair aux parties inférieures ; yeux très petits. Longueur, $3 \frac{1}{2}$; queue, $\mathrm{I}$.

Cette espèce se montre assez commune dans certains endroits de la province; elle habite aussi le nord des Etats-Unis. C'est la plus grosse de nos Musaraignes, et par celá même, la plus facile à reconnaître des précédentes. Elle fréquente les terrains secs des champs, des prairies et des forêts; mais elle semble préférer ces dernières puisqu'on la trouve plus fréquemment près des troncs d'arbres vermoulus, sous les racines où elle fixe ordinairement sa demeure.

Elle se nourrit de vers de terre, de limaces, de larves d'insectes ou autre petits invertébrés, qu'elle cherche dans les souches et les racines des arbres à demi pourris, dans l'herbe, sous des amas de feuilles mortes, ou encore en creusant sous terre des galeries, afin de découvrir les vers qui se cachent dans le sol. Les galeries qu'elle creuse sont nombreuses et sont ordinairement situées à une faible profondeur. S'il arrive que cette Musaraigne rencontre un obstacle, tel qu'une roche ou une racine, au lieu de faire une courbe et passer par le côté, elle creuse davantage et passe en dessous. Elle tra- 


\section{$-86-$}

vaille aussi bien le jour que la nuit, et demeure sous terre ou sous les feuilles desséchées la plus grande partie de son existence.

En hiver, on peut voir cette Musaraigne allant d'une souche à l'autre pour se nourrir des insectes et des vers qui y font leur demeure; et souvent, pour atteindre ces souches, elle est obligée de passer à travers la couche de neige qui les recouvre, guidée en cela par son instinct qui ne lui fait jamais défaut.

On affirme que cette espèce s'attaque aux milots et aux souris des bois qu'elle finit quelquefois par tuer et manger.

La forte odeur qu'elle répand empêche souvent les oiseaux de proie de la dévorer après l'avoir tuée, c'est ce qui explique pourquoi on trouve parfois son cadavre abandonné par ces animaux.

Il est probable que la femelle met bas deux ou trois fois dans l'année.

\section{Fanille TALPIDE. TAUPES.}

Ces animaux ont un corps lourd, allongé et cylindrique, sans distinction apparente du cou; le museau est allongé ; les yeux sont très petits et plus ou moins cachés dans le pelage ; les oreilles sont également peu visibles; la queue et les jambes sont courtes ; les pieds sont robustes, larges et armés d'ongles très forts, disposés pour fouir ; les membres antérieurs sont plus forts que les postérieurs ; le pelage est épais et doux au toucher.

La nourriture de ces animaux consiste en vers, insectes, limaces, larves et autres petits animaux analogues. 


\section{Genre SCALOPS, Cuvier.}

Le nombre de dents se chiffre à trente-six; le museau est allongé, flexible et cartilagineux, sans frange à l'extrémité ; la queue est courte et presque dénudée de poils.

\section{Scalops aquaticus, (LINNÉ).}

\section{La Taupe ordinaire.}

Pelage lustré, d'un gris de plomb foncé, moins intense sous le corps et lavé quelquefois de brun; pieds et ongles de couleur chair claire; les membres sont situés quelque peu sur les côtés du corps; ceux de derrière sont plutôt faibles et déliés; les doigts sont réunis entre eux par une petite membrane. Longueur, $4^{1 / 2}$; queue, $I$.

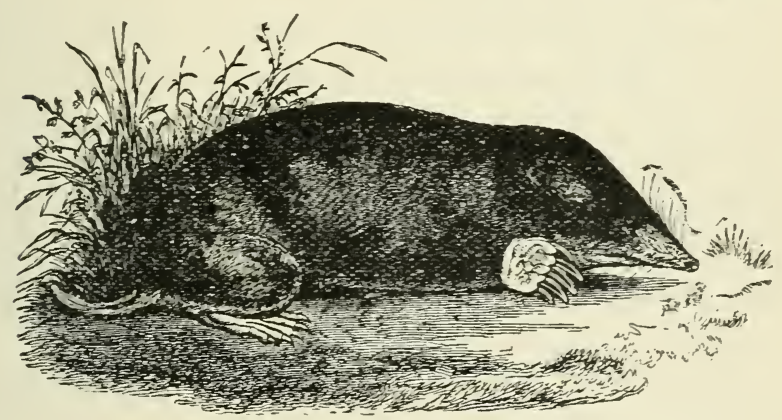

Fig. If-Ia Taupe ordinaire.

Cette espèce est généralement commune dans notre province ; quoique ses habitudes soient nocturnes on la rencontre cependant durant le jour. Sa nourriture consiste en insectes, larves, vers et limaçons, qu'elle recherche en remuant la terre, en pratiquant des galeries dans toutes les directions. Ces 
galeries sont généralement creusées à une profondeur de trois ou quatre pouces; l'animal pénètre rarement plus bas à moins que ce ne soit pendant les sécheresses ou encore en hiver, alors que les vers s'enfoncent plus profondément dans le sol, afin d'éviter la gelée.

Cette Taupe est presque constamment occupée à creuser de nombreux chemins souterrains qui atteignent souvent plusieurs centaines de pieds de longueur, et, semblable à la précédente, si un obstacle se rencontre en poursuivant sa chasse, elle creusera en dessous pour l'éviter. On remarque sur le parcours de ces galeries un nombre plus ou moins considérable de monticules formés de terre molle, qui atteignent ordinairement un diamètre de sept à dix pouces et une hauteur de trois à six pouces. Il est probable, comme le pensent quelques naturalistes, que cette Taupe rencontre là quelques colonies de vers ou de larves d'insectes, et qu'elle remue alors la terre en tout sens afin de se nourrir de ces animaux.

Elle peut sans doute causer des dommages à la végétation en coupant les petites racines des plantes qui se rencontrent sur son passage, dans les sentiers qu'elle creuse journellement, et par ces monticules de terre, surtout dans les jardins, où les fleurs sont arrachées et renversées, la symétrie des plates-bandes détruites, ce qui fait souvent le désespoir des jardiniers qui la poursuivent à outrance ; mais le nombre considérable de vers et de larves nuisibles qu'elle 
détruit, compense amplement ces petits méfaits involontaires.

I'opinion émise que cet animal ronge les racines des plantes pour s'en nourrir est erronée, puisqu'il est essentiellement insectivore, et ne peut par conséquent se nourrir de inatières végétales.

Cette Taupe met bas probablement deux fois durant l'année, de cinq à neuf petits, qu'elle dépose dans un nid creusé dans la terre, et situé presque toujours sous un tronc d'arbre à une profondeur d'environ un pied; ce nid est tapissé de feuilles et d'herbes sèches.

On peut capturer ce petit animal en lui tendant un piège à l'entrée de sa galerie principale.

\section{Genre CONDYLURA, Illiger.}

Dents, en tout quarante-quatre. Museau allongé terminé par une excroissance charnue et frangée en cercle; quetre presque aussi longue que le corps et recouverte de poils.

\section{Condylura cristata, (LINNÉ). \\ La Taupe à museau étoilé.}

Corps lourd et épais; mains larges; membres postérieurs plus faibles que ceux de devant, quoique robustes; pelage soyeux, noirâtre. Longueur, 4 ; queue, $23 \%$.

Cette espèce, facile à reconnaître par les appendices charnus de son museau, habite l'est du Canada et des Etats-Unis du nord. Elle se montre assez commune dans la province, quoique distribuée irrégulièrement. 
Elle fréquente les terrains bas et humides, le bord des cours d'eau, aussi bien que les terrains

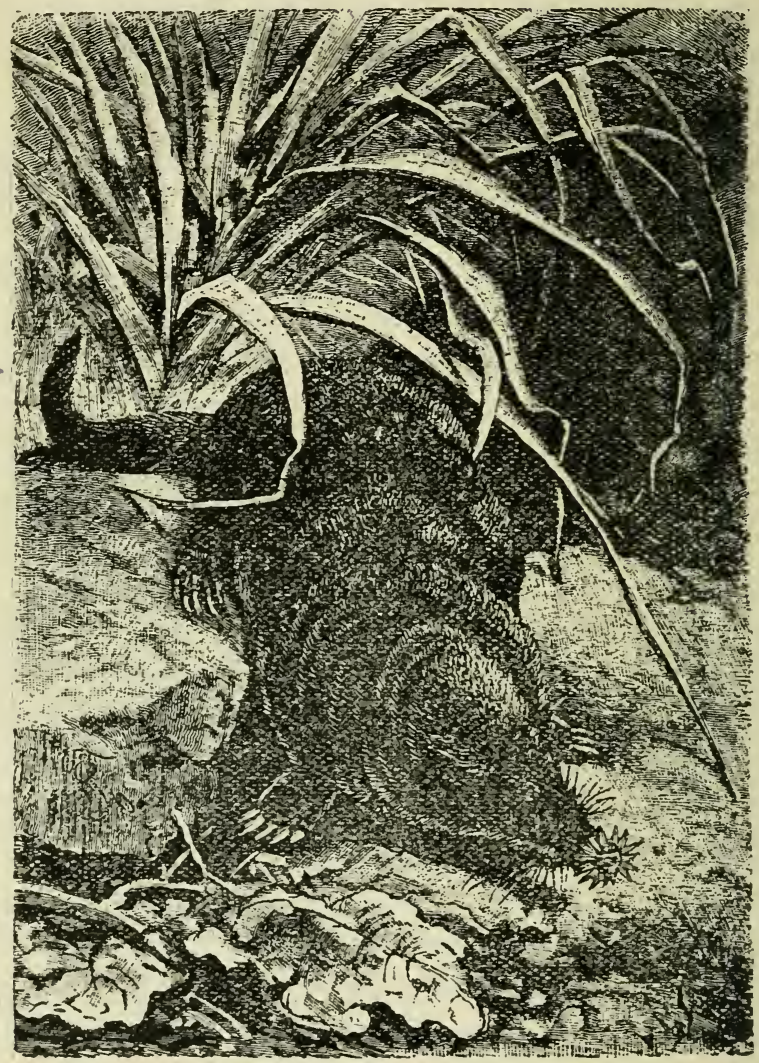

Fig. I5. - La Taupe à museau étoilé

élevés et secs; semblable à la précédente, elle se nourrit des mêmes petits invertébrés ; elle en a d'ail- 
leurs les habitudes. Toutefois ses galeries sont moins longues, mais on remarque que les monticules de terre sont de plus grande dimension.

Comme cette espèce vit sous terre et échappe ainsi à nos observations, on ne connaît que peu de close de ses mœurs.

\section{Ordre CHIROPTERA.-Chautes- SOURIS}

On peut facilement reconnaître à la simple inspection de leurs membres transformés en ailes, ces singuliers animaux que les anciens naluralistes classaient même parmi les oiseaux, avec lesquels ils n'ont pourtant de commun que la faculté de pouvoir voler. Leurs membres antérieurs qui sont très développés, sont réunis aux postérieurs par une membrane mince et nue, formée par une extention considérable de la peau des côtés du corps; leurs dents ressemblent beaucoup à celles de la famille précédente; leurs yeux sont petits.

Les Chéiroptères ou Chauves-Souris, comme on les nomme toujours, se nourrissent d'insectes ou de fruits. Leurs sens sont bien développés, particulièrement celui du toucher, aussi savent-elles se diriger avec une rare adresse dans les endroits les plus difficiles sans jamais se heurter aux obstacles qu'elles rencontrent. Leurs pieds sont pourvus d'ongles 
crochus, qui leur permettent de s'accrocher et se suspendre à un objet quelconque, car il est rare qu'elles se posent à terre, puisqu'elles ne peuvent marcher que très difficilement, et encore cette progression ne s'exécute que par une sorte de reptation.

Les Chauves-Souris recherchent leur nourriture au crépuscule et durant la nuit.

Quant aux espèces canadiennes, c'est à la poursuite des insectes nocturnes que nous les voyons voltiger dans l'air durant les soirs de la belle saison.

Elles fréquentent de préférence la lisière des bois, volent autour des bouquets d'arbres, autour des granges ; rasent parfois la surface de l'eau; mais lorsque le jour commence à poindre, elles se retirent dans des lieux tranquilles et sombres, où ne pénètre pas la lumière du jour ; ainsi les cavernes, les crevasses de rochers, les vieux murs, les clochers, les vides entre le bois et son écorce, sont les endroits qu'elles choisissent pour se reposer et dormir tout le jour; elles se suspendent aux parois de ces demeures sombres, par les pieds de derrière à l'aide de leurs ongles crochus, la tête en bas, et enveloppées de leurs ailes.

Dans les régions froides, les Chauves-Souris passent l'hiver engourdies; elles adoptent pour cette fin les mêmes lieux que ceux où elles se reposent durant le jour, et prennent également la même position. Cependant il est quelques espèces qui émigrent dans des contrées plus chaudes, lorsque la température commence à se refroidir. 


\section{$-93-$}

\section{FAMILLE VESPERTILIONIDE. ChaUYfis-}

SOURIS

Les animaux de cette famille sont caractérisés par la membrane de l'aile qui s'étend jusqu'à la queue, l'enveloppant dans toute sa longueur ; les narines sont sous-elliptiques. Tous sont insectivores.

Cette famille compte un grand nombre d'espèces dont trois seulement existent dans notre faune.

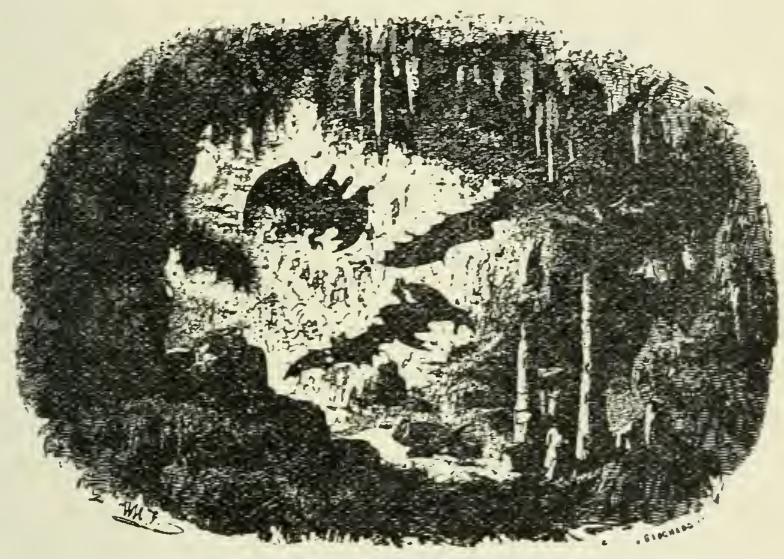

Fig. 16.-Chauves-Souris.

\section{Genre MYOTIS, Kaup.}

Le nombre total de dents se chiffre à trente-huit, dont quatre incisives supérieures et six pour les inférieures; les oreilles sont aussi longues que la tête; cette dernière est recouverte de poils jusque sur le museau qui est étroit; la membrane alaire est mince. 


\section{$-94-$}

\section{Myotis subulatus, (SAY). \\ La Chauve-Souris commune.}

D'un brun jaunâtre ou olivâtre, terne en dessus et un peu plus clair ou plus jaunatre en dessous; le pelage à la base est d'un gris de plomb foncé; la membrane de l'aile est très délicate et presque transparante, les oreilles sont délicates et longues, dépassant le bout du museau lorsqu'elles sont ramenées en avant; les membres antérieurs sont plutôt petits et faibles. Longueur, 3 ; extension des ailes, 8-9; queue, I $1 / 2$.

Cette espèce est commune dans la province, comme elle l'est également dans l'est de l'Amé. rique du Nord. Qui ne l'a remarquée dans les beaux soirs d'été, alors que les ombres de la nuit envahissent les dernières clartés du jour, qui ne l'a vue, dis-je, de son rol incertain et tremblotant, passer et repasser devant nos yeux à la recherche de sa nourriture? En effet, dès que le soleil a disparu de 1'horizon, la Chauve-Souris sort de sa retraite en quête d'insectes ailés, qu'elle recherche et capture en voltigeant autour des maisons, des granges, des clochers, des arbres isolés, à la lisière des bois ; elle pénètre même dans les appartements par les fenêtres restées ouvertes.

La Chauve-Souris n'est pas aimée d'ordinaire, et de fait, sa forme singulière et laide, ainsi que ses habitudes nocturnes, contribuent en quelque sorte à inspirer une certaine répugnance mêlée d'une crainte superstitieuse, chez quelques personnes; et pourtant, s'il est un petit animal que nous devons 
aimer pour son utilité, c'est bien la Chatuve-Souris, puisqu'elle nous débarrasse de ces myriades d'insectes nuisibles, et surtout des papillons de nuit, dont la larve cause des dommages considérables dans les champs comme dans les jardins. De plus, elle est tout à fait inoffensive pour nous et ne peut nous faire aucun mal.

\section{Myotis lucifugus, (LE COMTF).}

\section{La Chauve-Souris brune.}

Pelage d'un brun terne lustré, oreilles courtes et pointues, atteignant à peine le bout du museau, lorsqu'elles sont dirigées en avant. Pieds plus gros et plus forts que ceux de la précédente; membrane des ailes plutôt épaisse. Longueur environ un demi pouce de plus que celle de la subulatus.

Cette espèce est commune dans tout l'est de l'Amérique du Nord.

\section{Genre LASIONYCTERIS, Peters.}

Dents, trente-six en tout; museau presque nu en avant des yeux; oreilles courtes presqu'aussi larges que longues.

\section{Lasionycteris noctivagans, (LE COMTE). La Chauve-Souris grise.}

Pelage long et soyeux, noir ou presque noir, arec l'extrémité des poils d'un blanc d'argent ou blanchâtres. Longueur, $3 \frac{1}{2} 2$; extension des ailes, I2 ; queue, I I 12 .

Cette espèce est facile à reconnaître par le nombre de dents, qui se chiffrent à trente-six.

Elle habite l'Amérique du Nord, de l'Atlantique 
au Pacifique, et d'après le Dr Hall et l'abbé Provancher, elle aurait été rencontrée dans la province.

\section{Genre LASIURUS, Gray.}

Dents, trente-deux; dont deux incisives supérieures et six à la mâchoire inférieure. Des petites touffes de poils se voient sur les ailes.

\section{Lasiurus cinereus, (BFAUVOIS).}

\section{La Chauve-Souris cendrée.}

Pelage d'un brun chocolat vif entremêlé de blanc; lèvres et oreilles maculées de noir. Longueur, $23 / 4$; extension des ailes, It; queue, 2 1/4.

Cette Chauve-Souris, qui est rare, se rencontre dans le nord de l'Amérique septentrionale. En I 898, je me suis procuré un spécimen de cette espèce, capturé dans la ville, et deux ans plus tard, on m'en a apporté deux autres également capturés dans Québec.

Il paraît que cette espèce émigre vers le sud à l'automne pour se soustraire aux froids de l'hiver.

\section{Ordre CETACEA.-Cétacés}

Les Cétacés sont des animaux essentiellement conformés pour la vie aquatique, et leur apparence extérieure rappelle tellement celle des poissons, que les anciens auteurs les avaient classés parmi ces derniers. Cependant l'étude plus approfondie de 


\section{$-97-$}

leur organisation a démontré qu'ils appartiennent véritablement à la classe des Mammifères. En effet, chez les Cétacés comme chez les Mammifères terrestres, la circulation est double, le sang est chaud et de couleur rouge; la respiration s'effectue au moyen de poumons, ce qui les oblige à venir respirer à la surface de l'eau ; enfin ils sont vivipares, comme les autres Mammifères.

Le corps des Cétacés est plus ou moins fusiforme ; la tête est ordinairement grosse, sauf chez quelques espèces, et le cou qui la supporte est si court extérieurement que, dans la plupart des cas, on ne le distingue pas toujours du thorax. Les membres antérieurs, dont les os sont analogues à ceux des Nammifères terrestres, sont transformés en nageoires larges et aplaties, sans distinction extérieure de doigts ni d'ongles, à l'exception de quelques espèces qui portent des traces d'ongles. Les membres postérieurs n'existent pas, et il n'y a absolument rien qui en tienne lieu. Le corps est terminé par une queue, large, aplatie en forme de rame, et disposée horizontalement. Cet appendice très puissant est le principal moteur de ces animaux ; une nageoire dorsale, qui n'est qu'une modification de la peau, existe chez un certain nombre d'espèces.

I.es sens des Cétacés sont très obtus; l'oreille externe ou plutôt le pavillon de l'oreille est nul; les yeux, très petits, sont presque toujours placés dans le voisinage de la commissure de la bouche; les narines sont situées à l'extrémité du museau, ou sur 
le dessus du front à la partie la plus élevée, ce qui permet à l'animal de respirer sans émerger la tête de l'eau. Le cerveau est très petit comparativement à la taille de l'animal, mais il offre de nombreuses circonvolutions à sa surface; ainsi, dans une baleine d'une longueur de dix-neuf pieds et du poids de onze mille livres, on a constaté que le cerveau pesait à peine quatre livres.

La peau est lisse et dépourvue de poils ; toutefois, chez certaines espèces, on remarque quelques poils dans la région du museau. Il existe d'ordinaire, sous le derme, une épaisse couche de graisse qui empêche la déperdition de la chaleur de l'animal, le rend plus insensible au froid et contribue anssi à diminuer sa pesanteur.

Les Cétacés sont distribués daus toutes les mers du globe; ils sont ordinairement de forte taille; c'est parmi eux que se voient les géants de la créa. tion; tous nagent avec une grande facilité, et la plupart d'entre eux avec beaucoup d'élégance même ; ils sont rapides dans leur course et se jouent arec grâce au milieu des flots. Ils se rencontrent d'ordinaire en troupeaux plus on moins nombreux.

Certaines espèces sont carnivores, tandis que les autres sont herbivores. Ces dernières fréquentent les fleuves et les grandes rivières pour rechercher sur leurs bords les végétaux dont ils se nourrissent; les espèces carnivores, au contraire, et yarticulièrement celles de grande taille, habitent la haute mer; toutefois quelques petites espèces se plaisent à pren- 


\section{$-99-$}

dre leurs ébats à l'embouchure des fleuves ou des grandes rivières, et les remontent même sonvent à de longues distances.

La femelle, dans les grandes espèces, met au monde 11 seul petit chaque fois, tandis que les petites espèces en ont ordinairement deux. On affirme que la femelle témoigne beaucoup d'affection pour ses petits, et qu'elle expose même sa vie pour les sauver du danger.

On chasse les Cétacés, surtout ceux de forte taille, pour se procurer l'huile que fournit cette épaisse couche de graisse dont ils sont recouverts.

Les Cétacés se divisent en deux grandes catégories ou sous-ordres: les Cétacés carnivores ou souffleurs et les Cétacés herbivores. C'est parmi les premiers que se rencontrent les espèces qui fréquentent nos eaux, tandis que les herbivores, auxquels se rattache l'histoire fabuleuse de la sirène, sont tous étrangers à notre faune.

Quelques naturalistes ont cru devoir faire de ces sous-ordres deux ordres distincts, mais la division en sous-ordre me parait plus rationnelle.

SOUS-ORdRF CE'TACEA CARNIVORA. CÉTACÉS CARNIVORES

Ces animaux se distinguent surtout par leurs narines situćes sur le front, et que l'on nomme évents. Chez eux l'inspiration et l'expiration s'opèrent toujours avec plus ou moins de bruit, de là le nom de 
souffleurs qu'on leur donne. L'opinion répandue que les Baleines lancent l'eau au dehors par les évents est fausse; pendant l'expiration, la vapeur d'eau se condense par l'effet du refroidissement et s'élève en colonne, c'est ce qui a donné lieu à cette opinion. Il n'y a aucune trace extérieure d'ongles aux membres antérieurs chez ces animaux. Quelques espèces ont les mâchoires garnies de dents, d'autres en sont entièrement dépourvues; uve rangée de lamelles cornées et frangées au bord inférieur et à l'extrémité, est fixée verticalement au palais et en tient lieu. Ces lamelles sont connues sous le nom de fanons.

Les poumons atteignent de fortes dimensions et permettent d'emmagasiner de grandes quantités d'air atmosphérique, ce qui explique pourquoi ces animaux peuvent demeurer très longtemps sous l'eau sans respirer.

L'eau est leur élément naturel et essentiel; la terre leur est funeste puisqu'ils sont incapables de se mouvoir sur le sol, et, s'ils échouent soit pendant une tempête, soit dans la poursuite d'une proie, ils sont dès lors voués à une mort certaine ; aussi, instinctivement évitent-ils toujours les côtes.

Ces animanx vivent de poissons, de crustacés, de mollusques, de méduses et autres invertébrés marins ; ils sont très voraces et n'épargnent même pas les individus de leur espèce plus faibles qu'eux. Ils poursuivent leur proie avec ardeur et lorsqu'ils s'aventurent trop près du rivage, ils s'échonent et 
deviennent ainsi victimes de leur voracité. Les petites espèces sont généralement celles qui se nourrissent des plus grosses proies et les grandes espèces, des plus petites ; l'œsophage, très étroit chez ces dernières, ne permettant pas le passage de grosses pièces.

Cette catégorie est divisée en deux groupes distincts, les Denticete et les Mysticete. Les premiers sont caractérisés par la présence de dents coniques aux deux mâchoires ou à une seulement ; les évents ou narines sont réunis en un seul orifice à l'extérieur, s'ouvrant en forme de demi-lune, tandis que les Mysticete se reconnaissent par l'absence de dents, qui sont remplacées à la mâchoire supérieure par une série de fanons implantés verticalement, et les évents sont séparés.

CLEF POUR IA DISTINCTION DES FAMILLES DE CÉTACÉS

Everts réunis en un seul orifice extérieur; tête de moyenne grosseur; museau se terminant plus ou moins en pointe; les deux mâchoires garnies de dents qui, dans le genre Grampus, disparaissent à la mâchoire supérieure; yeux situés en arrière de l'angle de la bouche. Denticete.

DELPHINIDA

Events réunis en un seul orifice extérieur; tête très grosse ; tronquée à l'extrémité ; mâchoire inférieure très aplatie, rétrécie et garnie de dents ; yeux situés au-dessus de l'angle de la bouche. I,ongueur $60-80$ pieds. Denticete.

PHYSETERIDA

Events distincts ; mâchoires dépourvues de dents ; mâchoire supérieure munie de lames cornées ou fanons. Mysticete.

BALENIDA 


\section{Famille DELPHINIDE. Dauphins, MaRSOUINS.}

Les deux mâchoires sont garnies de dents coniques, excepté dans un genre où celles de la mâchoire supérieure tombent chez les adultes; les yeux sont placés en arrière et quelque peu au-dessus de l'angle que forme la bouche; le museau est plus ou moins pointu; les narines sont réunies en un seul évent extérieurement.

Cette famille a des représentants dans presque toutes les mers du globe.

Tous ces animaux nagent et plongent avec une grande vitesse et aussi avec beaucoup d'aisance; quelques-uns s'amusent souvent à bondir et à faire mille évolutions différentes à la surface de l'onde.

Bien des fables ont été brodées sur l'intelligence de quelques espèces qui appartiennent à cette famille et notamment sur celle du dauphin commun de l'Océan Atlantique et de la Méditerranée. Les livres des anciens sont remplis d'anecdotes où l'on mentionne le goût de cet animal pour la musique, son affection pour l'homme, et une foule d'autres choses analogues.

Trois espèces de dauphins, y compris cette dernière, habitent le nord de l'Océan Atlantique et se rencontrent du côté de l'Amérique, vers le sud, jusque vis-à-vis le nord des Etats-Unis. Mais je ne sache pas qu'aucune de ces espèces ait encore été signalée dans nos eaux, quoiqu'il ne soit pas impossible toutefois qu'on puisse en rencontrer quelquesunes accidentellement. 


\section{Genre PHOCENA, Cuvier.}

Tête arrondie en avant, à maxillaires courts ; dents comprimées et nombreuses, aux deux mâchoires; nageoire dorsale de moyenne longueur et de forme triangulaire.

\section{Phocæna phocæna, (LINNÉ).}

\section{Le Marsouin commun.}

Couleur d'un noirâtre uniforme en dessus, devenant grisâtre sur les côtés du corps inférieurement, et se transformant en blanchâtre sous le corps; nageoires pectorales noirâtres. Longueur, $4 \cdot 5$ pieds.

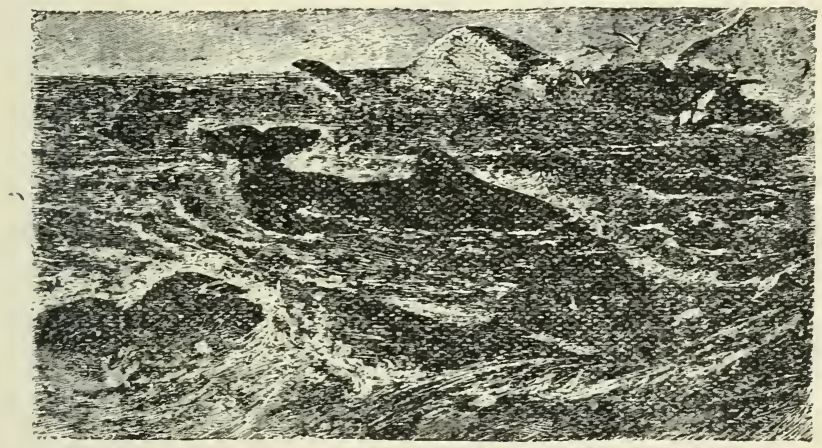

Fig. 17.-Le Marsouin commun.

Cette espèce habite également 'es océans Pacifique et Atlantique nord. Elle se montre très commune dans le golfe St-Laurent, où on la rencontre fréquemment, surtout à l'approche des ouragans; elle remonte souvent le fleuve à de grandes distances. Les marins la connaissent sous le nom de Pourcil. 
On ne fait guère la chasse à cette espèce, car le peu d'huile qu'on en retire ne compense pas toujours le trouble qu'elle donne.

\section{Genre GLOBICEPHALA, Lesson.}

Front large et globuleux, nageoires pectorales très étroites et longues; la dorsale petite et située quelque peu en avant du milieu du corps; dents aux deux mâchoires, plutôt faibles et moins nombreuses que dans le genre pré cédent.

\section{Globicephala melas, (TraILL).}

\section{I'Epaulard à tête ronde.}

Couleur noire. Longueur, 20 pieds ; nageoires pectorales, 4 pieds.

Cette espèce habite en troupes nombreuses l'Océan Atlantique boréal; elle se rend vers le sud jusque vis-à-vis des côtes du New-Jersey. Stearns la mentionne comme étant commune dans le golfe ou au moins à l'entrée du détroit de Belle-Ile. (I)

\section{Genre ORCA, Gray.}

Nageoire dorsale très longue, terminée en pointe, et plus longue que les pectorales; dents peu nombreuses, mais très grosses et fortes, en forme de cône ; elles sont au nombre de six à douze paires à chaque mâchoire.

Ce sont les cétacés les plus gros de la famille des delphinidés.

(I) Stearns, Notes on the Nat. Hist. of Labrador, p. 6. 


\section{Orca orca, (LinNé). \\ L'Orque épaulard.}

Couleur noire en dessus passant au blanc sous le corps. Longueur, plus de 20 pieds ; nageoire dorsale, 5 pieds ou plus.

Cet animal se trouve également dans l'Océan Pacifique comme dans l'Atlantique. Il est très vorace et s'attaque à toutes les grandes espèces de poissons, comme aux Cétacés; les baleines de grande taille mêmes ne sont pas à l'abri de ses atteintes. Son courage et sa voracité sont tels qu'il finit par vaincre des ennemis d'une taille beancoup plus forte que la sienne. Aussi est-il une cause d'ennui et de désappointement pour les pêcheurs lorsqu'il se rencontre dans les parages où se fait la chasse à la baleine ou autres animaux analogues, parmi lesquels il sème la terreur.

Cet animal est si agile et si vif dans ses mouvements qu'il est presque impossible de le harponner avec succès. On préfère le tuer au fusil. Il fournit une grande quantité d'huile. Il est connu dans le bas du fleuve, où il se montre commun, sous le nom de Gibbar.

Semblable aux espèces précédentes, il se nourrit de poissons, de céphalopodes et autres animaux sans vertèbres.

\section{Genre DELPHINAPTERUS, Lacépède.}

Pas de nageoire dorsale, les pectorales sont courtes; les dents sont peu nombreuses; la tête est obtuse et large. 


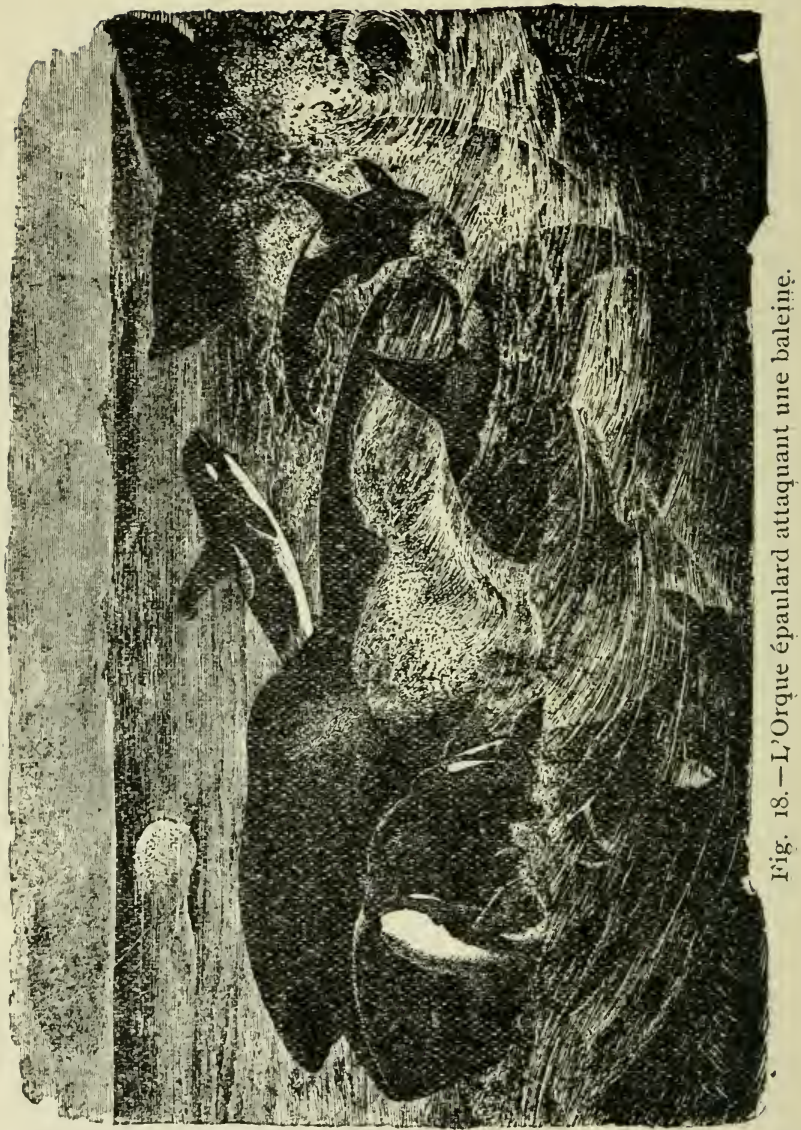




\section{Delphinapterus leucas, (PALLAS). \\ Le Marsouin blanc.}

Dents courtes et obtuses, environ huit ou neûf paires à chaque mâchoire. Couleur générale d'un blanc de crême chez les adultes et d'un gris bleuâtre chez les jeunes; ce n'est que lorsqu'ils ont atteint les trois quarts de leur taille qu'ils deviennent blancs. Longueur, i 5 pieds ou plus.

Au printemps, la femelle met au monde ordinairement deux petits, qui sont l'objet de toute sa sollicitude, et qui l'accompagnent dans tous ses déplacements.

Sa nourriture principale consiste dans diverses sortes de petits poissons, qu'il capture en les poursuivant. Comme toutes les grandes espèces, le Marsouin détruit un nombre incalculable de poissons et se rend par là même très nuisible.

Il habite l'Océan Atlantique boréal, et se voit souvent en bandes considérables dans les eaux du St-Laurent, qu'il remonte en troupeaux jusqu'à l'Ileaux-Coudres, quelques uns se rendant même à la poursuite des bancs de petits poissons jusque vis-àvis de Québec.

C'est le printemps seulement qu'on fait la pêche aux Marsouins lorsqu'ils remontent le fleuve; ils sont alors capturés en grand nombre, à l'Ile-auxCoudres, à la Rivière-Ouelle, et, l'automne, à l'enbouchure du Saguenay où un grand nombre séjonrne durant l'hiver. Cet animal est très gras et fournit une grande quantité d'huile d'excellente qualité.

C'est vraiment un beaı et intéressant spectacle 
que de voir, par une mer calme, ces immenses troupeaux de Marsouins, aux formes élégantes, et aux teintes variant depuis le blanc crêtne jusqu'au gris bleuâtre prendre leurs ébats, jouant, se poursuivant l'un l'autre au milieu des flots.

\section{Genre GRAMPUS, Gray.}

Dents de la mâchoire supérieure caduques; mâchoire inférieure munie de six à quatorze dents émoussées; nageoire dorsale courte, située plutôt à l'arrière du corps qu'au milieu.

\section{Grampus griseus, (Cuvier). \\ Le Grampus gris.}

Tête sensiblement renflée, couleur ardoise avec taches blanches irrégulières. Longueur, I 5 à 20 pieds.

Cette espèce est commune dans l'Océan Atlantique nord.

Stearns dit qu'elle n'est pas rare le long des côtes de Belle-Ile et peut-être plus loin. (I)

\section{FAMILLE PHYSETERIDÆ, CACHALOTS.}

Tête d'une grosseur énorme, atteignant environ le tiers de la longueur du corps; la mâchoire inférieure est étroite et très aplatie; elle est muuie d'une rangée de dents nombreuses, de forme conique ; la mâchoire supérieure est très épaisse et dépourvue de dents; les yeux sont placés bien au-dessus de la commissure de la bouche; les évents sont réunis en une seule ouverture extérieure.

Les Cachalots, si l'on er excepte une espèce de

(I) Stearns, Notes on the Nat. Hist. of Labrador, p. 7 . 
petite taille, comptent parmi les plus grands Cét acé des mers.

Ils fournissent à l'industrie une substance appelée spermaceti ou cétine, que l'on nomme aussi blanc de baleine. Cette substance est contenue surtout dans les cavités de la tête; elle est cristallisable et de conleur blanche, et on l'emploie à faire d'excellentes bougies. Dans une grosse espèce, on peut en retirer jusqu'à trois tonnes. La quantité d'huile que fournit leur graisse est évaluée à cent tonnes d'après Figuier.

Outre ces deux produits importants, on retire encore des intestins du Cachalot une substance odorante employée dans la parfumerie, et que l'on nomme ambre gris. Cette matière, assez dure, flotte sur l'eau et, lorsqu'elle est expulsée du corps de l'animal, les vagues la rejettent sur le rivage où on peut la trouver. L'ambre gris est le résultat d'une affection morbide du Cachalot, produite par une partie des aliments mal digérés.

\section{Genre PHYSETER, Linné.}

Tête très longue et très grosse, tronquée au bout, et dont la cavité antérieure est remplie de blanc de baleine et d'huile; les dents, grosses et émoussées, sont au nombre de quarante à cinquante. La nageoire dorsale manque.

\section{Physeter macrocephalus, Linné. Le Cachalot à grosse tête.}

Une protubérance charnue, espèce de nageoire adipeuse, apparaît à la partie postérieure du dos, et remplace en quelque sorte la nageoire dorsale. Couleur noirâtre en 
dessus et blanchâtre sous le corps. Longueur, So pieds. I a femelle est plus petite.

Ces animaux se nourrissent de petits poissons, de seiches, de méduses et autres invertébrés marins.

Cette espèce, qui est la plus connue, est l'objet d'une chasse constante à cause des produits considérables que l'on en retire.

Le Cachalot est moins farouche que la baleine; il ne fuit pas d'ordinaire à l'approche de ses ennemis.

"La pêche du cachalot, dit Brehm, est bien plus dangereuse que celle de la baleine. Il est rare que celle-ci tienne tête à ses ennemis; celui-là, au cortraire, quand il est attaqué, non seulement se défend, mais encore s'élance courageusement sur ses agres. seurs, faisant arme de sa queue vigoureuse et de sa terrible denture. L'histoire rapporte plusieurs sinistres causés par les cachalots.

"Des matelots de l'Essex, qui avaient blessé un de ces animaux, durent regaguer leur navire, car l'animal, d'un coup de queue, a vait avarié leur canot. Tandis qu'on cherchait à le radouber, un autre cachalot apparut à peu de distance du navire, le considéra pendant environ une demi-minute,et s'enfonça dans les flots. Un instant après, il reparut à la surface, s'élança contre le bâtiment, le frappa d'un tel coup de tête, que les matelots crurent avoir touché à un récif. L'animal furieux se dégagea, se retourna, et fit une seconde attaque, enfonça la proue et fit sombrer le navire; une partie de l'équipage fut seule sauvée. Un autre bâtinent américain, 
l'Alexander, fut de mêne coulé bas par un cachalot; un troisième, la barque Cook, ne dut son salut qu'à un coup de canon bien pointé. Quatre nois après le naufrage de l'Alexander, l'équipage de la Rebecca captura un énorme cachalot, qui se laissa prendre sans résistance. On trouva dans son corps deux harpons avec le nom Alexander; sa tête était fortement blessée, et dans ses plaies horribles étaient enfoncés de grands morcearx de planclies de navire." (I)

Le Cachalot habite la haute mer où il vit dans la société de ses semblables; il est plus commun dans les mers australes que dans celles du nord.

La femelle ne met bas que d'un seul petit pour lequel elle montre beaucoup d'attachement.

Stearns, sur la foi des habitants des côtes du Labrador, dit qu'il a été capturé quelquefois dans ces parages.

\section{Famile BALENID正. Baleinfs.}

Tête très grosse; évents séparés; bouche largement fendue ; mâchoires dépourvues de dents ; la supérieure est munie de chaque côté d'une rangée de nombreux fanons, implantés rerticalement et disposés à peu de distance entre eux, se terminant en franges; yeux très petits placés tout près de l'angle de la bouche.

Quoique ces animaux soient, pour la plupart, d'une taille énorme, ils ne se nourrissent cependant que de petites espèces marines, telles que petits

(I) Brehm. Les Mammiferes, Vol. 2, pp. $849-850$. 
poissons, méduses, mollusques, crustacés, etc., leur œsophage, très étroit, ne leur permettant pas l'entrée de plus grandes espèces.

Lorsque la Baleine veut assouvir sa faim, elle s'avance, la bonche ouverte, au milieu des bandes de petits poissons ou d'invertébrés; puis lorsqu'elle a fait une provision suffisante de ces animaux, elle referme la bouche et avale sa proie, après avoir chassé l'eau à travers les espaces qui séparent les fanons. Elle recommence ainsi le même manège jusqu'à ce qu'elle soit rassasiée.

La pêche des grands cétacés de cette famille ainsi que de celle du cachalot, fait l'objet d'un commerce important, et bon nombre de personnes sont intéressées chaque année dans cette industrie si dangereuse et qui pourtant n'est pas toujours productive, car il arrive parfois que cette pêche manque complètement, et les pêcheurs malheureux en sont alors pour la perte de leur temps et de leur argent.

Ce sont surtout les grandes espèces que l'on chasse d'ordinaire, soit pour l'huile qui est plus abondante, soit pour les fanons qui ont une plus grande valeur. On les préfère encore aux petites espèces parce que celles-ci, grâce à leur faible taille, et douées d'une grande souplesse et d'une grande rapidité de mouvements, sont d'une capture encore plus difficile et plus dangereuse.

Une courte description d'une expédition de chasse à la Baleine, qui est la même que pour le cachalot, 
ne se lira pas sans intérêt. Je l'emprunte de Brehın:

"Quand les navires sont arrivés dans les parages que fréquentent les baleines, ils croisent ou se mettent à l'ancre, explorant continuellement l'horizon tout autour d'eux. Le cri de la vigie "un souffenr !" émeut tout l'équipage. On met à la mer des canots parfaitement équipés, montés par six ou luit vigoureux rameurs, un pilote et un harponneur, et tous se dirigent rapidement et silencieusement vers la baleine. Le harpon est un fer acéré, très pointu, muni d'un crochet et attaché à une corde très longue et très flexible; celle-ci est enroulée à une bobine placée à l'avant du canot. En approchant de l'animal, on redouble de prudence, et lorsqu'on est arrivé tout auprès, le harponneur lance son harpon sur le colosse. Au même instant, les rameurs se penchent sur leurs avirons, pour éloigner le plus rapidement possible le canot du voisinage de l'animal blessé.

"Ordinairement la baleine plonge au fond de l'eau, en dévidant la corde avec une telle rapidité qu'on est obligé de la mouiller pour qu'elle ne prenne point feul. Mais bientôt sa fuite est moins rapide, elle nage plus lentement, et les pêcheurs peuvent la suivre. Souvent aussi ils sont entraînés loin de leur navire par une baleine harponnée, à plusieurs heures, à une demi-journée même. Cependant le colosse, après la première attaque, n'est jamais plus d'un quart d'heure à reparaitre à la surface de l'eaul pour respirer. Abordée de nouveau, elle reçoit un 
second harpon. On ne pourrait, dit un témoin oculaire, imaginer un spectacle plus horrible. La baleine effrayée se roule dans les vagues; dans son agonie, elle bondit hors de l'eat, la mer est couverte de sang et d'écume. L'animal disparaît, un tourbillon indique la place où il a plongé; il revient à la surface, mais c'est pour recevoir une nouvelle blessure mortelle; de quelque côté qu'il se dirige, un nouveau fer s'enfonce dans son corps. En vain redouble-t-il d'énergie, en vain fait-il bouillonner l'eau autour de lui; un tremblement a saisi son corps monstrueux; on dirait Vulcain ébranlant les montagnes. Il a perdu tout son sang, il se couche sur le flanc, ballotté par les vagues." (I)

Lorsque la Baleine est morte, des chaloupes la remorquent jusqu'au navire; là on enlève le lard par lanières que l'on fait immédiatement fondre pour en extraire l'huile qui est mise en quarts; on détache les fanons, et, si c'est un cachalot, on recueille le spermaceti de sa tête, puis on abandonne la carcasse aux oiseaux de mer, aux ours blancs ou autres animaux marins.

Il peut arriver quelquefois que le canot soit submergé, si la corde ne se déroule pas assez vite, de même si le colosse se trouve trop près de l'embarcation, il peut, d'un coup de sa formidable queue, faire sauter hommes et barque à plusieurs pieds audessus des flots ou bien les submerger.

(I) Brehm, Les Mammiferes. Vol. 2, p. 860. 
Comme on le voit, cette pêche offre toujours de graves dangers, mais l'appât du gain fait fermer les yeux aux baleiniers et leur fait oublier les périls auxquels ils s'exposent.

C'est ordinairement au printemps, en mai, juin et même en juillet que se font les expéditions de pêche à la Baleine franche dans les régions du nord. L'endroit le plus propice pour harponner la Baleine est en arrière de la nageoire pectorale, d'abord parce que la peau y est plus mince et ensuite parce qu'on a plus de chance de pénétrer jusque dans les poumons, le foie ou le cœur. A cause des grands dangers qui accompagnent généralement le harpornage à la main, on a cherché à le remplacer par des balles explosives ou par le harpon lancé par un mousquet. Mais ces diverses tentatives ont eu si peu de succès qu'on en est revenu au harponnage à la main qui donne plus de satisfaction.

\section{Genre BALENOPTERA, Lacépède.}

Museau large à peine bombé; corps allongé; ventre offrant de nombreux sillons longitudinaux; nageoires pectorales plus courtes que la tête; fanons petits; nageoire dorsale petite, mais bien développée.

\section{Balænoptera physalus, (LivNé). Le Rorquai commun.}

Parties supérieures d'un gris ardoise foncé, blanchissant sous le corps; nageoire dorsale située à la partie postérieure du corps ; fanons de couleur ardoise, mélangée de brunâtre. Longueur, 7 o pieds. 
Ce Rorqual habite le nord de l'Océan Atlantique, et se rencontre fréquemment dans le golfe.

De tous les balénidés qui se voient dans les eaux du St-Laurent, celui-ci est sans aucun doute le plus commun. Il remonte parfois le fleuve à des distances considérables pour un animal de sa taille et, l'an dernier, un de ces individus est venu s'échouer en face de la ville de Montréal où il fut tué; ce spécimen n'avait que trente-trois pieds de longueur. Ce fait n'est pas unique, puisqu'il y a une trentaine d'années, un autre individu est venu se faire tuer sur les rivages de l'Ile d'Orléans.

Le Rorqual se nourrit de petits poissons, particulièrement de harengs. Par son agilité il est, de tous ceux de son espèce, un des plus difficiles à harponner; aussi les pêcheurs ne tiennent-ils pas à s'en emparer, car il fournit peu d'huile et sa capture offre trop de dangers.

\section{Balænoptera musculus, (LinNé).} Le Rorqual gris.

Couleur générale d'un gris bleuâtre foncé; de petites taches blanchâtres se remarquent sur la poitrine; nageoires pectorales très longues; nageoire dorsale très petite, et située très loin à la partie postérieure du dos ; fanons noirs. Longueur, So pieds.

MM. Fortin et St-Cyr font mention de ce Rorqual comme se trouvant dans les eaux du golfe StLaurent, et, c'est sur leur autorité que je !e consigne ici. Il vit dans l'Océan Atlantique nord. 
Cet animal, comme le précédent, est agile et vif dans ses mouvements, et les pêcheurs n'aiment pas noir plus à lui faire la chasse.

On dit que ce Rorqual fait beaucoup de bruit lorsqu'il respire et que le jet de vapeur d'eau qu'il lance atteint une hauteur plus considérable que celui projeté par la baleine ordinaire.

\section{Genre HEGAPTERA, Gray.}

Nageoires pectorales aussi longues que la tête; nageoire dorsale remplacée par une bosse charnue ou espèce de petite nageoire adipeuse ; ventre arec des sillons longitudinaux.

\section{Megaptera nodosa, (BonnaterRE).}

\section{La Baleine à bosse.}

Corps court et épais, avec une protubérance dorsale; corps de couleur noire. Longueur de 60 à 75 pieds.

Cette Baleine vit dans le nord de l'Océan Atlantique où elle était autrefois commune, et se voit aussi dans le St-Laurent. C'est cette espèce que nos pêcheurs recherchent ordinairement; elle est plus lente dans ses mouvements et aussi plus facile à tuer que celles dont il a été parlé précédemment; elle donne aussi beaucoup plus d'huile; les grosses en fournissent jusqu'à deux mille quatre cents gallons.

On dit qu'elle vient fréquemment à la surface de l'eau pour respirer. 


\section{Genre BALÆENA, Linné.}

Dessous du corps lisse, sans sillons; point de nageoire dorsale; fanons très longs et de couleur noirâtre; museau rétréci en avant et fortement bombé. Corps lourd.

\section{Balæna glacialis, BONNATERRE.}

La Baleine franche.

Couleur générale noire, blanchissant parfois sous le ventre. Longueur, 40 pieds.

Cette espèce est commune dans l'Océan Atlantique nord.

Elle n'était pas rare autrefois dans le golfe StLaurent, d'après M. Fortin. Il rapporte qu'en I 845, trois individus de cette espèce firent leur apparition dans le fleuve qu'ils remontèrent jusque vis-à-vis de Kamouraska; plus tard on en vit apparaître cinq autres dans ces mêmes parages. Mais elle est maintenant devenue très rare. On dit que cette espèce donne au delà de sept mille gallons d'huile.

Malgré sa taille prodigieuse et sa grande force, cet animal est des plus timides et des plus inoffensifs; le moindre bruit l'effraie et il fuit au lieu de se défendre contre les attaques de ses ennemis.

Il est étonnant que cette masse puisse se mouvoir avec vivacité. "Autant la Baleine est lourde, dit Scoresby, autant ses mouvements sont adroits et rapides. En cinq ou six secondes, elle peut être hors de l'atteinte de ceux qui la poursuivent. Mais elle ne peut conserver une telle vitesse que pendant 


\section{- II9 -}

quelques minutes. Parfois elle s'élance avec tant de force qu'elle bondit hors de l'eau. " (I).

Les Baleines sont des animaux stupides et lâches, qui ne déploient de courage que pour défendre leur progéniture. Une Baleine vient d'ordinaire respirer à la surface de l'eau toutes les deux ou trois minutes, mais lorsqu'elle est harponnée ou inquiétée, elle peut demeurer une vingtaine de minutes submergée avant de venir respirer de nouveau.

La Baleine est incommodée par de nombreux parasites, des milliers d'invertébrés, entr'autres les cirrhipèdes et les pous de baleine, qui se fixent sur sa peau et s'y nourrissent.

Avec cette dernière espèce se termine la liste des cétacés que l'on donne comme se rencontrant dans les eaux du fleuve et du golfe St-Laurent. Comme ils ont été jusqu'ici peu étudiés, quant à leur présence dans nos eaux, il peut se faire que des recherches et des études ultérieures en augmentent ou en restreignent le nombre.

\section{ORdRE UNGULATA.-MAMMFÈres À SABOTS.}

Ces animaux, nombreux en espèces, sont distribués sur toute la surface du globe. On les rencontre dans tout l'ancien continent et, dans le nouveau

(I) Brehm, Les Mammifères, Vol. 2, p. 858 . 
monde, depuis les régions arctiques jusque vers le sud de l'Amérique méridionale. Ils offrent dans leur taille, leur structure, ainsi que dans leurs mœurs, des variations très diverses. En effet, on trouve parmi eux des animaux terrestres et aquatiques, ou du moins qui passent à l'eau la plus grande partie de leur vie; quelques-uns ont la tête ornée d'une excroissance cornée qui prend, chez certaines espèces, des dimensions énormes; d'autres ont le museau allongé en forme de tube, d'autres enfin sont munis d'estomacs multiples dans lesquels les aliments, après avoir été concassés dans la bonche, descendent dans un de ces estomacs pour remonter de nouveau dans la bouche de l'animal afin d'y subir une seconde mastication, puis ils passent définitivement dans un autre estomac, où ils viennent en contact avec divers sucs qui les rendent assimilables à l'organisme.

Les ongulés sont essentiellement herbivores, à l'exception du cochon qui peut manger de tout; ils font entrer dans leur nourriture des herbes, des feuilles, des fruits, des écorces d'arbres et des mousses.

Le caractère distinctif et essentiel de cet ordre repose dans la conformation du pied dont le ou les doigts sont enveloppés dans un sabot, espèce de gaîne cornée qui met l'animal dans l'impossibilité de rien saisir et lui enlève à cet endroit le sens du toucher. Les doigts se nombrent de un à quatre à chaque membre. 
Ils sont, par conséquent, incapables de grimper ou de creuser dans le sol. Les molaires sont à surface large et sont conformées pour broyer les aliments; les canines inanquent chez la plupart, et les incisives, qui sont larges, font défaut chez un bon nombre à la mâchoire supérieure; leur progression est digitigrade.

Les ongulés se recrutent parmi les plus grands mammifères terrestres; cependant il s'en rencontre quelques-uns dont la taille est au-dessous de la moyenne.

De tous les Mammifères, ce sont sans aucun doute ceux dont l'homme retire le plus grand avantage; il les utilise comme bêtes de somme, se nourrit de leur chair et se sert de leur dépouille pour les convertir en habillements.

Notre faune n'est représentée que par quelques espèces indigènes.

\section{FaMille CERVID无, Cerfs, Elans.}

Formule dent. $-i \cdot \frac{0-0}{3-3} c$. (d'ordinaire) $\frac{0-0}{1-1} p m \cdot \frac{3-3}{3-3} m \cdot \frac{3-3}{3-3}$

Ces animaux sont bien caractérisés par la forme particulière de leurs prolongements frontaux qui prennent un déreloppement plus ou moins considérable. Ces bois ou cornes sont pleins sur toute leur longueur, et portent des ramifications ou andouillers plus ou moins nombreux: ils tombent annuellement et sont remplacés par d'autres qui, dans les premiers temps de leur croissance, sont rerêtus d'une peau recouverte de poils courts; cette peau finit par se dessécher et tomber après quelques mois; le 
panache a alors atteint son entier accroissement. Ces bois sont l'apanage exclusif des mâles, à l'exception toutefois de quelques espèces où ils sont communs aux deux sexes.

Un large espace existe entre les incisives et les molaires, cependant un bourrelet cailleux remplace les incisives supérieures qui manquent; les pieds sont terminés par deux doigts enfermés séparément dans un sabot; et en arrière se trouvent deux petits ergots, vestiges de doigts latéraux; le cou est bien développé et musculeux; les yeux sont grands et expriment la douceur; des larmiers se voient presque toujours extérieurement au-dessous de 1 'œil.

Les Cervidés, de même que les bœufs et les moutons domestiques, ont la faculté de ramener dans la bouche, pour les mâcher de nouveau, les aliments qu'ils ont déjà avalés une première fois, c'est ce que l'on appelle ruminer; à cet effet, ils sont pourvus de quatre estomacs qui ont reçu les noms de panse, de bonnet, de feuillet et de caillette. Le premier et le plus grand des estomacs est la panse, qui reçoit les aliments grossièrement concassés par une première mastication; de là, ces aliments passent dans le bonnet où ils sont imprégnés d'un liquide sécrété par ses parois ; puis, transformés en petites pelottes, ils remontent dans la bouche pour subir une dernière mastication, et enfin, descendent de nouveau dans l'œsophage en pénétrant de suite dans le feuillet, puis dans la caillette, qui correspond à l'estomac des autres mammifères, et dont les parois sécrètent un liquide analogue au suc gastrique. 
Ces animaux sont presque tous de grande taille; leur corps est élancé, leurs mouvements sont aisés et leur course rapide. Ils vivent en troupeaux dans les grandes forêts; ils sont d'un caractère timide, ce qui contribue à leur faire aimer la solitude.

\section{Genre ODOCOILEUS, Rafinesque.}

Taille ordinaire; panache chez les mâles seulement et plutôt petit que grand, à ramures dirigées en avant ; queue plutôt longue; museau petit avec un large espace nu au bout ; oreilles grandes.

\section{Odocoileus americanus, (ERXLEBEN).}

\section{Le Cerf d'Amérique.}

Pelage fauve ou châtain roux en été, avec le dessous du corps blanc, depuis le ventre jusqu'à l'extrémité de la queue en dessous, ainsi que le dedans des jambes antérieures; en hiver le poil est plus long et plus fourni; il est d'un roux grisâtre supérieurement. Longueur, 4 pieds. 6 pcs; queue, I pied.

Les jeunes sont roux canelle avec taches de blanc sur tout le corps.

Le Cerf d'Amérique, communément nommé Chevreuil, est certainement le plus élégant et le plus beau des grands mammifères qui peuplent nos forêts. On le rencontre dans l'est des Etats-Unis? et du Canada; mais dans notre province, son parcours géographique ne s'étend pas aussi loin que celui de son voisin le caribou; il ne paraît pas dépasser la limite nord du fleuve St-Laurent en bas de Québec. Il était autrefois très commun sur toute cette étendue de l'Amérique du Nord; aujourd'hui on l'y ren- 
contre bien encore en grand nombre dans certaines régions, mais il est disparu de plusieurs endroits, et cette espèce s'éteindra dans un avenir peu éloigné si on ne la protège par des lois plus efficaces.

Le Chevreuil vit par bandes plus ou moins nombreuses dans les endroits qu'il chosit et qu'il ne quitte guère. Sa nourriture varie suivant les.saisons : en été, il mange des feuilles de divers arbres, des herbes les plus délicates, des plantes aquatiques, des baies, telles que bluets, ronces et autres; mais en hiver, il se contente des bourgeons de pruche, de cèdre, de bouleau, des monsses et des lichens.

Lorsque la neige, dans la forêt, atteint une certaine épaisseur, les Chevreuils se fixent dans un endroit plus restreint et y demeurent jusqu'au printemps, c'est ce que l'on appelle en terme de chasse, leur ravage.

Le panache tombe en janvier ou février et pousse de nouveau en mai ; en septembre, le velouté qui le recouvre tombe, c'est alors qu'il a acquis son complet accroissement.

"Le Cerf de Virginie, nous dit Audubon, est un animal nocturne, mais il faut ajouter que, dans les prairies, et là où il est peu troublé, il sort aussi le matin et l'après-midi pour chercher sa nourriture. Il ne se repose alors qu'au milieu du jour.

"Dans les contrées de l'Atlantique, où il est continuellement chassé, il ne quitte que rarement son gîte avant le coucher du soleil. On le voit, de jour, plus souvent en été ou au printemps qu'en hiver. 
"Dans les pays où cet animal est l'objet de poursuites incessantes, il laisse le chasseur approcher de son gîte plus près que là oì il est peu chassé. Il reste couché, non qu'il dorme, mais par crainte de se montrer et dans l'espoir d'échapper à l'œil de son ennemi. J'en ai vu qui étaient couchés, les jaubes de derrière ramassées, prêts à sauter, les oreilles rabattues sur la nuque, les yeux ne quittant pas l'importun. Dans ce cas le chasseur ne peut espérer un succès qu'en tournant lentement l'animal, sans faire semblant de l'apercevoir, et en tirant subitement, pendant qu'il est encore dans son gîte. Avant d'avoir été poursuivi, le cerf cherche, à l'approche du chasseur, à s'échapper en glissant dans le fourré.

- La démarche du cerf de Virginie est variable. Lorsqu'il court, il baisse la tête, avance silencieusement et avec prudence, en agitant continuellement la quene et les oreilles. L'individu le plus fort conduit la bande, les autres le suivent un à un; rarement on en voit deux de front. Quand ces animaux ne sont pas effrayés, ils vont lentement et au pas. Surpris mais non épouvanté, le cerf saute deux ou trois fois en l'air, et retombant arec une sorte de maladresse apparente sur trois jambes, se retourne vers l'endroit suspect, lève sa queue blanche et l'agite. Puis, il fait quelques bonds, tourne la tête de côté et d'autre, et cherche ce qui a pu le troubler. Tout cela s'exécute avec une élégance qu'on ne peut assez admirer. 
"Si, par contre, l'animal aperçoit, étant dans son gîte, un objet de terreur, il s'élance rapidement, la tête et la queue étant tendues dans la même ligne que le reste du corps, et parcouri ainsi plusieurs centaines de pas, comme s'il voulait rivaliser de vitesse avec un cheval de course. Mais il ne soutient pas cette allure; plus d'une fois, je l'ai vu atteint et dépassé par un cavalier bien monté ; au bout d'une heure de chasse, une bonne meute s'en empare, à moins qu'il n'ait rencontré un étang ou une rivière dans les eaux de laquelle il cherche immédiatement un refuge. Il va d'ailleurs volontiers à l'eau et nage avec une grande vitesse, le corps submergé, n'élevant que la tête au-dessus de la surface. J'ai vu des cerfs traverser de larges fleuves, parcourir à la nage une distance de deux milles anglais, et avec une telle rapidité, qu'un canot avait peine à les joindre. Sur les côtes du sud, le cerf poursuivi et pressé par les chiens s'élance dans les flots, s'éloigne à un ou deux milles du rivage, et revient ensuite d'ordinaire à l'endroit d'oì il est parti.

"En traversant, de nuit, les forêts, j'ai souvent entendu un cerf frapper du pied à notre approche ou pousser un fort soupir. Puis tonte la bande s'élançait, s'arrêtait, frappait du pied et soupirait de nouveau. Mais cela paraît n'arriver que la nuit. " (I)

La femelle met bas en mai ou juin de un ou deux petits, qu'elle cache dans un buisson ou dans de

(1) Audubon. Voy. Brehm. Les Mammiferes. Vol. 2., pp. 509-510. 
hautes herbes; aussitôt que les petits peuvent marcher, ils suivent leur mère.

En hiver on chasse le Chevreuil de deux manières, soit en le surprenant dans son ravage, soit en le poursuivant dans le bois; on choisit à cet effet le moment où la neige est abondante et molle, ou bien celui où elle est couverte d'une couche de verglas; dans ces conditions l'animal enfonce beaucoup ou se blesse les jambes en passant à travers la couche de verglas, et ne peut aller bien loin sans se fatiguer. Alors le chasseur monté sur ses raquettes peut l'atteindre facilement et le tuer. Il arrive même quelquefois que l'animal est tellement épuisé que le chasseur le saisit par les cornes, et lui coupe la carotide avec un couteau,sans qu'il offre beaucoup de résistance.

En été en peut encore le chasser la nuit, au bord de l'eau, au moyen d'un flambeau; à cette fin, on alume un feu que l'on pose sur le devant du canot, de telle sorte que le chasseur reste dans l'ombre, puis, lentement et sans bruit, on côtoie le bord du bois; la vue de cette lumière inaccoutumée excite la curiosité du Chevreuil, qui s'approche de l'eau, et on peut alors faire le coup de feu. Cette manière de chasser le Chevrenil a quelquefois occasionné des erreurs regrettables, car en croyant faire feu sur cet animal, on a tué des animaux domestiques, que la lumière avait également attirés à cet endroit.

Aubudon, parlant des diverses manières de chasser le Chevreuil, dit que celle qui consiste à aller 
tuer l'animal dans son gîte est la plus destructive, et, dans son style toujours pittoresque, il la décrit de la manière suivante:

"La chasse au repos est considérée comme un métier par nombre d'hommes de nos frontières. Pour être pratiquée avec succès, elle réclame une grande activité, une adresse consommée dans l'usage de la carabine, et une connaissance approfondie de tous les réduits de la forêt. Ajoutons qu'il faut que le chasseur soit parfaitement au courant de chaque habitude du cerf, non seulement aux diverses saisons de l'année, mais encore à chaque heure du jour: pour savoir exactement quelles sont les différentes remises que le gibier préfère, et dans lesquelles, à tout moment, on a le plus de chance de le rencontrer....

"Toute scène pour frapper a besoin d'être présentée, s'il est possible, en pleine lumière; je supposerai donc que nous sommes maintenant sur les pas de notre chasseur, du vrai chasseur, comme on l'appelle aussi, et que nous le suivons au plus fourré des bois, à travers les marécages, les précipices, et là partout où le gibier peut se rencontrer plus ou moins abondant, au risque quelquefois de n'y rien trouver du tout. Le chasseur, cela va s'en dire, est doué de toute l'agilité, de toute la patience,de toute la vigilence enfin qu'exige sa délicate profession; et nous, nous marchons à l'arrière-garde, épiant chacune de ses manœuvres, ne perdant aucun deses mouvements. 
"Son équipement, comme vous pouvez le voir, consiste en une sorte de blouse de cuir, avec pantalon à l'avenant; ses pieds sont chaussés de mocassins solides; une ceinture lui relie les reins; sa pesante carabine repose sur sa large épaule; à l'un de ses côtés pend son sac à balles surmonté de la corne d'un vieux buffle, autrefois la terreur du troupeau, et qui sert maintenant à mettre une livre de poudre de chasse superfine.

"C'est là aussi qu'il a fourré son grand couteau ; il n'a pas même oublié son tomahawk, dont le man. che est passé derrière lui, daus sa ceinture; et il marche d'un tel pas, que peu d'hommes probable. ment, si ce n'est vous et moi, pourraient le suivre; mais nous avons résolu d'être témoins de ses sanglants exploits, et d'ailleurs le voilà qui s'arrête; il examine sa pierre à fusil, son amorce, la pièce de cuir qui recouvre sa platine; puis il regarde en haut, il s'oriente et cherche à reconnaitre dans quelle direction il fera le meilleur pour le gibier.

"Le ciel est clair, le vif éclat du soleil levant rayonne à travers les basses branches des arbres; les gouttes de rosée, perles liquides, scintillent à l'extrémité de chaque rameau. Déjà la couleur émeraude du feuillage a fait place aux teintes plus chaudes des mois d'automne; une légère couche de gelée blanche recouvre les perches qui enclosent le petit champ de blé du chasseur, et lui, tout en marchant, a les yeux sur les feuilles mortes qui jonchent à ses pieds la terre; il y cherche les traces 
bien connues du sabot de quelque cerf. Maintenant, il se baisse vers le sol où quelque chose vient d'attirer son attention... Regardez, il change d'allure, hâte le pas ; bientôt il atteindra, là-bas, cette petite montagne. A présent, comme il marche avec précaution, faisant halte à chaque arbre, jetant les yeux en avant comme s'il était déjà à portée du gibier. Il avance encore, mais lentement, lentement ; enfin, le voilà sur le penchant de cette éminence qu'éclaire le soleil dans toute la pompe de son réveil... Voyez, voyez; il prend son fusil, découvre la platine, nettoie avec sa langue le tranchant de la pierre; maintenant il se tient debout et fixe comme une statue ; peut-être mesure-t-il la distance entre lui et le gibier qu'il couve de l'œil; puis sa carabine se relève tout doucement, le coup part, et le voilà qui court! courons aussi... Lui parlerai-je, pour lui demander comment a réussi son début? Certes oui, car c'est une de mes vieilles connaissances.

"Eh bien! l'ami, qu'avons-nous tué? (lui dire: qu'avons-nous tiré? ce serait supposer qu'il a pu manquer, et risquer de le mettre en colère.)-Ah! pas grand'chose, un cerf.-Et où est-il ? -Ah! il a voulu faire encore un ou deux sauts; mais il n'est pas loin, je l'ai trop bien touché; ma balle a dû lui traverser le cœur. n

- Nous arrivons au lieu où l'animal s'était mollement couché parmi les herbes, sous un bosquet de vignes d'où pendent des grappes enlacées aux branches du sumac et des sapins touffus. C'est là que,dans 
un doux repos, il espérait passer le milieu du jour ! La place est couverte de sang, ses sabots se sont profondément enfoncés dans le sol lorsqu'il bondissait dans l'agonie de la douleur. Mais le sang qui lui dégoutte du flanc trahit le chemin qu'il a pris. Enfin le voilà, gisant sur la terre, la langue pendante, les yeux éteints, sans mouvement, sans souffle.. Il est mort !. .

- Si la saison eût été chaude, c'est du côté de la montagne où l'ombre donne, que le chasseur aurait cherché les traces du cerf. Au printemps, il nous eût conduits au plus épais d'un marécage couvert de roseaux, sur les bords de quelque lac solitaire où vous eussiez vu le cerf plongé jusqu'au cou, pour échapper aux insupportables piqûres des cousins. Si l'hiver, au contraire, eût recouvert la terre de neige, il se serait dirigé vers les bois bas et humides que tapissent la mousse et le lichen dont les cerfs se nourrissent en cette saison, et qui parfois encroûtent les arbres jusqu'à plusieurs pieds de hauteur. En d'autre temps, il eât remarqué les endroits où l'animal, frottant ses cornes contre les branches des arbrisseaux, les débarrasse de leur enveloppe veloutée; ceux où il a coutume de creuser la terre de ses pieds de devant; ou bien, il l'eût attendu au lieu où abonde le pommier sauvage et le plaqueminier sous lesquels il s'arrête de préférence, parce qu'il aime à mâcher leurs fruits. Au printemps, dès les premiers beaux jours, notre chasseur, imitant le bramement de la femelle, parvient 
souvent ainsi à s'emparer de la mère avec son faon....." (I)

En captivité, le Chevreuil s'apprivoise facilement et il s'attache même à la personne qui en prend soin.

\section{Genre CERVUS, Linné.}

Bois, chez les mâles seulement, grand, arrondi, très rameux, et renversé en arrière avec les andouillers dirigés en avant. Animaux de grande taille; sabots grands et arrondis ; queue très courte.

Cervus canadensis, (ERXLEBEN.) Le Cerf du Canada.

Pelage d'un roux marron clair, plus foncé sur le cou et les jambes, presque blanc jaunâtre dans la région du croupion, et noirâtre sur la gorge et la ligne médiane du ventre ; menton noirâtre. Grande taille, cinq pieds de hauteur à l'épaule.

Le Cerf du Canada, plus communément appelé Wapeti, était autrefois distribué dans toute l'Amérique du Nord, de l'A tlantique au Pacifique, comme l'attestent ses restes enfouis dans le sol. Mais il a dû, à l'exemple de bien d'autres habitants de nos bois, restreindre son parcours géographique, et reculer devant les déboisements successifs des forêts, de telle sorte que dans bien des localités, il est entièrement disparu, surtout dans l'est de l'Amérique du Nord, où aujourd'hui on ne le retrouve plus que dans certaines régions des Etats-Unis, ainsi que dans l'ouest canadien.

(I) Audubon. Trad. de Bazin. Scènes de la nature dans les $E$. $U$. Vol. I, pp. 294-299. 
Jadis, sur les rives du St-Laurent, ce bel animal n'était point rare, s'il faut en croire ce qu'en disent certains auteurs. Toutefois, il ne paraît pas y avoir plus d'une centaine d'années qu'il soit disparu, car ses restes trouvés dans la terre ne dénotent pas un plus long séjour; ainsi des bois et des fragmentsede bois ont été trouvés dans le sol végétal, immédiatement sous la couche de feuilles et de mousse en décomposition qui recouvre le sol. En creusant le canal Rideau, on a découvert un squelette entier possédant encore son panache; ce dernier mesurait cinq pieds de longueur.

Le Wapeti est de haute stature, il dépasse celle du cerf d'Europe, avec lequel il a beaucoup d'analogie; voilà pourquoi on a cru pendant longtemps que ces deux individus appartenaient à la même espèce ; mais on admet aujourd'hui que ce sont deux espè. ces distinctes.

Le panache de cet animal tombe dans le mois de février oul au commencement de mars; il croît de nouveau en quelques mois, recouvert d'un velouté qui tombe plus tard.

Le Cerf du Canada vit d'herbes, de branches de saules, d'écorce d'arbres, de mousse et de lichens. En hiver il gratte la neige de son pied pour atteindre la mousse, les herbes et les jeunes pousses dont il se nourrit à cette saison de l'année.

Pendant les fortes chaleurs de l'été il va souvent à l'eau, pour de se débarrasser des insectes qui le tourmentent. 
Cet animal est d'un naturel farouche et par cela même difficile à atteindre; mais lorsqu'il est blessé, il devient furieux, dit-on, et il défend sa vie avec beaucoup de courage.

Son odorat est très subtil. "L'air est à peine imprégné de l'odeur de son ennemi, qu'il lève vivement la tête, incline les oreilles dans toutes les directions, afin de percevoir le moindre bruit, et son grand œil brun brille d'un vif éclat, exprimant l'inquiétude la plus grande. Aussitôt qu'il aperçoit le chasseur, le Wapeti bondit en avant, fait quelque pas comme s'il voulait essayer ses forces, puis il s'arrête, fait un demi tour, et toise son ennemi d'un regard ferme, puis il rejette en arrière son gros panache, avançant son fin museau, il s'élance aussitôt avec une telle vitesse qu'il laisse bientôt loin de sa vue l'objet de sa frayeur. " (I)

La femelle met bas en mai ou en juin de un on deux petits.

\section{Genre ALCES, Gray.}

Animaux de grande taille, hauts sur jambes ; corps lourd; tête longue ; museau cartilagineux, renflé et velu, à l'exception d'un petit espace nu au bout ; yeux comparativement petits, fossettes lacrymales petites; oreilles longues et larges; bois chez les mâles seulement, très large, en forme de palettes et à nombreuses dentelures; queue courte.

(I) Canadian Nat. and Geol. Vol. I, p. 85. 
Alces americanus, JARDINE.

L'Elan d'Amérique.

Pelage d'un gris noirâtre mélangé de jaunâtre; cette dernière teinte domine en dessous et vers le museau. La crinière est de longueur moyenne.

C'est le plus grand et le plus robuste des animaux de nos forêts. Il atteint parfois une hauteur de huit pieds et son bois, qui prend des dimensions énormes, pèse jusqu'à soixante livres, et la distance entre l'extrémité de ses cornes peut aller jusqu'à soixantequatorze pouces.

L'Elan ou Orignal, comme on le nomme ordinairement, habite la partie nord de l'Amérique septentrionale. A l'exemple des autres animaux de nos forêts, il diminue peu à peu; toutefois on le retrouve encore plus ou moins commun dans certaines régions boisées du nord des Etats-Unis comme dans celles de la Puissance.

L'Orignal est loin d'avoir l'élégance de formes et la légèreté du chevreuil et du caribou. Sa haute stature, son corps gros, sa tête allongée qu'il porte presque toujours basse, son museau épais, ses grandes oreilles, son poil long et grossier, tout contribue à lui donner un air de stupidité et de gaucherie.

M. J. E. Powell, qui a étudié en détail les mœurs de l'Elan, nous en a laissé l'intéressante description suivante :

"Lorsque la neige est entièrement disparue de la 
surface de la terre, ce qui a lieu, dans les retraites favorites dâs Elans, vers le milieu de mai, ils quittent ce gîte d'hiver pour se rapprocher des étangs, des marais et des rivières oì croissent, dans ces endroits, diverses plantes aquatiques qu'ils mangent. Néanmoins leur nourriture favorite consiste surtout dans les nénuphars et les joncs de diverses espèces; à cette saison, ils les broutent aussitôt qu'ils apparaissent et ils les rongent jusqu'à la racine, se tenant la tête sous l'eau durant l'espace d'une minute ou quatre-vingt secondes; ils vont même dans l'eau à une telle profondeur que, lorsqu'ils plongent la tête pour y atteindre les jeunes pousses et en arracher les racines de nénuphars (qu'ils mangent souvent à cette saison de l'année) avant que les feuilles soient nombreuses, on ne leur aperçoit qu'une partie du dos. C'est aussi vers cette époque que les femelles s'éloignent des mâles, cherchent les bois les plus touffus de la forêt et le plus près de l'eau possible, pour y inettre bas. Les femelles de trois ans ou plus ont invariablement deux petits. Néanmoins, j'ai vu quelquefois une portée de trois, mais c'est très rare; celles de deux ans n'en ont jamais plus d'un.

"C'est également vers cette période de l'année qu'ils quittent leurs poils longs et grossiers pour se revêtir d'un beau poil doux et court, de couleur brun foncé, qui devient bientôt d'un noir lustré sur les côtés et le dos, et gris sur les jambes... A mesure que la saison avance, les Elans fréquentent 


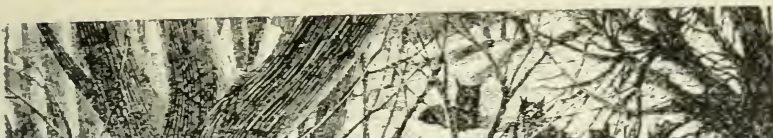

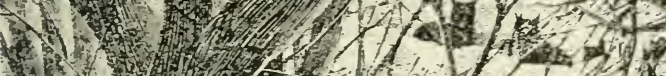
1 (1)

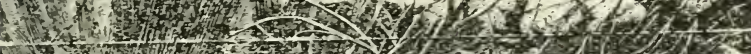
a.1.

a. ㄱ. N.

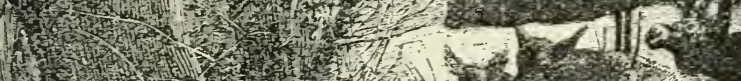

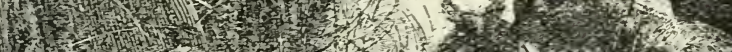

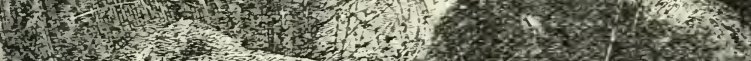

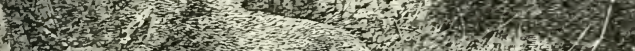

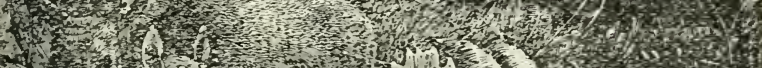

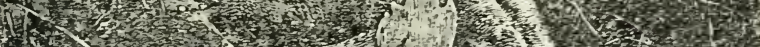
15.

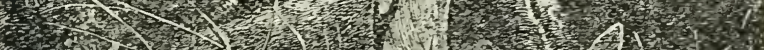

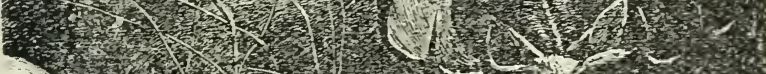

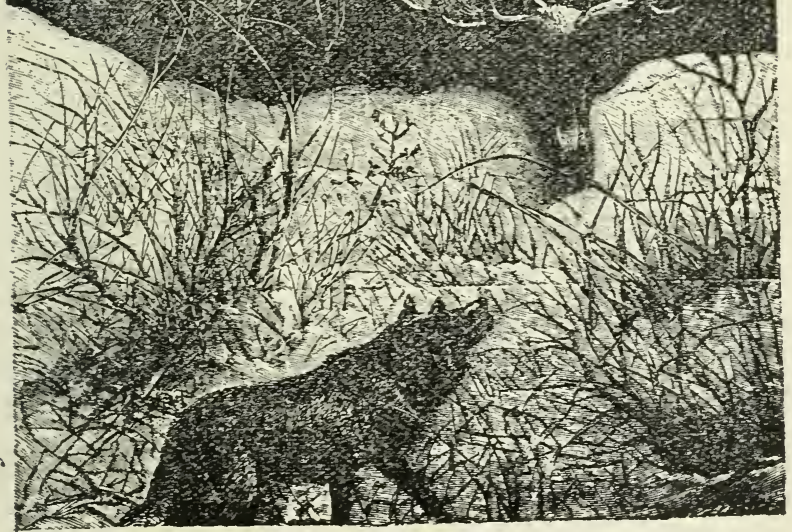

Fig. I9.-Les Elans dans leurs quartiers d'hiver. 
l'eau davantage, et y restent plus longtemps chaque fois. Vers la fin de mai ou au commencement de juin, ils demeurent dans l'eau rarement plus d'une demi-heure, mais en juillet et en août, ils y passent quelquefois des heures entières; même la nuit, ils vont souvent se baigner, surtout lorsque la température est cliande, sèche et suffoquante, ou pendant les orages accompagnés de tonnerre. Dans ces circonstances, ils semblent prendre un plaisir particulier à nager çà et là, et manifestent des signes de la plus grande joie.

"L orsque les feinelles vont à l'eau, elles cachent leurs petits avec beaucoup de soin, afin de les protéger contre la férocité des vieux mâles qui les tueraient. A cette fin, elles choisissent d'ordinaire une touffe de gros arbrisseaux ou un massif de sapins ou de mélèzes qui, par sa densité, empêche les inâles de les atteindre, arrêtés qu'ils sont par leurs cornes qui commencent à pousser en avril. Ces cornes, qui croissent rapidement, sont alors très tendres et peuvent facilement se casser à cette époque. Au mois de septembre, le velouté qui les recouvre disparaît, et c'est alors qu'elles acquièrent toute leur dureté. A la fin du même mois, les Elans quittent le bord des eanx pendant deux ou trois semaines, pour se retirer dans les montagnes. Les mâles sont alors très gras (j'en ai tué qui avaient presque trois pouces de graisse sur le croupion). Ils sont souvent très sauvages, très féroces, et attaquent même parfois le chasseur. 
"Dans l'espace de quelques semaines, ils deviennent maigres, par suite de leurs courses vagabondes, des nombreux combats qu'ils se livrent entre eux, et aussi parce qu'ils négligent de prendre de la nourriture. A cette époque, les mâles font entendre des mugissements qui, durant les nuits silencieuses, peuvent être perçus et reconnus par le chasseur attentif, à une distance de deux à trois milles.

"Les mâles produisent aussi un autre bruit particulier, que les chasseurs appellent bûcher; ce bruit est produit par les mâchoires qui s'ouvrent et se ferment avec force, d'une manière spéciale, qui ressemble, comme son nom l'indique, au bruit que fait une hache entendu à une grande distance; ils émettent aussi divers autres cris et sons singuliers.

"Lorsqu'ils reviennent vers l'eau, ils se baignent souvent, et demelirent longtemps dans l'eau, et cela, pendant une couple de semaines; mais après, ils y diminuent graduellement leurs visites jusqu'au moment de la gelée, et même ils se baignent encore parfois jusqu'à ce que la glace atteigne une épaissenr d'un pouce en une seule nuit.

"Ils retournent alors dans les montagnes, où ils choisissent leurs quartiers d'automne et d'hiver, errant d'abord de côté et d'autre, se nourrissant de l'écorce de petits arbres, qu'ils pèlent ou rongent, ainsi que des rameaux de sapins et autres arbres. Lorsque la neige devient épaisse, ils se choisissent un endroit bien adapté à leurs besoins, et commencent à ronger et à brouter autour d'eux, c'est ce que 
l'on appelle ravage. A inesure que la neige augmente et qu'elle se durcit, ils se contentent de peler les arbres et de dévorer les jeunes arbrisseaux les plus proches, plutôt que de se frayer un chemin dans la neige, à la recherche d'une nourriture plus choisie.

"Un ravage occupe fréquemment un espace d'environ une centaine d'arpents; mais dans les dernières semaines de la saison des neiges, cet espace est beaucoup plus restreint, et ne comprend guère plus d'une douzaine d'arpents. Les vieux mâles et les femelles n'hivernent jamais ensemble, inais les jeunes passent quelquefois l'hiver avec les vieux, quoiqu'on ne les trouve pas en société bien intime; les femelles et leurs petits passent l'hiver ensemble; ces derniers demeurent avec leur mère pendant un an.

"Les vieux mâles hivernent invariablement seuls, ils aiment la solitude et se choisissent quelque lieu écarté ou quelque montagne isolée ; de fait; à mesure que l'Orignal vieillit, il devient de plus en plus solitaire dans ses habitudes, et évite la société de ses semblables, fréquentant en été quelques petits lacs ou étangs solitaires. Les jeunes de deux ou trois ans font aussi bande à part ; mais ceux de trois à dix ans, vont ordinairement par troupeaux plus ou moins nombreux. J'en ai vu jusqu'à neuf dans le même ravage.

"Lorsqu'ils sont poursuivis par les chasseurs, ils vont à la file, chacun marchant dans la piste de son prédécesseur, de sorte qu'il n'y a qu'un chasseur 
expérimenté qui puisse reconnaître qu'il y en a plus d'un, lorsqu'en réalité il peut y en avoir six ou sept. Sont-ils cernés de près, le premier, dès qu'il sent ses forces faiblir, par suite de la neige profonde et durcie qu'il est obligé de fouler, fait un pas de côté et laisse passer les autres qu'il suit à son tour; ils se relèvent à tour de rôle, les mâles aidant ainsi les femelles ou les jeunes; s'il arrive qu'ils rencontrent, dans leur course, un arbre renversé et qu'ils soient traqués de très près, chacun franchit l'obstacle en rompant l'ordre de la marche, pour la reprendre après comme auparavant. Ce sont les daguets ou les mâles de deux ans, qui offrent la chasse la plus longue et la plus fatiguante; mais les vieux inâles combattent avec beaucoup de vigueur. De fait, ils refusent souvent de fuir et attendent le chasseur qu'ils ne craignent pas d'attaquer parfois.

"Un ravage d'Orignal avec ses arbrisseaux cassés et ses arbres pelés, offre un spectacle singulier à voir pour celui qui n'y est pas habitué. Souvent même, lorsque la neige est profonde et durcie, rendant par là leurs courses plus difficiles, ils cassent, à cinq ou six pieds de terre, et dévorent entièrement les jeunes têtes des sapins, lorsque ces derniers n'ont pas un diamètre de plus de deux à trois pouces. Quant aux arbres, s'ils ne peuvent les abattre, ils les pèlent jusqu'à la hauteur de dix à douze pieds du sol, appuyant leurs pieds de devant sur le tronc de l'arbre, leurs membres postérieurs supportant ainsi 
tout le poids de leur corps. Quoique l'Orignal soit très friand de bourgeons de sapins, il ne mange jamais l'écorce de cet arbre, qui est cependant le seul qu'il détruise pour se nourrir. Les autres arbres survivent généralement, car il ne les pèle que d'un côté; de sorte que le chasseur, pour peu qu'il ait d'expérience, peut toujours se rendre compte de la direction prise par l'Orignal.

"Lorsque leur bois tombe, les mâles se frottent la tête contre les troncs des sapins, leur instinct les guidant à se servir des propriétés de la gomme de cet arbre pour cicatriser la plaie que laisse le bois lorsqu'il se détache.

"La nourriture favorite de l'Orignal, durant l'hiver, se compose de rameaux de sapins, de l'écorce de frêne, d'une espèce d'érable nain et des jeunes rameaux du viorne, vulgairement appelé bois $d$ 'orignal.

"Pendant l'été, la femelle est ordinairement accompagnée de ses deux petits, mais en hiver on en voit rarement plus d'un, d'où je conclus que les jeunes de l'Orignal sont sujets à beaucoup de dangers dans le jeune âge... L'Orignal est doué d'une grande force et de beaucoup de persévérance; il peut supporter de très grandes fatigues. Il consomme peu de nourriture proportionnellement à sa taille, et il boit peu en hiver, n'ayant souvent que la neige pour étancher sa soif...

"L'Orignal ne vit pas vieux. Je ne sache pas que l'on en ait trouvé âgé de plus de vingt ans. 
"Les sens de l'ouie et de l'odorat sont très développés chez cet animal, ce qui, joint à sa défiance naturelle, le rend très difficile à approcher. " (I)

L'hiver est la meilleure saison pour chasser l'Orignal; le chasseur, monté sur ses raquettes, se dirige avec beaucoup de précautions vers leur retraite d'hiver, et s'il peut y parvenir sans en être aperçu, il peut alors faire le coup de feu. Mais s'il attire l'attention de ces animaux par le bruit d'une branche cassée ou qu'il soit aperçu par eux, toute la bande prend la fuite, et la chasse est finie; car si la neige est molle, leur grande force musculaire triomphe de cet obstacle et ils parviennent toujours à s'échapper. Le mois de mars est préférable à tous les autres pour cette chasse, la neige est alors recouverte d'une couche plus ou moins épaisse de verglas, et l'énorme pesanteur de l'animal le fait enfoncer. De plus il se blesse les jambes au contact du ver. glas, de sorte qu'il finit par se fatiguer, et le chasseur, après une course de deux ou trois heures et souvent plus, a une chance de l'approcher.

Au mois de septembre, les mâles se recherchent pour se livrer des combats acharnés. Ils font alors entendre un cri particulier, et le chasseur met à profit cette ardeur belliqueuse pour les tuer.

A cette fin, deux chasseurs, par un clair de lune, montent en canot et, sans bruit, suivent le bord de l'eau, se tenant sous l'ombre que projette le feuillage

(I) Canadian Nat. \& Geol. Vol. I, pp. 63-65. 
à ces endroits ; puis l'un d'eux imite alors le cri de l'Orignal mâle. S'il s'en trouve un dans le voisinage, il répond aussitôt en se dirigeant vers l'endroit d'où vient ce cri, dans l'espoir de rencontrer un de ses semblables. Un chasseur habile peut alors facilement le tuer.

La vue d'une lumière, la nuit, le fascine, le met en fureur, et il se précipite sur elle ; si on l'éteint, sa rage cesse. Il attaque son ennemi ou se défend avec son panache, mais surtout avec ses pieds de devant qui sont des armes terribles.

Il est maintenant reconnu que l'élan d'Europe est une espèce distincte de la nôtre.

\section{Genre RANGIFER, H. Smith.}

Aninaux de grande taille ; bois délié, lisse, et à ramures palmées, existant dans les deux sexes ; museau assez petit, entièrement recouvert de poils; gorge portant des poils allongés ; sinus lacrimal extérieur.

\section{Rangifer caribou, (GMEI,IN).}

Ie Renne caribou.

Pelage variant suivant l'âge et les saisons ; ordinairement d'un brun grisâtre en dessus pendant l'été, et d'un gris blanchâtre en hiver; le dessous du corps et la gorge, blancs. Longueur, 6 pieds; queue, 6 pcs. Hauteur à l'épaule, $3 \frac{1}{2}$ à 4 pieds. Il pèse environ 250 à 300 livres.

Le Caribou, ainsi qu'on le nomme d'ordinaire, vit par bandes dans les épaisses forêts de l'Amérique du Nord; on le rencontre depuis le nord des EtatsUnis et, dans le Canada, jusqu'à la limite du bois 
au nord, où il est remplacé par une sous-espèce, l'arcticus, qui est de taille plus petite et qui, en été, se voit jusqu'aux régions polaires; mais en hiver, elle descend au sud jusqu'à la latitude de la Baie d'Hudson, et peut-être mêtne plus bas encore.

Le Caribou est un animal aux formes sveltes, aux mouvements aisés et vifs; il est remarquable par la vitesse de sa course. Il est timide et farouche, un rien le met en éveil et le fait fuir ; aussi le chasseur qui veut l'abattre a-t-il besoin de toute son énergie et de toute son habileté pour l'approcher sans bruit sans en être vu ni flairé. En effet, aussitôt que le Caribou s'aperçoit de la présence de son ennemi, il part avec une telle vitesse, qu'en un instant une grande distance sépare déjà le chasseur de l'objet de sa convoitise; il est alors inutile d'essayer de le poursuivre s'il y a peu de neige, car il marchera des heures et des jours sans qu'il puisse l'atteindre. On trouve dans le Forester les notes suivantes sur les mœurs du Caribou:

"Quant à ses habitudes, tandis que le renne de la Laponie ou de la Sibérie, est le moins farouche et le plus docile du genre, le Caribou d'Amérique en est le plus farouche, le plus agile, le plus sauvage, le plus soupçonneux et le plus indomptable; de sorte que les chasseurs blancs le poursuivent rarement et ne l'abattent que par hasard. Les Sauvages seuls semblent être doués de la patience et de l'adresse nécessaires pour approcher le Caribou sans en être aperçus, car le flair de cet animal est si subtil 


\section{$-\mathrm{I} 46-$}

qu'il peut reconnaître la présence d'un être humain à une distance de deux milles, du côté du vent, sans que le chasseur lui-même soupçonne qu'il est là. Il est inutile d'essayer de le poursuivre quand la peur le fait fuir : c'est comme le vent qui passe.... C'est en vain que le chasseur monté sur ses raquettes se mettrait à sa poursuite, car le caribou monté lui-même sur les grandes raquettes naturelles de ses jambes longues et élastiques, sur ses larges sabots longuement fendus et raisonnants, vole plutôt qu'il ne court sur la croûte de la neige qu'il effleure à peine de ses pieds. Là où le noble et gigantesque élan s'enfoncerait jusqu'aux épaules et se débattrait en vain, et où le cerf à la course légère tomberait désespéré, implorant en vain la pitié du chasseur, le Renne, ce navire des solitudes glacées, fuit avec célérité parmi les pins et les mélèzes de ces vastes régions. On dirait le dromadaire, fuyant devant le simoun brûlant du Sahara. Une fois que le caribou est lancé, le chasseur le plus endurci à la fatigue et le plus agile peut renoncer à l'atteindre, car la chasse pourra durer un jour, une semaine et même deux, jusqu'à ce qu'une couche de neige vienne dérober les traces du caribou à la vue du chasseur, qui n'est pas plus près de l'animal que le premier jour; il ne lui reste plus que la fatigue, le désappointement et le souvenir de sa folle tentative.

"Voilà pourquoi les chasseurs blancs ou sauvages n'entreprennent cette chasse que lorsque la neige, 
déjà à une grande hauteur, est recouverte d'une mince couche de verglas, insuffisante pour supporter le poids du caribou ; la fuite derient alors tellement fatiguante, que l'animal est obligé de s'arrêter souvent pour se reposer; le chasseur pent alors l'atteindre...

"L'époque la plus propice pour chasser le caribou est la fin de février ou le commencement de mars; on peut choisir le moment où une petite couche de neige récemment tombée est venue recouvrir l'ancienne; cette neige molle amortit le bruit des raquettes, tandis que la croûte de l'ancienne lui offre un pied sûr; il peut alors poursuivre le gibier à la piste avec silence et rapidité. Le chasseur penché en avant se glisse silencieux, à travers les arbres, traversant les collines et les vallons, suivant la trace du caribou qu'il trouvera errant ou broutant les lichens ou les bourgeons de jeunes arbres. Le chasseur vieilli dans cette chasse juge à certains indices inconnus du novice, de la distance ou de la proximité du gibier. Il a le plus grand soin de se tenir sous le vent, car la moindre odeur donnerait l'alarme au caribou. Il approche toujours avec plus de précaution encore, surprend le troupeau et en fait un massacre, ou bien il découvre bientôt que l'animal a pris l'alarme et s'est échappé.» (I)

Le bois du caribou tombe ordinairement en janvier, et commence à pousser de nouveau en mars ou avril.

(I) Voy, Can. Nat. \& Geol. Vol. I, pp. 79-8o. 
Le Caribou se nourrit des mêmes végétaux que ceux de ses congénères.

Il met bas au printemps de un ou deux petits.

\section{Ordre FER AE.-Carnivores.}

Les Carnivores sont, après les rongeurs, les animaux les plus nombreux en espèces, et leur distribution est très vaste; on les rencontre en effet depuis les régions glacées jusque sous les zônes tempérées et tropicales; mais c'est particulièrement dans ces deux dernières zônes qu'ils sont le plus communs.

D'un naturel féroce et d'un appétit sanguinaire, secondés par des forces musculaires très grandes, les Carnassiers sèment le carnage et la mort partout où il y a des victimes à immoler. Aussi leur présence seule inspire-t-elle la terreur et l'effroi aux animaux plus faibles. Quoique instinctivenent l'on éprouve une certaine crainte en présence de ces animaux altérés de sang, il faut pourtant admettre qu'ils ont aussi un rôle providentiel à remplir dans la nature, rôle qui consiste à restreindre la trop grande multiplication des herbivores, qui, sans cette barrière, causeraient des dommages incalculables. Dans les endroits où les Carnivores n'existent pas, on a souvent eu à enregistrer des dégâts fort considérables, 
causés par certaines espèces de rongeurs. Mais d'un autre côté il faut reconnaître que là où ils sont nombreux, ils prélèvent trop souvent de lourdes rançons sur les animaux domestiques. Quoiqu'il en soit, ce sont des voisins fort incommodes.

On reconnaît les Carnassiers à leurs mâchoires garnies de dents puissantes et aptes à saisir et déchirer une proie; chaque mâchoire est armée de six incisives, quelquefois moins, de deux canines fortes et très développées, et d'un nombre variable de molaires. Les membres, terminés par quatre ou cinq doigts, sont armés d'ongles très forts et crochus, qui constituent, pour le plus grand nombre, d'excellentes armes offensives et défensives. Les Carnassiers sont, pour la plupart, également propres à grimper ou à saisir les objets, ou encore à creuser des terriers. Leur cerveau est pourvu de circonvolutions à la surface des hémisphères ; l'estomac est simple et le canal digestif court.

De tous les Mammifères, ce sont les mieux doués sous le rapport de l'instinct; leurs sens sont tous très développés, surtout ceux de l'odorat et de l'ouie, chez certaines espèces.

Comme leur nom l'indique, ils se nourrissent exclusivement de chair ; ce n'est qu'exceptionnellement que quelques-uns mangent des fruits ou autres substances végétales.

Ils vivent solitaires, par couples, ou se réunissent en bandes pour chasser en commun ; plusieurs élisent domicile dans des antres de rochers ou dans des 
troncs d'arbres creux, ou bien se creusent un terrier; d'autres vivent constamment dans l'eau ou y passent une grande partie de leur vie; d'autres enfin n'ont point de gîte et errent continuellement. Tous sont monogames.

"L'habitat et les mœurs des Carnassiers, dit Brelım, sont naturellement en rapport avec leur organisation et leurs besoins. Ils se trouvent partout et dominent toujours, sur le sol comme sur la cîme des arbres, dans l'eau et sous la terre, dans la montagne et dans la plaine, dans la forêt et dans les champs, au nord comme au sud. Ils sont à la fois diurnes et nocturnes, ils poursuivent leur proie pendant le crépuscule aussi bien qu'à la clarté du soleil ou dans les ténèbres de la nuit.

"Les plus intelligents forment des sociétés, les autres vivent solitaires; les plus forts attaquent ouvertement leur proie, les autres se mettent en embuscade et sautent à l'improviste sur leur victime.

"Les uns vont directement à leur but, les autres emploient des chemins détournés; tous se dissimulent le mieux et le plus longtemps qu'ils peuvent dans l'intention de ne pas effrayer trop tôt leur proie ; quelques rares espèces ont le sentiment de leur propre faiblesse et se sauvent dès que quelque chose leur inspire de l'inquiétude. Ils évitent d'autant moins la clarté du jour, ils sont d'autant plus gais, vifs, animés et aimables, qu'ils sont bien doués du côté de la force; ils sont, au contraire, d'autant plus nocturnes, moroses, méfiants, farouches et soli- 
taires, qu'ils sont moins favorisés au point de vue physique. La manière dont ils se nourrissent contribue aussi à les unir ou à les séparer, à former leur intelligence ou à l'émousser. n (I)

Les Carnassiers se divisent en deux sous-ordres qui se reconnaissent aux caractères suivants :

Membres courts, dirigés en arrière et propres à nager; doigts enveloppés par une extension de la peau ; aquatiques........................................ PINXIPEdiA

Membres de longueur moyenne, disposés pour la progression terrestre.

Fissipedia

\section{SOUS-ORdRE PINNIPEDIA, PinNiPÈdES.}

Les Pinnipèdes sont des animaux organisés pour la vie aquatique; leur corps est allongé et recouvert de poils ras et couchés sur la peau; la colonne vertébrale est mobile sur toute son étendue; leurs pieds, courts et disposés en nageoires, sont enveloppés dans la peau du corps qui est très distendue à ces endroits; les doigts sont réunis entre eux par une palmure; l'oreille externe est nulle ou rudimentaire ; les yeux sont grands et vifs ; leur système dentaire est simple; les incisives supérieures sont ordinairement au nombre de six, parfois de quatre ou même de deux seulement; les inférieures ne dépassent jamais le nombre de quatre; les canines sont bien développées et atteignent chez quelques espèces des proportions énormes.

Ces animaux vivent en troupeaux plus ou moins

(I) Brehm, Les.ITammiferes. Vol, I, p. I8I. 
nombreux. On les rencontre dans presque toutes les mers et les grands fleuves du globe. Ils nagent et plongent avec la plus grande facilité, pouvant demeurer sous l'eau un temps assez long, une vingtaine de minutes à peu près, sans respirer.

Leur nourriture consiste en poissons, mollusques, crustacés et autres productions animales de la mer.

CLEF POUR LA DISTINCTION DES FAMILIES DE PINNIPÈDES

Canines supérieures de longueur moyenne............. PHOCID.E

Canines supérieures très développées. ODOBANIDAE

\section{FAMilie PHOCIDE, Phoques.}

Formule dentaire. $-i \frac{3-3}{2-2}, \frac{2-2}{2-2}$ ou $\frac{2-2}{1-1} ; c \cdot \frac{1-1}{1-1} m \cdot \frac{5-5}{5-5}$.

Les Phoques ont un corps effilé aux deux extrémités; une tête petite et arrondie; les canines sont courtes; les molaires sont à tubercules aiguës; les membres, courts et aplatis, ne peuvent supporter le poids du corps et sont terminés par cinq doigts très courts et enveloppés dans un des replis de la peau; tous les Phoques sont recouverts de poils jusque sous la plante des pieds.

Ces animaux recherchent le voisinage des côtes; ils aiment à se reposer sur le rivage, sur les rochers, ou bien ils viennent sur les glaces pour y dormir ou se chauffer au soleil. Autant leurs mouvements dans l'eau sont souples et rapides, autant ils sont pénibles et disgracieux à terre; ils ne peuvent, en effet, avancer que par bonds et, pour ainsi dire, en rampant.

"L'eau est et reste leur véritable élément, dit 
Brehm. Sur terre, ils sont étrangers et maladroits ; dans l'eau, ils se meuvent avec la plus grande rapidité. Ils se traînent avec peine sur les falaises et sur les glaçons flottants, et s'y étendent nonclialamment, pour se chauffer au soleil ; au premier danger, ils se hâtent de chercher un refuge dans l'eau. Ils plongent et nagent avec la plus grande habileté, sur le dos comme sur le ventre, en avant comme en arrière. Dans l'eau, ils vont, viennent, toument, se retournent avec facilité; sur terre ils n'ont qu'un moyen d'avancer; ils rampent en quelque sorte, comme le font certaines chenilles. Ils se courbent à la façon d'un chat qui fait le gros dos, s'appuient sur le ventre, puis allongent rapidement le corps. Cet acte répété les fait progresser assez vite. Les pattes ne leur servent que quand ils gravissent une pente. Sur un sol plat, ils s'appuient dessus, mais si faiblement que l'aide qu'ils en retirent est plus apparente que réelle. " (I)

Les Phoques sont des animaux sociables que l'on rencontre toujours en bandes. Ils recherchent ordinairement leur nourriture durant la nuit. La plupart sont intelligents, pleins de vivacité, et leur regard est doux et expressif. Réduits en captivité, ils s'apprivoisent assez facilement et on parvient même à leur faire exécuter divers jeux en rapport avec leur capacité physique.

La femelle met bas en avril de un ou deux petits, qu'elle dépose sur la glace dans un enfoncement.

(I) Brehm. Les Mammifères. Vol. 2, p. 787 . 
Les petits naissent revêtus d'une abondante fourrure laineuse; la mère se montre pleine d'affection pour eux et elle les défend contre ses agresseurs au péril même de sa vie.

Les Phoques sont fort nombreux et l'huile que l'on retire de ces animaux, ainsi que leur dépouille, font l'objet d'un commerce considérable, car audelà d'un million d'individus sont tués annuellement. On les chasse de diverses manières, soit avec des armes à feu, soit en les harponnant, ou encore en les tuant lorsqu'ils viennent se reposer sur les glaces, et c'est de cette dernière façon que le plus grand nombre de ces animaux sont immolés.

Outre l'homme, le Phoque a encore pour ennemis quelques gros habitants des mers, et surtout l'ours polaire qui le chasse également sous l'eau comme sur les glaces.

Les Phoques sont ordinairement connus sous le nom de Loups marins.

\section{SOUS-FAMILLE PHOCIN 王.}

Les phoyues appartenant à cette sous-famille sont carac. térisés par six incisives supérieures et quatre inférieures; chaque pied est pourvu de cinq ongles bien développés.

\section{Genre PHOCA, Linné.}

Incisives petites et coniques, molaires tranchantes, à plusieurs lobes et à racines simples, à l'exception de la première; le premier 'doigt des membres antérieurs est. plus long que les autres. 


\section{Phoca vitulina, Linvé.}

\section{Le Phoque commun.}

Pelage variable, ordinairement d'un gris jaunâtre en dessus, marbré de brun foncé ou de noir; le dessous du corps est d'un blanc jaunâtre presque toujours tacheté de brun foncé; certains indiridus sont d'un jaune brunâtre uniforme en dessus, un peu plus pâle en dessous, ou encore blanc jaunâtre avec le dessus du corps d'un gris foncé, sans aucune tache nulle part. Longueur, 5 à 6 pieds. La femelle est plus petite.

C'est le plus commun et le mieux connu des Phoques qui fréquentent le fleuve St-I.aurent. Il est aussi un de ceux que l'on voit le plus souvent près de terre; on le désigne toujours sous le rom de Loup marin d'esprit. Son aire de distribution est considérable, elle s'étend, dans l'Atlantique, depuis le New Jersey, au nord, jusqu'aux régions arctiques et, dans le Pacifique, depuis la Californie et le Kamtschatka jusqu'à la Mer Glaciale. Il aime souvent à remonter les fleuves et les grandes rivières; de temps en temps, il se montre à Québec et à Montréal; on l'a même rencontré dans les lacs Ontario et Champlain.

La femelle met rarement bas de plus d'un petit.

\section{Phoca fœtida, FAbricius.}

Le Phoque annelé.

Pelage ordinairement d'un brun noirâtre en dessus; plus intense sur le dos, et marqué de taches oralaires. blanchâtres; dessous du corps d'un blanc jaunâtre pres- 


\section{$-{ }_{156}-$}

que uniforme; le nez et un cercle autour de l'œil le plus souvent noirs. Longueur, 5 à 6 pieds.

Les nouveaux-nés sont ordinairement blancs, lavés parfois de jaunâtre, puis en vieillissant ils deviennent brunâtres avec de petites taches noirâtres, ou bien ils conservent encore le blanc du premier âge qui est alors lavé de jaunâtre et parsemé de petites taches noirâtres; le milieu du dos étant plus foncé.

Cette espèce se distingue de la précédente par un corps plus élancé, une tête plus étroite et un museau plus allongé.

"Bien qu'il soit constaté " dit M. St-Cyr, "que ce Phoque habite les mers arctiques des deux hémisphères, la limite inéridionale de son parcours géographique ne saurait être déterminée avec certitude. Cependant, il est reconnu qu'il fréquente les côtes septentrionales du golfe St-Laurent et celles du Labrador. Il ne paraît pas qu'il ait été rencontré sur les côtes de Terre-Neuve, ni sur celles de la Nouvelle-Ecosse, et encore moins plus au sud. Vers le nord et surtout le long des côtes du Détroit de Davis et du Groënland, il se trouve en grand nombre." (I)

\section{Phoca groenlandica, FABRICIUS. I. Phoque du Groenland.}

Pelage variant du blanc au gris blanchâtre ou jaunâtre, avèc de grandes taches de noir ou de brun foncé; le museau et la tête noirs jusqu'en arrière des yeux, un large croissant irrégulier, également noir, sur les côtés du dos,

( I) St. Cyr, Mammifères pinnipèdes du golfe St-Laurent, Québec 1887 , p. 68. Doc. sess. 
dont les extrémités antérieures remontent sur les épaules en se rejoignant. I.es couleurs de la femelle sont moins prononcées. Longueur, 5 à 6 pieds.

Les jeunes naissent blancs et sont souvent teintés de jaune; leur robe qui est laineuse devient plus tard grisâtre.

Ce Phoque, qui est connu vulgairenent sous le nom de Brasseur, est très commun chez nous; il habite les mers arctiques circompolaires et se rencontre également à l'automne et en hiver dans le

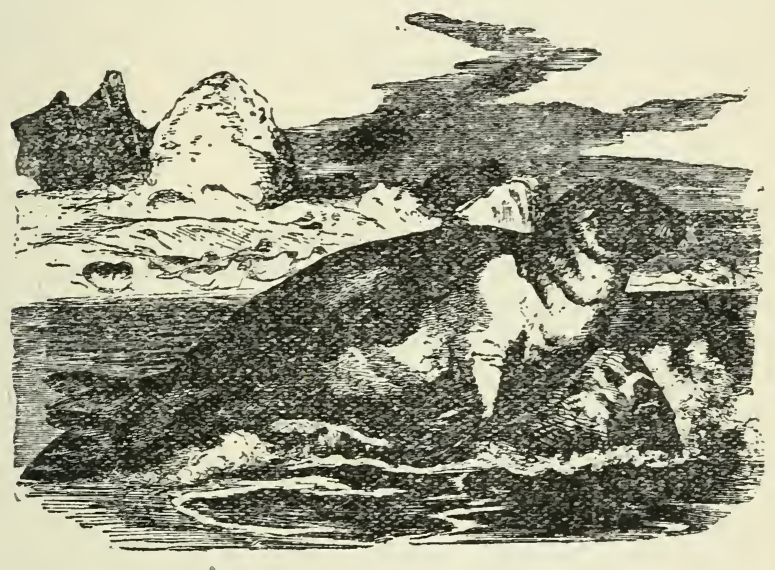

Fig. 20.-Le Phoque du Groënland.

fleuve St-Laurent. C'est ordinairement au printemps que ces animaux sont capturés en plus grand nombre sur les glaces.

M. J.-A. Allen nous dit que dans l'Atlantique Nord et les mers arctiques où il abonde, la saison de pêche de ce phoque, qui ne dure que quelques semaines, emploie des milliers d'hommes, montés. 


\section{$-{ }^{1} 5^{8}-$}

sur des centaines de vaisseaux, et la moyenne annuelle de Phoques tués-presque tous de cet espèce-est évaluée à environ un million d'individus et le produit se chiffre dans les trois millions de piastres. (I)

\section{Genre ERIGNATUS, Gill.}

Même système dentaire que chez le genre précédent, mais les dents sont plus petites; les molaires sont plus écartées entre elles, et peu solides; elles s'usent et finissent par tomber avec 1'âge; museau gros; front haut et offrant une certaine convexité ; les doigts du milieu des membres antérieurs sont plus longs que les autres.

\section{Erignatus barbatus, GiLL.}

Le Phoque barbu.

Ce Phoque, comme les précédents, offre des variations dans la couleur de sa robe; toutefois il se présente le plus souvent avec une livrée grise en dessus, plus foncée sur le dos. Quelques spécimens sont mélangés de noir, d'autres sont d'un gris clair parsemé de larges taches jaunâtres à peine visibles, ou encore d'un gris pâle en dessus, et blanchâtre sous le ventre. Longueur, 9 à Io pieds.

Les jeunes sont d'un gris foncé.

Cette espèce est confinée aux mers arctiques des deux continents, elle descend vers le sud jusque sur la côte nord du golfe St-Laurent et sur celle de Terre-Neuve.

\section{Genre HALICHOERS, Nilsson.}

Doigts des membres antérieurs et sytème dentaire connme dans le genre phoca; les molaires sont coniques et

(I) Allen, Hist. of N. A. Pinnipeds. Washington, I88o, p. 653. 
aussi larges que longues ; le museau gros; la partie d'en avant du crane est très développée et élargie.

\section{Halichœrus grypus, Nilssox. \\ Le Phoque gris.}

Pelage variant du gris argenté ou cendré, au gris foncé, avec des taches brunes ou noirâtres. La femelle est de couleur moins foncée. Longueur, 7 à 9 pieds.

Cette espèce, qui est plus rare que les précédentes, habite l'Atlantique Nord et se voit au sud jusqu'à l'Ile de Sable, la Nouvelle-Ecosse, le Détroit de Belle-Ile et les côtes du Labrador.

\section{SOtS-FAMILLE CYSTOPHORINE.}

Un des principaux caractères de cette division consiste dans le nombre de quatre incisives à la mâchoire supérieure, tandis que l'inférieure n'en possède que deux.

\section{Genre CYSTOPHORA, Nilsson.}

Le caractère le plus saillant de ces animaux consiste dans une dilatation de la peau du dessus de la tête, qui, chez les mâles, se gonfle à volonté de manière à figurer un capuchon; ce gonflement s'étend depuis le bout du museau jusqu'au dessus des yeux; les narines se gonflent également; les ongles des doigts sont gros et forts; les molaires sont à couronnes petites et plissées.

\section{Cystophora cristata, Nilsson. I e Phoque à capuchon.}

Pelage d'un gris foncé, mélangé de brun ou de noir bleuâtre, plus clair sur les côtés du corps et sous le ventre, arec de nombreuses petites taches irrégulières blanchâtres; la tête et les membres sont d'un noir presque uniforme; le 
renflement du dessus de la tête peut atteindre, chez les adultes, une longueur de douze pouces et une épaisseur de neuf pouces. Longueur, 7 à 8 pieds; la femelle un peu moins. Les jeunes naissent blancs.

Cette espèce habite également l'Atlantique Nord, et se montre commune à la Baie d'Hudson, à TerreNeuve et dans le golfe St-Laurent. Il s'en tue chaque année un grand nombre.

Il est toujours prudent de ne pas approcher de trop près ces Phoques de grande taille lorsqu'ils se reposent sur les glaces, car ils peuvent faire de graves blessures avec leurs dents. Ces animaux sont aussi plus difficiles à tuer que les petites espèces, qu'un seul coup de bâton bien appliqué sur le museau suffit presque toujours à réduire à l'impuissance.

\section{FAMILLE ODOBENIDE. MORSES.}

Formule dentaire pour les adultes. $-i . \frac{\mathrm{I}-\mathrm{I}}{0-0,}, \quad \frac{\mathrm{I}-\mathrm{I}}{\mathrm{0}-\mathrm{C},} m \cdot \frac{4-4}{4-4}$

La forme générale des Morses rappelle celle des phoques, mais ils s'en distinguent par un corps lourd, une tête petite, ronde et épaisse, un museau court, gros et recourert de poils, et surtout par deux grosses canines très longues à la mâchoire supérieure et dirigées vers le bas. L'énorme développenient de ces défenses relève le museau de chaque côté de telle sorte que l'ouverture des narines est située presque en pente verticale. Dans le jeune âge, les dents des Morses sont semblables à celles des autres Phoques, mais en vieillissant leurs incisives tombent par suite du développement excessif des canines supérieures; deux seulement persistent à la mâchoire supérieure ; la mâchoi- 
re inférieure, qui se comprime considérablement, afin de pouroir se loger entre ces deux énormes défenses, ne laisse aucune place pour les incisives qui disparaissent; les molaires sont à pointes émoussées.

Les Morses ont à peu près les mêmes mœurs que les phoques. Comme eux ils aiment à se reposer et à dormir sur le rivage ou sur les glaces; ils sont également agiles et gais dans l'eau, tandis qu'à terre ils sont lourds et maladroits ; ils avancent lewtement en s'aidant de leurs défenses qu'ils enfoncent dans la terre, ramassant et allongeant alternativement leur corps. L'énorme dimension qu'atteignent les défenses du Morse et l'absence d'incisives inférieures modifient de beaucoup son régime alimentaire ; aussi fait-il entrer dans sa nourriture certaines plantes aquatiques er même temps que des mollusques, des petits poissons, des crabes, des homards et autres crustacés.

\section{Genre ODOBENUS, Linné.}

Mêmes caractères que ceux de la famille.

Il n'existe que deux espèces qui appartiennent aux régions boréales, l'une à l'Atlantique et l'autre au Pacifique.

\section{Odobænus rosmarus, MALMGREN.}

\section{Le Morse de 1'Atlantique.}

Pelage d'un brun jaunâtre passant au brun roux foncé sous le rentre et à la base des nageoires. Longueur, Io à I 5 pieds ; canines, IS pouces.

(II) 


\section{$-162-$}

Le Morse, aujourd'hui confiné dans le nord de 1'Atlantique, fréquentait autrefois les plages du StLaurent, comme l'attestent des défenses que l'on trouve enfouies sur les rives du fleuve.

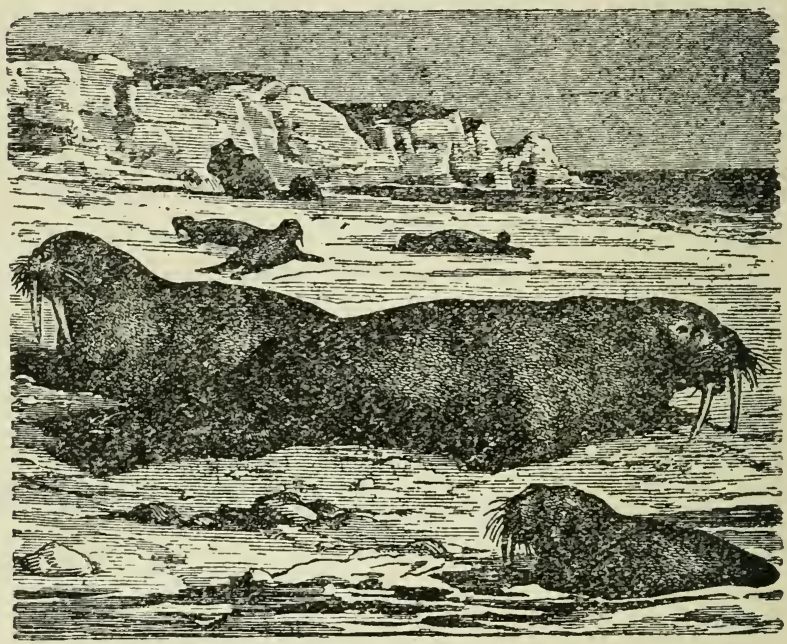

Fig. 21.-Le Morse de l'Atlantique.

Il remontait ce dernier jusqu'à la Rivière-Ouelle, n'y a pas plus d'une cinquantaine d'années, si l'on en croit les personnes qui en ont fait mention. Mais aujourd'hui, il ne descend pas plus bas qu'à la Baie.d'Hudson, où il est encore assez cominun.

Le Morse est connu sous le nom vulgaire de Vache marine.

La femelle ne fait qu'un petit chaque année. 


\section{$-163-$}

2. SOUS-ORDRE FISSIPEDI 玉, FISSIPÈDES.

Les Fissipèdes sont caractérisés par des membres libres, bien développés, munis de doigts libres ou réunis à leur base par une petite membrane; ils sont tous propres à la marche, appuyant sur le sol toute la plante des pieds ou simplement les doigts; la plupart sont aptes à grimper ou à creuser des terriers. Les incisives sont au nombre de six à chaque mâchoire.

CLEF POUR LA DISTINCTION DES FAMILLES DE FISSIPÈdES

Membres postérieurs terminés par 5 doigts.

Plantigrades; queue de longueur moyenne, touffue et annelée. Longueur, 33 pcs............. Procyonid

Plantigrades ; queue très courte, corps lourd, pelage noir ou blanc. Grande taille................ URSID王

Imparfaitement plantigrades ou digitigrades ; taille petite et moyenne; bas sur pattes, comprenant tout le reste de nos carnassiers qui ont 5 doigts aux membres postérieurs................... MUSTELID.E Membres postérieurs terminés par 4 doigts.

Ongles des doigts non rétractiles; dents, $42 \ldots$ CANID

Ongles des doigts rétractiles; dents, 28-30...... FELID.

\section{FAMILLE PROCYONIDE. RATONS.}

Formule dentaire. $-i \cdot \frac{3-3}{3-3} c \cdot \frac{1-1}{1-1} p m \cdot \frac{4-4}{4-4} m \cdot \frac{2-2}{2-2}$

La dernière prémolaire supérieure et la première d'en bas sont tuberculeuses; le museau est plus ou moins allongé ; la queue est de longueur moyenne et touffue ; les pieds sont munis de cinq doigts, et sont conformés pour la marche plantigrade.

Ces animaux sont de taille moyenne, au corps 
plus trapu qu'élancé, et leur régime est plutôt omnivore que simplement carnivore.

\section{Genre PROCYON, Storr.}

Tête assez grosse et déprimée, museau effilé et comme tronqué au bout ; oreilles de grandeur moyenne et arron. dies; quene annelée de noir et de blanchâtre ; ongles recourbés, non rétractiles et de force moyenne.

\section{Procyon lotor, (Linné).}

\section{Le Raton ordinaire.}

Pelage variable, ordinairement d'un blanc grisâtre ou jaunâtre, plus ou moins entremêlé de noir, résultat d'un certain nombre de poils terminés de noir; le duvet ou poil de la base est d'un gris brun; une large tache oblique d'un brun noirâtre s'étend sur la joue et autour de 1 'ceil ; une autre tache de même couleur se trouve en arrière de 1'oreille; la queue est touffue et annelée de noir et de blanc grisâtre ou jaunâtre ; le dernier anneau est noir; iris noir. Longueur, 22 ; queue, 10 $1 / 2$ pcs.

Le Raton, que l'on appelle vulgairement Chat sauvage, habite l'est de l'Amérique du Nord où, dans certaines localités, il se montre encore collmun. Chez nous, on le rencontre plutôt dans le sud de la province. Cet animal est nocturne et vit dans les forêts; toutefois on le rencontre assez souvent durant le jour, à la recherche de sa nourriture. Il est omnivore, mange également bien des céréales, des noix, des fruits de toutes sortes ainsi que des œufs d'oiseaux, des mollusques, des insectes, de petits poissons, des grenouilles, de petits man1mifères et des oiseaux. Il aime à aller se 
repaître de blé vert ou autres céréales qui croissent dans les champs ensemencés, à proximité de son habitation. Comme il est excellent grimpeur, c'est dans un arbre creux qu'il établit son domicile, et c'est également dans les arbres qu'il cherche un

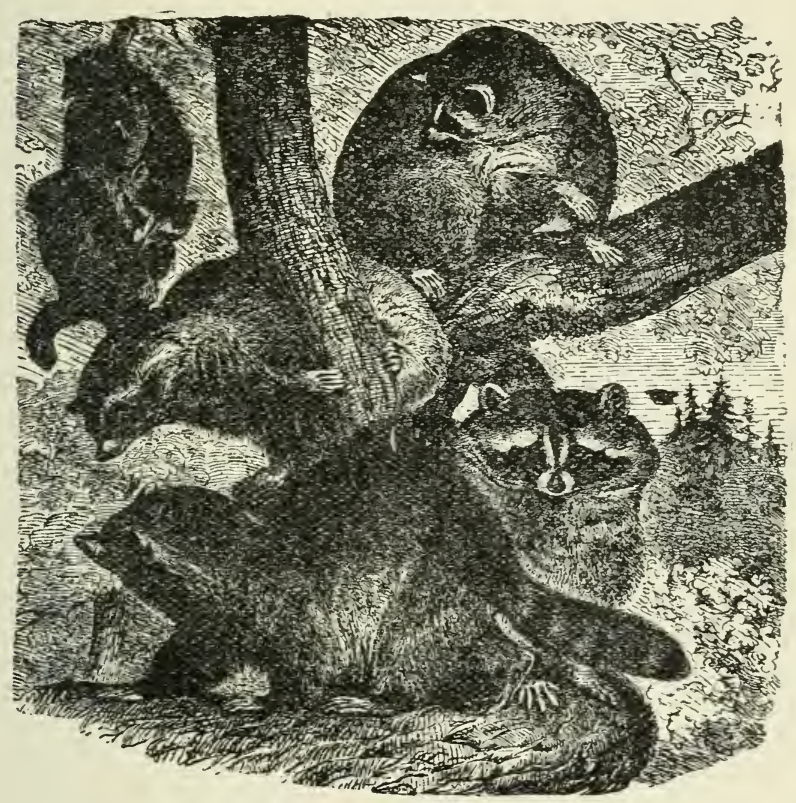

Fig. 22.-Groupe de Ratons.

refuge lorsqu'il est poursuivi par ses ennemis; il aime à fréquenter le bord des étangs et des rivières, à prendre ses ébats dans les eaux pell profondes tout en cherchant des grenouilles, des mollusques, ou des petits poissons. Quoique bon nageur, il ne 
poursuit pas sa proie sous l'eau, non plus que sur les arbres lorsqu'elle y cherche un refuge. Cet animal est peu farouche, mais il est méfiant et rusé, et dans certains cas sa ruse égale presque celle du renard.

Dans plusieurs endroits des Etats-Unis, on a fait de la chasse au Raton un sujet de divertissement. Des chasseurs armés de fusils et munis de - torches se rendent, vers minuit, avec des chiens, à l'endroit où le Raton doit se trouver. Dès qu'un de ces animaux a été éventé par les cliiens, la chasse commence; le pauvre animal qui n'est pas très agile se sauve le mieux qu'il peut, et s'il rencontre un arbre, il y grimpe dans l'espoir d'échapper à ses assaillants. Si cet arbre est petit, on le coupe à la base, et dans sa chute il entraîne le Raton qui tombe dans la gueule des chiens. Mais si l'arbre est gros, le chasseur se donnera parfois le plaisir de poursuivre l'animal sur les branches. Lorsque le Raton arrive au sommet ou à l'extrémité d'une branche, le chasseur la secoue fortement, l'animal perd alors l'équilibre et tombe à terre; si on ne veut pas se donner ce plaisir on le tue au fusil. Le Raton est très habile à se dissimuler sur un arbre; il se tapit près du tronc ou sur une grosse branche, et ne laisse apercevoir d'ordinaire qu'un seul œil qui brille dans la nuit à la lueur des torches.

Audubon nous raconte de la manière suivante, une chasse qu'il fit dans le Kentucky, où il avait traqué un Raton dans un marais: "Le Raton, dit- 
il, ne nageait pas, mais se soutenait avec ses pieds qui touchaient le fond du marais. L'éclat de la torche semblait beaucoup le gêner; son poil était hérissé, et sa queue annelée paraissait trois fois plus grosse qu'à l'ordinaire. Ses yeux brillaient comme des émeraudes; la gueule écumante, il surveillait chaque mouvement des chiens, prêt à saisir par le museau le premier qui tenterait de s'approcher. Ceux-ci le tinrent en haleine pendant quelques minutes; l'eau commençait à se charger d'une vase épaisse; le poil tout trempé lui retombait à plat sur le corps, et sa queue, couverte de boue, flottait immobile à la surface. Son grognement guttural, au lieu d'intimider les assaillants, ne faisait que les exciter d'avantage, et tous, sans relâche ni miséricorde, le harcelaient de leurs aboiements furieux. Enfin, l'un d'eux se hasarda à le happer au derrière, mais il dut promptement en démordre; à un second qui l'avait attaqué par le côté, le Raton rendit son coup de dent, et je vous assure qu'il était mieux appliqué que celui qu'un troisième venait de lui porter à la queue. C'était vraiment pitié d'entendre gueuler Tike que le Raton ne lâchait pas. Cependant, les autres s'étaient rués tous ensemble sur lui, avec des cris de mort; mais, jusqu'au bout il tint bon, et resta suspendu au museau de son ennemi. A la fin, frappé à coup de hache sur la tête, il tomba, rendant le dernier soupir; et le pénible battement de ses flancs faisait douleur à voir. Debouts autour du marais, les chasseurs contemplaient son agonie; 
l'éclat de la torche donnait aux objets environnants un aspect plus sombre et quelque chose de sinistre; c'était une de ces scènes que les peintres aiment à reproduire." (I)

On capture aussi le Raton au moyen de trappes, avec une tête d'oiseau ou un morceau de poisson comme appât. Un antre moyen de s'en emparer est de faire pénétrer dans son trou un crochet en fer que l'animal, dans sa rage, essaye de mordre, et se trouve ainsi pris par la gueule.

En captivité il s'apprivoise très bien et il mange de tout ce qu'on lui donne; mais c'est un mauvais voisin pour la basse-cour, car, s'il y pénètre, il étranglera dans une seule nuit, sinon tous, du moins une grande partie de ses habitants.

Cet animal dort durant les mois de l'hiver.

La femelle met bas vers le mois de mai, de quatre à six petits qu'elle dépose dans un nid grossièrement fait, et situé dans un arbre creux.

\section{FAMII,LE URSID压, OURS.}

Formule dentaire. $-i \cdot \frac{3-3}{3-3} c \cdot \frac{1-1}{1-1} p m \cdot \frac{4-4}{4-4} m \cdot \frac{2-2}{3-3}$.

Cette famille renferme de gros mammifères plantigrades, aux formes trapues et pesantes, à fourrure épaisse. Leurs membres sont gros et sont terminés par cinq doigts armés d'ongles très fort et non retractiles; leur tête est large supérieurement et est terminée par un museau allongé et pointu ; leurs oreilles sont courtes ; leurs yeux sont petits et vifs, et leur queue est courte ou rudimentaire.

(1) Audubon, trad. de Bazin. Scène de la Nature, Vol. 2, pp. I5t-I55. 
Les Ours sont distribués sur presque toute la surface du globe, quoique le nombre des espèces en soit pourtant assez restreint. On les rencontre en Amérique, en Europe et en Asie.

Ces animaux ont la faculté de se tenir assis sur leur train de derrière, dans une position verticale, et cela avec une grande facilité. Il grimpent aisément sur les arbres; la plupart vivent solitaires et habitent dans d'épaisses forêts; ils se choisissent pour demeure des arbres crenx, ou des anfractuosités de rocher; leurs habitudes sont noctnrnes et crépusculaires. Les Ours sont omnivores ; ils mangent également bien des céréales, des fruits, des baies, des mollusques, des insectes, du miel, etc., ainsi que la chair des animaux; ils ne dédaignent pas non plus les charognes lorsque la faim les presse.

Ces animaux sont de dangereux voisins lorsqu'ils. se rencontrent dans les environs des fermes, car non seulement ils se nourrissent de grain, mais encore ils enlèvent des montons, des porcs, de jeunes veaux, et même, lorsque la faim se fait trop vivement sentir, ils n'hésitent pas plus à attaquer les grands animaux de la ferme que ceux de la forêt. Ils fuient d'ordinaire à la vue de l'homme lorsqu'ils ne sont point excités par la colère.

\section{Genre URSUS, Linné.}

Corps gros, lourd, trapu, à pelage toujours unicolore ; plante des pieds nue; tête grosse, cou court. 


\section{Ursus americanus, Pallas.}

\section{L'Ours noir d'Amérique.}

Pelage d'un noir uniforme ou noir brunâtre. Longueur, 4 à 6 pieds.

L'Ours noir est commun dans l'Amérique du Nord, partout où on ne l'a pas encore complètement détruit ; il habite essentiellement les forêts, où il trouve une nourriture suffisante dans les fruits et

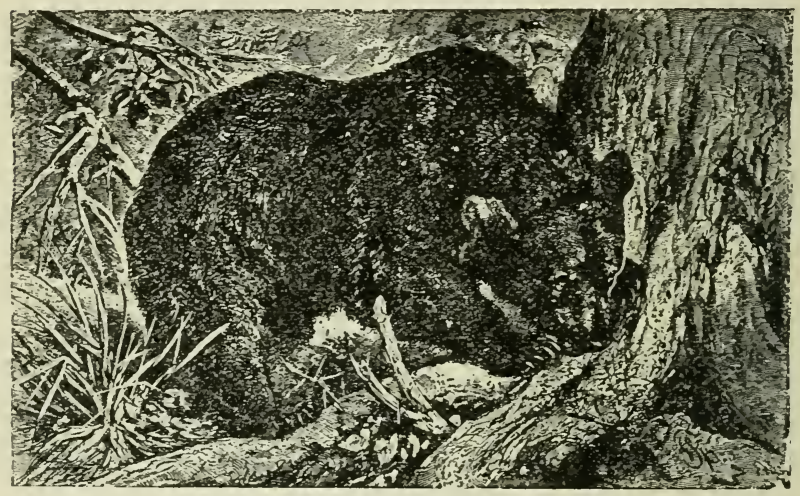

Fig. 23 L'Ours noir d'A mérique.

baies de tontes sortes qui croissent dans les bois, tels que bluets, framboises, bourdaine, etc. ; mais lorsque ces productions végétales lui deviennent insuffisantes, il n'hésite pas à sortir de sa retraite pour faire, à l'automne, de fréquentes excursions dans les champs de grain qu'il abîme, moins par la quantité qu'il consomme, que par celle qu'il écrase, soit 
en marchant, soit en s'asseyant pour manger, car dans ce dernier cas, il s'appuie sur son train de derrière et avec ses bras il embrasse une certaine quantité de plantes qu'il réunit pour en manger tranquillement les épis. S'il ne peut se procurer ces aliments, il tourne son affection du côté des moutons et des jeunes veaux qui paissent dans les champs. On a souvent constaté qu'après s'être introduit la nuit dans des bergeries mal protégées, il en enlevait des moutons qu'il dépeçait ensuite dans son repaire; aussi cause-t-il souvent des dommages considérables aux cultivateurs qui le chassent à outrance pour s'en débarrasser. On dit qu'à la Baie d'Hudson, lorsque les baies ou autres fruits ne sont pas encore mûrs, il se nourrit d'insectes aquatiques et autres petits invertébrés qui flottent à la surface de l'eau. Il les capture en nageant la gueule ouverte, et quand celle-ci en est remplie il les arale.

Si maladroit et lourd que paraisse l'Ours, il n'en est pas moins un animal vif, agile et vigilant; il grimpe sur les arbres avec une grande facilité et il court si vite que l'homme ne peut l'atteindre. Il est fort et courageux ; il peut supporter de longues fatigues et de dures privations pour échapper aux poursuites des chasseurs et cela sans beancoup en souffrir.

D'ordinaire l'Ours n'attaque point l'homme; il fuit même devant lui. Toutefois, s'il est blessé ou traqué de près, ou bien encore si c'est une mère avec ses petits, sa rencontre peut être dangereuse, car 
dans ces circonstances il devient très agressif et se défend avec une adresse et un courage étonnants.

L'Ours combat dans une position verticale, assis sur son train de derrière, cherchant à étreindre son ennemi entre ses bras, afin de le déchirer avec ses dents et ses griffes redoutables.

Dans les pays froids, l'Ours est sujet au sommeil hibernal; c'est ordinairement à la tombée des premières neiges qu'il se retire dans son trou pour ne s'éveiller et ell sortir qu'au printemps, aussi gras, dit-on, que lorsqu'il y est entré. Ce trou est ordinairement situé dans un arbre creux ou sous un gros arbre rellversé, ou encore dans une crevasse de rocher.

Les bûcherons qui travaillent dans les endroits fréquentés par les Ours, découvrent assez souvent leur gîte d'hiver, grâce à la glace qui s'accumule autour d'une petite ouverture produite par la chaleur qui se dégage de l'animal et qui sert à sa respiration.

Richardson dit que la femelle met bas de $u n$ à cinq petits, et Audubon prétend qu'elle n'en fait que deux.

On chasse l'Ours de différentes manières, soit en allant le guetter dans les endroits où il doit passer, soit en le poursuivant avec des chiens qui le forcent à grimper sur un arbre où le chasseur le tue au fusil. Malheur au chien qui s'approche de trop près de la griffe de l'animal, car il est bientôt mis hors de combat. On le chasse encore avec un fusil 
tendu qu'il fait partir lui-même en tirant sur un appât fixé par une corde à la détente du fusil. Un autre moyen de le capturer consiste à tendre une forte trappe qui l'écrase lorsqu'il s'empare d'un appât qui y est placé. Pour cela on coupe denx gros morceaux de bois de longueur raisonnable, on en couche un sur le sol et on fixe l'autre au-dessus, dans la même direction, à une hauteur suffisante pour que l'animal puisse passer dessous, puis on charge fortement cette pièce de bois qui doit être disposée de telle sorte que l'Ours, en saisissant l'appât, fait basculer la poutre qui, en tombant avec sa charge, écrase l'animal. Il arrive assez souvent que l'Ours vit encore lorsqu'on le trouve ainsi captif; il est alors prudent de se tenir à distance de ses griffes comme de ses dents, car il ne ménage aucunement ses caresses dans cette circonstance, et plus d'un chasseur a été victime de son imprudence.

Audubon nous raconte ainsi les péripéties d'une chasse à l'Ours qu'il fit dans les Etats-Unis du Sud : "On convînt d'un plan d'attaque : les barrières à l'entrée ordinaire du champ devaient être abaissées sans bruit ; et de là, hommes et chiens, après s'être partagés, s'avanceraient pour cerner les ours; enfin, au son de nos cornes, on chargerait de tous côtés vers le centre du champ, en criant et faisant le plus de tapage possible; ce qui ne pouvait manquer d'effrayer tellement les animaux qu'ils s'empresseraient de chercher un refuge sur les arbres morts dont le champ était en partie couvert. 
a Notre plan réussit; les cornes sonnèrent, nos chevaux partirent au galop, les hommes se mirent à crier, les cliiens à aboyer et à hurler. Les nègres à eux seuls faisaient assez de vacarne pour épouvanter une légion d'ours. Aussi ceux qui étaient dans le champ commencèrent-ils à détaler; et quand nous nous rencontrâmes au milieu, nous les entendînes qui grimpaient en tumulte vers la cime des arbres. On fit immédiatement allumer de grands feux par les nègres; la pluie avait cessé, le ciel s'était éclairci, et l'éclat de ces flammes pétillantes nous fut d'un grand secours. Les ours avaient été pris d'une telle panique, que nous pûmes en apercevoir quelques-uns qui s'étaient blottis entre les plus grosses branches et le tronc. On en abattit deux sur le coup : c'était des oursons de petite taille; et comme ils étaient déjà plus d'à denimorts, on les abandonna aux chiens, qui les eurent promptement dépêchés.

"Nous ne cherchions qu'à nous amuser le plus possible. Ayant remarqué l'un des ours qu'à l'apparence nous jugeâmes être la mère, nous ordonnâmes aux nègres de couper par le pied l'arbre sur lequel elle était perchée. Il avait été préalablement convenu que les chiens auraient à s'escrimer avec elle, et que nous, nous les appuyerions et viendrions à leur aide, en blessant l'animal à l'une des jambes de derrière pour l'empêcher de s'échapper. Et déjà retentissait dans les bois le bruit de la liache répété par les échos d'alentour; mais l'arbre était 
gros, d'un bois très dur, et l'opération menaçait d'être longue et fatigante. A la fin pourtant, on le vit qui tremblait à chaque coup; il ne tenait plus que par quelques pouces de bois ; et bientôt, avec un effroyable craquement, il tomba sur la terre avec une telle violence, que sans doute commère l'ourse dût en ressentir un choc aussi terrible que le serait pour nous la secousse de notre globe produite par la collision subite d'une comète.

"Les chiens s'élancèrent à la charge, harassant à l'envi la pauvre bête; et nous, étant remontés à cheval, nous la tenions enfermée de tous côtés. Comme sa vie dépendait de son courage et de sa vigueur, elle déploya l'un et l'autre avec toute l'énergie du désespoir; tantôt, saisissant l'un des chiens, qu'elle étranglait à la première étreinte ; tantôt, d'un coup bien appliqué d'une de ses pattes de devant, vous en envoyant un autre brailler au loin d'une façon si piteuse, qu'on pouvait dès lors le regarder comme hors de combat. L'un des assaillants, plus rude que les autres, avait sauté au nez de l'ourse et y restait bravement pendu ; tandis qu'une douzaine de ses camarades faisaient rage à son derrière. L'animal, rendu furieux, roulait autour de lui des regards altérés de vengeance ; et nous, de peur d'accident, nous songions à en finir lorsque, tout à coup et avant que nous pussions tirer, d'un seul bond il se débarrasse de tous les chiens et charge contre l'un des nègres qui était monté sur un cheval pie. L'ourse saisit le cheval avec ses dents et ses griffes, et se 
colle contre son poitrail ; le cheval,épouvanté, se met à renifler bruyamment et s'abat. Le nègre, jeune homme d'une force athlétique et excellent cavalier, avait gardé la selle qui ne consistait pourtant qu'en une simple peau de mouton, mais heureusement bien sanglée, et il priait son maître de ne pas faire feu. Nonobstant tout son sang-froid et son courage, nous frémissions pour lui, et notre anxiété redoubla quand nous vîmes homme et cheval rouler ensemble sur la poussière. Mais ce ne fut que l'affaire d'un instant; Scipion s'y était pris en mâ̂. tre avec son redoutable adversaire; d'un seul coup de sa hache, bien assené, il lui avait fendu le crâne! Un sourd et profond grognement annonça la mort de l'ourse; et déjà le vaillant nègre était sur ses pieds, triomphant et sain et sauf.

- L'aurore commençait à poindre; nous continuâmes nos recherches. Les deux ours qui restaient furent bientôt découverts; ils étaient juchés sur un arbre, à environ cent pas de l'endroit où le dernier venait de succomber. Quand nous les eûmes cernés, nous reconnûmes sans peine qu'ils n'étaient pas d'humeur à descendre. En conséquence, on résolut de les enfumer. Un tas de broussailles et de grosses branches fut apporté au pied de l'arbre qui, sec comme il l'était, ne tarda pas à présenter l'apparence d'une colonne de feu. Les ours grimpèrent à l'extrémité des branches. Quand ils furent tout à fait au bout, on les vit un moment hésiter et chanceler; puis les branches craquant et enfin ayant 
éclaté, ils dégringolèrent, en entraînant avec eux une masse de menu bois. Ce n'étaient non plus que des oursons; les chiens les eurent promptement mis à mort. " (I)

Lorsque l'Ours est pris jeune, il s'apprivoise assez facilement et on parvient même à lui faire exécuter certains exercices.

\section{Genre THALARCTOS, Gray.}

Corps allongé, surtout en avant ; haut sur jambes ; pieds robustes; plante des pieds garnie de longs poils; tête un peu plus petite que chez le genre précédent.

\section{Thalarctos maritimus, (PHIPPs.) \\ L'Ours polaire.}

Pelage blanc, parfois teinté de jaunâtre. Longueur, 8 à 9 pieds ; pesanteur, environ Iooo lbs.

L'Ours polaire ou Ours blanc, habite les régions glacées du cercle arctique et, si loin que l'homme ait pu pénétrer dans le nord, il a toujours rencontré ce singulier animal, qui semble se plaire au milieu des neiges et des glaces éternelles et que les froids les plus intenses et les tempêtes les plus violentes n'importunent nullement.

L'Ours blanc est commun dans ces contrées désertes et, sur notre continent, il se montre au sud jusqu'aux environs de la Baie d'Hudson et celle de Baffin, où il est encore assez commun. Il arrive quelquefois qu'il se laisse entraîner par les glaces

(I) Audubon. Trad. de Bazin. Scènes de la nature. Vol. I, pp. 374-37\%. (I:) 
vers le sud jusqu'au milieu de l'océan, où il trouve la mort.

On l'a rencontré quelquefois sur la côte nord du Labrador, vers le détroit de Belle-Ile, et même plus haut. Cependant ce n'est que par accident qu'il quitte sa solitude pour descendre vers le sud.

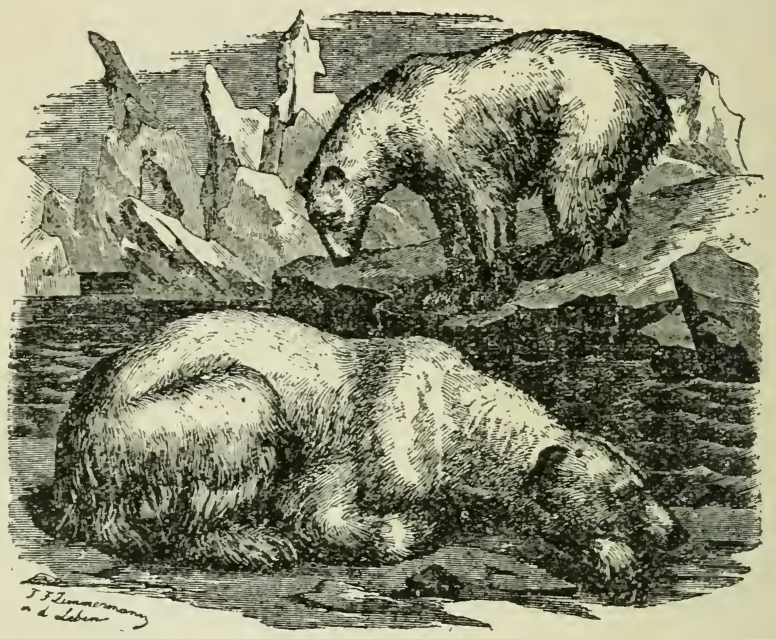

Fig. 24.-Ours polaires.

Il se nourrit particulièrement de phoques qu'il surprend ou poursuit sur les glaces, favorisé autant par sa couleur blanche que par la facilité avec laquelle il peut marcher sur cette surface glissante ; à l'occasion il se contente de ronger les carcasses de baleines, de phoques ou de poissons, que les vagues rejettent sur la plage; en $111 \mathrm{mot}$, il mange de tont 
ce qu'il peut rencontrer dans ces régions désertes.

L'Ours blanc marche avec autant de rapidité sur la glace que sur la terre; il nage et plonge avec une grande aisance. En été, il chasse les phoques et les poissons qu'il poursuit sous l'eau et qu'il réussit souvent à capturer.

En hiver, si l'Ours aperçoit des phoques se reposant sur les glaces, aux alentours d'un trou d'eau libre, d'où ils sont sortis-et prêts à s'y précipiter au premier danger-il nage sous la glace dans cette direction, puis tout-à-coup il émerge du trou, au grand effroi de ces pauvres animaux qui voient s'évanouir leur unique chance de salut, se trouvant ainsi à la merci de l'un de leurs plus terribles ennemis, qui en fait alors un massacre.

Les sens de l'odorat et de la vue sont très développés chez l'Ours polaire; il perçoit les objets de très loin, comme il flaire également les cadavres à des distances incroyables. Il est bien rare que l'Ours blanc se montre agressif pour l'homme si ce dernier ne le provoque. "Il faut, dit Brehm, que sa faim soit bien vive pour qu'il attaque l'homme sans y avoir été provoqué ; d'ordinaire il s'enfuit à son approche. Mais si on le pousse au combat, il fait front et se retourne contre son ennemi. C'est l'adversaire le plus terrible que l'homme puisse rencontrer dans ce pays. Celui qui l'a défié ne peut se salver qu'en le tuant. Une balle qui ne l'atteint pas au cœur où à la tête ne fait qu'augmenter sa rage et grandir ainsi le danger. Il saisit une lance entre 
ses dents, la brise ou l'arrache des mains de son assaillant. On raconte bien des malheurs qu'il a causés, et plus d'un baleinier a payé de sa vie la témérité qui l'a poussé à combattre l'ours blanc." (I)

La femelle met bas de un à trois petits; elle a pour eux la plus grande sollicitude, les soigne et les défend au péril même de sa vie. Les auteurs nous ont laissé le récit de plusieurs exemples touchants de cet amour maternel dont les femelles font preuve pour leur progéniture. Je n'en citerai qu'un qui a été rapporté par l'équipage du navire La Carcasse: "Pendant que le bâtiment était emprisonné dans les glaces, on signala du haut des hunes trois ours blancs qui s'acheminaient vers le bâtiment, attirés par l'odeur de la viande de morse que les matelots faisaient cuire sur la glace. C'était une ourse conduisant deux oursons déjà presque aussi forts que leur mère. Ils se précipitèrent sur le foyer, saisirent un grand morceau de viande que le feu n'avait pas encore consumée, et le dévorèrent. L'équipage leur lança d'autres morceaux, la mère les ramassa et fit la distribution, donnant à ses petits la plus grosse part. Au moment où elle prenait le dernier morceau, les matelots firent feu sur les deux oursons qui restèrent sur la place; ils tirèrent aussi sur la mère, qui fut atteinte mais non abattue. Son désespoir eût ému les cœurs les moins accessibles à la compassion; sans faire attention aux blessures dont elle était couverte, au sang qu'elle répandait, elle

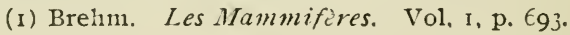


ne s'occupait que des deux oursons, les appelait par des cris lamentables, plaçait devant eux la part de nourriture qu'elle s'était réservée et la leur dépeçait ; comme ils restaient inmobiles, ses gémissements devinrent encore plus touchants; elle essaya de relever les pauvres créatures, et reconnaissant l'impuissance de ses efforts, elle s'éloigna de quelques pas, renouvela ses appels, revint auprès des deux morts, lécha leurs blessures et ne les quitta que lorsqu'elle fut bien convaincue qu'ils avaient perdu la vie. Alors, elle tourna lentement la tête vers le navire, avec des rugissements de colère et de désespoir qui semblaient accuser les meurtriers. Les matelots lui répondirent par une nouvelle décharge; elle tomba à côté de ses petits et mourut en léchant leurs blessures. " ( I)

La chasse à l'Ours blanc se fait au fusil, et est très dangereuse. Une fois blessé, il marche droit sur són assaillant, et si ce dernier ne peut lui envoyer une seconde balle au cceur, il est perdu, car doué d'une force extraordinaire cet animal triomphe toujours de son ennemi.

Capturé jeune, l'Ours polaire s'apprivoise assez facilement, mais en vieillissant il devient méchant. Il souffre beaucoup de la chaleur. Son attitude haletante et le balancement continuel de sa tête, lui donnent une singulière apparence.

(I) Brehm. Les Mammiferes, Vol. I., p. 695 . 


\section{FAMille MUSTELID压. LoUTRES,}

\section{HERMINES, etc.}

Ces animaux ont les oreilles courtes et arrondies; leurs pieds sont terminés par cinq doigts ; ils sont plantigrades ou digitigrades; la plupart sont pourvus de deux glandes anales spéciales sécrétant un liquide fétide qui, chez certaines espèces, peut leur servir de moyen d'attaque ou de défense; leurs dents sont au nombre de trente-deux à trente-huit ; ils possèdent une paire de dents tuberculeuses à chaque mâchoire.

C'est parmi les petites espèces que se recrutent les animaux de cette famille, bien que cependant certaines d'entre elles soient de taille moyenne; tous sont bas sur jambes et leur corps, ordinairement allongé, leur a valu, pour la plupart d'entre eux, la dénomination de vermiforme.

Quoique petits et faibles et en apparence inoffensifs, ces animaux sont pourtant cruels et féroces; ils se montrent altérés de sang, et égorgent souvent beaucoup plus de victimes qu'il ne peuvent en manger; ils sont méfiants, rusés et courageux. On les rencontre dans toutes les parties du monde, excepté en Australie.

Ils vivent par bandes, par couples, ou isolément; tous peuvent grimper et, au besoin, peuvent également nager; quelques-uns même sont d'excellents nageurs ; ils se creusent des terriers ou s'emparent des trous creusés par des animaux plus faibles, qu'ils égorgent; ou bien ils se fixent dans des troncs d'arbres creux, sous des racines, dans des fentes de 
rochers, sous des amas de roches. Ils voient également bien le jour comme la nuit; mais c'est surtout pendant la nuit qu'ils recherchent leur nourriture.

Ils vivent de petits mammifères, d'oiseaux, d'œufs, de reptiles, d'insectes, quelques-uns de poissons; d'autres sont omnivores.

Leur fourrure, pour la plupart, est très estimée, et par le haut prix qu'elle commande sur le marché, elle fait l'objet d'un commerce considérable; voilà pourquoi on sacrifie chaque année, un très grand nombre de ces animanx, afin de se procurer leur dépouille. Ainsi dans une seule année, en I868, la compagnie de la Baie d'Hudson a vendu plus de roo,000 peaux de martes; 73,000 de visons ; I 4,000 de loutres ; 6,000 de moufettes; I, roo de carcajous ; I,500 de blaireaux; I 23 de loutres de mer, sans compter toutes celles qui ont été vendues par d'autres compagnies, des chasseurs et trappeurs isolés.

\section{SOUS-FAMILLE LUTRINE.}

Formule dentaire. $-i \cdot \frac{3-3}{3-3} c \cdot \frac{1-1}{1-1} p m \cdot \frac{4-4}{3-3} m \cdot \frac{1-1}{2-2}$

Corps gros, allongé, cylindrique; pieds courts, forts ; doigts palmés, adaptés pour la vie aquatique; queue longue, conique et déprimée; tête petite; museau obtus ; oreilles petites.

\section{Genre LUTRA, Linné.}

Mêmes caractères que ceux de la sous-famille. 


\section{Lutra canadensis, (SCHREBER). La Loutre du Canada.}

Pelage d'un brun noirâtre lustré, moins foncé aux parties inférieures, particulièrement sous la gorge et le dessous du cou; le fond du poil est d'un blanc jaunâtre. Tête arrondie; yeux petits. Longueur, 30 ; queue, I 5.

La Lontre habite l'est de l'Amérique du Nord. On la rencontre sur les bords de presque tous nos lacs et rivières, près desquels elle établit sa demeure dans un terrier qu'elle creuse à cet effet. Comme ses congénères d'Anérique et de l'ancien continent, elle est essentiellement organisée pour la vie aquatique, et elle nage et plonge avec la plus grande facilité, pouvant même demeurer sous l'eau un temps assez long. Sa nourriture consiste surtout en poissons qu'elle saisit fort adroitement; elle mange aussi des grenouilles, des crustacés, des petits mammifères, etc.

Lorsqu'elle a capturé un poisson, elle l'emporte sur la rive ou dans son trou, pour le manger; Sur terre sa démarche est loin d'être embarrassée, mais c'est surtout dans l'eau qu'elle montre le plus d'élégance dans ses mouvements. Elle peut nager, dit-on, un quart de mille avant de venir respirer à la surface.

En hiver, la Loutre parcourt souvent de grandes distances afin de trouver, dans les chutes ou dans les rapides, quelque place d'eau libre. Dans ses pérégrinations, si elle est rencontrée par des chasseurs qui la poursuivent, elle se sauve en s'élançant sur 


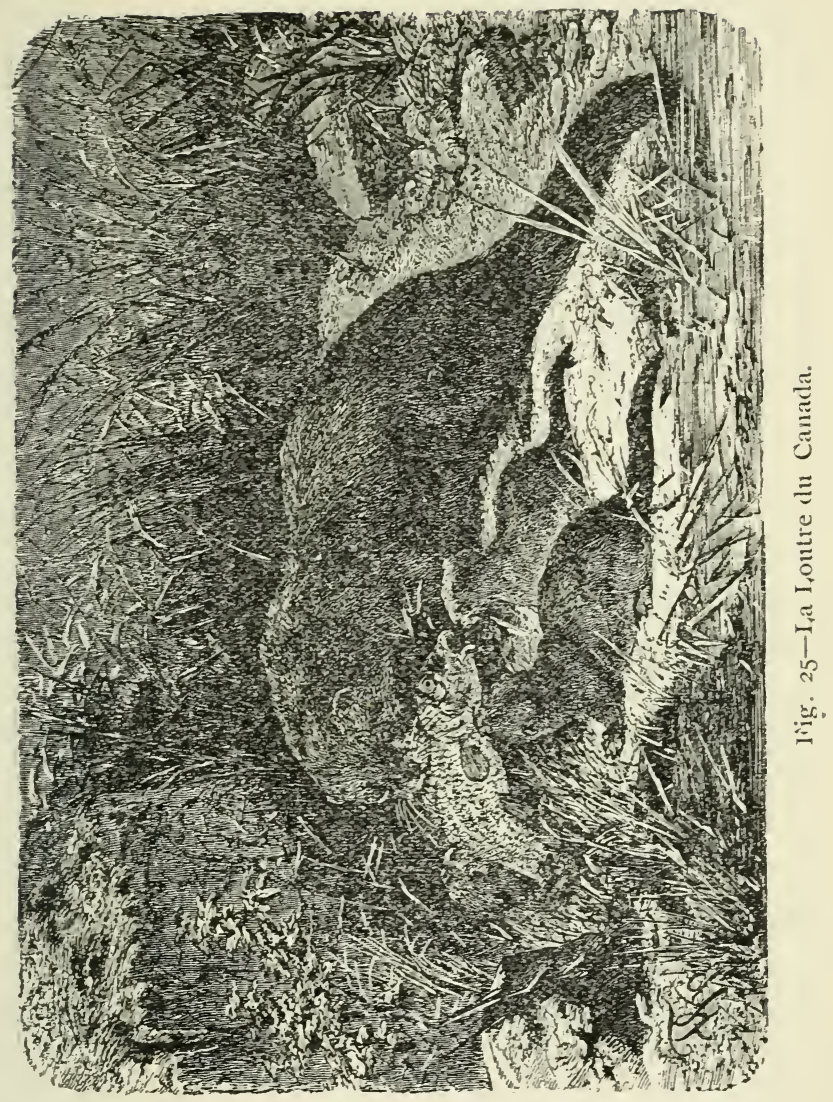


la neige, glissant ainsi sur le ventre l'espace de plusieurs verges et exécutant ces mouvements avec tant de rapidité que son agresseur peut à peine la suivre. Il arrive même sonvent qu'il ne pent s'en emparer.

Un fait singulier à noter dans les habitudes des Loutres ce sont ces glissades qu'elles entreprennent sur les pentes inclinées des rivières et des lass, ou bien en hiver sur la glace et la neige, et cela dans le seul but apparent de s'anniser. Même là où la pente est rapide, et qu'elles ont beaucoup de peine à parvenir jusqu'au sommet, cette difficulté ne les empêche pas de se livrer à cet exercice favori. Audubon, entre plusieurs auteurs qui relatent ce fait, nous dit qu'un jour, alors qu'il se reposait sur le bord d'un ruisseau qui se décharge dans l'Ohio, près d'Henderson, il vit deux Loutres qui, ne le remarquant pas, firent l'ascension de la rive et commencèrent à s'annuser en glissant sur cette surface vaseuse "coulante comme du savon," et cela avec la rapidité d'une flèche; elles firent ainsi vingt-deux glissades avant qu'il ne les dérangeât.

Lorsque la Loutre est prise jeune, elle s'apprivoise aisément et finit par suivre son maitre comme un chien; elle est intelligente, enjouée et se n110ntre docile.

M. A. Dickson, qui a gardé une Loutre en captivité et en a étudié les mœurs, nous donne les renseignements suivants: "La Loutre vit principale- 
ment de poisson, mais elle mange également toute espèce de chair; il est surprenant de voir la quantité de chair qu'elle mange dans l'espace de vingtquatre heures; nuit et jour elle marche, soit pour chercher sa nourriture, soit pour s'amuser. Ses habitudes diffèrent beaucoup de celles du castor, car ce dernier a une habitation locale, tandis que la Loutre voyage sans cesse d'un étang ou d'un lac à un autre, quoique toutefois elle visite régulièrement ses endroits favoris, où elle a ce que l'on appelle ses glissoires, qui sont situées sur le bord d'une rivière ou d'un lac, où elle roule ou glisse le ventre contre terre ; c'est aussi sur la rive, près de ces lieux, qu'elle fait son terrier. J'ai vu une Loutre,ce qui peut paraître singulier, mettre bas dans un tronc d'arbre mort, à environ un mille de l'eau....

"On capture ordinairement la Loutre au moyen d'un piège placé, soit dans l'eau, soit sur terre, à l'entrée de son trou ou aux alentours de sa glissoire ; il doit être recouvert de feuilles. Lorsqu'elle est prise au piège par une patte de devant, elle ne la coupe pas pour reconvrer sa liberté, comme le font. le castor et le rat musqué.

"Dans ses courses vagabondes, elle tombe souvent sous les coups du chasseur lorsqu'il la rencontre dans le bois, surtout s'il est accompagné d'un bon chien.

"Lorsque la Loutre est poursuivie et qu'elle échappe à son agresseur en se précipitant dans un étang ou dans un lac, presque toujours elle en sortira 
immédiatement sur la rive opposée pour se rendre à quelqu'autre lac, et si le chien a l'habitude de la chasser, il la suivra en contournant le lac jusqu'à ce qu'il retrouve sa piste. Il $\epsilon$ st à ma connaissance qu'une Loutre traversa cinq petits lacs et qu'elle se réfugia dans un arbre creux où elle fut tuée. Il faut un bon chien pour terrasser une Loutre, car elle a des dents plus aiguës qu'aucun autre quadrupède du Canada, et aussi parce qu'elle possède une peau épaisse et lâche qui la protège.

"Lorsque la Loutre est prise jeune, elle aime à joner et montre beaucoup d'attachement. J'en avais une aussi domestiquée qu'un chien; elle me suivait partont autour de la ferme et dans le village, mais elle préférait parcourir le bord d'une rivière. Lorsque je faisais une excursion en canot, elle saisissait parfois un poisson. Le nombre de grenouilles qu'elle tuait était étonnant; cependant je ne lui en ai jamais vu manger; mais elle semblait prendre plaisir à les capturer, pour les laisser de côté dès qu'elle en aperçevait une autre. Dans une de ces excursions, elle parut tout à coup inquiète et elle faisait beaucoup de bruit; je me retournai pour voir ce qu'il y avait et je in'aperçus qu'elle était en présence d'une grosse tortue qui se trouvait dans les joncs sur la rive; elle sembla contente lorsque j'allai vers elle, car elle ne pouvait rien faire de cet animal. Elle se régala de sa chair lorsqu'elle fut coupée par morceaux. Je ne crois pas qu'une loutre puisse tuer une grosse tortue. 
"Lorsque je prenais ma ligne pour aller pêcher, elle paraissait tout à fait joyeuse ; je n'ai jamais vu un chien aimer plus un fusil qu'elle n'aimait à voir une perche de ligne. Elle allait peut-être une douzaine de fois par jour pêcher pour son propre compte, étant toujours accompagnée d'un jeune chien de berger, qui se tenait sur le haut d'un radeau, suivant tous les mouvements de son amie au milieu de la gente poissonneuse.

Avant que la Loutre eût songé à se faire un trou pour s'y réfugier, elle et le chien couchaient ewsemble enlacés.

" Je coupais fréquemment un poisson par morceaux que je jetais dans la rivière, du pont où je me trouvais; aussitôt la Loutre s'élançait en ligne droite dans l'eau, mais avant qu'elle y fut arrivée, un grand nombre de petits poissons se disputaient ces morceaux; Nekeek-c'était son nom-mettait. bientôt fin à ces disputes en saisissant le premier des poissons qui se présentait. Si ces derniers se sauvaient, elle s'emparait toujours des morceaux du poisson jetés à l'eau, et, pour les manger, elle nageait vers la rive, tantôt sur le dos, tantôt sur ses pattes. Lorsqu'elle mangeait, elle sé tenait la tête élevée et elle fermait les yeux ; c'est ce qui explique le succès que j'obtenais quand je tuais au fusil des. Loutres au moment où elles prenaient leur nourriture.

"Quand celle que je gardais avait fini de pêcher, on était sûr qu'elle viendrait se rouler sur les tapis. 
si elle pouvait pénétrer dans la maison, et quand elle ne le pouvait pas, elle venait se frôler le long des jambes de quelques amis ou sur n'importe quel chien de la maison s'il dormait...

"Elle se creusa un trou dans le jardin et se confectionna un logis confortable sous le perron de la porte de derrière, où elle passa ensuite ses nuits sur un lit de paille qu'elle y avait transporté.

"Comme tout être animé, Nekeek eut une fin et, à l'instar de plusieurs d'entre eux, elle périt dans l'élément qui faisait ses plus grandes délices. Elle avait, dans un moulin, des amis qui souvent lui donnaient une anguille pour son déjeuner, puis elle passait là une partie de la journée; lorsqu'un jour elle se trouva engagée dans une des roues du moulin où elle se noya... A près cet accident, le petit chien passa bien des heures sur le radeau, cherchant des yeux s'il verrait dans l'eau son amie disparue. " (I)

La Loutre met bas, vers le milieu d'avril, de deux petits qu'elle dépose dans son terrier, sur un lit d'herbes et de feuilles.

La Loutre est très recherchée pour sa fourrure, et cliaque année on en tue un nombre considérable.

\section{SOUS-FAMILLE MEPHITINA:}

Molaire de la mâchoire supérieure quadrangulaire, large, très forte; ongles non rétractiles; ceux des doigts antérieurs aptes à creuser la terre; démarche plantigrade; habitudes terrestres.

(I) Canadian Nat. and Geol. Vol. I, pp. 230-23I. 
Sous l'empire de la crainte ou de la colère ces animaux répandent, au moyen de glandes spéciales très développées, une odeur fétide qui les distingue suffisamment de ceux des autres genres de la famille et même de tous les quadrupèdes. Leurs mouvements sont lents.

\section{Genre MEPHITIS, Cuvier.}

Formule dentaire. $-i \cdot \frac{3-3}{3-3} c \cdot \frac{1-1}{1-1} p m \cdot \frac{3-3}{3-3} m \cdot \frac{1-1}{2-2}$

Taille moyenne; museau allongé et comme tronqué verticalement au bout; queue longue et touffue, relevée en panache ; ongles des pieds de devant longs, peu recourbés ; oreilles courtes et rondes; pieds courts.

\section{Mephitis mephitica, (SHAW). \\ La Mouffette commune.}

Pelage noir, ordinairement long, surtout à la queue ; une étroite barde blanche sur le front et une large tache de même couleur sur la nuque, qui se prolonge en deux bandes sur les côtés du dos jusque près de la queue; cette dernière est noire, arec du blanc au bout, presque tous les poils de la queue sont blancs à la base. Longueur, It I 122 ; queue, $8 \mathrm{~s} / 2$

Cette espèce commune habite l'est de l'Amérique du Nord, depuis la baie d'Hudson jusqu'au Texas.

La Moufette est un joli petit animal timide et peu farouche, aux mouvements lents, et que l'on prendrait à première vue pour un petit chien; mais elle possède un moyen de défense que n'oublient pas ceux qui en sont les victimes. C'est ce qui la fait détester et fuir par tous ceux qui la comnaissent. 
Sous l'influence de contractions musculaires, les glandes anales projettent au dehors, à une distance de dix à quatorze pieds, un liquide jaunâtre qui répand une odeur si fétide que nul animal ne peut en supporter les émanations sans en être pour ainsi dire suffoqué ; voilà pourquoi elle est connue sous la dénomination bien méritée de Bête puante.

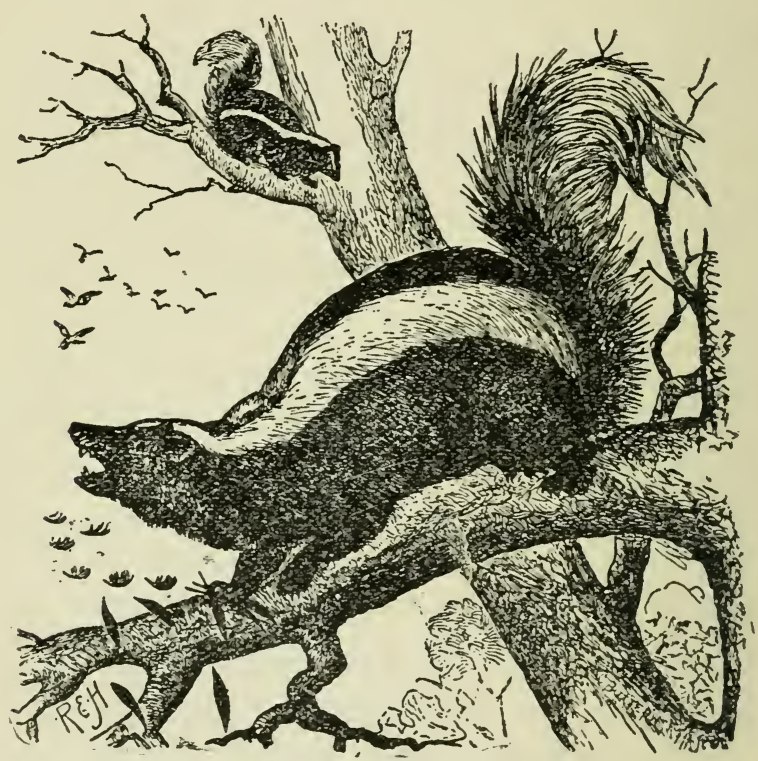

Fig. 26.-La Moufette commune.

Lorsque la Moufette aperçoit son ennemi, au lieu de fuir, comme le feraient les animaux faibles, elle s'arrête, présente son train de derrière, relève sa quene touffue, laissant apercevoir l'orifice de deux 
glandes anales, puis lorsyu'elle juge son agresseur suffisamment proche, elle lance sur lui son liquide fétide en deux jets, qui s'étendent à mesure qu'ils s'éloignent.

La Moufette est connue depuis longtemps, et Sagard qui, le premier, en fait mention, la désigne sous le nom de Enfan du diable.

Comme la plupart des mammifères, la Moufette est nocturne; mais on la rencontre souvent aussi le jour.

Elle se nourrit de petits mammifères, de grenouilles, d'oiseaux, etc., et lorsquelle se trouvera à proximité des fermes, elle égorgera des poules, volera des œufs, boira du lait et cela sans trop se soustraire à l'œil du fermier, qui la tuera invariablement; aussi est-elle souvent victime de la trop grande confiance que lui inspire son unique moyen de défense, qui ne réussit pas toujours à éloigner ses ennemis, car les loups et certains chiens la tuent en dépit de sa mauvaise odeur; il en cst de même du grand duc, qui en fait quelquefois sa proie.

Audubon nous dit "qu'il n'y a aucun quadrupède sur le continent de l'Amérique du Nord dont la présence soit plus généralement détestée que celle de la Moufette; de là nous pouvons conclure que, quoique nous ayions à craindre des animaux qui sont gros et forts, cependant ceux qui sont faibles et insignifiants en apparence, peuvent avoir le pouvoir de nous importuner au delà même de ce que nous pouvons supporter. 
"Dans l'espèce humaine nous constatons quelquefois qu'une faculté spéciale a reçu un développement extraordinaire, résultat d'une étude constante d'un sujet spécial, tandis que, d'un autre côté, l'intelligence de l'individu peut être bien ordinaire. La même remarque s'applique également à n'importe quel organe du corps qui, par un emploi constant, (tels que les organes du toucher chez les aveugles) se perfectionne jusqu'à remplacer ceux qui font défaut. Mais chez les animaux inférieurs, ce développement dans un organe particulier résulte de sa conformation spéciale ou de l'instinct; ainsi la force du rhinocéros repose dans sa corne nasale; celle du sanglier, dans ses énormes défenses ; la sécurité du kangaroo dépend de ses membres postérieurs qui, non seulement lui permettent de faire des sauts prodigieux, mais encore de donner de forts soufflets; le bœuf attaque ses ennemis avec ses cornes ; le venin mortel du serpent à sonnettes est communiqué au moyen de ses crochets, et l'abeille avec son aiguillon peut tuer quelques-uns de ses ennemis.

" D'un autre côté pour attaquer ou se défendre, ces animaux sont comparativement faibles.

"Quoique armée de griffes et de dents assez fortes et assez aiguës pour capturer sa proie, la Moufette ne court pas vite et, d'apparence timide, elle serait incapable d'échapper à ses ennemis, si elle ne possédait pas un moyen de défense qui fait fuir les animaux même les plus féroces, leur fait frotter le nez contre la terre et se rouler ou culbuter sur le 
sol, comme s'ils étaient en convulsions. Assez souvent même, le plus brave de notre fière espèce est forcé par ce petit animal à changer d'idée, à se boucher le nez, et à courir comme si un lion était sur ses talons.

- Parmi les premiers spécimens d'histoire naturelle que nous avons essayé de nous procurer, ce fut la Moufette et, cette fois-là, c'est par le sens de l'odorat que fut gravé dans notre esprit le sage conseil qui dit de regarder devant soi avant de marcher.

"Un soir, au temps où nous étions écolier, le soleil venait de se coucher. Comme nous revenions tran quillement de chez un voisin, nous vîmes devant nous, dans le sentier, un beau petit animal, gentil comme un petit chat, marchant doucement; il s'arrêta comme s'il eût voulu nous attendre, levant en l'air sa queue touffue, se détourna et nous regarda comme de vieilles connaissances. Nous nous arrêtames et le regardâmes fixement. Qu'est-ce que c'est? ce n'est pas un jeune chien ni un chat, il est plus gentil que cela; il semble désireux de nous tenir compagnie et, semblable à un caniche favori, il paraît très heureux lorsque nous avançons vers lui. Quel beau petit animal à emporter dans nos bras à la maison! il semble trop gentil ponr mordre, prenons-le. Nous courons vers lui, il ne fait aucun pas pour fuir, il nous attend et il lève sa queue comme pour nous inviter à la prendre; nous la saisissons à l'instant, l'empoignant avec l'énergie d'un 
avare qui s'empare d'une cassette de diamants, et... Pouah! nous sommes suffoqués, les yeux, le nez, la figure sont soudainement arrosés avec le fluide le plus horrible et le plus fétide.

Inaginez vous-même, lecteur, notre surprise, notre dégoût et cette odeur qui nous rendait malade; nous laissâmes là le petit animal et prîmes notre course, trop entêté pour crier, mais trop alarmé et déconfit dans le moment pour songer à nous rendre compte de ce qui était la cause de notre infortune, effectivement césabusé, quant au caractère de douceur et de gaieté apparentes de cette petite bête. (I)"

La Moufette fait quelquefois son nid dans un arbre cremx, dans des crevasses de rochers; mais le plus souvent elle creuse, près de la surface du sol, un terrier de six à huit pieds de longueur qui se termine par un agrandissement capable de contenir plusieurs individus.

Les Moufettes, à l'instar des animaux hibernants, s'engourdisent en hiver, mais ce n'est que tard à l'au. tomne qu'elles s'enferment dans leurs gîtes. Elles se réunissent en famille pour cette fin, et l'on en a rencontré jusqu'à quinze qui avaient passé l'hiver dans un seul terrier Dans le sud, où l'hiver est peu rigoureux, elles ne s'endorment point à cette saison de l'année.

Lorsque la Moufette est prise jeune, elle s'apprivoise facilement ; elle est joyeuse, manifeste beau-

(I) Audubon, Quadrupeds of N. A. Vol. I. p. 32I. 
coup d'attachement pour son maître et le suit comme un petit chien.

Elle met bas en mai, de huit à dix petits.

On utilise sa fourrure sous le nom de Marte d'Alaska.

\section{SOUS-FAMILLE MELINE.}

Molaire de la mâchoire supérieure très grosse, sub-triangulaire, tuberculeuse; ongles des doigts antérieurs très allongés, disposés pour fouir ; doigts non-rétractiles.

Ces animaux ont une démarche presque rampante; leurs habitudes sont nocturnes; ils ne grimpent pas ; ils se creusent des terriers. La longueur démesurée des ongles des doigts antérieurs les distinguent facilement des autres espèces de cette famille.

\section{Genre TAXIDEA, Waterhouse.}

Formule dentaire. $-i \cdot \frac{3-3}{3-3} c \cdot \frac{\mathrm{I}-\mathrm{I}}{\mathrm{I}-\mathrm{I}} \mathrm{pm} \cdot \frac{3-3}{3-3} \mathrm{~m} \cdot \frac{\mathrm{I}-\mathrm{I}}{2-2}$

Corps court et trapu, bas sur jambes; pelage long et lâche; queue très courte.

\section{Taxidea americana, (BODDAERT). Le Blaireau d'Amérique.}

Belage variant, comme chez beaucoup d autres animaux, suivant l'âge et les saisons; ordinairement grisâtre, plus foncé sur le dessus de la tête; cette dernière est séparée dans le sens de sa longueur par une bande blanche; le dessous du corps est blanchâtre, lavé parfois de gris ou de fauve; la tête en dessous est blanche jusqu'aux yeux; les jambes et une tache en avant de l'oreille, noirâtres; la couleur grisâtre est le résultat d'un mélange de poils noirâtres, de blancs, de gris ou de fauves. Longueur, 22; queue, 5 . 


\section{- $198-$}

On assigne à cet animal, comme habitat dans les Etats-Unis, depuis le Wisconsin jusqu'au Texas, à l'ouest jusqu'au Pacifique et, dans l'ouest de l'Amérique britannique, jusqu'à la Baie d'Hudson à l'est, et vers le nord.

Le Dr Hall mentionne cet animal dans sa liste des mammifères du district de Montréal, (I) et c'est sur son aulorité que je l'inclus parmi les mammifères de la province.

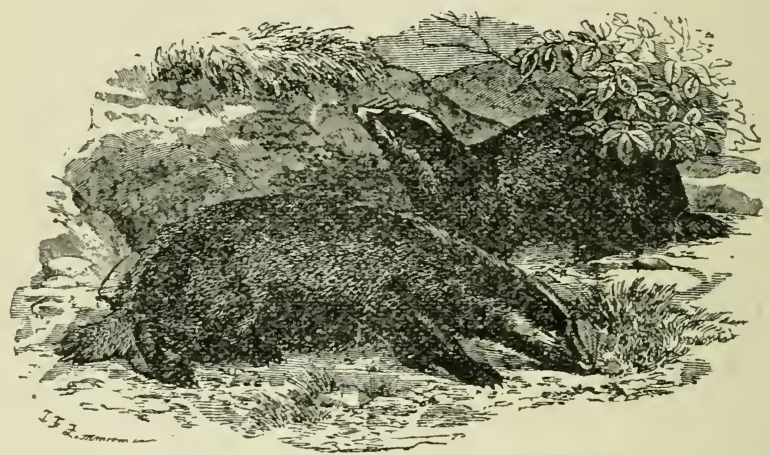

Fig. 27.-Le Blaireau d'Amérique.

Le Blaireau est un animal aux habitudes nocturnes, dormant le jour dans son terrier et n'en sortant que la nuit pour chercher sa nourriture, laquelle consiste en œufs d'oiseaux qui nichent à terre, en petits serpents, insectes, et surtout en petits mammifères. Le petit rongeur qui s'enfonce dans sa retraite souterraine n'est pas toujours à l'abri de la dent meurtrière du Blaireau. Ce dernier le poursuit,

(I) Canadian Nat. Geol. Vol. VI, p. 294. 
élargit très vite avec ses pattes le trou dans lequel le petit animal s'est caché, et il parvient alors à s'en emparer.

Le Blaireau est doué d'une grande force musculaire comparativement à sa taille, aussi, à l'exception de l'homme, n'a-t-il pas d'ennemis à redouter dans ce pays, car il est de force à résister aux attaques des loups et des renards. Mais c'est un animal timide qui préfère, par mesure de prudence, se cacher dans son terrier, plutôt que de s'exposer à un combat inégal où les chances de succès lui paraissent douteuses. Toutefois, il ne manque pas de courage lorsqu'il est traqué de près, ou que sa retraite est coupée; il se bat alors avec autant d'ardeur que de force, et il faut que son assaillant soit d'une grande capacité pour le vaincre, car il offre une résistance opiniâtre, ne calculant ni la valeur ni le nombre de ses ennemis, et les blessures qu'il fait sont sérieuses.

Au sujet de la force du Blaireau, Sir J. Richardson nous dit que deux jeunes gens forts essayèrent un jour de sortir un de ces animaux hors de son terrier, dans lequel il n'avait que la moitié antérieure du corps d'engagé; les jeunes gens le tenaient par les pattes de derrière et par la queue, et quelques efforts qu'ils fissent, ils ne purent jamais réussir à le tirer de là (I).

Le même auteur, parlant de l'hibernation de cet animal dans l'Amérique britannique, depuis no-

(I) Richardson, Fauna Boreali-Americana. London, 1829. Vol. I, p. 39 . 
vembre jusqu'à avril, ajoute que, comme l'ours, le Blaireau ne semble pas perdre beaucoup de sa graisse durant cette période d'engourdissement puisqu'il en sort gras au printemps. Cependant Audubon, qui en a gardé un en captivité, dit qu'il ne paraissait pas vouloir s'endormir, bien qu'il fut séquestré dans un endroit assez froid pour faire geler l'eau qu'on lui donnait.

Comme le Blaireau est constitué pour la vie souterraine, et qu'en réalité il passe une grande partie de son existance dans son terrier, on ne comnaît encore que bien imparfaitement ses habitudes.

On dit que la femelle met au monde trois ou quatre petits au printemps.

On capture le Blaireaı au piège on avec une trappe, en y plaçant un rat ou autre petit animal comme appât.

Le Blaireau est très rusé et déjoue souvent les plans du trappeur; il retourue les pièges, les détend, puis il mange l'appât. De bonne heure au printemps, lorsque la terre est encore gelée, on peut le faire sortir de son trou en y versant de l'eau.

4. SOUS-FAMILLE MUSTELINA.

La dernière molaire de la mâchoire supérieure est courte et située transversalement; doigts courts, arqués ; ongles rétractiles. Corps trapu.

\section{Genre GUL0, Storr.}

Formule dentaire. $-i \cdot \frac{3-3}{3-3} c \cdot \frac{1-1}{1-1} p m \cdot \frac{4-4}{4-4} m \cdot \frac{1-1}{2-2}$ 
Corps robuste et bas sur jambes ; cou court ; dos arrondi ; tête large ; museau allongé ; semi-plantigrade ; ongles forts et recourbés ; queue courte et touffue.

\section{Gulo luscus, (Linné).}

Le Glouton ordinaire.

Poil long; pelage variable, ordinairement d'un brun foncé, plus clair sur le dessus de la tête, entre les oreilles et les yeux, sur les épaules et les côtés du corps; et noir ou presque noir aux parties inférieures, $y$ compris les jambes; des taches blanches plus ou moins grandes se voient sur la poitrine. Longueur, 28 ; queue, 8.

Le Glouton est propre aux régions arctiques des deux continents, et, en Amérique, il se rencontre au sud, quoique plus rare, jusque dans le nord des Etats-Unis.

Le Glouton est connu depuis longtemps des trappeurs comme des naturalistes, et ceux qui, les premiers, ont écrit l'histoire de ses mœurs, se sont plu à nous le représenter sous un jour plus ou moins fabuleux. Ainsi, on lui prête une queue d'une longueur telle qu'il peut l'enrouler plusieurs fois autour de son corps. D'après O. Magnus, lorsque le Glouton trouve le cadavre d'un gros animal, il en mange jusqu'à ce que son ventre soit gonflé comme un tambour, et, pour se soulager, il passe entre deux arbres très rapprochés qui le pressent ; puis il recommence à manger de nouveau jusqu'à ce qu'il ait tout dévoré. (I) Malgré le ridicule qu'offre cette histoire, elle paraît avoir rencontré des adeptes, puis-

(I) Olaus Mragnus, Historia de gentibus septen. Romæ, I555, p. I38. 
que C. Gessner la reproduit et va même plus loin, car il ajoute que "la force de ses bras est prodigieuse, qu'elle lui permet de fendre en deix un arbre assez gros, ce qui lui arrive quelque fois lorsqu'il a besoin de se presser le ventre pour recommencer à manger."

Goldsmith, de son côté, nous apprend que le Carcajou se cache dans les branches d'un arbre pour guetter sa proie, et cela parfois pendant plusieurs jours de suite. Si un orignal ou un caribou vient à passer, il s'élance sur cette proie, lui enfonce ses griffes et ses dents dans les chairs jusqu'à ce qu'enfin fatiguée et épuisée par une course furibonde et par la perte de son sang, la victime tombe privée de sentiment. Le Glouton se dédommage alors de son long jeûne. Le même auteur ajoute qu'il préfère la chair des animaux en putréfaction, qu'il déterre les cadavres, etc. (I).

Il est étonnant que de nos jours encore, quelques personnes ajoutent foi à de telles fables.

Dépouillé de toutes ces histoires fantaisistes, le Carcajou, comme on le nomme vulgairement, est un animal bien ordinaire, dont la taille et la forme trapue le feraient prendre pour un petit ourson plutôt que pour un des représentants de la famille à laquelle il appartient. Il ne possède ni assez d'agilité ni assez de force pour s'emparer des cerfs ou autres grands animaux de chasse, comme certains auteurs

(1) Goldsmith. Earth and animated nature. London, 1862. Vol. I., p. 425 . 


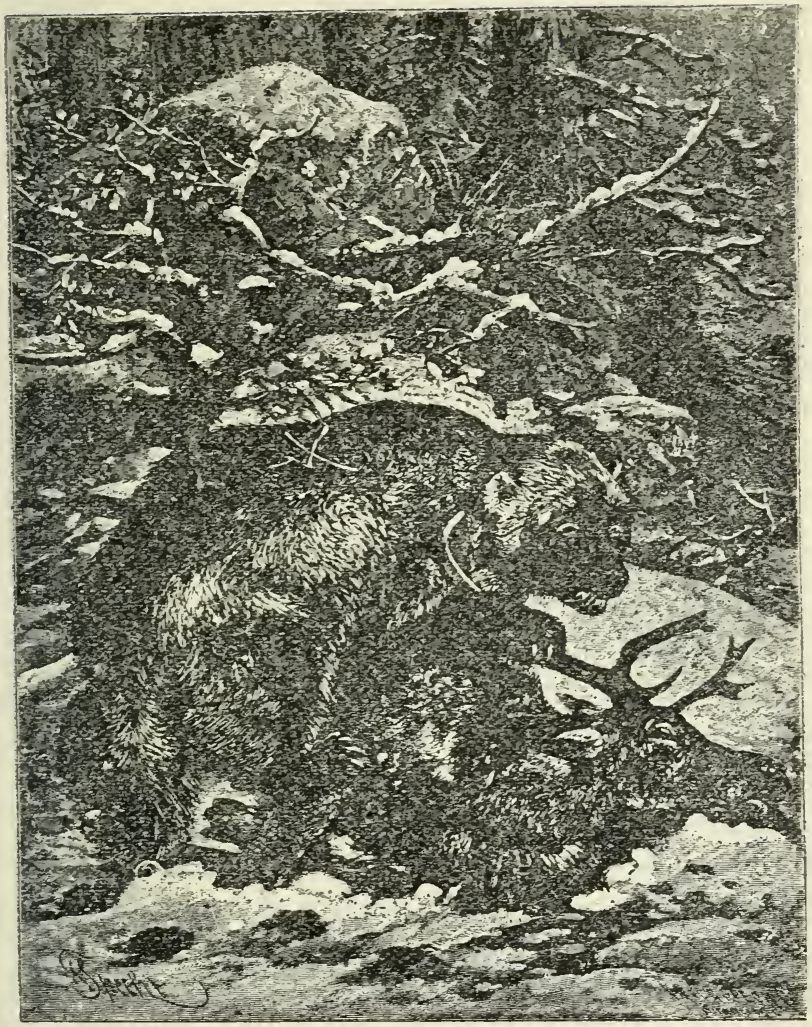

Fig. 23.-Ie Glouton ordinaire. 
l'ont prétendu. De plus il ne grimpe pas dans les arbres, puisqu'il vit sur la terre $\epsilon t$ dans un terrier qu'il creuse.

A l'appui de ce que j'avance, je citerai Sir John Richardson qui a étudié ces animaux chez eux et qui, par conséquent, fait autorité en cette matière. Voici ce qu'il dit : "Il se nourrit particulièrement de carcasses d'animaux qui ont été tués par accident; il dévore aussi des campagnols, des marmottes et autres rongeurs, et à l'occasion, de grands quadrupèdes blessés, incapables de fuir ou de se défendre., (I)

On peut également consulter le Dr Cones, qui a aussi étudié les mœurs de ces animaux dans leurs domaines. Ce savant naturaliste, dont l'autorité ne saurait être révoquée en doute, a de plus mis à contribution l'expérience qu'ont acquise, dans les régions boréales, plusieurs trappeurs intelligents et dignes de foi.

A près avoir relaté quelques-unes des fables racontées par les auteurs anciens, il ajoute: "Néanmoins, dans cette voie du merveilleux, nous lisons encore comment le Glouton, trop pesant et trop lourd pour attrapper à la course les gros ruminants, grimpe sur les arbres, s'y blottit et attend sa victime, puis, lorsqu'elle vient à passer près de lui, avec la rapidité d'un coup de feu il s'élance sur le cerf, l'orignal ou le caribou, inconscients du danger, leur enfonce ses griffes et ses dents dans les chairs, suce leur

(I) Richardson. Fauna Boreali Americana. Vol. I, p. 43 
sang et les fait mourir dans leur course. Afin que rien ne soit oublié pour assurer le succès de sa chasse, l'animal a l'instinct de jeter de la mousse et des lichens dans le dessein d'attirer sa victime; bien plus, il accepte les services amicaux des renards qui lui chassent sa proie à l'endroit fatal. Je fais allusion à ces choses, non pas que ces stupides exagérations demandent une plus ample réfutation, mais parce quelles sont une partie, et non la moindre, de l'histoire de l'espèce, et aussi parce qu'elles sont également, comme nous le verrons dans la suite, une narration parfaitement juste et véridique des habitudes réelles de l'animal, attestant suffisamment qu'il possède des qualités vraiment remarquables, qui n'ont besoin que d'être mises en caricatures pour être transformées en de telles fables...

"Afin de ne pas prolonger cette partie du sujet, je dirai de suite que l'animal dont les mœurs seront parfaitement exposées dans le cours de cet article, est simplement une grosse Marte ou Belette, lourde, reconverte de longs poils rudes, d'une grande force, essentiellement carnivore, qui ne correspond pas à l'agilité qui caractérise le reste de sa tribu, déployant beaucoup de persévérance et de sagacité pour se procurer de la nourriture dans ces régions boréales, alors que cette nourriture est limitée ou précaire, étant obligé d'entreprendre de longs voyages, pour un animal aux jambes si courtes. Il est imparfaitement plantigrade, et ne grimpe pas dans les arbres, comme la plupart de ses alliés. Il vit dans un. 
antre ou dans un terrier, et ne s'engourdit pas en hiver. Il se nourrit de la chair de grands animaux qu'il trouve blessés à mort, mais il ne les capture pas, et ce sont les petites espèces qui lui servent de proie ordinaire." (I)

D'un autre côté, le Carcajou est un animal rusé, qui évite presque toujours, avec un instinct remarquable, les divers moyens que les trappeurs emploient pour le capturer et se débarrasser d'un animal aussi incommode. Ajoutez à cela qu'il est encore un voleur notoire, et que, non content de dérober les aliments qui servent à sa nourriture, il enlèvera et cachera tout ce qu'il peut trouver, lors même que ces objets ne lui sont d'aucune utilité. Cette tendance prononcée à recéler tout ce qu'il trouve est d'un grand embarras pour les trappeurs de ces endroits. Entre plusieurs exemples de cette nature je mentionnerai le suivant. Ce fait, raconté par MI. Ross, est arrivé dans les Territoires du NordOuest :

La famille d'un trappeur ayant laissé son habitation sans gardien, la trouva entièrement vide à son retour. Il ne restait de l'habitation que les quatre pans et rien de plus; couvertures, fusils, chaudières, haches, couteanx et autres ustensiles, attirail de chasse, tout avait disparu, et les empreintes de pas des Carcajous sur la neige témoignaient suffisan1ment que les voleurs ne pouvaient être autres que ces mauvais garnements; on suivit leurs traces et on

(1) Coues, Fur-bearing animals, Washington, 1877 , p. 44. 
trouva presque tous les effets enfouis dans la neige. (I)

Guidé par son flair très développé, le Glouton suit le trappeur pour lui voler des portions de chair d'animaux qui doivent servir d'appât pour ses pièges, et une fois qu'il a fait la découverte de ces derniers, il les visite régulièrement chaque nuit pour dévorer les animaux qui y sont capturés ou pour manger l'appât qu'on y a placé, quand il ne détruit pas les trappes ou les pièges mêmes. Ce qu'il ne peut consommer, il le traîne souvent à de grandes distances pour le cacher dans la neige en y pratiquant un trou qu'il comble, de manière à dissimuler toute trace de l'objet enfoui; c'est ce que l'on appelle, en terme de trappeur, une cache. Puis il laisse tomber des déjections, afin que l'odeur qui s'en dégage, détourne de cette cachette les martes, les pécans, ou les lynx.

Lorsqu'un Carcajou est dans les environs des pièges d'un trappeur, celui-ci peut considérer sa chasse comme finie, enlever ses pièges et tenter fortune ailleurs, car l'animal les visitera régulièrement chaque nuit, à moins qu'il ne le capture, mais ce n'est pas chose facile.

$\mathrm{Ce}$ carnassier sait également bien trouver les matières animales cachées dans la neige, quelles que soient les précautions prises et la profondeur où elles sont enfouies; et si l'on veut mettre ces choses à l'abri de sa dent, il faut qu'elles soient entourées

iI) Coues. Fur-bearing animals. p. 5r, 
par une petite construction en bois, assez solide pour résister aux efforts qu'il fera pour pénétrer à l'intérieur, car on pent être sûr qu'il fera l'impossible pour atteindre son but.

M. Lockhart nous dit que pendant un liver passé aı fort Simpson, il tendait, sur ın grand espace des trappes et des pièges pour les martes, les renards et les lynx. Un jour, il alla les visiter et y trouva un lynx prisonnier; après l'avoir tué, il lui enleva la peau. Comme il ne pouvait l'emporter avec lui, il fit un trou profond dans la neige, puis y déposant la peau, la foula et l'arrangea de telle sorte qu'aucune trace ne pouvait laisser croire qu'elle avait été remuée à cet endroit. Il laissa ensuite la carcasse en ayant soin de l'ouvrir pour en extraire les entrailles qu'il dispersa sur la neige; il prit ces précautions pour dérober la peau au flair des Carcajous qui fréquentaient ces lieux. Le lendemain matin, il s'aperçut que la carcasse et les intestins du lynx avaient été enlevés, et regardant à l'endroit où il avait enfoui la pea $\mathrm{l}$; il vit qu neige n'avait apparemment pas été reinuée. Il se dit en lui-même, apostrophant le Glouton absent": "Ah! ma canaille; je t’ai enfin joné un tour, " puis tranquillement il alluma sa pipe, prit une de ses raquettes et commença à creuser la neige pour en retirer la peau; mais qu'elle ne fut pas sa surprise de constater qu'elle avait été enlevée! Un Carcajou l'ayant flairée, l'avait extraite, puis avait comblé le trou absolument comme il l'était auparavant. Car- 
casse et peau de lynx avaient été transportées ailleurs, puis cachées dans la neige. (I)

Lorsque le Carcajou est pris dans un piège, il déploie une grande énergie pour se dérober aux poursuites du trappeur ; s'il peut s'échapper, même avec le piège, il le fait, comme nous l'apprend le capitaine Cartwright, qui, passant un jour ${ }_{3+}^{\top \%}$ au pied de Table Hill, aperçut la trace d'un Carcajou qui trainait un piège dans lequel il avait une patte prisonnière ; des renards l'avaient suivi àlla trace du sang qui s'échappait de la blessure. L'animal traversait un bois touffu sur le versant de la montagne, où la neige était si profonde et si molle, que le capitaine, monté sur ses raquettes, avait beaucoup de peine à marcher. Il était à se demander comment cet animal pouvait faire pour traverser ainsi le bois, sans que le piège ne s'accrochât à quelque branche ou sans qu'il ne s'enfonçât lui-même dans la neige, lorsqu'il le vit qui se reposait ; le Glouton, dans un suprême effort qu'il fit pour se sauver, prit le piège entre ses dents, puis il courut sur ses trois pattes. On a calculé la longueur du chemin qu'il avait parcouru, y compris'les détours, et l'on a constaté qu'il avait fait ainsi six milles traînant un piège du foids de huit livres à sa patte. L'animal, qui fut tué, pesait vingt-six livres. (2)

Le Glouton peut être pris au piège ou encore à

(I) Coues. Fur-bearing animals. p. 53 .

(2) Idem, p. 55.

(14) 
l'aide d'une trappe analogue à celle que l'on emploie pour la marte; mais il faut que pièges et trappes soient d'une grande force; les trappes doivent être construites avec deux entrées, et disposées de manière qu'elles ressemblent le plus possible à une cache. On peut se servir aussi, mais avec moins de succès, de fusils tendus. L'appât peut consister en un écureuil, un rat, de la chair de castor, de celle au rat-musqué ou de perdrix; mais il faut que le tout soit bien dissimulé sous des feuilles, de la mousse, des lichens, des branches de pins ou autres plantes analogues. Cependant, malgré tout l'art que l'homme apporte dans ses tentatives pour s'emparer de cet animal, il échoue encore bien souvent. Le Carcajou semble prendre plaisir à déjouer ses ruses, à détruire ses trappes, à manger les appâts ou les animaux qui y sont capturés, et même à transporter les pièges à de grandes distances, quand il peut réussir à les enlever, pour les enfouir dans la neige.

Lorsqu'il est pris jeune, le Glouton s'apprivoise assez bien. Audubon raconte qu'étant au Danemark, il eut lavantage de voir 111 de ces animanx. On le fit sortir de sa cage; il était doux, ouvrait la bouche et se laissait examiner les dents, et pendant que le naturaliste admirait ses longues griffes, il se cachait la tête sur ses genoux. On lui avait appris à se tenir droit, à porter une pipe à la bouche. Il paraissait souffrir de la chaleur; il mangeait avidement de la viande, et en consommait plus en hiver qu'en été. 
La femelle met bas de quatre ou cinq petits, dans le mois de juin ou au commencement de juillet.

\section{Genre MUSTELA, Linné.}

Formule dentaire. $-i \cdot \frac{3-3}{3-3} ; c \cdot \frac{I-I}{I-I}, p m . \frac{4-4}{4-4} m \cdot \frac{I-I}{2-2}$

Corps allongé; museau pointu; queue touffue, plutôt longue, cylindrique ou terminée en pointe; digitigrades ; plante des pieds recouverte de poils à l'exception d'un endroit nu sous les doigts; ongles longs, recourbés et aigus ; un petit tubercule sur le côté interne de la première molaire inférieure; pelage long et soyeux.

Les Martes sont légères et souples dans leurs mouvements; elles grimpent avec une grande agilité et passent une bonne partie de leur vie sur les arbres.

\section{Mustela americana, KERR. I a Marte d'Amérique.}

Pelage très variable suivant l'âge et la saison; ordinairement d'un jaune rougeâtre ou brun orangé, entremêlé de noir, ce qui lui donne parfois une teinte brune; plus clair ou jaunâtre aux alentours de la tête, sous la gorge et sous - le ventre; les jambes et la queue sont noirâtres. Longueur I4-I6; queue, 8 . La femelle un peu moins.

La Marte est commune dans l'Amérique septentrionale, depuis la limite nord des régions boisées jusque dans le nord des Etats-Unis, et de l'Atlantique au Pacifique.

Dans certains endroits, elle est même très commune. Elle se plaît au milieu des épaisses forêts qu'elle ne quitte jamais, et où elle tronve une ample 
nourriture dans les lièrres et autres petits mammifères, qu'elle poursuit aussi bien à terre que sur les arbres, et l'écureuil, tout agile qu'il est, n'est pas toujours à l'abri de sa dent meurtrière. Elle fait beaucoup de ravages chez les perdrix et autres oiseaux qui nichent à terre ou sur les arbres, et dont elle dévore les petits ou les œufs; elle s'approche de ces oiseaux en rampant, et s'en empare avant même qu'ils aient pu soupconner sa présence. Elle ne dédaigne pas non plus les charognes, ni le poisson.

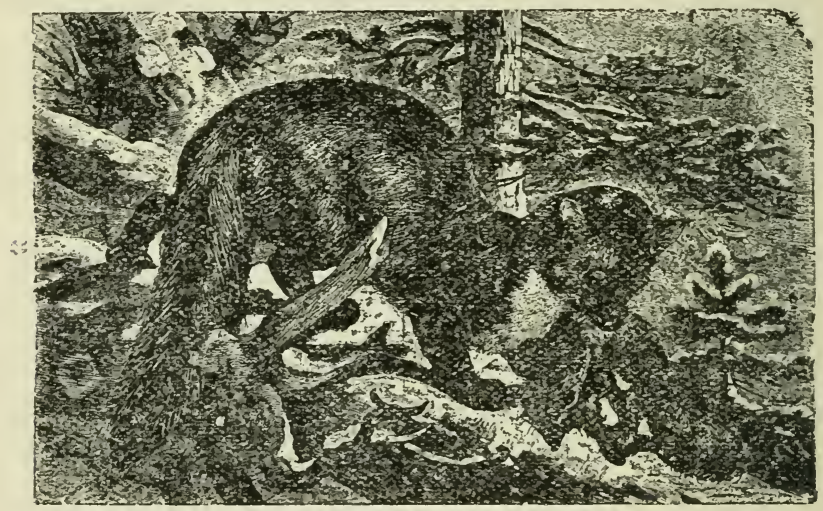

Fig. 29. - La Marte d'Amérique.

Lorsqu'elle est molestée, elle se défend énergiquement avec ses griffes et avec ses dents, qu'elle montre en se contractant les lèrres ; elle hérisse son poil, se courbe le dos et gronde comme un chat. Elle établit son gîte dans des troncs d'arbres. 
creux, dans des nids d'écureuils qu'elle agrandit selon ses besoins, ou encore sous des racines.

On capture bien facilement la Marte au piège ou au moyen d'une trappe quelconque, dans lesquels on place comme appât des morceanx de chair, du poisson, ou une tête d'oiseau quelconque.

Dans les endroits où se fait la chasse à la Marte, les carcajous, les loups et même les pécans causent beaucoup d'ennuis aux trappeurs, en s'emparant des Nartes captives et détruisant en même temps les trappes, tout en enlevant les appâts. Il est des exemples où, sur une longueur de cinquante milles, I 50 trappes qui avaient été tendues furent détruites soit par les loups soit par les carcajous, au grand désespoir de leurs propriétaires.

La femelle met bas vers la fin d'avril de quatre à six petits.

\section{Mustela pennantii, ERxleben. La Marte de Pennant.}

Le pelage varie suivant l'âge et les saisons, mais il est ordinairement noirâtre ou brun noirâtre aux parties postérieures, y compris la queue, le ventre et les jambes; le reste du corps, aux parties antérieures, de couleur plus claire. Queue touffue; doigts armés d'ongles forts et crochus. Longueur, 20 à 22 ; queue, 14 .

Cette Marte, appelée aussi Pécan, est bien moins commune chez nous que la précédente, et sa fourrure atteint aussi un prix beaucoup plus élevé. Elle se rencontre sur une grande partie de l'Amé- 
rique septentrionale, mais elle est moins rare vers le nord où on la retrouve jusqu'au $65^{\circ}$ de latitude.

La forte taille de cette Marte, sa queue touffue et sa tête allongée la feraient prendre, à première vue, pour un jeune renard.

Le Pécan aime la solitude des épaisses forêts, et préfère les terrains bas et humides à ceux qui sont secs et élevés.

Il se nourrit de petits quadrupèdes, tels que lièvres, souris, mulots, et autres ; il ne dédaigne ni les perdrix, ni les grenouilles, pas mêne la Marte d'Amérique, sa voisine, qu'il poursuit sur les arbres, ainsi que l'attestent les observations des chasseurs.

Sir John Richardson dit que cet animal détruit beaucoup de grenouilles; et qu'il s'empare du porcépic en le mordant sons le ventre, seul endroit oì il n'y ait point de piquants ; mais cette assertion est mise en doute par Audubon. Cependant M. Gilpin, de la Nonvelle Ėcosse, dit avoir tronvé des piquants de porc-épic dans l'estomac d'un Pécan.

Cet animal ne se gêne nullement de visiter les pièges et trappes tendus pour les martes, qu'il dévore lorsqu'il en trouve. A ce sujet, on rapporte qu'un instituteur s'occupait, dans ses loisirs, à tendre des trappes aux martes, et que, pendant plusieurs jours de suite, il trouva ses trappes brisées et les appâts disparus; il constata même qu'une marte capturée $\mathrm{y}$ avait été détruite; il se procura alors un piège de plus grande dimension, et le lendemain il aperçut 
un Pécan pris dans lè piège; l'animal se défendit avec acharnement contre un chien que l'on avait lancé sur lui. Les trappeurs sont souvent témoins d'incidents analogues.

Un individu qui tendait des trappes pour les martes, à l'embouchure de la rivière de l'Esclave, à environ I 5 milles du fort Résolution, voyant ses trappes dérangées et ses appâts disparus, et cela durant quinze nuits consécutives, résolut de capturer l'animal qui venait ainsi entraver ses chances de succès. Il fit une forte trappe qu'il tendit; mais le Pécan car-c'en était un-au lieu d'entrer dans la trappe par le bas, grimpa par dessus, y entra et dévora l'appât. Un fusil fut tendu, mais sans succès ; alors le chasseur résolut de placer, au milieu du sentier, un gros piège qu'il dissimula soigneusement ; il disposa ensuite des appâts de chaque côté, de distance en distance. D'après la grandeur des pistes, il était sous l'impression que ce pouvait être un petit carcajou qui lui causait tout ce trouble, aussi il fut très surpris de trouver le lendemain un Pécan pris au piège. L'animal se défendit comme un chat enragé, mordant le piège, et essayant de mordre le chasseur à la jambe. (I)

On dit que le Pécan, doué d'une grande force musculaire, s'attaque an raton; on prétend même que là où il se rencontre, les ratons sont rares et que, lorsque ces derniers sont communs, on est sûr de n'y point trouver de Pécans.

(I) Coues, Fur-bearing animals. p. 7.3. 
Le Pécan est d'une nature morose, intraitable et, lorsqu'il est fâché, il gronde, mord, montre ses dents et crache; il hérisse son poil et fait le dos rond à la manière du chat domestique. Il est nocturne, mais on peut le voir aussi durant le jour.

On prétend qu'il ne met bas qu'une fois dans l'année, de deux à quatre petits; il recherche à cet effet un arbre creux dont l'entrée est située souvent à trente ou quarante pieds du sol; c'est là aussi qu'il fait sa demeure.

\section{Genre LUTREOLA, Wagner.}

Formule dentaire. $-i \cdot \frac{3-3}{3-3} c \cdot \frac{1-1}{1-1} p m \cdot \frac{3-3}{3-3} m \cdot \frac{1-1}{2-2}$

Taille petite, corps allongé et cylindrique ; queue ordinairement longue; jambes courtes ; oreilles courtes et rondes ; museau court ; molaire antérieure d'en bas sans tubercule interne. Digitigrades; partie nue du dessous des doigts peu apparente; doigts palmés; queue touffue; pelage ordinairement court et fourni.

\section{Lutreola vison, (SCHREBER).}

Le Vison ordinaire.

Pelage épais, lustré et soyeux, d'un brun foncé presque noir sur la queue; une tache blanche au menton; de petites taches également blanches se voient souvent sur la gorge, la poitrine et le ventre. Doigts adaptés pour la vie aquatique. Longueur, 17 ; queue, $8 \mathrm{~s} / 2$.

I.e Vison habite l'A mérique du Nord. On le rencontre dans tous les endroits où il peut se procurer 
de la nourriture; il fréquente le bord des rivières, des lacs et des étangs; il est excellent nageur et il plonge avec la plus grande facilité ; il peut demeurer sous l'eau un temps assez long. Cet animal répand une odeur fétide, sécrétée par des glandes spéciales.

Il se nourrit d'oiseanx, de grenouilles, de poissons, d'œufs, de mollusques, de petits mammifères, et de rats-musqués qu'il poursuit sous l'eau jusque dans leurs terriers où il les tue.

Lorsque le Vison se trouve dans le voisinage de quelque ferme, il ne manque pas de rendre visite aux petits animaux de la basse-cour, et il arrive souvent que des méfaits imputés aux belettes ont eu le Vison pour auteur. Il détruit beaucoup de poisson dans les rivières et dans les lacs. Audubon a vu un Vison poursuivre sous l'eau une grosse truite, et quelques minutes plus tard, reparaître avec le poisson dans sa gueule. Le même auteur a également vu un Vison chasser des rats et les traîner par le cou, à la manière des chats; il a même été témoin qu'un de ces carnassiers s'était attaqué à des canards domestiques qui prenaient leurs ébats dans un étang.

Un fermier de l'état de l'Illinois rapporte qu'en I887: un Vison s'introduisit dans son poulailler et, dans une seule nuit, y tua dix-huit poules; ce poulailler était situé à environ quarante verges d'un grand marais où ces animaux étaient communs; l'hiver précédent le fermier avait perdu plus de cent volailles égorgées par ces maraudeurs. 
Il avait mis couver une poule cochinchinoise, dans une étable, et un matin il vit rôder un Vison près de cet endroit; quelques jours plus tard, visitant le nid de la poule, il ne trouva plus qu'un seul œuf, les autres étaient disparus; le lendemain c'était le tour de la poule. Cherchant alors où elle pouvait se trouver, il l'aperçut bientôt à l'entrée d'un trou: elle était morte et portait au cou une profonde blessure. Le Vison fut tué le lendemain, à cet endroit. On trouva non loin de là, dans un nid, cinq petits Visons, et presque tous les œufs volés et qui étaient encore intacts. (I)

Comme la plupart des carnassiers, le Vison est un animal nocturne, qui chasse tout de même aussi bien le jour. C'est un fin voleur, et plus d'un pêcheur s'est fait enlever le poisson qu'il capturait lorsqu'il ne prenait pas le soin de le mettre hors de son atteinte.

Le Vison est très fort pour sa taille, et par conséquent, il est plus à redouter des fermiers que la belette, quoique toutefois cette dernière ne soit pas une voisine à tolérer. Enn effet, tandis que le Vison cesse de tuer lorsque sa faim est apaisée, la belette au contraire, toujours altérée de sang, tue sans jamais se rassasier.

Il est étonnant de constater combien le Vison a la vie dure, comparé aux animaux de sa taille. "Il vit plusienrs leures, dit Coues-dans quelques cas

(I) Report of the Commissioner of Agriculture, Washington. ISS9, p. 489 . 
à ma connaissance, plus d'un jour et une nuit-sous la pression d'un bloc de bois très pesant, le tenant enserré comme dans un étau, et ayant le milieu du corps complètement aplati. Néanmoins, dans ces conditions, il montra encore beaucoup de ré:istance quand on l'approcha.

"Lorsqu"il est pris par une patte, dans un piège, il ronge et déchire le membre captif, le lacérant d'une manière pénible à voir; mais ce qui est singulier à constater, c'est qu'il mord le membre au delà des mâchoires du piège ; ce fait ne paraît pas être un moyen bien intelligent de recouvrer sa liberté, mais c'est plutôt un acte de furie aveugle déterminée par le fait de se sentir prisonnier...

"Les efforts de violence et de résistance que fait pour s'échapper ce pauvre animal ainsi torturé, sont démontrés par l'état de ses dents fréquemment cassées contre le piège ; c'est plutôt la règle que l'exception. Celui qui n'a pas pris de Vison au piège, peut à peine se faire une idée de la terrible expression que prend la face de l'animul à l'approche du trappeur. Cela m'a toujours frappé comme étant à peu près l'expression la plus diabolique que j'aie encore vue dans la physionomie animale; un regard fixe et sombre de l'animal accroupi et sans mouvement, fait place à un nouvel aspect de surprise et de crainte, accompagné des contractions du corps les plus violentes, avec un nouvel essai de mordre le piège, jusqu'à ce que, épuisé, haletant et la gueule ouverte, écumante de bave, l'animal s'abat de nou- 
veau et surveille d'un regard de haine concentrée, mêlé de rage impuissante et de désespoir horrible.

- La physionomie du Vison, sa tête large et aplatie ses oreilles courtes, ses petits yeux, son nez pointu, ses dents formidables, offrent toujours l'expression des passions les plus basses et les plus brutales, qui se montrent surtout dans ces moments-là. Comme on peut le supposer, lorsqu'il est dans une telle colère il faut l'approcher avec précaution." (I)

Audubon dit que le Vison s'apprivoise facilement, qu'il est très gentil, et qu'il est susceptible d'attachement à ses maîtres. Il peut être laissé en liberté ; il fait alors des excursions au dehors, dans les marais, et revient toujours vers son maître. Il s'accorde bien avec les chiens et les chats du foyer, et il n'attaque jamais les oiseaux de basse-cour.

La femelle met bas de bonne heure en mai de quatre ou cinq petits; son nid, qui est ordinairement tapissé de plumes d'oiseaux, est placé dans un tronc d'arbre creux ou autre endroit analogue. Les petits accompagnent leur mère jusqu'à l'automne.

Lorsque cet animal est dans l'eau, on dit qu'il plonge aussitôt qu'il aperçoit la flamme d'un fusil, et avant que le plomb soit arrivé à lui ; mais comme il se capture bien facilement au piège ou à la trappe, c'est de cette manière que l'on s'en empare, afin de ne pas détériorer par le plomb la peau qui a une certaine valeur commerciale.

(I) Coues. Fur-bearing animals, pp. 175-176. 


\section{Genre PUTORIUS, Cuvier.}

Endroit nu du dessous des doigts apparent ; doigts libres ; queue déliée. Les autres caractères sont les mêmes que ceux du genre précédent.

Ces petits animaux sont les plus féroces de toute la famille et, si leur taille secondait leur appétit sanguinaire, ils se rendraient plus redoutables que les félins ; leurs ongles forts et acérés leur permettent de grimper sur les arbres et de marcher le long des murs. Ils rôdent souvent autour des habitations, cherchant à pénétrer dans les basses-cours, et une fois qu'ils y sont entrés, tout ce qui a vie est immolé : poules, canards, pigeons, lapins, et rats même, rien n'échappe à cette soif innée de destruction.

\section{Putorius noveboracensis, Emaoxs. La Belette hermine.}

Parties supérieures d'un brun châtain ou roussâtre, en été, avec le dessous du corps blanc, lavé parfois de jaune souffre. Dans les régions froides, en hiver, tout le pelage devient blanc, plus ou moins teinté de jaune souffre aux parties postérieures, et, au printemps, l'animal reprend sa livrée d'été. Le bout de la queue est noir en toute saison. Longueur, 8 ; queue, 3 .

Cette Belette se rencontre dans l'Amérique septentrionale, depuis le nord où la vie des petits mammifères est possible, et au sud jusque dans les Etats-Unis du nord.

Le Dr Coues prétend que cette espèce se rencontre également en Europe et en Asie. 
Elle se plaît dans les lieux habités et les champs, aussi bien que dans la forêt; grâce à sa petite taille, elle trouve partout un abri contre ses ennemis, en se logeant dans un tronc d'arbre creux, dans des tas

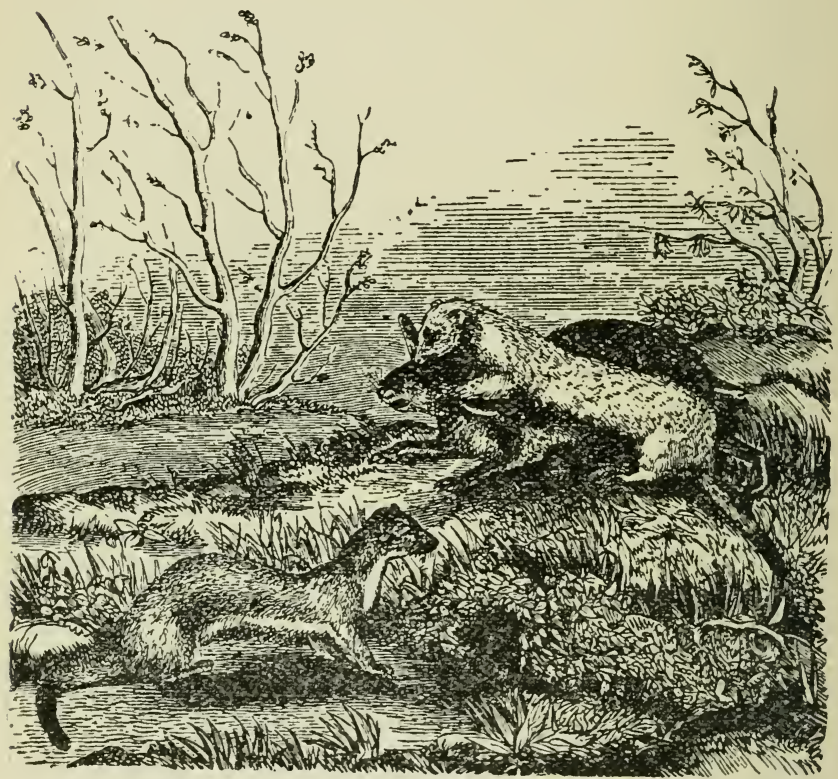

Fig. 30.-I, Belette hermine.

de pierres, dans des trous de rats, dont elle égorge les habitants, dans des granges, des greniers, des caves ; elle est partoat chez elle et partout en sûreté. Lors que tout est tranquille dans son canton, elle 
sort souvent le jour à la recherche de sa proie ; c'est alors qu'on peut la voir parfois "se glisser à travers les herbes, les buissons, entre deux sillons, s'arrêter le cou tendu, la tête haute, regardant, écoutant, disparaissant subitement dans un trou pour se montrer presque aussitôt un peu plus loin à moitié engagé dans un autre trou."

Pas un petit animal n'est en sûreté dans le voisinage d'une Belette; elle poursuit sa proie jusque dans sa retraite; elle égorge les oiseaux, surtout les gallinacés, qu'elle surprend à terre ou dans le feuillage à la faveur des ténèbres de la nuit.

"Gracieuse dans sa forme, dit Audubon, vive dans ses mouvements et d'une ardeur infatigable, elle est en même temps une petite créature brave et intrépide; confiante et se croyant en sécurité à travers les sinuosités de sa retraite, au milieu des blocs de bois ou des tas de pierres, elle nous laisse approcher jusqu'à quelques pieds d'elle et alors subitement retire la tête; nous demeurons encore un moment, et elle revient de nouveau à l'endroit de ses observations, surveillant avec curiosité cliacun de nos mouvements, semblant vouloir se plaire en notre compagnie aussi longtemps que nous nous abstenons de lui faire aucun mal.

"Néanmoins, avec tous ces attraits extérieurs, cette petite Belette est féroce et sanguinaire, ayant une inclination naturelle de détruire tout animal qu'elle rencontre, dont quelques-uns, tels que le lièrre d'Amérique, la perdrix des bois francs, les pou- 
les domestiques, ont dix fois sa taille. Ce petit animal est un destructeur notoire des habitants des poulaillers, et il est à notre connaissance que quarante volailles furent tuées en une nuit par une seule hermine. Rassasiée probablement avec le sang d'une poule, ce qui reste, semblable au troupeau égorgé par le loup dans la bergerie, est détruit par elle pour satisfaire un instinct de destruction inné chez cette espèce. Nous avons suivi sur la neige l'empreinte des pas de l'un de ces petits suceurs de sang, à la poursuite d'un lièvre d'Amérique; bien qu'elle ne pût le rejoindre par une vitesse supérieure, le timide lièvre dut toutefois se réfugier bientôt dans le creux d'un arbre ou dans un trou creusé par une marmotte ou par une moufette. Là il fut atteint par la belette qui le tua; le peau et autres restes du lièvre trouvés à l'entrée du trou attestaient la véracité de ce fait.

"Nous avons constaté qu'une hermine, après avoir capturé un lièvre de l'espèce ci-dessus mentionnée, lui enleva d'abord la tête et traîna ensuite le cadavre sur la neige nouvellement tombée, dans laquelle elle le cacha, et qu'elle foula cet endroit. Par cet acte, le petit marandeur nous fit découvrir une habitude que nous ignorions jusque là, et pour éviter un chien qui la poursuivait de près, il monta dans un arbre à une hauteur de vingt pieds, et se blottit sur une branche, où il fut tué.

"Nous avons plus de cent fois constaté avec succès, par des expériences, que l'Hermine, est suscep- 
tible d'être utilisée à la manière du furet d'Europe, pour faire sortir le lièvre d'Amérique du terrier dans lequel il s'est réfugié. Dans une de ces occasions, l'Hermine dont on s'était servi avait été capturée depuis quelques jours seulement; on lui avait limé les canines afin de l'empêcher de tuer le lièvre; on lui avait aussi attaché une corde au cou pour s'assurer son retour. Elle poursuivit le lièvre à travers les sinuosités de son trou et le força à revenir à l'entrée du terrier où il put être capturé avec la main ou dans un filet.

"En hiver, la perdrix a l'habitude de s'enfoncer dans la neige molle et d'y demeurer parfois un ou deux jours ; l'Hermine la découvre souvent et la met à mort.

"Malgré ces habitudes destructives et nuisibles, il est douteux si l'Hermine n'est pas plutôt une bienfaitrice qu'une ennemie pour le fermier, chassant de ses greniers et de ses champs un grand nombre de destructeurs des produits de son travail, qui dévoreraient dix fois la valeur des volailles et des œufs que, à la longue et par intervalle, dans l'occasion, elle peut détruire. Elle semble avoir un rôle à remplir, assigné par la Providence : celui de restreindre la trop grande multiplication des souris et autres petits rongeurs...

"Là où une Hermine a fixé sa demeure, on s'aperçoit de suite que les souris et autres rongeurs diminuent rapidement, et cela jusqu'à un demi 
mille à la ronde; leur active ennemie, avec son corps fin et délié, est apte à pouvoir pénétrer dans leurs trous; aussi elle les poursuit jusqu'à l'extrémité de leurs galeries et elle détruit la famille entière. En plusieurs occasions, après une légère couche de neige, nous avons pu suivre la piste d'une Belette à travers les champs et les prairies, et nous avons été témoin de l'immense destruction de petits animaux opérée par elle en une seule nuit. Elle pénètre dans chaque trou situé soit sous des souches, sous des tas de bois, sous des amas de roches ou sous les clôtures, et on constate ses actes sanguinaires par les restes mutilés des rongeurs que l'on trouve épars sur la neige. Le petit suisse $T$. lysteri, fixe sa demeure dans le voisinage des champs de grain, et l'on sait qu'il transporte dans ses abajoues, de grandes quantités de blé et de sarrasin pour sa provision d'hiver. Instinctivement l'Hermine découvre ces retraites confortables, et dans l'espace de quelques minutes elle détruit toute la famille de ces beaux petits Tamias, sans même se reposer un instant, jusqu'à ce qu'elle ait consommé cette abondante nourriture du moment; sa soif ardente de sang n'étant pas encore satisfaite, comme si elle était poussée par une destinée irrésistible, elle cherche d'autres sujets sur lesquels elle puisse satisfaire cette soif insatiable de sang.

"Le rat et la souris de maison se logent dans nos granges, sous des tas de gerbes de blé, dans les greniers, et détruisent de grandes quantités de grain. 
Dans certains cas, le fermier est forcé malgré lui de payer plus qu'une dîme, pour contribuer à la nourriture de ces petits malfaiteurs; mais qu'une Hermine pénètre dans ces granges ou ces greniers et qu'elle y fasse son séjour d'hiver, la destruction des rats et des souris sera bientôt chose apparenite. L'Hermine les poursuit jusque dans leurs retraites les plus profondes et, dans quelques semaines, ces lieux sont entièrement débarrassés de ces animaux.

"Un jour nous avions mis une Belette à demi apprivoisée, dans une bâtisse isolée qui était infestée par des rats, et nous avions bouché toutes les issues afin de les empêcher de s'échapper. Le petit animal commença son œuvre de destruction. Les cris des rats furent entendus pendant toute la journée, et le soir elle sortit de là se léchant la bouche comme un chien courant, après une longue chasse; elle semblait très fatiguée. On enleva une planche du pavé, afin de constater le résultat de notre expérience et nous vîmes un nombre considérable de rats qui, quoique tués dans différentes parties de la bâtisse, avaient été traînés à un seul endroit, formant ainsi un amas compact. Dans ces circonstances l'Hermine est certainement très utile aux fermiers. (I)

L'Hermine vit solitaire dans son gîte. On affirme qu'en hiver elle fait des chemins sous la neige afin de communiquer d'un trou à l'autre, et Audubon

(I) Audubon. Quadrupeds of N. A. Vol. 2. pp. 59-60. 
entr'autres, dit qu'il a fréquemment vu des galeries pratiquées dans la neige, communiquant d'un trou à un autre, et cela sur une longueur de vingt à trente verges, préférant passer à travers la neige plutôt que de voyager à sa surface.

Quoique l'Hermine se voit très souvent durant le jour, elle n'en est pas moins un animal nocturne, et c'est vers le soir surtout qu'elle fait preuve d'une grande activité; elle examine tous les endroits de son canton, s'arrête devant un trou de mulot ou de souris, inspecte les tas de roches, les amas de bois, en quête de nourriture, et si un petit animal s'y rencontre il est bien vite étranglé.

Elle se nourrit de petits mammifères, de poules, de lièvres, d'œufs, d'oiseaux, etc.

Audubon prétend que la Belette fuit l'eau et que si elle est forcée de nager, elle le fait avec la maladresse d'un chat ; il dit aussi qu'elle ne poursuit point les animaux dans les arbres, elle n'y grimpe que lorsqu'elle est serrée de près, comme par le chien, son implacable ennemi. Toutefois, l'opinion contraire est pourtant maintenue par des naturalistes, qui citent à ce propos plusieurs faits établissant que la Belette nage et grimpe avec facilité.

La femelle met bas en avril ou mai dans un trou sous terre, sous des racines d'arbres,', dans un tas de pierres ou encore dans un tronc d'arbre; ses petits sont au nombre de quatre ou cinq. On prétend que la mère défend sa progéniture avec beaucoup d'éner- 
gie et qu'il est bien difficile de la chasser ; elle suit même très longtemps le ravisseur de ses petits.

On capture bien facilement la Belette avec des pièges ou des trappes de différentes sortes.

L'Hermine, prise jeune, s'apprivoise facilement ; on cite des exemples d'individus qui suivaient leurs maîtres comme de petits chiens; on leur laissait leur entière liberté et elles sortaient et entraient à volonté.

\section{Putorius cicognani, (BONAPAR'TE).}

\section{La petite Belette.}

Coloration à peu près semblable à celle de la précédente, d'un brun roux en dessus, et blanc pur en dessous, rarement teinté de jaune; la queue est déliée, cylindrique avec l'extrémité à peine noirâtre. Longueur, 6 à 8 ; queue, 2.

On assigne à cette petite espèce, comme sphère d'habitation, le nord de l'Amérique septentrionale, au sud, jusqu'au Long Island, et le Dr Coues dit qu'elle se voit depuis le nord des Etats-Unis vers le nord, ainsi que dans le nord de l'Europe et de l'Asie.

Cette Belette a à peu près les mêmes mœurs que la précédente. DeKay et Audubon nous disent qu'elle possède le même instinct carnassier qui distingue sa famille; mais il faut avouer qu'on ne connaît que bien peu de choses sur ses habitudes.

Faute de connaissances suffisantes de cette Belette par des auteurs américains, je citerai ce qu'en dit un naturaliste européen, M. Bell, qui a étudié les 
mœurs de cette espèce. "Je ne voudrais pas certifier, dit cet auteur, que la Belette, pressée par la faim, ne s'attaquera pas avec audace aux volailles, ou dans l'occasion, qu'elle ne s'emparera pas d'un jenne lièvre ou d'une perdrix endormie, mais sa proie ordinaire consiste en animaux d'une nature plus humble, ce qui est prouvé par des observations constantes. Souris de toutes espèces, campagnols terrestres et aquatiques, rats, taupes et petits oiseaux font sa nourriture ordinaire.

" D'après des rapports d'observateurs now préjugés, il paraîtrait que ce joli petit animal devrait être protégé comme destructeur de vermine, plutôt que d'être exterminé comme déprédateur nuisible. Mais surtout il ne devrait pas être molesté dans les granges, les greniers et les amas de gerbes de grain, où il rend de grands services en détruisant des colonies de souris qui les infestent. Ceux-là seulement qui ont été témoins du nombre prodigieux de ces petites pestes qu'on trouve surtout dans les tas de gerbes de blé, et qui ont vu de quelle manière l'intérieur en est troué dans toutes les directions par leurs galeries, peuvent comprendre toute l'étendue de leurs déprédations, et sûrement le vol d'occasion d'un poulet ou d'un petit canard, même en supposant qu'on pourrait l'attribuer à la Belette plus souvent qu'on ne le peut réellement, ne serait qu'une bagatelle comparée au bénéfice qu'on en retire par la destruction de ces multitudes de petits voleurs. "La Belette grimpe sur les arbres avec une grande 
facilité ; elle surprend les oiseaux dans leurs nids, enlève les jeunes, ou mange les œufs. On a prétendu qu'elle attaquait et détruisait les petites couleuvres, mais je crois que ceci est erroné. J'en ai fait l'expérience en mettant une Belette avec une couleuvre ordinaire, dans une grande cage, dans laquelle la première pouvait se retirer dans une petite boîte où elle avait l'habitude de dormir. La crainte mutuelle des deux animaux les tint à une distance respectueuse l'un de l'autre. Néanmoins, la couleuvre montrait tout autant de disposition à attaquer que son fort compagnon; la Belette donnait de temps à autre de légers coups de dents à la couleuvre, soit sur un côté du nez, soit sur l'autre, sans trop la blesser et sans aucun désir évident de s'en nourrir. Enfin après les avoir laissés ainsi penđant deux ou trois heures ensemble, voyant qu'en définitive ils paraissaient indifférents l'un à l'autre, je pris le pauvre serpent et le tuai.

"La conduite de la Belette fut bien différente lorsque je mis une souris dans sa cage : elle sortit à l'instant de sa petite boîte et d'un seul coup de dents sur la tête, elle fit jaillir la cervelle de la souris, la faisant mourir à l'instant, sans qu'elle fit aucune résistance. J'ai remarqué que quand la Belette s'empare d'un petit animal, au moment où elle inflige la blessure fatale, elle exerce avec son corps long et souple, une pression sur sa proie, comme pour s'en assurer, dans le cas où le premier coup de dents 
n'aurait pas réussi ; incident que je n'avais encore jamais remarqué.

"La faculté qu'a Belette d'incliner la tête à angle droit avec son cou long et flexible, quoique fort, lui est d'un grand avantage dans son mode de tuer de petites proies. Elle prend aussi fréquemment cette position lorsqu'elle s'élève sur ses pattes de derrière pour regarder autour d'elle.

"L'habitude qu'on a attribuée à la Belette de sucer le sang de sa victime est, je crois, beaucoup exagérée; quelques personnes ont nié l'existence d'un tel penchant, et suivant moi, en autant que j'ai pu le constater, mes expériences tendraient à confirmer cette réfutation de la croyance générale. Le premier coup est donné sur la tête ; dans les cas ordinaires, les dents pénètrent dans le cerveau, et le premier acte d'épicurisme de la Belette est de manger toute la cervelle; la carcasse est alors cachée près de son domicile, afin de pouvoir la retrouver au besoin ; mais il arrive souvent qu'une partie de cette carcasse demeure là jusqu'à ce qu'elle commence à se putréfier.

"La Belette poursuit sa proie avec facilité, dans les petits trous et à travers les herbes épaisses des buissons et des haies; elle poursuit la taupe et la souris des champs jusque dans leurs galeries souterraines; elle passe à travers les dédales que font, dans les meules de blé, les colonies de souris qui les infestent.

"Son corps allongé et souple, la longueur extra- 
ordinaire de son cou, son pelage serré, son extrême agilité et la vitesse de ses mouvements, tout est combiné pour s'adapter à de telles habitudes, auxquelles son flair aide beaucoup, qualité qu'elle partage à un égal degré avec l'hermine.

"Voilà pourquoi, en poursuivant un rat ou une souris, la Belette ne le poursuit pas seulement aussi longtemps qu'elle le voit, mais elle continue encore à le poursuivre lors même qu'il est disparu de sa vue, élevant quelque peu la tête au-dessus du sol pour suivre la trace de la proie qu'elle convoite. Vient-elle à perdre sa trace, elle retourne au point où elle l'a perdue, elle cherche en flairant dans les environs jusqu'à ce qu'elle la retrouve, et ainsi, à force de persévérance, elle finira par rejoindre un animal d'une plus grande vitesse qu'elle. Mais ceci n'est pas tout ; dans la tenacité qu'elle déploie à la poursuite de sa proie, elle n'hésitera pas à se lancer à l'eau, car elle nage avec facilité.

"Néanmoins elle est quelquefois la proie de l'épervier. Mais le fait suivant démontre que la violence et la rapine, même quand elles sont accompagnées d'une force supérieure, ne sont pas toujours l'égal de l'ingénuité d'un ennemi inférieur. Un individu du nom de Pinder, résidant alors à Bloxworth, dans le Dorsetshire, parcourant à cheval ses terres, vit, à une petite distance de lui, un milan se lancer à terre sur quelqu'objet, et s'envoler avec cet objet dans ses serres. Cependant, quelques minutes après, le milan commença à manifester des signes d'inquié- 
tude, s'élevant rapidement dans l'air ou s'abaissant avec la même vitesse, tournoyant d'une manière irrégulière, essayant en même temps avec ses pattes à se débarrasser de quelque chose de désagréable. Après une lutte courte mais vigoureuse, le milan tomba subitement à terre, non loin de l'endroit où M. Pinder observait attentivement ce spectacle; il se rendit aussitôt sur les lieux et vit une Belette quitter le milan et s'enfuir en courant, sans blessure apparente, laissant l'oiseau mort, avec un trou dans les chairs, sous l'aile." (I)

Un autre fait analogue, raconté par John Franklin, fut constaté en Ecosse par des cultivateurs, qui virent un aigle tenant une Belette dans ses serres, s'élever dans l'espace; mais bientôt après ils remarquèrent que l'oiseau agitait ses ailes d'une manière inaccoutu. mée. Ils continuèrent à l'observer jusqu'à ce qu'ils l'eurent perdu de vue; peu après, il le virent descendre avec vitesse vers la terre frappant l'air de ses ailes avec des mouvements rapides et irréguliers ; puis s'affaissant sur le sol, près des observateurs qui, curieux de savoir ce qui se passait, se rendirent auprès de l'oiseau qui venait de rendre le dernier soupir. Au même moment ils virent une Belette se dresser sur ses pattes de derrière, les regarder, puis tout à coup quitter l'oiseau et se sauver dans un buisson voisin. La Belette avait réussi à s'échapper des serres de l'oiseau, et lui avait fait une profonde blessure au cou, d'où le sang jaillissait encore.

(I) Bell. Hist. of British quadrupeds, pp, I42-I45. 
La femelle met au monde de quatre ou cinc petits, qu'elle dépose dans un nid tapissé d'herbes et de feuilles desséchées; ce nid est ordinairement situé dans un tronc d'arbre creux; dans un trou creusé en terre ou sous des racines d'arbres. On dit qu'elle met bas deux ou trois fois dans l'année.

\section{Familte CANIDE. Loups, RENARDS.}

Formule dentaire typique $-i \cdot \frac{3-3}{3-3} c \cdot \frac{1-1}{1-1} p m \cdot \frac{4-4}{4-4} m \cdot \frac{2-2}{3-3}$.

Les Canidés sont des animaux digitigrades ; leurs membres antérieurs sont terminés par cinq doigts dont un, le pouce, est rudimentaire, et les postérieurs, par quatre; les ongles sont non rétractiles, à pointe émoussée, résultat de leur contact habituel avec le sol, ne pouvant servir à l'attaque ni à la défense; leurs membres sont de longueur ordinaire; le museau est allongé; la langue est douce et molle; le poil est long; la queue est plus ou moins touffue.

Ces animaux ne grimpent point; ils vivent pour la plupart en société et ils capturent leur proie à la course; ils se nourrissent particulièrement de chair animale; ils ne dédaignent pas les charognes et dans certains cas, ils se contentent d'une nourriture végétale.

Les Canidés ont en général des mœurs sociables ; ils sont sans contredit les plus intelligents de tous les carnassiers; ils font preuve, dans tontes leurs actions, d'une prudence extrême que la faim même ne saurait leur faire oublier. Leurs sens sont très développés, particulièrement celui de l'odorat. Sans 
parler des preuves manifestes de sagacité que nous donne le chien domestique, qui ne connaît les ruses du loup et l'astuce du renard lorsqu'il s'agit de s'assurer d'une proie, ou pour se soustraire à un danger?

On rencontre parmi les Canidés des espèces diurnes, crépusculaires et nocturnes. Tous se plaisent dans des endroits solitaires, se creusent des terriers profonds ou se cachent au inilieu d'épaisses broussailles d'accès difficile, quelques-uns même n'ont pas de gîte et rodent presque continuellement, ne séjournant dans un endroit que pour donner des soins à leurs petits. On les rencontre dans toutes les parties du monde.

\section{Genre VULPES, Brisson.}

Tête assez grosse; museau allongé; queue longue et touffue ; corps plutôt délié ; pupille elliptique.

\section{Vulpes pennsylvanicus, (BODDAERT).} Le Renard roux.

Pelage de couleur fauve ou d'un brun roux vif et lustré, un peu plus foncé sur le dos et blanchissant sous le ventre, la gorge et l'extrémité de la queue; le devant de la poitrine est gris; le dessus des oreilles et la partie antérieure des pattes sont noirs. Longueur, 30 ; queue, I5.

On distingue deux variétés chez le Renard roux : l'une que l'on appelle Renard croisé, var. decussatus, (Desm.), porte une large bande de couleur foncée ou d'un brun noirâtre sur le cou et le dos, dans le sens de la longueur, et une autre de même teinte, 
qui la traverse à l'endroit des épaules; les parties inférieures ainsi que les pattes, sont noires. La seconde, le Renard argenté ou noir, var. argentatus, (Shaw), est de couleur noire avec le bout de la queue blanc. On voit souvent chez eux des individus dont la robe est plus ou moins parsemée de poils d'un gris argenté.

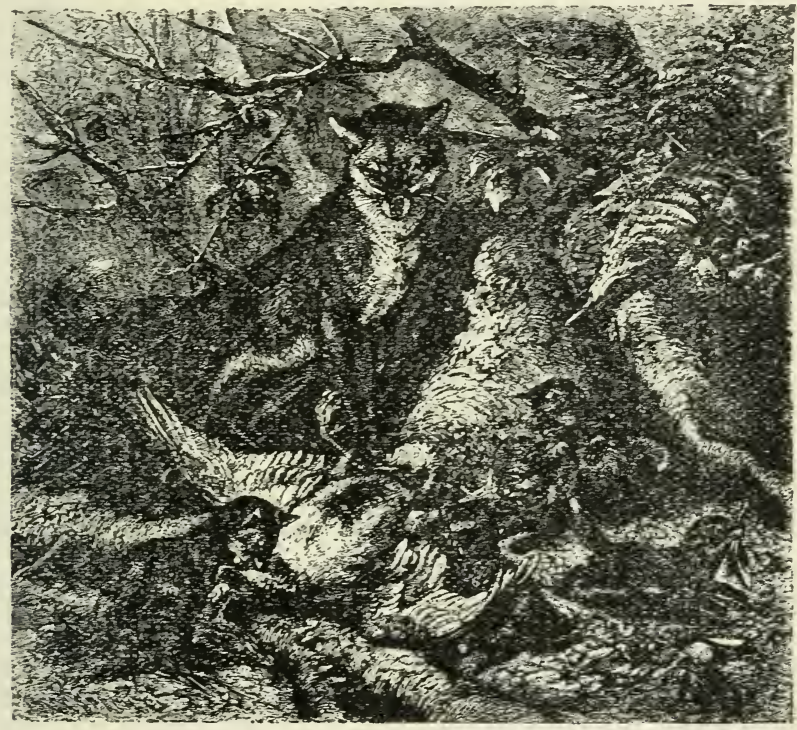

Fig. 31,-Le Renard roux.

On rencontre parfois des pelages intermédiaires entre ces deux variétés et celui du Renard roux.

Le Renard roux habite l'A mérique septentrionale, depuis le nord jusqu'au Texas. 
Notre Renard offre une ressemblance frappante avec le renard vulgaire de l'ancien continent, et il n'est peut-être pas illogique, comme le pensent certains auteurs, de supposer que cet animal, ainsi que le loup, le castor et quelques autres habitants du nord des deux continents, aient eu primitivement une origine commune et que dans la suite, en se répandant vers le sud, leur taille comme leur pelage, se soient quelque peu modifiés sous les influences climatériques.

Depuis très longtemps le Renard jouit d'une réputation de finesse qui a été redite sur tous les tons, et de fait, il n'y a peut-être pas un animal plus défiant, plus rusé et plus fécond en ressources. "Il est fameux, dit Buffon, par ses ruses et mérite sa réputation; ce que le loup fait par la force, il le fait par adresse, et réussit plus souvent ; il emploie plus d'esprit que de mouvement, ses ressources semblent être en lui-même, ce sont connme l'on sait, celles qui manquent le moins. Fin autant que circonspect, ingénieux et prudent, même jusqu'à la patience, il varie sa conduite, il a des moyens de réserve qu'il sait n'employer qu'à propos." (I)

Le Renard a des liabitudes nocturnes, il faut que la faim le presse beaucoup pour le décider à chasser durant le jour; il préfère plutôt se reposer de ses courses de nuit, dans d'épais fourrés à proximité de sa retraite, ou dormir dans son terrier; il arrive

(1) Buffon. Euvres compl. Bruxelles, 1856, Vol. 7 , p. 27. 
'quelquefois qu'on le surprend couché dans des endroits découverts, se chauffant au soleil.

C'est ordinairement à la tombée de la nuit que ce maraudeur se met en quête de proies; il parcourt sans bruit les buissons, les haies, les petites touffes de bois, rôde dans les champs ou dans la forêt avec l'espoir de surprendre quelques petits rongeurs nocturnes ou une perdrix sur ses œufs, ou bien encore de petits oiseaux qui dorment sur les branches inférieures des arbres; dès qu'il a aperçu ou flairé une proie, il s'en approche avec prudence et s'en empare avant même que celle-ci ait pu soupçonner la présence de son ravisseur.

Sa nourriture habituelle consiste en souris, mulots, lièvres et autres petits mammifères dont il sait très bien découvrir la retraite, guidé en cela par les sens excessivement développés chez lui de la vue, de l'odorat et de l'ouie, qui le servent aussi bien dans la recherche de sa nourriture que pour éviter un danger. Il mange aussi des grenouilles, des insectes et autres invertébrés, mais il ne touche que très rarement aux animaux morts; il en est de même d'un appât qu'on lui tend: il n'y touchera qu'après l'avoir flairé plusieurs fois, et s'il soupçonne quelque chose d'anormal, il le laissera plutôt pour courir à une autre proie.

I C'est particulièrement près des habitations, lorsqu'elles sont à proximité de sa demeure, qu'il aime à rôder, cherchant là des proies plus sûres et plus faciles à capturer, car il évite toujours de se mesurer 
avec un animal de sa taille et capable de lui résister; toutefois, s'il arrive qu'il soit obligé de se défendre contre des animaux plus forts que lui, il le fait avec beaucoup de courage et d'acharnement. C'est un grand destructeur de volailles ou autres petits animaux de basse-cour et si, dans ses courses nocturnes, le chant matinal d'un coq vient frapper son oreille, il se dirige de suite et avec précaution vers l'endroit d'où lui viennent ces sons, puis il fait le tour du poulailler ou de la grange, cherchant un passage pour pénétrer à l'intérieur, et s'il y a un trou, on peut être certain qu'il le trouvera, dût-il passer le reste de la nuit à le chercher. Si le passage est trop étroit, il l'agrandira ou se fera petit pour se glisser à l'intérieur, et une fois qu'il y est entré, il égorgera toute la gent emplumée, puis il transportera une à une ses victimes et les cachera à différents endroits dans la forêt, près de son gîte, pour se repaître de leur chair lorsqu'il aura faim.

Le Renard ne tue pas, à l'exemple des belettes, pour le seul plaisir de tuer, mais seulement par prévoyance et dans l'unique but de s'assurer une nourriture qu'il utilisera plus tard. Souvent aussi il se contente d'une seule proie qu'il saisit au passage pour la dévorer à loisir en lieu sûr, sauf à revenir au même endroit le lendemain ou quelques jours plus tard, se inettre à l'affût pour s'emparer d'une autre victime, car si rien ne le dérange il détruira ainsi petit à petit tous les oiseaux d'une basse-cour. Rien n'égale sa patience, il peut attendre 
pendant des heures, tapi dans sa cachette, suivant des yeux tous les mouvements de sa victime, attendant l'occasion de s'en emparer; ou bien il se traîne le long d'une haie, se glisse derrière un buisson, un tronc d'arbre, puis, parvenu à proximité, il s'élance sur sa proie et l'emporte dans le bois pour la dévorer à loisir.

Audubon parlant de la manière de chasser du renard gris, dit que le Renard roux emploie les mêmes moyens.

"Par une journée pluvieuse et froide, dit-i1, lorsque nous voyagions dans les Carolines, ayant vu dans un champ de genêt, un renard gris courant contre le vent et chassant comme un chien d'arrêt, nous nous arrêtâmes pour observer ses mouvements ; soudain l'animal s'assit sur son train de derrière, puis aussitôt il continua de nouveau à marcher, mais plus doucement et avec précaution, de temps en temps élevant le nez et sentant de côté et d'autre. Enfin, il sembla sûr de sa proie, avança en ligne droite et très doncement, se traînant parfois à terre ; de temps à autre il se trouvait caché par les herbes, de sorte que nous ne pouvions pas le voir bien distinctement. Cependant nous le vîmes s'arrêter enfin complètement; il ne faisait aucun mouvement horizontal de la queue comme le fait le chat domestique lorsqu'il se prépare à s'élancer sur sa proie, mais sa queue semblait toucher la terre tandis que ses oreilles étaient couchées en arrière et sa tête élevée de quelques pouces de terre; il demeura dans (I6) 
cette attitude presque une demi-minute, puis d'un bond il s'élança sur sa proie. A l'instant même nous entendîmes des battements d'ailes d'une couvée d'oiseaux effrayés, comme s'ils s'envolaient avec beaucoup de précipitation; deux ou trois cris perçants se firent entendre, et l'heureux maraudeur s'enfuit immédiatement à travers le champ avec une infortunée perdrix dans la gueule, dans l'intention évidente de chercher un endroit plus solitaire pour faire son friand repas. "Puis le même auteur, continuant, fait la réflexion suivante: "Nous avions un fusil et le renard passa à portée ; mais pourquoi le blesser ou le tuer? Il nous a mis à même, pour la première fois, de constater qu'il n'est pas seulement un chien, mais aussi un bon chien d'arrêt; il a obéi à une impulsion de la nature, et il s'est procuré un repas suivant le moyen dont le Créateur l'a doué pour pourvoir à sa subsistance. Il a saisi une seule perdrix; tandis que l'homme qui se vengerait sur ce voleur de gibier, n'est satisfait qu'après avoir tué la moitié de la couvée avec son fusil meurtrier, ou avoir capturé toute la couvée dans une trappe, puis lui avoir tordu le cou en signe de triomphe. Ne condamnez pas trop vite le Renard : il a une dent carnassière beaucoup plus prononcée que vousmêmes, faisant voir par là le genre de nourriture qu'il est obligé de chercher; il ne détruit pas les oiseaux pour le plaisir de tuer et n'exhibe pas à ses compagnons les trophées de son adresse ; mais il se contente d'un repas, tandis que vous n'êtes peut- 
être pas satisfaits, lors même que votre gibecière est remplie d'oiseaux. " (I)

Le Renard vit dans un terrier profond, à plusieurs issues, qu'il creuse le plus souvent à la lisière du bois, dans les taillis, et dont l'entrée principale se trouve presque toujours située sous des troncs d'arbres ou à travers des tas de roches; mais toujours sur un sol en pente afin d'éviter les inondations et l'humidité.

Le Renard se chasse de différentes manières : en le tuant au fusil à l'affût, en l'appâtant avec de la chair empoisonnée, ou encore au piège. Mais cet animal est si fin et son flair est si subtil, qu'il faut toute la tactique d'un habile chasseur pour s'en emparer. L'hiver est le meilleur temps pour lui faire la chasse, parce qu'alors la nourriture est beaucoup plus rare qu'en été, et il donne plus facilement dans les pièges qu'on lui tend.

La femelle met bas dans son terrier de quatre à six petits, de bonne heure au printemps. Les jeunes ont un poil laineux d'un gris roux pâle. Pris jeune, le Renard s'apprivoise facilement, il joue même avec son maître si celui-ci s'occupe beaucoup de lui.

\section{Vulpes lagopus, Linvé. Le Renard arctique.}

Le Renard arctique a les oreilles courtes et arrondies; la queue très touffue; le pelage, qui varie, est ordinairement brun ou gris de plomb en été, et entièrement blanc

(I) Audubon. Quadrupeds of N. A. Vol. I. p. 165 
en hiver, pour la plupart. Sa taille est plus petite que celle du précédent.

Cet animal habite les régions arctiques des deux continents, et, en Amérique, il émigre au sud jusqu'au 53e degré de latitude ; on l'a même vu en hiver en grand nombre jusque sur la côte du Labrador.

Le Renard arctique que l'on nomme aussi Renard bleu et Renard blanc, diffère de l'espèce précédente par sa forme, ainsi que par ses habitudes; ses pattes sont courtes; son museau est obtus, et son pelage est plus fourni.

Ses oreilles courtes et rondes le feraient prendre, à première vue, pour un petit chien plutôt que pour un renard.

Ses habitudes, dont il est l'esclave, sont aussi différentes. Tandis que le renard roux est farouche, difficile à capturer, fin, sachant profiter de son expérience pour éviter un danger ou pour se procurer une proie, le Renard arctique, an contraire, est sot et importun; il se fera tuer à coups de bâton; il retournera de nonveau dans les mêmes pièges, les mêmes embûches d'où il se sera échappé une première fois; et s'il faut en croire les récits de certains voyageurs, on aurait même fait feu sept fois, à la brunante, sur un individu qui suivait des chasseurs, avant qu'il songeât à changer de direction.

Le navigateur Steller rapporte que, lors de son séjour à la terre de Behring, ces animaux étaient 
d'une audace incroyable, qu'ils pénétraient dans leurs habitations, dévoraient ou enlevaient, pour les cacher dans la terre ou dans la neige, suivant le cas, tous les objets qu'ils rencontraient, alors même que ces objets ne leur étaient d'aucune utilité, et que rien ne pouvait être placé en dehors de leur atteinte; ils grimpaient sur leurs cabanes, sur des tonneaux ou autres endroits élevés pour en dérober les provisions de bouche, et cela avec un t 1 art que tout d'abord Steller ne songeait pas même à les accuser de rapine. Ils étaient sur pied aussi bien le jour que la nuit.

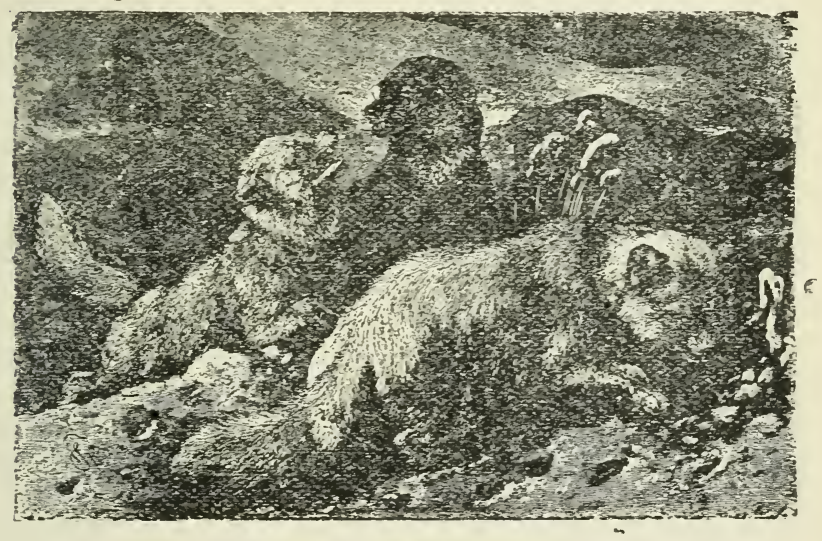

Fig. 32.-Le Renard arctique.

Lorsque Steller et ses gens dormaient en plein air, les Renards venaient les flairer pour s'assurer s'ils vivaient, et lorsqu'ils retenaient leur respiration, ils essayaient de les mordre à la figure. Armés 
de couteaux ou de bâtons, ils allaient se placer près d'un cadavre de phoque ou autre animal que la mer rejetait sur le rivage et aussitôt que les Renards en flairaient les émanations, ils arrivaient en grand nombre pour les manger. Alors avec ces armes ils les tuaient tous sans qu'aucun prit la fuite. "Nous creusions un trou, dit-il, dans lequel nous jetions de la viande ; à peine avions-nous les talons tournés, que déjà le trou était plein de renards qu'il nous était facile d'assommer à coups de bâton. Nous ne tenions aucun compte de leur belle fourrure, nous ne les dépouillions même pas, cependant nous étions avec eux en guerre continuelle comme avec nos plus grand ennemis. Tous les matins, nous traînions par la quene, devant la caserne, sur la place d'exécution, ceux que nous avions pris vivants; aux uns, on leur coupait la tête, aux autres on leur brisait les membres, à d'autres encore on leur crevait les yeux, ou bien on les pendait deux à deux par les pieds, et ils se mordaient alors l'un l'autre jusqu'à la mort ; on brûlait les uns, on faisait périr les autres à coups de fouet. Le plus amusant était d'en tenir un par la queue, et de la lui couper tandis qu'il tirait de toutes ses forces pour se sauver, il faisait alors quelques pas et tournait plus de vingt fois en rond. Cela ne ne les éloignait cependant pas de nos habitations, et finalement on en vit dans l'île un grand nombre sans queue, ou courant sur deux ou trois pattes. " (I)

(1) Brehm. Les Mammiferes. Vol, 1, pp. 525-526. 
Cette manière cruelle et barbare de martyriser ainsi de pauvres animaux, trouve encore trop souvent des imitateurs.

Comme ces Renards se trouvaient là en si grand nombre, ils devaient nécessairement souffrir beaucoup du manque de nourriture dans ces parages inhospitaliers, et c'était sans doute l'extrême besoin qui les rendait si audacieux et si tenaces à se procurer de la nourriture.

Voici ce que nous dit encore le capitaine Lyons sur les mœurs de cet animal. "Le Renard arctique est un animal extrêmement propre, faisant bien attention de ne pas salir l'endroit où il mange et où il couche. Il n'exhale aucune mauvaise odeur, même chez le mâle, ce qui est un fait remarquable. Surprendre un de ces animaux est, dans mon opinion, chose impossible; car même lorsqu'ils dorment, au moindre bruit fait près deux, ils ouvrent les yelıx, quoique toutefois ils ne fassent pas attention aux bruits produits à une faible distance. D'ordinaire, ils se reposent le jour, pendant lequel ils semblent inattentifs; mais à peine la nuit arrive-t-elle que toutes leurs facultés sont éveillées, ils commencent leurs jeux et vont rapidement de côté et d'autre, cherchant leur nourriture, et restent en activité jusqu'au matin. Ils sont muets lorsqu'ils chassent, mais lorsqu'on les réduit en captivité ou quand ils sont en colère, ils font entendre de courts grognements semblables à ceux des jeunes chiens. Un fait singulier à constater chez eux, c'est leur gla- 


\section{$-248-$}

pissement qui est modulé de manière à nous donner l'idée que l'animal est à distance, tandis qu'au moment même, il est couché à nos pieds. • (I)

La femelle met bas vers le mois de mai de sept ou huit petits.

\section{Genre CANIS, Linné.}

La tête et le museau forment un cône tronqué au bout et assez régulier; la pupille est de forme circulaire; les incisives supérieures sont lobées des deux côtés; la queue, de longueur moyenne, est touffue; dents, quarante en tout.

\section{Canis nubilus, Say.}

Le Loup ordinaire.

Pelage variable, ordinairement gris, plus ou moins foncé suivant les individus; mélangé de roux, plus clair en dessous et plus foncé sur la ligne dorsale que sur les côtés du corps. Les poils du dessus du cou, du garrot et de la queue sont plus allongés que sur le reste du corps; le devant des pattes antérieures et les moustaches sont noirâtres ; la queue est mélangée de blanc, de noir et roux ferrugineux; les yeux sont verdâtres. Longueur, 4 pieds ; queue, i 5 pouces.

Le Loup habitait autrefois l'Amérique du Nord, depuis le golfe du Mexique jusqu'aux régions arctiques; mais la guerre acharnée qu'on lui a faite et les déboisements successifs des forêts, l'ont fait disparaître entièrement d'un bon nombre de localités; toutefois on le rencontre encore plus ou moins nombreux dans plusieurs parties des Etats-Unis du nord,

(1) Canadian Nat. \& Geol., Vol. I, p. 224. 


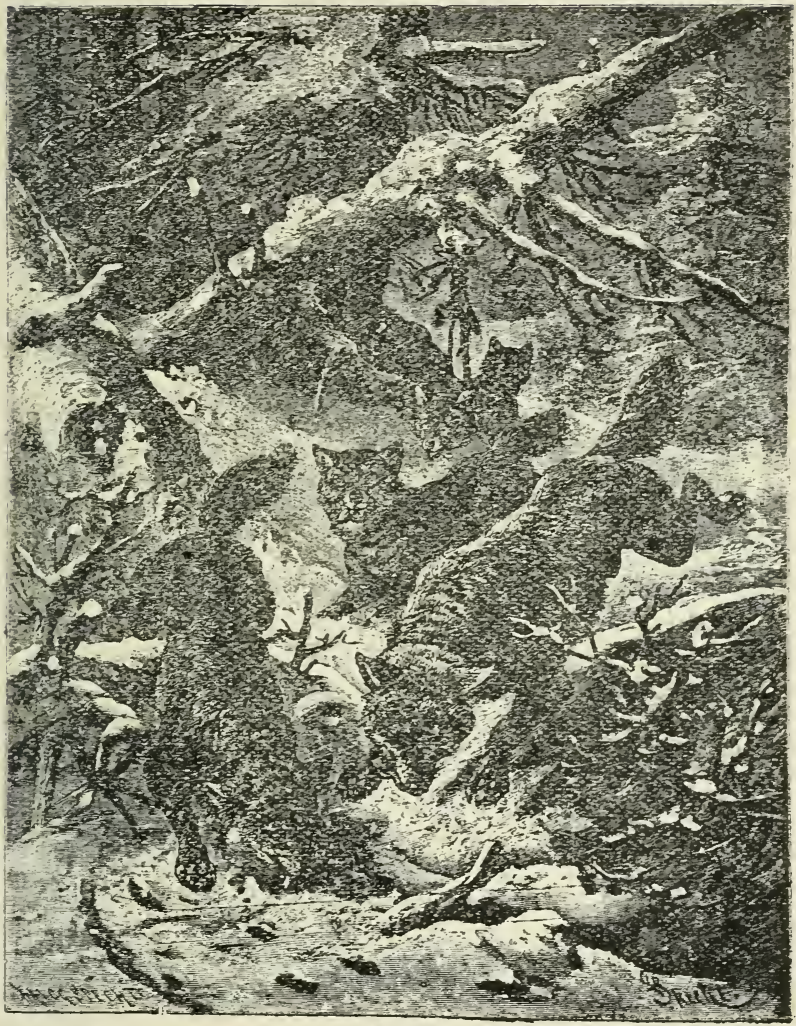

Fig. 33.-Groupe de Loups. 
de l'ouest, sur le versant des Montagnes-Rocheuses, etc., ainsi que dans l'ouest canadien, la Baie d'Hudson, le Labrador, la vallée de l'Outaouais, et dans quelques endroits des provinces maritimes. Quoiqu'il soit disparu depuis longtemps de l'est de la province au sud du fleuve, on signale pourtant à de rares intervalles, la présence de quelques individus écartés dans ces parages qu'ils fréquentaient autrefois en grand nombre. Ainsi, il y a à peine une quinzaine d'années, un Loup a été tué dans une paroisse non loin de Québec, où il avait déjà montré son savoir faire parmi les troupeaux de moutons.

Plusieurs opinions ont été émises au sujet du degré de parenté de notre Loup avec celui d'Europe. Les uns étaient d'avis qu'ils appartenaient tous deux à une même espèce; les autres, que l'eșpèce américaine n'était qu'une variété ; d'autres encore en ont fait deux espèces distinctes basées sur certaines différences anatomiques.

Il est certain toutefois que le Loup d'Amérique offre beaucoup de ressemblance avec celui de l'ancien continent; il a la même forme, la même aspect et il est au moins d'égale taille que son congénère. Il en a aussi les mêmes mœurs; il est fin et rusé, et pour le moins aussi lâche et aussi sanguinaire que lui. Il déploie le même acharnement dans la poursuite de sa proie. S'il pénètre dans une bergerie, il peut mettre à mort une dizaine de moutons dans une seule nuit, sans même toucher à la chair de ces animaux, s'abreuvant uniquement de leur 
sang, tandis que un ou deux auraient suff pour apaiser sa faim; car $j 1$ est reconnu que le Loup consomme beaucoup d'aliments dans un seul repas. Il se gorge tellement de chair que sourent il est incapable de fuir, et peut alors être tué à coups de bâton.

L,e Loup, qui ressemble beaucoup au chien, son implacable ennemi, par sa forme aussi bien que par ses sens très développés de l'odorat et de l'ouie, est loin pourtant d'avoir les mə̂̀mes qualités que ce fidèle ami de 1'homme. Tous les auteurs s'accordent à nous le représenter comme un animal lâche, fuyant devant l'homme et même devant des animaux plus faibles que lui, agissant plutôt de ruse et de finesse pour se procurer sa nourriture, que de vive force et ouvertement. Il suivra sa proie longtemps à pas de loup, comme on dit, épiant tous ses mouvements, choisissant le moment favorable pour s'élancer sur elle. Mais il est démontré aussi que, lorsque la faim le presse trop vivement, le courage lui revient, et c'est alors qu'il se montre véritablement dangereux. Avec nne audace incroyable, il peut attaquer l'homme comme il poursuit arec fureur les grands mammifères.

Tontefois ses attaques contre l'homme, en Amérique, sont rares; les Loups trouvent tonjours assez de nourriture dans les perdrix et autres oiseaux, les lièvres et les petits mammifères de toutes sortes, ainsi que dans le chevreuil qu'ils poursuivent à outrance, sans qu'ils songent à troubler l'homme 
qu'ils évitent, différant en cela de ceux de l'ancien continent. Cependant on cite ie cas d'un nommé Cloutier, homme très fort, qui fut autrefois dévoré par un troupeau de Loups dans les environs de Hull. On a constaté, en retrouvant les os épars de cet homme, qu'il avait tué, en se défendant, quatorze loups, qui eux aussi avaient été dévorés par les survivants. Audubon cite le cas de deux nègres demeurant sur les bords de l'Ohio, qui furent attaqués un soir par une meute de Loups que la fairn rendait furieux. Après une lutte acharnée, l'un des deux nègres succomba, et l'autre ne trouva son salut qu'en grimpant sur un arbre qui se trouvait à cet endroit. Il y passa la nuit et le lendemain inatin, il vit les restes de son malheureux ami rongés et dispersés sur la neige, où gisaient également les cadavres de trois Loups.

Dès qu'une bande de Loups a flairé un cerf, ils se lancent en hurlant à sa poursuite, et le pauvre animal, après une course furibonde, sent bientôt les forces lui manquer, et finit enfin par succomber, devenant ainsi la proie de ces féroces carnassiers, qui le dévorent sur le champ. Si le cerf se trouve à proximité d'un lac ou d'une grande rivière, il se lance tout de suite à l'eau, traverse de l'autre côté, ou se cache dans les joncs; par ce subterfuge, il réussit souvent à mettre ses ennemis en déroute. Pendant l'hiver, le chevreuil a encore beaucoup moins de chance de se soustraire à la poursuite de ses agresseurs, car si la neige est molle, il y enfonce 
et est bientôt rendu aux abois ; de même ercore, si une forte couche de glace recouvre la neige: il glisse en essayant de fuir sur cette surface polie, et dans ces deux cas, il devient, pour ses ennemis, une proie facile à capturer.

MI. W. P. Lett, vieux trappeur, qui croit que le Loup est au moins aussi fin que le renard, nous raconte qu'un jour ayant pris un Loup au piège, il essaya par divers moyens, d'exciter sa colère, et jamais il ne put le faire crier ni gronder, ni même tenter de le mordre. L'animal se couchait à terre, la tête entre les pattes de devant ; mais lorsque MI. Lett s'éloignait quelque peu il se levait sur ses jambes, et quand il s'en approchait, le Loup se couchait de nouveau; il semblait être très craintif, et timide. Mais il était trop rusé pour montrer de la férocité, tel que l'aurait fait un pécan, un lynx, une marte, ou autre carnassier. De ce qu'il voyait il vint à la conclusion que s'il eut eu une corde, il aurait pu facilement l'emmener chez lui, en la lui passant autour du cou comme on fait pour un chien. Tout de même, il résolut de l'emmener vivant, et il détacha la chaîne qui fixait le piège à terre; le Loup se leva et suivit au bout de cette chaîne pendant un quart de mille, jusqu'au moment où MIr. Lett tomba accidentellement, les pieds embarrassés dans une racine d'arbre. Connaissant d'avance les mœurs des Loups, il se retourna immédiatement vers son captif, avant même de se lever debout; il le vit les yeux étincellants et se disposant à s'élancer sur lui. 
Nais du moment qu'il rencontra le regard de son maître, il se coucha de suite. Alors Mr. Lett l'assomma à coups de bâton. Il savait depuis longtemps qu'il était dangereux de tomber à terre même en présence d'un Loup apprivoisé. (I)

On peut longtemps voyager dans les bois fréquentés par les Loups sans en rencontrer un seul; leur flair est si subtil et leur oreille est si fine qu'ils s'aperçoivent de l'approche de l'homme bien avant que ce dernier puisse les voir ou les entendre.

Les Loups, dit encore M. Lett, ne creusent pas de terrier, ils dorment en plein air, ou dans des crevasses de rochers; cependant Sir John Richardson dit qu'ils se creusent un terrier, qu'il en a vu, et que la femelle y élève même ses petits, qui sont au nombre de quatre à huit ou neuf. Le même auteur ajoute que le Loup poursuit les renards comme il suit aussi les troupeaux de buffles pour en attaquer les jeunes veaux ou les individus malades. Il a egalement vu un Loup donner la chasse à un caribou et finir par l'atteindre; il aurait fait un excel. lent repas si à ce moment, un Indien ne fût sorti de sa cachette, du bord d'un lac où il se trouvait, pour s'emparer du caribou exténué par la fatigue, et lui trancher la gorge. Le Loup, à son grand désappointement fut obligé de retraiter. (2)

Afin de compléter l'histoire des mœurs du Loup, je citerai encore ce qu'en dit M. A. Dickson: "Le

(I) Ottawa naturalist. Vol. 4. p. 8I.

(2) Richardson. Fauna Boreali Americana. Vol. I, p. 64. 
Loup canadien est féroce et poltron, avec une disposition telle qu'il tuera tout un troupeau de noutons pour la seule satisfaction de rassasier sa soif de sang, lorsque un ou deux auraient suffi à ses besoins. J'ai toujours trouvé les Loups les plus lâches de tous les animaux; lorsqu'ils sont pris au piège ou blessés au fusil, ou encore acculés dans un coin, d'où ils ne pouvaient s'échapper, je les ai invaria. blement tués avec un bâton, ou une hachette, sans qu'ils fissent de résistance. Il est vrai que je les ai vus se montrer audacieux lorsque étant en bande et ayant capturé un chevreuil, j'ai essayé de les chasser de là; néanmoins j'ai tonjours réussi en tirant un coup de fusil au milieu d'eux. Ils sont fréquemment tués sur la route lorsque, par faiblesse, ils sont incapables de marcher sur la neige épaisse et molle. Ils se gorgent quelquefois sur un chevreuil à tel point qu'ils ne peuvent offrir de résistance et on peut également les tuer.

"Les Loups détruisent beaucoup de chevreuils ; ils les chassent seuls ou en troupeaux, aussi bien en été qu'en hiver. Lorsque le chevreuil est poursuivi, il se jette à l'eau, s'il en trouve, car il a plus de chance d'échapper aux poursuites du Loup puisqu'il nage plus vite et avec plus de facilité ; le Loup perd ordinairement un peu de temps avant de retrouver la piste du chevreuil lorsqu'il atteint la rive opposée, puisqu'il nage presque toujours en remontant ou en descendant le courant, au lieu de traverser en ligne droite. Quelquefois même le 
chevreuil revient sur la rive d'où il est parti, mettant ainsi le Loup hors de sa piste, et si de grandes herbes émergent de l'eau, il s'y cachera souvent, ne laissant voir que sa tête hors de l'eau. Dans cette circonstance, le Loup en est uniquement pour sa course. Mais en hiver, lorsque le chevreuil court sur la glace vive, il glisse et tombe presque à chaque pas; le Loup l'atteint facilement et la chasse est alors plus courte.

"Si le chevreuil gagne un rapide suffisamment creux pour s'y maintenir debout en touchant le fond et pouvoir y marcher, mais trop profond pour que le Loup puisse faire la même chose, les chances sont qu'un vieux mâle peut tuer un Loup en le frappant avec ses pattes de devant. J'ai perdu de cette manière un bon nombre de chiens. Dans cette circonstance le chevreuil montre beaucoup de tact, soit en frappant son ennemi, soit en sautant de coté, laissant le Loup se faire entraîner par le courant.

"En hiver, lorsque la neige est abondante et qu'il n'y a pas de couche de glace suffisante pour supporter les Loups, ils meurent de faim en grand nombre." (I)

Audubon nous raconte un fait étonnant sur la lâcheté du Loup :

Un soir, alors qu'il voyageait entre Henderson et Vincennes, il s'arrêta pour passer la nuit dans une ferme, et après quelques minutes de conversation avec le fermier "qui me demanda, dit-il, si je voulais

(I) Canadian Nat. \& Geol., Vol. I. p. 2 II. 
aller avec lui rendre visite à quelques fosses à loups qu'il avait établies à environ un demi-mille de chez lui. J'accédai bien volontiers à sa proposition et le suivis, à travers champs, jusque sur la lisière d'un bois épais où j'aperçus bientôt les engins de destruction. Les fosses, au nombre de trois, à quelques centaines de mètres l'une de l'autre, et pouvant avoir huit pieds de profondeur, étaient plus larges d'en bas, de manière qu'une fois tombé dedans, aucun animal ne pût s'en échapper. L'ouverture était couverte d'une plate-forme à bascule, construite de branchages et fixée à un axe central qui formait pivot. Dessus, on avait attaché un gros morceau de renaison corrompue, dont les exhalaisons, peu flatteuses pour mon odorat, étaient cependant propres à attirer les loups. Mon hôte était venu les visiter ce soir-là, simplement parce qu'il avait l'habitude de le faire chaque jour, pour s'assurer que rien n'était dérangé. Il me dit que les loups abondaient, cet automne, et lui avaient mangé presque tous ses moutons et l'un de ses poulains, mais qu'il s'apprêtait à le leur faire payer cher ; il ajouta que si je voulais tarder de quelques heures, le lendemain matin, il promettait de me procurer une partie de plaisir telle qu'on en voit rarement dans le pays. Sur ce, nous rentrâmes à la ferme, et après une nuit employée à bien dormir, nous étions, le lendemain, debout avec 1'aurore.

"Je crois que tout va à souhait, dit mon hôte, car les chiens me paraissent impatients de partir. Ce (ii) 
ne sont pourtant que de pauvres chiens de berger; mais leur nez n'en est pas pour cala plus mauvais. Effectivement, en le voyant prendre son fusil, sa hache et un grand couteau, ils se mirent à hurler de joie et à gambader autour de nous.-A la première fosse, nous trouvâines l'appât enlevé et toute la plate-forme bouleversée: l'animal s'était pris, mais à force de gratter, il était parvenu à se creuser un passage souterrain par où il avait pu s'échapper. Le fermier alla regarder dans l'autre... Ah ! ah ! s'écria-t-il, il parait que nous avons là-dedans trois camarades, et de la belle espèce, je vous en réponds. J'avançai la tête et je vis les loups, deux noirs, le troisième roussâtre, et tous, pour sûr, d'une taille respectable. Ils étaient étendus à plat par terre, les oreilles conchées, et leurs yeux manifestant plus de frayeur que de colère.-Maintenant, dis-je, comment faire pour mettre la main dessus? -Comment, monsieur? mais probablement en descendant dans la fosse où nous leur couperons le nerf du jarret. Un peu novice en ces matières, je demandai au fermier la permission de rester simple spectateur.-A votre aise, me répondit-il, demeurez ici et regardezmoi faire à travers les broussailles. Ce disant, il se laissa glisser en bas, après s'être armé de sa hache et de son couteau, tandis que je gardais la carabine. C'était pitié de voir la couardise des loups. Il leur tira, l'une après l'autre, les jambes de derrière, et d'un coup de son couteau, leur trancha le principal tendon au-dessus du joint. Il y allait d'un air aussi 


\section{$-259-$}

tranquille que s'il se fût agi de marquer des agneaux. -Ah! s'écria-t-il, quand il fut remonté, nous avons oublié la corde; je cours la chercher! Et il partit vif et léger, comme un jeune lomme. Bientôt il était de retour, essouffé, tout en nage, et s'essuyant le front du revers de sa main. A présent, en besogne. Moi, je dus relever et maintenir la plate-forme, pendant que lui, avec la dextérité d'un Indien, jetait la corde et passait un nœud coulant au cou de l'un des loups. Nous le hissâmes en haut, complètement immobile, comme mort de peur, ses jambes, désormais sans mouvement et sans vie, ballottant çà et là contre les parois du trou, sa gueule toute grande ouverte, et indiquant, par le seul râle de sa gorge, qu'il respirait encore. Une fois qu'il fut étendu sur le sol, le fermier défit la corde au moyen d'un bâton, et l'abandonna aux chiens, qui tous se ruèrent dessus et l'étranglèrent. Le second fut traité sans plus de cérémonie; mais le troisième, le plus noir et qui sans doute était le plus vieux, montra moins de stupidité, du moment qu'on l'eût détaché et qu'il se vit à la merci des chiens. C'était une femelle, comme nous le reconnûmes après, et quoique n'ayant l'usage que de ses jambes de devant, elle s'en servit pour fuir et batailler avec un courage que nous ne pouvions nous empêcher de juger digne d'un meilleur sort. Elle se défendit en effet vaillamment, donnant de droite et de gauche un coup de dent au premier chien assez hardi pour l'approcher, et qui s'en retournait avec cela, braillant et 
piteux, en lui laissant toute une gueulée de sa peau. Enfin, elle fit tant et si bien, que le fermier, de peur qu'elle ne s'échappât, lui envoya une balle à travers le cœur. Alors les chiens se jetèrent dessus, et assouvirent leur vengeance dans le sang de la maudite bête qui avait ravagé le troupeau de leur maître. " (I)

On chasse le Loup au fusil, on lui tend des pièges ou trappes ou encore on se sert du poison pour s'en débarrasser.

On distingue plusieurs variétés du Loup, basées sur la couleur de son pelage. Ces variétés ne se rencontrent point dans la province.

\section{FAMILLE FELIDE. ChaTs.}

Formule dentaire. $-i$. $\frac{3-3}{3-3}$ c. $\frac{1-1}{1-1} p m \cdot \frac{3-3}{2-2}$ ou $\frac{2-2}{2-2} m \cdot \frac{1-1}{1-1}$

Les Félins sont des animaux digitigrades; leurs doigts sont au nombre de cinq pour les membres antérieurs et de quatre pour les postérieurs ; la plante des pieds est recouverte de poils épais et soyeux, à l'exception d'un petit endroit nu sous chaque doigt ; les ongles sont forts, comprimés et rétractiles; la tête est courte et arrondie ; la langue offre à sa surface des papilles cornées, souvent très dures; les mâchoires sont courtes; les canines sont longues, plus ou moins recourbées et ordinairement sillonnées.

Ces animaux sont nocturnes ne chassant qu'au crépuscule et durant la nuit; ce n'est que pressés par la faim qu'on les voit chasser pendant le jour; leur pupille, qui ne supporte que difficilement les

(I) Audubon, Trad. de Bazin, Scènes de la nature. Vol. 2, pp. 216-219. 
rayons d'une lumière vive, se contracte de manière à ne laisser apercevoir qu'une simple fente, afin de diminuer autant que possible l'intensité des rayous lumineux, tandis que dans les ténèbres ou les demijours, elle se dilate jusqu'à devenir presque circulaire, ce quii permet à la lumière d'y pénétrer en plus grande abondance.

Ces fauves sont les plus redoutables et les plus féroces de tous les carnassiers ; leur corps élancé et souple, actionné par des muscles puissants, leur permet d'exécuter des sauts prodigieux, soit pour s'emparer d'une proie ou pour fuir un danger. Le chat domestique qui appartient à cette famille, nous donne en petit, une idée fort exacte de la souplesse et de l'élégance de formes de ces félins, en même temps qu'il nous fait connaître leur astucieuse férocité. Soit qu'ils guettent, dissimulés dans le feuillage d'un arbre, soit qu'ils se dirigent en rampant vers la proie qu'ils convoitent, lorsqu'ils la jugent assez proche, d'un bond ils fondent sur elle, la saisissent et l'égorgent; s'ils ne réussissent pas à s'en emparer du premier coup, souvent ils s'élancent une deuxième fois ; mais il est très rare qu'ils la poursuivent si elle leur échappe encore ; ils se postent alors de nouveau en embuscade et attendent là qu'une autre proie vienne à passer, ou bien il se mettent à sa recherche. Leurs pattes velues leur permettent de marcher sans faire, le plus souvent, aucun bruit, ce qui les favorise admirablement bien dans la recherche du gibier. 
Brehm nous donne une excellente description des mœurs de cette famille de carnassiers. "Tous les chats, dit-il, mangent de préférence les animaux qu'ils ont eux-mêmes tués: très peu d'entre eux s'attaquent aux charognes; il faut que la proie soit fraîche et en quelque sorte saignante pour qu'ils $y$ touchent. Presque tous se distinguent par des habitudes vraiment sanguinaires ; certaines espèces, lorsqu'elles le peuvent, se nourrissent même exclusivement de sang, et s'enivrent en quelque sorte avec ce liquide. Les félins attaquent tous leur proie de la même manière. Ils traversent à pas silencieux leur domaine, regardant attentivement dans tous les sens. Le moindre bruit éveille leur attention et les excite à en pénétrer la cause. Ils s'approchent en rampant de l'animal qu'ils convoitent, en ayant soin d'aller toujours contre le vent; lorsqu'ils en sont assez près, ils se jettent brusquement sur lui par un ou plusieurs bonds, lui donnent quelques coups de griffe dans la nuque ou sur les flancs, le jettent à terre, le saisissent avec les dents et le mordent plusieurs fois de suite de toute la force de leurs mâchoires. Puis, ils desserrent les dents, sans pourtant lâcher leur proie; ils l'examinent au contraire attentivement et lui font encore quelques morsures, si elle n'est pas complètement morte. Beaucoup d'entre eux poussent alors des cris rauques, qui expriment aussi bien la satisfaction, l'avidité ou la colère. La plupart ont la féroce habitude de tourmenter pendant quelque temps 
leur victime; ils lui donnent un peu de liberté, la laissent courir quelques pas, puis la saisissent de nouveau pour la laisser encore courir, et continuent ce jeu cruel jusqu'à ce que la pauvre martyre succombe à ses blessures... Les plus grandes espèces évitent les animaux qui peuvent leur résister sérieusement, et ne les attaquent que lorsque l'expérience leur a démontré que la victoire leur reste toujours...

"Les félins ne dévorent presque jamais leur proie sur place; après l'avoir tuée, ou l'avoir rendue incapable de se sauver, ils la traînent dans quelque endroit bien solitaire, où ils la mangent tout à leur aise...

"Les petits viennent au monde aveugles, chez les uns, voyant, chez les autres. La mère les élève; le père ne s'en occupe qu'accidentellement. Une mère avec ses petits est un des spectacles les plus attrayants dont le naturaliste puisse jouir. On voit la tendresse maternelle dans tous les actes de la femelle; chacun de ses cris exprime son amour pour sa progéniture et sa voix a quelque chose de tendre et de doux qu'on n'avait pas remarqué jusque-là. La mère observe ses nourrissons si attentivement, les entoure de tant de soins, que l'on sent combien son affection doit être profonde. On a du plaisir à voir comment elle leur inculque, dès leur jeunesse, l'amour de la propreté ; elle les nettoie, les lèche, les lisse du matin au soir et ne souffre pas la moindre tache sur leur robe, ni la moindre ordure dans le voisinage du repaire. Elle les défend au péril de sa vie; aussi 
les plus grandes espèces deviennent toutes très-dangereuses après la parturition. Chez les petites espèces, la mère est souvent obligée de défendre sa nichée contre le père, qui s'attaque à elle dans les premiers jours, et la dévore lorsque, par hasard, il peut pénétrer dans le repaire. C'est à cette crainte, qu'inspire le mâle, qu'il faut attribuer le soin avec lequel tous ces animaux cachent leurs petits. Il n'en est plus de même lorsque ceux-ci ont un peu grandi, le mâle alors ne leur fait plus rien. Alors, aussi, commence une vie pleine de gaieté et d'amusement pour ces êtres folâtres. Leurs premiers mouvements et leurs premiers jeux dénotent déjà l'instinct félin, et ne sont que des préludes aux chasses auxquelles ils se livreront plus tard. Tout ce qui remue attire leur attention; aucun bruit ne leur échappe; ils dressent les oreilles au plus léger bruissement. I^a quelie de leur mère est leur premier jouet ; ils observent chacun de ses mouvements et cherchent à les arrêter en la saisissant. La mère se prête à ces attaques et les provoque même.

"Quelques semaines après, on voit la famille tout entière se livrer aux jeux les plus folâtres, la mère, -aussi bien la lionne que la chatte domestiqueredevient littéralement enfant. Souvent toute la bande se roule en pelote, et l'un cherche à saisir la queue de l'autre. Avec l'âge, les jeux deviennent plus sérieux, les petits apprennent peu à peu que la queue est une partie d'eux-mêmes et cherchent à exercer leur force sur d'autres objets. La mère 


\section{$-265-$}

leur apporte alors de petits animaux à moitié ou même complètement vivants, qu'elle leur abandonne pour mettre leur instinct en jeu et les dresser à la rapinerie. Enfin la femelle, quelquefois la femelle et le mâle, les conduisent avec eux à la recherche du gibier, et leur apprennent les ruses, les détourrs, les moyens d'attaque prompts et sûrs, en un mot tout l'art de la chasse. Ils ne quittent leur mère ou leurs parents que lorsqu'ils peuvent se suffire complètement, et mènent alors pendant longtemps une vie solitaire et errante. (I)

On rencontre les félins dans toutes les parties du monde, excepté en Australie.

Cette famille n'est représentée dans notre faune que par trois espèces, dont deux ne se montrent plus qu'accidentellement.

\section{Genre LYNX, Kerr.}

Ces animaux se distinguent par des oreilles de forme triangulaire, munies à leurs extrémités d'un pinceau ou touffe de poils longs et raides; leur queue est très courte et comme tronquée au bout; prémolaires supérieures, 4 .

\section{Lynx canadensis, (DESMAREST) Le Lynx du Canada.}

Pelage grisâtre en hiver, entremêlé de poils roux et noirs, plus clair inférieurement; le fond du poil est d'un roux pâle; les oreilles sont marginées de roux et de noir; les pinceaux sont également noirs ; les pieds sont très gros et abondamment foumis de poils en hiver, de sorte que, à cette saison, ces poils recouvrent la partie nue des doigts

(1) Brehm. Les mammiferes, vol. I, pp. I86-187. 
qui n'est visible qu'en été; la queue, plus courte que la tête, est noire à l'extrémité ; les yeux sont jaunâtres. En été, le pelage est moins fourni, et prend une teinte un peu rousse. Longueur 35 ; queue $4 \frac{1}{2}$.

Le Lynx du Canada ou Loup-Cervier, comme on le nomme vulgairement, est largement distribué dans le nord de l'Amérique septentrionale; chez nous il est plus commun au nord qu'au sud du fleuve StLaurent. Son naturel sauvage lui fait rechercher l'intérieur des forêts, loin des habitations, où il trouve, dans ces endroits retirés, une abondante nourriture dans les lièvres, marmottes, mulots, écureuils, perdrix et autres oiseaux ou petits mamnifères, qu'il capture aussi bien sur les arbres qu'à terre. On dit même qu'il attaque le porc-épic, car on a trouvé un Lynx dont la gueule était remplie des piquants de ces animaux.

Lorsque le Loup-Cervier ne trouve rien dans la forêt et que la faim se fait sentir, il se rapproche alors des habitations, d'où il enlève parfois des moutons ou autres petits animaux des fermes.

Il est sans doute arrivé que l'on a parfois attribué au loup des rapines dont le I,ynx était l'auteur.

On a prétendu que le Loup-Cervier est un animal lâche et timide, qu'il fuit même devant un petit chien, qu'il se laisse dompter et assommer à coups de bâton; cette assertion est fausse, car le Lynx est un animal dangereux, sachant défendre sa vie avec bravoure, et les blessures qu'il inflige avec ses dents et ses puissantes griffes, sont terribles. 
Il est tout de même certain que quand le Lynx croit qu'il lui est possible de se dérober à la poursuite d'un ennemi, soit dans la fuite, ou en se cachant dans le feuillage d'un arbre, il n'hésite pas à recon1rir à ce moyen de salut, comme le font d'ailleurs un grand nombre d'animaux, lorsqu'ils appréhendent un danger; mais s'il se voit dans l'impossibilité de fuir, il se défend alors vigoureusement avec ses dents et ses griffes à la manière du chat domestique. Il sait même résister à des animaux en apparence plus forts que lui, comme le démontre le fait suivant raconté par M. D.-N. Saint-Cyr :

"Dans le cours du mois de juillet I869, je retournais, sur les dix heures du soir, à ma demeure. Deux gros chiens de Terre-Neuve, Captain et Sailor, me suivaient.... Arrivé à quatre ou cinq pas de ma porte, une apparition inattendue me tire subitement du pays des rêves. Un objet tangible me cloue à la place où je me trouvais. J'étais en face d'un Loup-Cervier. Il faisait clair de lune. Il était là assis, à la façon d'un chat, les yeux fixés sur moi. Mon arrivée subite ne le fit pas bouger. Je n'avais à la main qu'une pipe de plâtre, arme bien fragile contre un pareil adversaire, dont j'avais lu et entendu bien souvent raconter les prouesses plus ou moins sanguinaires. Avancer eût été folie, fuir n'aurait guère été faisable; la position était passablement critique. Je regarde autour de moi, pas un bâton, pas un éclat de bois. Voilà ce que c'est que d'être trop rangé ! Et vos deux chiens? me 
direz-vous. Eh bien! oui. Mes deux Terre-Neuves que j'avais d'ordinaire sur les talons ou gambadant autour de moi, étaient occupés ce soir-là à réduire au silence trois ou quatre caniches du voisinage, qui faisaient un tapage d'enfer au moment où j'étais arrivé ; ces derniers avaient sans doute flairé l'intrus. J'appelle les chiens, Captain arrive sautant, gambadant comme de coutume, me saisissant par mon habit comme pour me dire: me voilà. Captain! je lui criai, en lui montrant la bête de proie. Le chien s'élance, mais il recule aussitôt. Le LoupCervier s'est tourné de son côté. Il fait claquer ses dents avec rage, il souffle, il crache! Ses yeux étincellent, son attitude est vraiment formidable! Captain jappe, Sailor l'entend et arrive comme la tempête. Tous deux se précipitent sur le Lynx. Ce dernier roule sous l'impétuosité du choc. Il est terrassé! Oui, mais non pas vaincu. Il se relève, et joue si bien des griffes et des dents qu'il force les deux assaillants à reculer. Les deux chiens frémissants de rage, poussent des cris de douleur et se frottent le museau sur les pieds de devant. J'excite les chiens à renouveler l'attaque, ils s'élancent de nouveau, mais le Lyıx continue à les tenir en échec. Claque fois que les chiens s'élancent sur lui, le Lynx les repousse. Il y avait une bonne demi-heure que ce jeu durait, et $\mathrm{j}$ 'aurais certainement $\mathrm{pu}$, dans l'intervalle, trouver une arme quelconque et assommer la bête de proie; mais je voulait m'assurer si vraiment mes deux gros chiens 
pourraient la dompter. Enfin le Lynx, profitant d'un moment favorable, élude la vigilance de ses adversaires et s'élance dans une prairie avoisinant ma maison. Les chiens le poursuivent, mais en vain. Chaque fois que le Lynx se trouve pressé trop vivement, il se retourne vers les chiens et se défend avec tant de vigueur et d'acharnement qu'il finit par leur échapper tout à fait. L'un des deux chiens n'avait qu'un peu plus d'un an, mais l'autre était dans toute sa force. o (I)

Lorsque le Lynx court, il procède par bonds ou sauts à la façon du chat domestique, et quand il est traqué de près, il grimpe sur un arbre; s'il ne peut y réussir, il fait face à l'ennemi quels qu'en soient la force ou le nombre; il miaule, souffle et crache, tout en se préparant à défendre vigoureusement sa vie.

DeKay dit qu'il ne craint pas l'eau et qu'il nage bien, même à une assez grande distance. (I) Mais quelques chasseurs, dignes de foi, prétendent qu'il fuit l'eau.

La femelle met bas, une fois dans l'année, de deux petits, qu'elle dépose dans un arbre creux ou dans une fente de rocher.

On capture bien facilement le Lynx au piège, avec une trappe, ou bien on le tue au fusil lorsqu'il est monté sur un arbre.

(I) Naturaliste Canadien, Vol. 2, pp. 258-29o.

(I) DeKay, Nat. Hist. of N. Y. p. $5 \mathrm{I}$. 


\section{Lynx rufus, (GULDENSTADT). Le Lynx roux.}

Pelage d'un roux pâle en été, et d'un brun cendré en hiver, un peu plus foncé sur la ligne dorsale; le dessous du corps est maculé de blanchâtre, avec quelques taches noires ; les oreilles sont fauves en avant et noires en arrière, avec une tache grise au centre; la queue, qui est presque aussi longue que la tête, est noire à l'extrémité; les jambes sont blanchâtres en dedans, avec des bandes transversales noires. Longueur, 28 ; queue, 7 .

Le Lynx roux ou Lynx bai, se distingue aisément de l'espèce précédente par la couleur de sa robe, ainsi que par sa taille plus petite.

Il habite l'est de l'Amérique du Nord. Dans la province il ne se voit qu'accidentellement et vers le sud seulement; on le rencontre aussi dans Ontario et dans les provinces maritimes; mais il est plutôt confiné vers le centre et le sud de l'Amérique septentrionale.

Le Dr C. H. Merriam, dans une description des manmifères des Adirondacks, nous dit, en parlant du Lynx roux qu' "il fréquente les collines rocheuses et les chaînes boisées de rochers, et ne montre pas cette antipathie pour la civilisation si remarquable chez le Lynx du Canada, son congénère. De fait, il se montre assez commun dans les endroits de l'Etat où les habitations sont nombreuses et où il cause parfois de forts dommages aux fermiers en leur enlevant des agneaux, des petits cochons et des oiseaux de basse-cour: canards, oies, dindons et 
poules lui conviennent à merveilie. En dehors de la basse-cour, il se nourrit de lièvres, d'écureuils, de souris, de perdrix et de petits oiseaux qu'il peut capturer.

v Il fait généralement son lit dans une souche ou dans un arbre creux, qu'il tapisse suffisamment de mousse. Il met bas de deux à quatre petits, mais plus fréquemment trois.

"En I873 ou I874, je parcourais le versant nord du mont Tom, dans le Massachusetts, lorsque je tuai uné perdrix au vol. A peine avait-elle touché la pente rocheuse, qu'un Chat sauvage sortit d'un buisson voisin, s'élança sur elle, et, dans une succession de sauts rapides, il commença à escalader la montagne avec la perdrix dans sa gueule. Le contenu de l'autre canon de mon fusil lui fit changer d'idées, aussi bien que de direction...

"Je n'ai jamais vu un animal paraître aussi féroce que lorsqu'il est enragé ; il siffle, crache, et gronde de la manière la moins attrayante possible. " (I)

Audubon nous dit que cet animal "se plaît dans les endroits marécageux et solitaires ainsi que sur le versant boisé des montagnes; il se voit parfois dans cette partie des Alléghanies qui traversent les états de la Pennsylvanie et de New York. Il est fort commun dans les champs de cannes à sucre avoisinant les lacs, les rivières et les lagunes de la Caroline, de la Louisiane et autres états du sud, ainsi que de ceux de l'ouest méridional. Il habite aussi

(I) Transactions of the Linncean Society of $N$. Y. Vol. I p. 4I. 
les montagnes et les contrées ondulées des Etats du sud, et fréquente les fourrés d'arbustes qui poussent d'ordinaire dans les plantations abandonnées de coton dont quelques-unes ont de deux ou trois milles de longueur sur un mille de largeur environ, et qui offrent, par le nombre de ronces, d'arbustes et de jeunes arbres de différentes sortes qui y ont poussé, un excellent abri aux divers oiseaux et quadrupèdes.

"Dans ces vieux champs recouverts de buissons, les "chats " se nourrissent principalement de lapins et de rats qui font leur demeure dans ces lieux presque impénétrables. Il est bien rare que le chat sauvage quitte volontairement une place qui lui va si bien et où il est en sûreté, excepté à l'époque où il fait ses petits, ou encore pour visiter les petits ruisseaux ou les étangs que la sécheresse a presque taris, pour se repaître d'écrevisses, de petits poissons et de grenouilles qui se sont refugiés dans les cavités plus profondes.

"Non seulement le Chat sauvage cause beaucoup de dégâts parmi les poulets, les dindons, et les canards des planteurs; mais encore il détruit un grand nombre de petits quadrupèdes aussi bien que des perdrix et autres oiseaux qui passent la nuit à terre. Les chasseurs le poursuivent souvent avec des lévriers. . Lorsqu'il est traqué de près par les chiens, il grimpe dans un arbre avec l'agilité de l'écureuil; mais l'aboiement des chiens attire à cet endroit ceux qui le chassent, et la carabine meurtrière le fait tomber sur le sol. S'il n'est que blessé, 
il se défend courageusement contre les chiens jusqu'à ce qu'il soit mis à mort. Cependant lorsqu'il est poursuivi par les chasseurs et les chiens, il trouve souvent moyen de les dépister tous deux, et cela avec un tel art qu'on serait tenté de croire qu'il est doué de raison. A peine a-t-il reconnu que l'agresseur est sur sa piste, qu'au lien de fuir directement dans le plus épais de la forêt, il essaie de gagner quelque champ couvert de broussailles ou de buissons épineux, puis il décrit de nombreux cercles, passant et repassant souvent dans les sentiers déjà parcourus, et lorsqu'il croit avoir dépisté hommes et chiens, il s'élance prestement vers la forêt ou dans quelqu'endroit marécageux. S'il est assez chanceux pour rencontrer un étang récemment tari, ou un terrain argileux encore humide, il semble comprendre que la boue en lui couvrant les pieds et les jambes, empêchera les chiens de flairer ses pistes, et qu'une fois ces endroits franchis, il échappera à ses agresseurs. "(I)

On capture facilement cet animal au piège ou encore avec une boîte au fond de laquelle on place de la chair ou un petit animal comme appât; en voulant s'emparer de cet appât, le Lynx fait fermer le couvercle qui le retient prisonnier.

\section{Genre FELIX, Linné.}

Animaux de taille assez grande, au corps élancé, au pelage compact et lustré ; sans touffes de poils à l'extrémité des oreilles; la queue est longue, au moins aussilon-

(I) Audubon, Quadrupeds of N.A. Vol. I, pp. 6-7. 
gue que la moitié du corps, sans la tête ni le cou ; les prémolaires supérieures sont au nombre de six.

\section{Felix concolor, Linné.}

\section{Ia Panthère d'Amérique.}

La livrée ordinaire de cette espèce est d'un jaune brun pâle, plus foncé sur la ligne centrale du dos; le dessous du corps est d'un blanc sale; l'extrémité de la queue, d'un brun foncé ; une tache noire à la lèvre supérieure ; les oreilles noires en-dessus; le poil est court et fourni; la tête est petite.

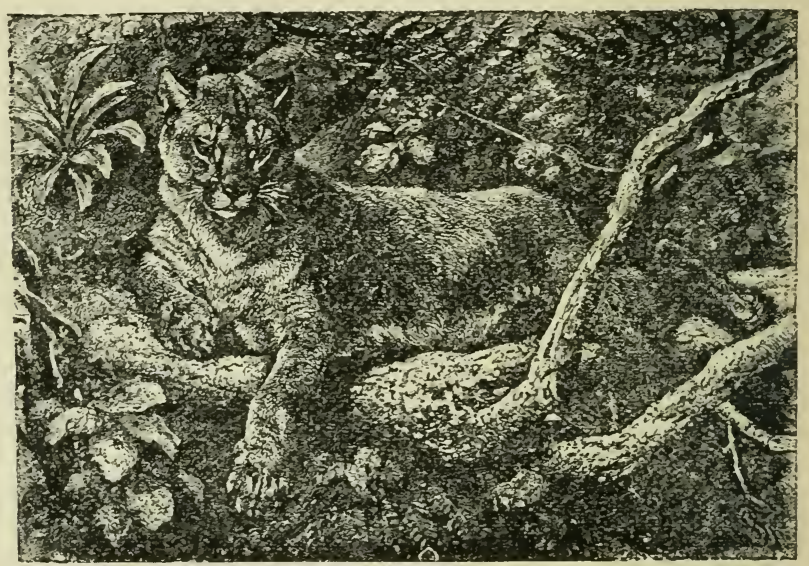

Fig. 34.-La Panthère d'Amérique.

$\mathrm{Vu}$ à distance son pelage, d'après Baird, (I) ressemble beaucoup à celui du chevreuil et comme ce dernier,il change de couleur suivant les saisons. Les jeunes sont tachetés et la queue annelée. Longueur, $5^{8}$; queue, 30.

(1) Reports of explorations and survey. Washington, 1857, Vol. VIII. p. 83, 
La distribution géographique de la Panthère, que l'on nomme aussi Puma et Couguar s'étend dans toute l'Amérique, depuis le Canada jusqu'au détroit de Magellaw. Dans l'Amérique du Nord, cependant, il a dû reculer devant les déboisements successifs, et disparaître même de bien des localités; toutefois on le retrouve en plus ou moins grand nombre dans le Colorado, le Nouveau-Mexique, l'Arizona, la Californie, sur les bords du Mississipi, etc. Au Canada, il existe encore dans la Colombie britannique, mais dans les autres provinces, il est pour ainsi dire disparu; le dernier représentant de cette espèce qui ait été vu dans notre province, fut tué le 3 octobre 1863 , près de St-François, sur la rivière St-Laurent, d'après Beaumont-Small.

La Panthère est un carnassier de forte taille, qui, sous le rapport de la férocité, aussi bien que sous celui de la rapine, ne le cède en rien à ses congénères de l'ancien monde. Elle aime la solitude et se plaît dans les endroits boisés, fuyant la présence de l'homme qu'elle n'ose attaquer à moins qu'elle ne soit blessée par lui ou pressée par la faim. Quelques chasseurs affirment que cet animal est poltron, et DeKay, qui semble partager cette opinion, rapporte qu'un chasseur lui a dit qu'ayant un jour rencontré une femelle avec ses deux petits, trop jeunes encore pour offrir de la résistance, il les prit dans ses bras et continua sa route sans que la mère

(I) Animals of N. A. part I. p. 49 . 
essayât de les défendre, se contentant de suivre le chasseur à distance, et au sortir du bois elle disparut. (I)

Le même auteur rapporte aussi que l'on avait traqué une Panthère dans une grange et qu'elle fut tuée sans offrir de résistance; on remarqua qu'elle avait la gueule remplie de piquants de porc-épic.

Il est avéré toutefois que cet animal s'attaque à l'homme, et Darwin raconte avoir entendu dire que deux hommes et une femme avaient été dévorés par des Panthères au Chili, (2) et McMurtrie, de son côté, dit " qu'il est reconnu que cet animal, la Panthère commune, ne se contente pas seulement d'exercer ses rapines parmi les troupeaux de moutons, etc., mais qu'elle a donné une autre preuve de sa férocité en attaquant une femme de la Pennsylvanie en janvier I830; le fauve s'est élancé sur elle au moment où elle passait dans un chemin et la tua instantanément. " (3)

Partout où cet animal se rencontre, il cause des dommages considérables dans les troupeaux de moutons, de porcs, de jeunes veaux, ou encore parmi les animaux sauvages. Ainsi, font remarquer Cones et Yarrow, dans l'Arizona et le Nouveau Mexique, où ils sont encore communs, ils détruisent par centaines les dindons sauvages. (4)

(1) DeKay. Nat. Hist. of N. Y. I842, Zoology p. 49.

(2) Voyage of the Beagle, p. 269.

(3) McMurtrie, Cuvier's Animal Kingdom, 1831. Vol. I, p. II5:

(4) Report. Wheeler's Survey Vol. v. Zoology, 1875, p. 40. 


\section{$-277-$}

Dans une de ses excursions à travers l'Amérique du Nord, Audubon nous raconte une chasse qu'il fit à la Panthère sur les bords du Mississipi, dans l'état du même nom. Arrivé chez un colon de l'endroit, qui lui apprit que ce carnassier décimait chaque nuit son troupeau de porcs, le naturaliste américain organisa de suite une chasse an fauve et " au jour fixé, dit-il, par une matinée superbe, les chasseurs arrivèrent à la porte de la cabane, juste au moment où le soleil paraissait au-dessus de l'horizon. Ils étaient cinq, en complet équipage de chasse, montés sur des chevaux que, dans quelque partie de l'Europe, on pourrait regarder comme de tristes coursiers, mais qui, pour l'haleine, la vigueur et la sûreté du pied, sont plus propres qu'aucun autre de ce pays à poursuivre le Couguar et l'ours à travers les bois et les marais. One bande de gros et vilains chiens étaient en train de faire connaissance avec ceux du pionnier; tandis que lui et moi nous montions sur ses deux meilleurs chevaux, et que ses fils en enfourchaient d'autres de moindre qualité.

"Ėn route on causa peu; et quand nous eûmes gagné le bord du marais, il fut convenu qu'on allait prendre chacun de son côté, pour chercher les traces fraîches de la peintère, et que le premier qui les trouverait, donnerait de sa corne et resterait sur place, sans bouger, jusqu'à ce que les autres l'eussent rejoint. Au bout d'une heure, nous entendîmes clairement le son de la corne, et nous étant rapprochés du pionnier, nous nous enfonçâmes dans l'épais- 
seur des bois, dirigés par l'appel, de temps en temps répété, des chasseurs. Cependant nous ne tardâmes pas à nous rencontrer avec les autres camarades au lieu du rendez-vous. Les meilleurs chiens furent dépêchés pour dépister le Couguar; et bientôt toute la meute était à l'œuvre, et se portait bravement vers l'intérieur du marais. Aussitôt les carabines furent apprêtées, et nous suivîmes les chiens à diverses distances, mais toujours en vue les uns des autres, et déterminés à ne pas tirer sur d'autre gibier que la panthère.

- Les chiens avaient commencé à donner; soudain ils hâtèrent le pas. Mon compagnon en conclut que l'animal était à terre, et mettant nos chevaux au petit galop, nous continuâmes à suivre les chiens, en nous guidant sur leur voix. Le tapage augmentait, les aboiements redoublaient; lorsque tout d'un coup nous les entendîmes faiblir et changer de note. "En avant, en avant! me cria le pionnier : 1 bête est maintenant perchée, c'est-à-dire qu'elle a gagné les basses branches de quelque gros arbre; et si nous ne parvenons à la tuer dans cette position, pour sûr elle nous fera longtemps courir." En approchant du lieu où elle devait être, nous ne formions plus qu'un peloton ; mais ayant aperçu les chiens qui, en effet, étaient tous postés au pied d'un gros arbre, nous nous dispersâmes au galop pour l'entourer.

"Chaque chasseur alors se tint en garde, l'arme prête, et laissant pendre la bride sur le cou de son 
cheval, tandis qu'il s'avançait à petits pas vers les chiens. Un coup de fusil retentit; et l'on vit aussitôt le couguar sauter à terre et repartir en bondissant, d'une façon à nous convaincre qu'il n'avait nulle envie de supporter plus longtemps notre feu. Les chiens détalèrent après, d'une ardeur au moins égale, et en criant à tue-tête. Le chasseur qui avait tiré nous rejoignit; sa balle, nous assurat-il, avait frappé le monstre dont l'une des jambes devait être cassée près de l'épaule, seule place où il eût pu l'ajuster. Ce qu'il y a de certain, c'est qu'une légère trace de sang marquait la terre; mais les chiens allaient d'un tel train, que nous ne pûmes en faire la remarque qu'en courant; et l'éperon dans le ventre de nos chevaux, nous nous lançâmes à plein galop vers le centre du marais. Une rivière fut traversée, puis une autre plus large et plus bourbeuse; et les chiens allaient toujours! Les chevaux commençaient à souffler d'une furieuse mavière; nous jugeâmes qu'il vaudrait mieux les laisser et continuer à pied. Ces déterminés chasseurs savaient que le couguar, étant blessé, ne tarderait pas à remonter sur un autre arbre, oì, selon toute probabilité, il resterait plus longtemps cette fois, et qu'il nous serait aisé de nous diriger sur la trace des chiens. Nous descendîmes, ôtâmes selles et brides à nos chevaux, et après leur avoir pendu des sonnettes an con, les abandonnâmes ainsi, chacun à ses propres ressources....

"Nous marchions depuis une couple d'heures, 
quand nous commençâmes à entendre de nouveau la meute ; chacun de nous redouble d'ardeur, s'emportant à la pensée de terminer soi-même la carrière du couguar. Nous entendions quelques chiens se plaindre; mais le plus grand nombre aboyait avec fureur. C'était le signe évident que la bête était de nouveau sur l'arbre; et sans doute elle y demeurerait assez pour se remettre de ses fatigues. En avançant vers les chiens, nous découvrîmes le féroce animal couché le long d'une forte branche et près du tronc, sur un cotonnier des bois. Sa large poitrine était tournée de notre côté, ses yeux se fixaient alternativement sur nous et sur les chiens qui étaient au-dessous de lui et l'assiégeaient; une de ses jambes de devant pendait inerte à son côté, et il se tenait tapi, les oreilles à ras de la tête, comme s'il croyait pouvoir échapper à nos regards. A un signal donné, trois coups partirent, et le monstre, après avoir bondi sur la branche, roula par terre, la tête en bas. Attaqué de tout côté par les chiens qui étaient comme des enragés, et lui-même rendu furieux, il combattit avec l'énergie du désespoir. Mais le pionnier, s'avançant au front de la troupe et jusqu'au milieu des chiens, lui logea une balle au défaut de l'épaule gauche. Le couguar se débattit un instant dans les convulsions de l'agonie, et bientôt retomba mort. " (I)

Dans le nord des Etats-Unis la femelle met bas

(1) Audubon, trad. de Bazin. Scènes de la nature. Vol. I, pp I $91-195$ 
vers la fin de l'hiver ou au commencement du printemps, et dans l'Amérique du Sud à la fin de décembre. Ses petits sont au nombre de deux à cinq, qu'elle dépose généralement dans une crevassede rocher, ou dans un fourré d'accès difficile. 



\section{TABLE DES MATIÈRES}

DES ORDRES, SOUS-ORDRES, FAMILLES, SOUSFAIILLES, GENRES ET ESPÈCES

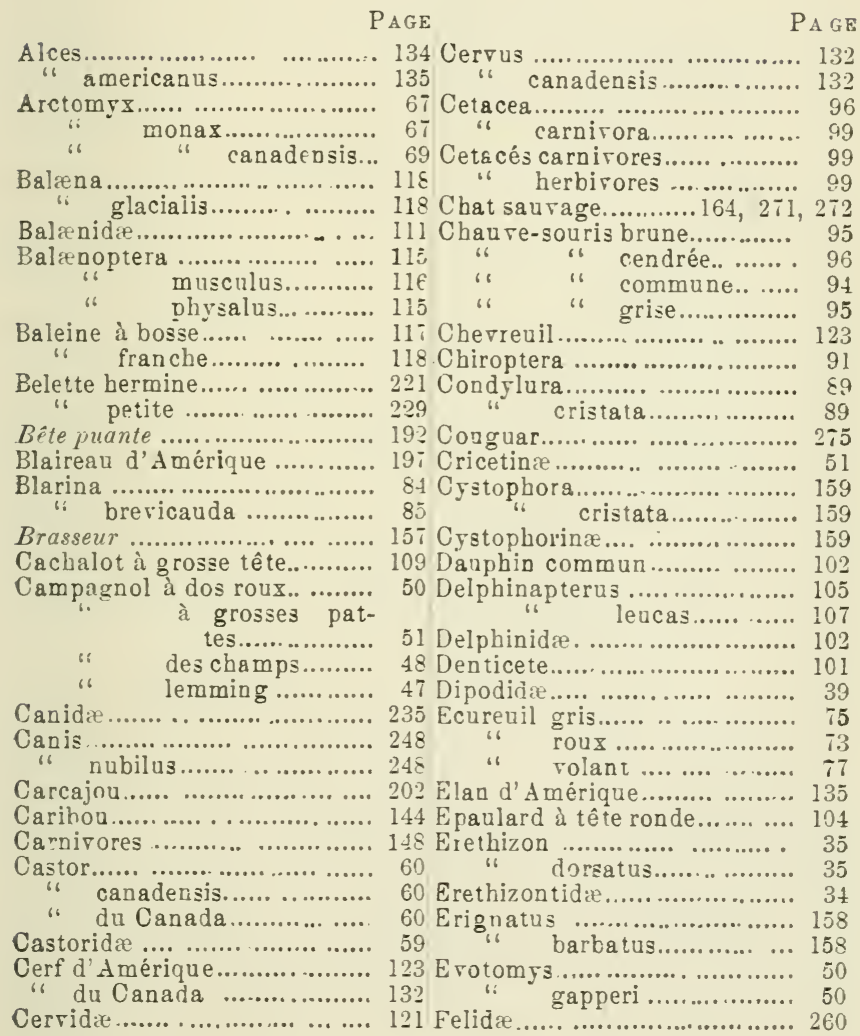




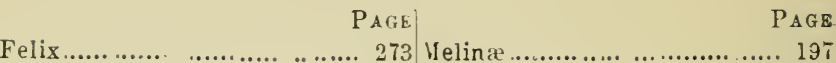

"6 concolor .................... 274 \ephitinæ......................... 190

Feræ........................... 148 I Iephitis......................... 191

Fiber............................. 43 :6 mephitica............... 191

" zebethicus.................... 43 IIérione de la Baie d'Hudson.. 39

Fissipèdes .......................... 163 " 163 des bois................ 42

Fissipedia .......................... 163 Jlicrotinæ......................... 42

Gibbar........................... 105 Hicrotus......................... 47

Glires............................ 27 " 27 pennsylvanicus........ 48

Globicephala ...................... 104 " " 104 acadicus 50

Grampus............................ 108 Morse de l'Atlantique........... 161

108 . Ioufette commune... ........... 191

108 . Mulot.......................... 48

Glouton ordinaire. ................. 201 Murida.......................... 42

Gulo............................... 200 Ifurinæ............................. 53

"6 luscus........................ 201 Mus ............................... 53

Halichœrus........................ 158 " 158 decumanus................... 51

" grypus .............. 159 " musculus...................... 57

Insectirora...................... 82 " rattus ......................... 56

Insectivores...................... 82 .Iusaraigne $\grave{a}$ moustaches

Lasionjcteris........................ 95 blanches ........

Lasiurus noctivagans.....

95
96
96 $\quad$ " $\quad \begin{aligned} & \text { à queue courte..... } \\ & \text { commune............. }\end{aligned}$

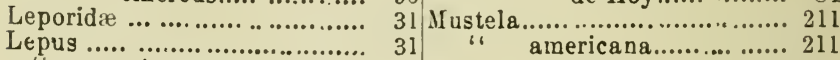

" americanus................. 31 " 31 pennantii.............. 213

Lièvre d'A mérique................ 31 Mustelinæ ..................... 200

Loup ordinaire ................ 248 IIustelidæ........................ 182

Loup-marin d'esprit. ............ 155 . 15 yotis............................ 93

Loups-marins.................... 154 " Iucifugus................... 95

Loutre du Canada............... 184 " subulatus ................. 94

Lutra ............................ 183 Mysticete ....................... 101

" canadensis................... 184 Odobænidæ ....................... 160

Lutreola.......................... 216 (1) dobænus....................... 161

Lutrina vison .................. 216 " rosmarus............. 161

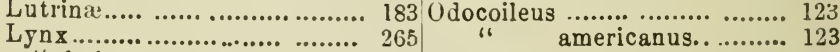

" bai........................... 270 Ondatra .. ....................... 47

" canadensis.................... 265 Orca orca ........................... 105

" du Canada.................. . 265 Orque épaulard.................... 105

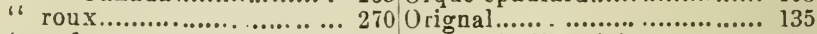

"rufus .......................... 270 (1urs noir d'Amérique............ 170

Mlammifères à sabots.... ........ 119 "b blanc....................... 177

Marmotte du Canada............ 67 " 67 polaire ..................... 177

Marsouin blanc.................... 107 Panthère d'Amérique........... 274

commun .............. 103 Pécan............................ 213

Marte d'Amérique................. 211 Peromyscus......................... 51

"d de Pennant............... 213 " canadensis......... 52

Megaptera..... .................... 117 Phenacomys................... 51

nodosa................ 117 " latimanus. ........ 51 


\section{$-285$}

PAGE

PAGE

Phoca.......................... 154 Sciuropterus ................. 77

6 fœtida.................. 155 of sabrinus.......... 77

"6 Groenlandica........... 156 Sciurus....................... 72

"vitulina................ 155 " carolinensis............ 75

Phocena phocæna............. 103. " " leucotis.... 77

Phocidre......................... 152 " hudsonicus............. 73

Phocinæ.......................... 154 Siffleur.......................... 67

Phoque d̀ capuchon............ 159 Sirène .......................... 99

"6 annelé.................. ]5j Sorex......................... 83

" barbu ................... 158 " albibarbis................ 83

" commun.................. 155 " huyi..................... 84

" du Groënland ........... 156 " personatus ............... 84

Pbyseter

gris ........................

159 Soricidæ.........................

109 Souris d pattes blanches du

$\begin{array}{llll}\operatorname{macrocephalus} & \ldots . . . & 109 \\ & & \\ & \end{array}$

Canada ...............

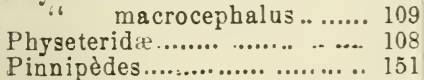

Pinnipèdes

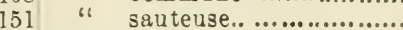

151 Suisse.................. :...........

Polatouche du Canada...........

Porc-épic du Canada.............

Pourcil.

77 Surmulot.

35 Synaptomys................... 47

Procjon...........................

103

164 Talpidæ.......................... 86

Procyonidæ ........................

164 Tamias............................ 70

Puma.............................

Putorius...........................

" cicognani ...............

Rangifer..........................

Rat..............................

163 " rayé..................... T0

275 " striatus................. 70

221 66 " lysteri............ 72

229 Taupe à museau étoilé.......... 89

221 " ordinaire................. 87

144 Taxidea........................... 197

144 "6 americana................ 197

145 Thalarctos ..................... 177

54 .6 maritimus.... ....... 177

43 Ungulata........................ 119

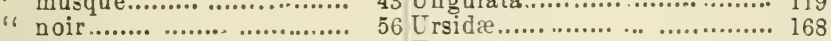

Raton ordinaire................ 164 Ursus.......................... 169

Renard arctique............. 243 " americanus.............. 170

". argenté................... 237 Vache morine.................... 162

" blanc..................... 244 Vespertilionidæ............... 93

" bleu.................... 241 Vison ordinaire................ 216

"6 croisé.................. 236 Vulpes .... .................... 236

" noir..................... 237 " lagopus ................. 243

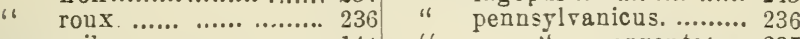

Renne caribou..................... 144 "6 prgentatus. 237

Ron yeurs....................... 27 " 6 decussatus. 236

Rorqual commun ............... 115 Wapetit........................... 132

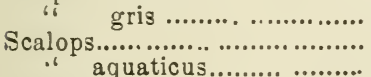

116 Zapus.......................... 39

87 "6 hudsonicus............... 39

Sciurida......................

87 "6 "6 ladas ........ 41

66 is insignis abietorum...... 42 



\section{ERRATA}

Page 98, ligne 28, au lieu de: yarticulièrement, lisez: particulièrement.

“ I09, “ I, au lieu de : cétacé, lisez : cétacés.

“ I33, “ 29, supprimez de.

" I36, " 2, au lieu de : dans, lisez : des.

" I6 3 , “ I, “ “ ": fissipedia, lisez : fissipedia.

"232, " 3, ajoutez: la avant belette. 


iibliothèque 'sité d'Ottawa chéance
The Library University of Ottawa Date Due

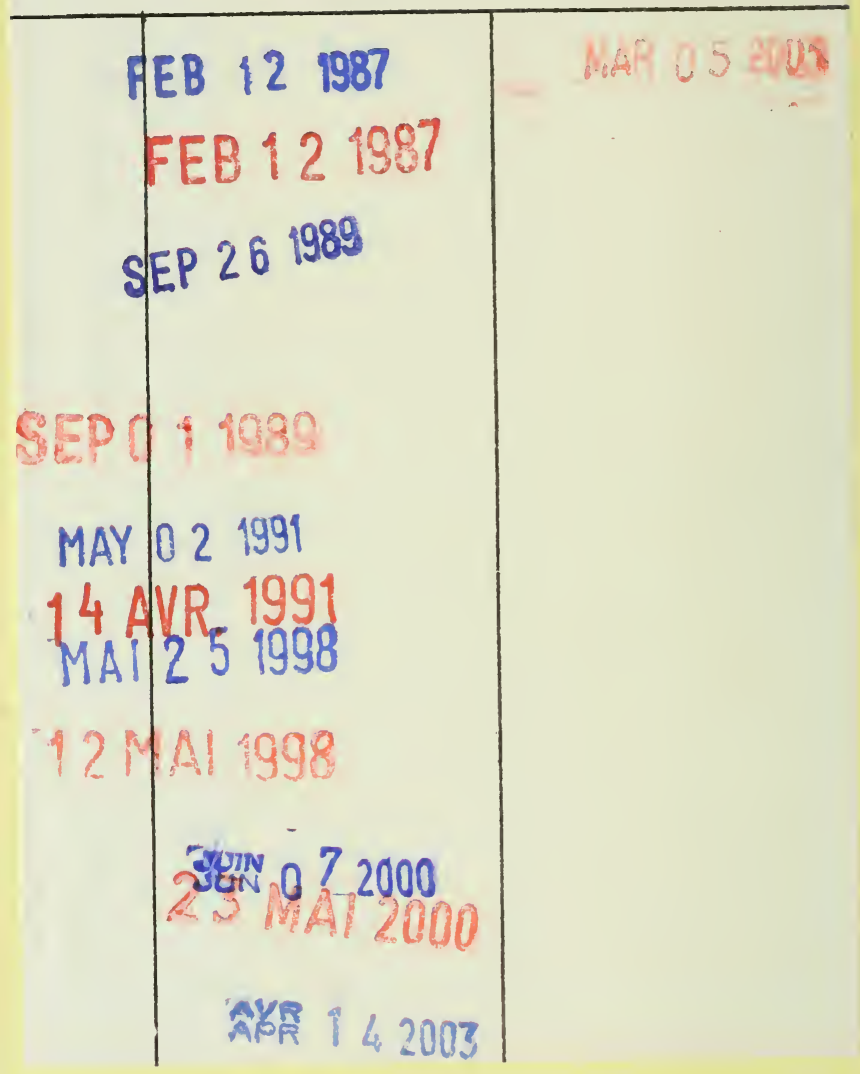


CE

$$
\begin{aligned}
& \text { QL PבU.D5M I9Oב }
\end{aligned}
$$

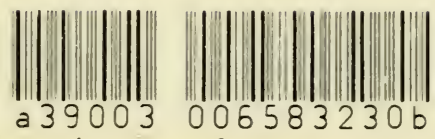




\section{U D' I OF OTTAWA}

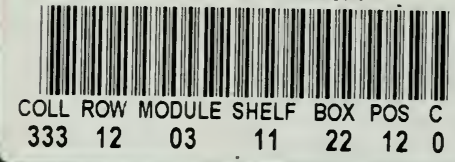

